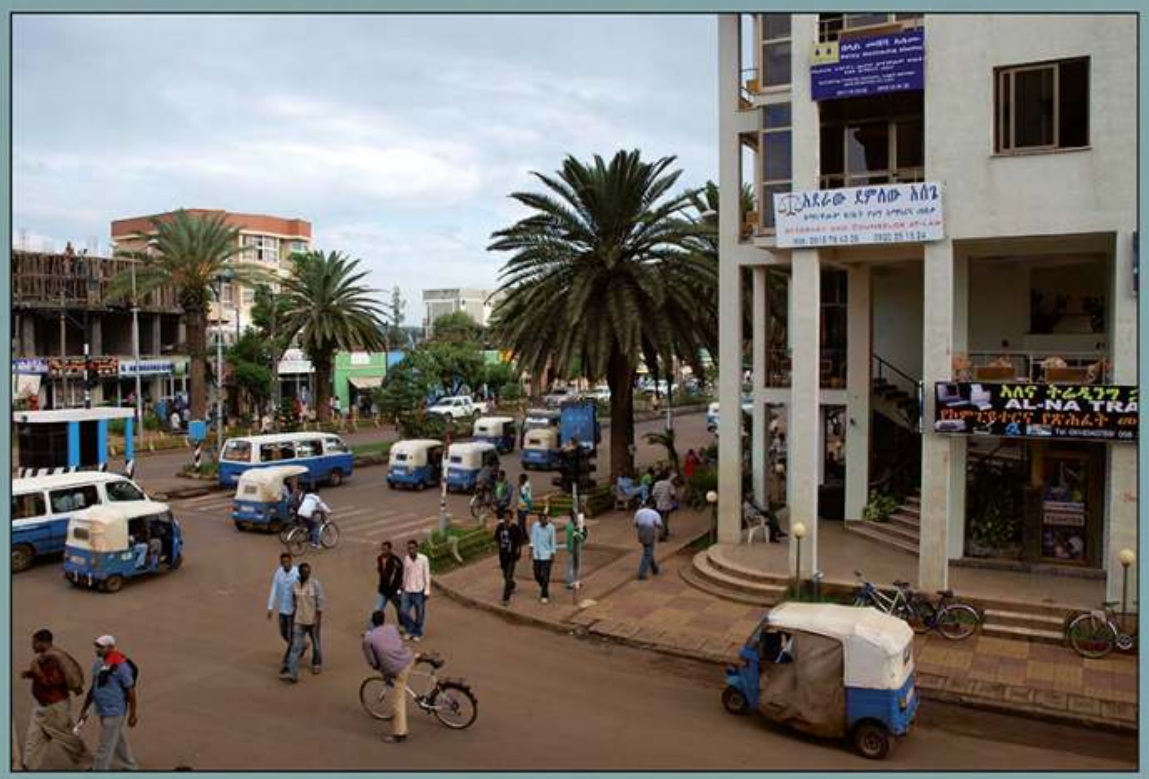

Nadine Appelhans

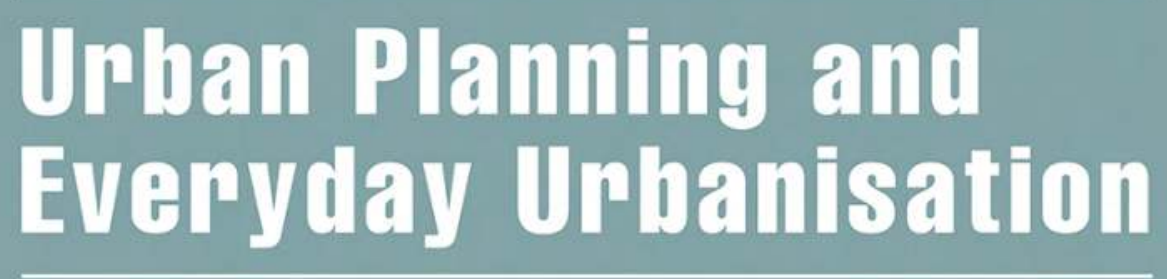

A Case Study on Bahir Dar, Ethiopia

[transcript] Urbanstudies 
Nadine Appelhans

Urban Planning and Everyday Urbanisation 
Nadine Appelhans (PhD) completed her doctoral studies at HafenCity University in Hamburg and is now a post-doctoral researcher at TU Dortmund University. 
Nadine Appelhans

\section{Urban Planning and Everyday Urbanisation}

A Case Study on Bahir Dar, Ethiopia

[transcript] 
Diese Arbeit wurde 2015 als Dissertationsschrift an der HafenCity Universität Hamburg vorgelegt.

An electronic version of this book is freely available, thanks to the support of libraries working with Knowledge Unlatched. KU is a collaborative initiative designed to make high quality books Open Access for the public good. The Open Access ISBN for this book is 978-3-8394-3715-5. More information about the initiative and links to the Open Access version can be found at www.knowledgeunlatched.org.

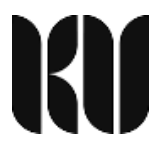

\section{Bibliographic information published by the Deutsche Nationalbibliothek}

The Deutsche Nationalbibliothek lists this publication in the Deutsche Nationalbibliografie; detailed bibliographic data are available in the Internet at http://dnb.d-nb.de

\section{(1) (1) $\Theta \Theta$}

This work is licensed under the Creative Commons Attribution-NonCommercial-NoDerivatives 4.0 (BY-NC-ND) which means that the text may be used for non-commercial purposes, provided credit is given to the author. For details go to

http://creativecommons.org/licenses/by-nc-nd/4.o/

To create an adaptation, translation, or derivative of the original work and for commercial use, further permission is required and can be obtained by contacting rights@ transcript-verlag.de

Creative Commons license terms for re-use do not apply to any content (such as graphs, figures, photos, excerpts, etc.) not original to the Open Access publication and further permission may be required from the rights holder. The obligation to research and clear permission lies solely with the party re-using the material.

\section{(C) 2017 transcript Verlag, Bielefeld}

All rights reserved. No part of this book may be reprinted or reproduced or utilized in any form or by any electronic, mechanical, or other means, now known or hereafter invented, including photocopying and recording, or in any information storage or retrieval system, without permission in writing from the publisher.

Cover layout: Kordula Röckenhaus, Bielefeld

Cover illustration: Nadine Appelhans, Bahir Dar, 2010. Copyright: Nadine Appelhans Printed by Majuskel Medienproduktion $\mathrm{GmbH}$, Wetzlar

Print-ISBN 978-3-8376-3715-1

PDF-ISBN 978-3-8394-3715-5

https://doi.org/10.14361/9783839437155 
Abstract | 9

Acknowledgement | 11

Glossary $\mid 12$

1. Introduction | 15

1.1. Objective $\mid 16$

1.2. The Research Process $\mid 18$

1.3. Structure of the Thesis $\mid 19$

2. Urbanisation in African Cities | 23

2.1. Concepts from Urban Studies $\mid 27$

2.2. Informing Urban Policy on Urbanisation | 31

2.2.1. Beyond the Formal-Informal Dichotomy $\mid 36$

2.2.2. Undoing the Modern-Traditional Division | 39

2.2.3. Establishing Rural-Urban Linkages $\mid 41$

2.2.4. Re-Framing Local-Cosmopolitan Constellations | 43

2.3. Assembling Narratives of Urbanisation in African Cities $\mid 45$

3. Accounts of Ethiopian Urbanisation 49

3.1. 1880-1936: Early Towns | 54

3.2. 1936-1941: Italian Facist Settlement Plans | 55

3.3. 1941-1974: Imperial Modernism | 58

3.4. 1974-1994: Towns under Socialism | 61

3.5. 1994-present: The Federalist Urban Network | 65

3.6. Missing Accounts of Urbanism | 68

4. Research Design | 73

4.1. Applying a Case Study Methodology $\mid 73$

4.2. The Case Study Site $\mid 76$

4.3. Research Questions $\mid 78$

4.4. Data Collection $\mid 80$

4.5. Analytical Framework $\mid 84$ 


\section{Urban Planning in Bahir Dar $\mid 87$}

5.1. Traditional Land-Administration and Settling Practices $\mid 87$

5.2. Italian Legacy $\mid 91$

5.3. The Modernist Layout | 94

5.4. Introducing the Kebele Administration | 99

5.5. Contemporary Planning $\mid 101$

5.5.1 The BDIDP | 104

5.5.2 Urban Development Practice | 111

5.6. Ruptures, Continuities and Parallels in Bahir Dar's Urban Planning | 118

6. Everyday Urbanisation in Bahir Dar | 127

6.1. The Sub-Cases | 131

6.1.1. Inner City Area | 133

6.1.2. Textile Settlement $\mid 140$

6.1.3. Informalised Village | 143

6.1.4. University Campus | 147

6.2. Ordinary Practices of Making the City | 154

7. The Relation of Planning and Everyday Urbanisation | 161

7.1. Constellations in the Neighbourhoods | 162

7.1.1. Historical Diversity | 163

7.1.2. Housing Area $\mid 169$

7.1.3. Urban Village | 171

7.1.4. Academic Compound| 173

7.2. Spheres of Negotiation | 175

7.2.1. Negotiations of Legal Status | 176

7.2.2. Disputed Modernity | 182

7.2.3. Understandings of Urbanity $\mid 186$

7.2.4. Questions of Citizenship | 193

8. Towards a Situated Agenda | 197

8.1. Bahir Dar's Idiom of Urbanisation | 197

8.2. Implications for Urban Development $\mid 202$

8.3. Inclusive Planning $\mid 209$ 
9. Furthering Synergetic Constellations 209

9.1. Mixed-Use Zoning $\mid 211$

9.2. Arrival Structures and Temporary Housing $\mid 213$

9.3. Incremental Building Zones $\mid 215$

9.4. Networks of Innovation | 218

Table of Resident Interviews | 221

List of Expert Interviews | 222

References | 223 



\section{Abstract}

Since the beginning of the 20th century, Ethiopia's cities have been growing in size, expansion and number. While master plans were drafted since the reign of Emperor Haile Selassie, construction and settlement processes have largely remained incremental and based on everyday practice. The discipline of urban studies is only in an early phase of gaining insights into the contingent nature of the social, economic and cultural implications of urbanisation in the country's cities, but has to assume a widening spectrum of urban practices within and among the towns. However, since 2005 Ethiopian politics has started drafting an urban policy to introduce new standards of development in the cities. Recently "Integrated Development Plans" (IDPs) have been introduced as planning instruments and form the policy base for resettlements and large scale restructuring in many of the Ethiopian cities.

The topic of the research presented here is the investigation of the relation of these statutory planning practices with the local everyday urbanisation. Therefore, Bahir Dar, the capital of the Amhara National Regional State and located on the mouth of the Blue Nile on Lake Tana, was chosen a case study location. The study is comprised of a theoretical review on urbanisation in Africa and two empirical parts. The first empirical part is a review of the historical urban development of Bahir Dar to the planning policies currently in place. The second empirical part is an evaluation of primary data on everyday urbanisation collected from the four sub-case sites in Bahir Dar. Fieldwork was conducted in a number of site visits over a period of four years from 2009 to 2013. In a multi-tool approach data on urbanisation practice was collected through documentation, review of policies and archival records, key-informant interviews, semi- structured interviews with residents and cross-section mapping. Four sub-cases in contrasting neighbourhoods founded in different time periods were studied to gain insights into the implications and mutual influences of current statutory planning and everyday rationales of the urbanising city and vice versa: The inner city, the textile area, an informal village and the Bahir Dar University main campus.

The dissertation aims to specify the insights on urbanisation rationales of residents in the four sub-case site neighbourhoods and how they relate to state- 
driven development policy. The inner-city houses a wide diversity of dwellers and serves as an arrival point, while current development plans seek to re-shape this area into a commercial zone. The residential area erected by workers of the textile mill has turned into an established middle-income neighbourhood with formal house ownership. An informal settlement now inhabited by the fourth generation of settlers accommodates livelihoods based on urban agriculture and city based job-opportunities and is facing eviction to make way for a commercial centre. The university's expansion is part of a priority programme, which provides students with fully serviced campus life but little exposure to Bahir Dar city.

Based on the empirical findings, the thesis concludes that informal, traditional and incremental urbanisation strategies continue to make up large parts of the urban fabric and provide housing for population groups that do not have access to formal housing provision. However, contrasting the IDP projects with evidence from the sub-cases reveals that these particular everyday urbanisation practices have not found sufficient consideration in urban development strategies and lack the negotiation power with state authority that economically better equipped projects display. This furthers tendencies of socio-economic segregation.

To counter these tendencies, ideas for policy revision placing urbanisation at its centre and towards contextualised planning and inclusion are, hence, conceptualised. In order to support inclusiveness for low-income practices of urbanisation, this thesis suggests implementing pilot projects aiming for synergies between statutory and everyday urbanisation. The city centre is designated to experiment with "mixed- use zoning", the textile settlement is proposed as a site for "arrival structures and temporary housing", the informal village can be declared an "incremental building zone" and the university can reconnect to Bahir Dar city via public programmes termed "networks of innovation". Thereby the proposals are intentioned to look for possibilities of cooperation between stakeholders to benefit the residents while attracting projects improving living conditions and urban facilities in Bahir Dar. 


\section{Acknowledgement}

Over time, the work on this thesis was accompanied by many, who have contributed to the completion of this research in their own way. I would like to express my appreciation for their trust and patience and thank my family and friends for being there.

As special mentions, I wish to thank all the interviewees for giving me their personal insights and the people of Bahir Dar who introduced me to how they live. I am most indebted to my supervisors Prof. Dr. Dieter Läpple and Prof. Dr. Einhard Schmidt-Kallert for their guidance throughout the ups and downs of the project. I thank Getie Gelaye from Hamburg University for giving me some insight into Ethiopia's rich culture and Genet Alem from Dortmund University for her insights into Ethiopia's planning system. Genet GebreEgziabher from the Regional Urban Planning Institute facilitated many of the expert interviews during data collection. Thank you to my research assistants Abnet Tarekegn, Henok Tsegaye, Lukas Grellmann, Konrad Putzier, and Janko Vollmer for their valuable contributions during the fieldwork. Special thanks to Benjamin Stähli for his companionship and hospitality. My thanks also to Kumneger and Tirufat Adane, Zerai Mesfin and Amare Tsedal for showing me around in Bahir Dar and for the many conversations. I thank Zegeye Cherenet and his colleagues at EiABC in Addis Ababa for backing me in my research endeavours and the staff members at Bahir Dar University for their support. I would like to thank my peers Heike Derwanz, Katja Heinecke, Katrin Klitzke, Dietmar Weiß and Verena Gernert for their thoughtful comments and helpful suggestions. Hauke Seeger and my sister Yasmin Appelhans offered their help in the finishing of the document, for which I am very grateful. Astrid Preuß has continuously supported the administrative side of writing this $\mathrm{PhD}$ on behalf of the HCU and through her interest and kindness.

Without the two scholarships of the IPSWaT Programme of the German Federal Ministry of Education and Research (BMBF) and of the City of Hamburg this research would not have been possible.

Despite careful inquests, all errors are mine. 


\section{Glossary}

$\begin{array}{ll}\text { Amhara } & \text { ethnic population native to the Amhara Region } \\ \text { araki } & \text { local grain spirit } \\ \text { Bajaj } & \text { motor-rickshaw used for public transport, also } \\ \text { known as tuc-tuc } & \text { Amharic for house, pl. houses } \\ \text { bet, pl. betocc } & \text { Bahir Dar Integrated Development Plan } \\ \text { BDIDP } & \text { Bahir Dar University } \\ \text { BDU } & \text { Ethiopian currency, Birr 24.67 equivalent to 1 } € \text { on } \\ \text { Birr } & \text { 29.01.2013 } \\ \text { bunna } & \text { coffee } \\ \text { chicka } & \text { clay and straw mixture traditionally used for } \\ \text { construction } & \text { Central Statistical Agency } \\ \text { CSA } & \text { name for the socialist government ruling between } \\ \text { Derg } & \text { 1974 and 1994 } \\ \text { EPRDF } & \text { Ethiopian People's Revolutionary Democratic Front, } \\ \text { current ruling party } \\ \text { white foreigner } \\ \text { ferenji } \\ \text { ghebbi }\end{array}$




$\begin{array}{ll}\text { MEDaC } & \begin{array}{l}\text { Ministry of Economic Development and } \\ \text { Cooperation }\end{array} \\ \text { MoFed } & \text { Ministry of Finance and Economic Development } \\ \text { official re-name for the Wayto community (see be } & \text { low) } \\ & \text { Plan for Accelerated and Sustained Development to } \\ & \text { End Poverty } \\ \text { PASDEP } & \text { Regional Urban Planning Institute } \\ \text { RUPI } & \text { Spatial Development Framework } \\ \text { SDF } & \text { Sub-Sahara Africa } \\ \text { SSA } & \text { reed boat } \\ \text { tanqwa } & \text { local grain, main staple food } \\ \text { teff } & \text { home-brewed beer } \\ \text { tella } & \text { honey wine } \\ \text { tej } & \text { traditional round hut made of clay and straw } \\ \text { tukul } & \text { local tribe with traditional livelihood based on the } \\ \text { Wayto } & \text { river Nile } \\ & \text { medium spatial administration unit at the sub-re } \\ \text { gional level, centre of administration for a number } & \text { of Kebeles }\end{array}$

Note: For practical reasons of legibility the spelling of the Amharic terms does not strictly follow the rules of literal transcription. 



\section{Introduction}

Bahir Dar is a rapidly growing secondary city in Amhara Region in Ethiopia. So far, the history of fixed settlements in Ethiopia is under-researched (see chapter 3). To date, urban theory does not adequately explain the ongoing process of urbanisation defining the urban realities in Ethiopia, as it does not include qualifications of the local urbanism and practices of settling and constructing. This thesis picks up on this point and looks in to the "ordinary" or "mundane" local practices of urbanisation such as migration, auto-construction, traditional land-practices and incremental building and refers to them as "everyday urbanisation". Until recently, not only informal housing but rather the majority of structures in Ethiopian towns were not constructed within state-led policies. Most of them built by urban residents in community efforts. Depending on the local context, availability of building materials and personal resources, these practices of urbanisation are diverse and have been shaped by a number of influences over time. They encompass strategies of the urban poor, the emerging middle-class, and also building activities by the affluent. It is a current development that these habits of construction in housing are changing; they obtain standardised designs available from the municipalities, order individual architectural designs and professional building contractors. The practices of everyday urbanisation to create shelter of various types and standards, as well as appropriating livelihood spaces in the cities are dynamic and subject to change in interaction with changing materiality and societal conventions and fashions. They are practised by residents, cooperatives, investors or NGOs outside of state institutions and are summarised as "everyday urbanisation" in the following. Be it outside or inside of land-use regulations, building standards or business regulations, they are responsible for large parts of Ethiopia's existing urban fabric.

However, living conditions in large parts of Ethiopia's cities are dire. The historical urban fabric has sanitary issues and the rapidly growing urban population needs to be accommodated in additional space. It is in this context that Ethiopian national politics first devised an Urban Policy in 2005 (Ministry of Works and Urban Development 2007: 20). Thereby the political vision of "development" (cf. Müller 2015) was expanded to the realm of urban development with the "Plan for Urban Development and Urban Good Governance" as part of the "Plan for 
Accelerated and Sustained Development to End Poverty" (PASDEP) issued by the Ministry of Works and Urban Development (2007). The topics of infrastructure provision and housing development have thus moved onto the Ethiopian political agenda. Thus everyday practices - whether traditional or adjusted to modernismare often not the starting point from which urban policy derives its design principles. Instead, to implement these visions, displacement and re-construction are widely spread actions in Ethiopian cities, making way for "development" plans.

While the dire living conditions many urban residents experience do need to be improved, it needs to be questioned how we can find site-specific instruments of urban development to address the local situation under conditions of urbanisation. Outcomes of current practices of urbanisation are commonly generalised and referred to as slums (Ministry of Works and Urban Development 2007: 4). Watson (2002: 36) describes the visible indifferentiated gap between the existing practices and structures and the new standards of development as a „lack of consensus“ between explanatory and presciptive positions. In Ethiopia, this topic resembled by the genesis of towns through practices of everyday urbanisation (see chapter 3.6) and their relation towards more recent statutory development projects have so far not been adequately structured as a topic of study. However, more qualitative data is necessary do so. To bridge this gap between competing interests, the question of development priorities in Ethiopian cities form the starting point for the investigations in this research project. Based on this, the thesis conducts a case study on the relation between statutory planning and everyday practices in this location. The thesis seeks to deliver insights into the processes that comprise urbanisation in this city as a socio-economic and cultural transition and how diverse lifestyles and habitats create the notion of contingent urbanism. It further asks, how urban development strategies can truly help to improve the diverse and challenging local living-situations of the urbanising population by developing suggestions for pilot projects. Therein rigorous discourse on local situations and contextually suited instruments has to replace a universalist attitude towards urban development at the cost of local values, assets and interests.

\subsection{Objective}

Regardless of the strong focus of the scientific discussion on the primate- and megacities, the overwhelming part of urban population growth in Africa can be found in the secondary cities with less than 500.000 inhabitants (UN-Habitat 2008: ix). These secondary cities have largely been overlooked in research so far and processes within the cities as sites of an ongoing urbanisation have not been qualified. As these cities have factually not received academic attention from urban studies, neither the process of rapid urbanisation, nor its causes or consequences have been conceptualised to devise planning instruments in the face of livelihoods being at 
stake. It is therefore time to shift the focus of urban research to the secondary cities, the sites that are actually most affected by the phenomenon of urbanisation, with the highest growth rates on the continent.

The PhD looks at the impact of urbanisation on city life in Bahir Dar. To do so, the thesis will compile a contextualised account of urbanisation for the City of Bahir Dar in Ethiopia and looks at living conditions in the town. The account is exploratory and will have the form of a structuring outline that can be complimented and modified by further research and findings. It serves to look into the policy implications resulting from social, cultural and economic change in the ongoing urbanisation process in Bahir Dar. As a consequence, this study is focused on the urban development of Bahir Dar as a site of impact of urbanisation. It further asks how the processes can be accompanied and shaped by urban development strategies encompassing the everyday practice. Here new concepts of spatial development are crucial, as African cities mostly do not conform to theoretical assumptions on urbanisation driven by industrialisation, and are regularly not accompanied by sizeable industrial growth (see chapter 2). Urban development theory assuming lifestyles exclusively based on industrial production and wage labour disregard large parts of the informal urban realties of these cities and, hence, need to be replaced by revised understandings of the local situation.

The underlying paradigms of urban planning will consequently be investigated to question their suitability for the environment they are applied in and find approaches to address the local context. In order to look at the situation in Bahir Dar, this thesis places the statutory planning practices next to existing "everyday urbanisation", in an attempt to expand the current narrative of urbanisation. The research attempts to establish their particular relation in Bahir Dar, in the assumption that this relation is fundamental to the quality of urban development under the conditions of rapid urbanisation. Leaving the path of traditional theories of urbanisation related to industrialisation, the thesis aims to translate the findings from the field into a comprehensive account to inform academic debate and decision makers in urban policy. The findings will be used to discuss the phenomenon of urbanisation and re-conceptualise it to suitably describe the contingencies and impacts of urbanisation in Bahir Dar. Beyond the academic audience, the thesis is therefore written for engaged citizens, urban planners, and decision-makers in urban politics, as well as administration, who wish to review the current underpinnings of urban policies and amplify the spectrum urban development tools. The recommendations regarding pilot projects may not be adequate in other locations and it can prove impossible to replicate their effects. Nevertheless, finding an approach to contextualised urban planning is relevant and acts also as a reference, just as the empirical results from the example can be used in comparison for more general theoretical discussions on current conditions of urbanisation in Ethiopia. The findings derived from the specific case further contribute to theoretical discussions by amplifying the scope of material available on urbanisation 
in Ethiopian towns and seeks to establish evidence towards a diversification and differentiation of the theoretical assumptions on African cities.

\subsection{The Research Process}

Access to the field was facilitated by the joint Ethiopian and Swiss lead "NesTown" project for settlement development in the Lake Tana area, by which I was introduced to the area and the local institutions. The Lake Tana region has been designated for the development of new settlements to accommodate population growth by the Ethiopian government (RUPI 2000 E.C.). The project lead me to look at other examples of urban development in the area and question the relation of government provided structures and appropriation practices in the growing cities of the Lake Tana region. With this initial research idea, I began a focused literature review to try to get an understanding of the cultural, social and economic context in Ethiopia and developed the research objective. After three short exploratory visits to Ethiopia between 2009 and 2010 and encountering the designs for the first master plans for Bahir Dar from 1962 in the university archive in Darmstadt (Germany), the theme of the research project was first formulated and Bahir Dar was chosen as the site for a historically grounded case study. Preliminary research questions guided further literature reviews on the general theories on urbanisation in Africa (see chapter 2) and on the local Ethiopian context (see chapter 3), from which more specific research objectives for the study of Bahir Dar were derived (see chapter 4). In a three-and-a-half-month period of field-work in Bahir Dar in 2010, a systematic mapping exercise with research assistants was undertaken to understand the city's layout and neighbourhood structure. Participating in an "Integrated Training and Capitalising on Experience" (ITC) workshop organised by the "NCCR North-South Research Partnership" of the University of Bern conducted in Bahir Dar in September 2010 allowed me to sit in on conversations with experts on urban development. Co-ordinating a workshop on the question of regional development in the larger city network on Lake Tana, organised jointly with the Bahir Dar University, Addis Ababa University and the ETH Zurich, established access to the network of professional planners. As a result of a contact made at the conference, there was an opportunity to sit in on an expert hearing for the development of the Bahir Dar Waterfront Development Plan, organised on 24th of February 2011 by the Canadian Urban Institute in Bahir Dar.

These impressions helped to revise and focus the eventual research design, which was set up during a methodological workshop conducted jointly by the Technical University Dortmund, the University of Dar Es Salaam and the Kumasi University in August 2012 in Arusha, Tanzania. A single-case approach with sub-cases now formed the methodological frame, on which four neighbourhood sub-cases were chosen within a single case set-up (see chapter 4.2 ). The research 
questions (see chapter 4.3) were broken down into a programme for situated data collection in the field (see chapter 4.4). These focus sites were studied in depth with the help of two student assistants from Bahir Dar University's newly established Faculty of Architecture, by conducting semi-structured interviews with residents. The students translated from Amharic into English during the interview sessions and approached the interviewees in their homes. This final round of fieldwork was completed during January and February 2013. The empirical results are collected in chapters 5 and 6 .

On returning to Germany, the data was interpreted and structured to relate to the research questions in an iterative process. The material was discussed with peer-groups from the HafenCity University, as well as the Technical University Dortmund. The results of these discussions are presented in the findings and proposals of this thesis (see chapters 7, 8 and 9).

\subsection{Structure of the Thesis}

The content of this thesis is divided into nine chapters (see Fig. 1). Following the introduction, the second chapter describes the main directions of theoretical discourse on urbanisation and how they relate to the issue of rapid urban growth currently observed across the African continent. The third chapter specifies this outlook for the Ethiopian situation, giving an overview of the current narrative regarding the country's urban growth and development. The second and third chapter thereby form the exploration of current theorisations on urbanisation and investigate how, to date, they have been regarded within the Ethiopian urban studies and urban policy context.

Based on these insights, the research gaps in the current discussion serve as the focus points from which chapter 4 develops the research design for the empirical study. It introduces the case-study methodology, by which Bahir Dar was chosen as a case study site for conducting empirical research, as well as the research questions. The research questions are intended to guide the research process to find empirical evidence that can overcome the assumption, that the urbanisation process we see in Sub-Saharan Africa is a homogeneous phenomenon that can be met with standardised answers in the shape of quantities of housing units. It is meant to produce information that can be used for diversified planning, geared to local demands, furthering inclusiveness and also targeting the majority of the population who is dependent on subsistence practices and informal incomes. The material from this data collection is presented in chapter 5 and chapter 6 . Chapter 5 gathers information on urban planning, urban policies and administrative practices exercised in the city. In order to present a first comprehensive overview of material on Bahir Dar's urban planning history, the material is presented in a historical timeline, which extends as far as the final field visit in 2013. The historical deve- 
lopment is portrayed in order to explain influences still notable in the built structure, planning policies and urban practise of the city today. The account of formal urban planning and the governmental implementation practices contrast with an exploration of everyday practices of urbanisation from four sub-case neighbourhoods presented in chapter 6 . Here, the residents' conventional practices of settlement and appropriation of space as producing urban structures by engaging with materiality is described. The findings from the two chapters 5 and 6 on "urban planning" and "everyday urbanisation" in Bahir Dar are then jointly discussed in a synthesis in chapter 7. In this synthesis, data interpretation is undertaken by juxtaposing the findings from these two different topics of data collection. Here, the aim is to establish the relations between statutory planning and practices on the one hand and mundane practices of settling, living and constructing in the city.

Chapter 8 goes on to revisit the theories first presented in chapter 2 and reviews the empirical findings from the case study to point out the specificities of the urbanisation process in Bahir Dar. Thereby, the findings from the empirical work contribute to theory building on rapid urbanisation for the case study location. The insights in turn form the basis through which recommendations for the case study are formulated. Here, the principle of inclusive planning is set as a planning objective. In chapter 9, this aim is broken down into site-specific approaches for the subcase sites, and suggestions for a revised spectrum of planning tools are made as a basis for discussion of a revision towards a situated urban development strategy. 
Fig. 1: Structure of the Thesis

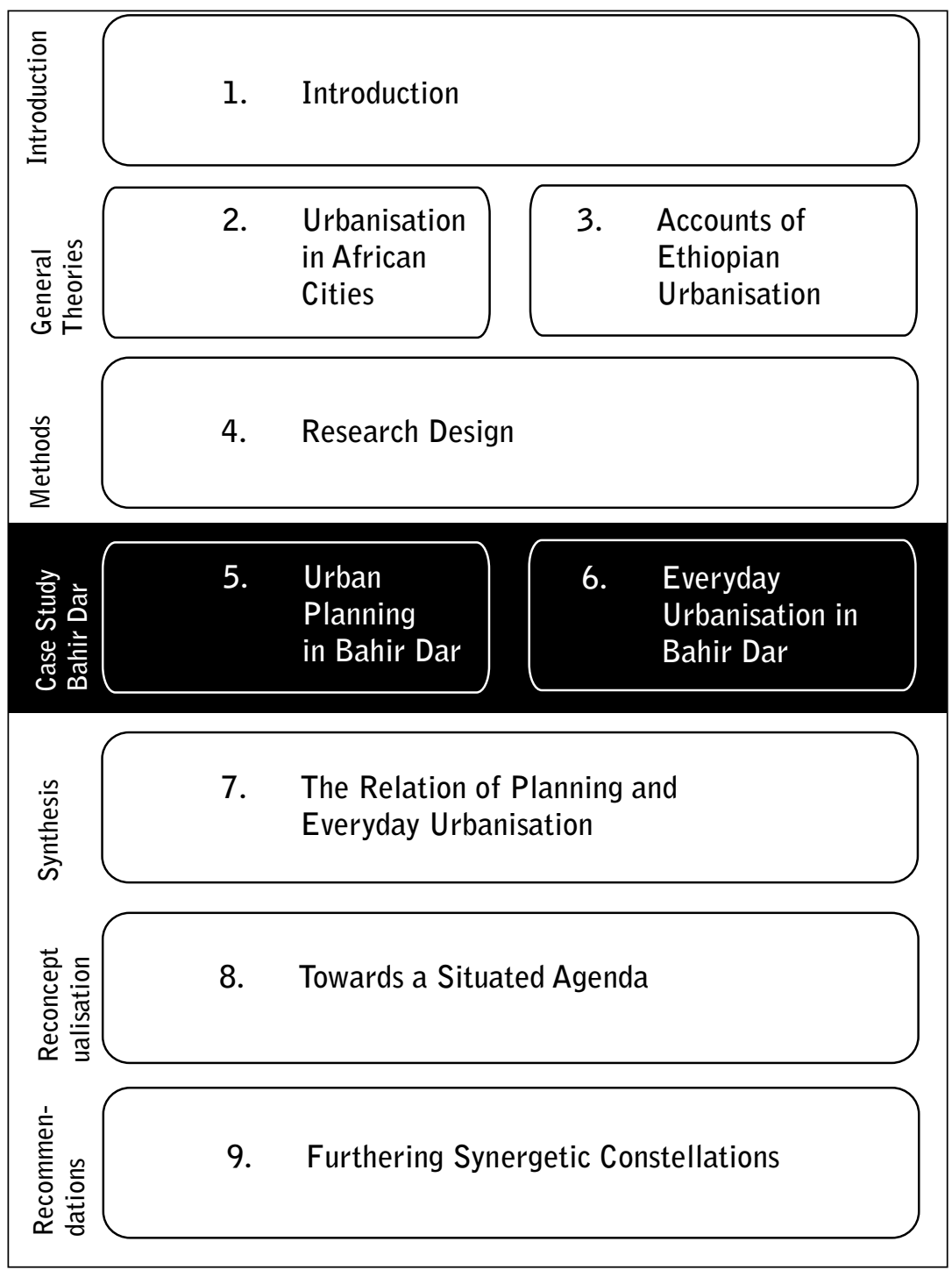

Image by the author. 



\section{Urbanisation in African Cities}

This chapter summarises the current state of discussion on theories of urbanisation for cities in Africa and their role in urban studies, based on a literature review. Urbanisation can, thereby, not only be seen as quantifiable urban growth in the form of built structures and population growth. The concept of urbanisation as a social, cultural and economic transformation that society is undergoing within the cities by shifting large proportions of its livelihood to urban environments is introduced as an alternative reading. However, the current discourse on urbanisation sees a division of data availability between contexts of the "Global North" and the "Global South" (Watson 2009). While the largest part of urbanisation theory was formulated on the basis of urbanisation processes triggered by industrialisation in late 19th century North America and Europe, current urban planning and urbanisation practices in the regions currently facing rapid urbanisation are increasingly running into difficulty implementing the urban planning tools developed outside of their context. It is, therefore, academically now quite widely acknowledged that not all current urbanisation processes can be explained with the theories that until recently had been considered universal. Moving supposedly universal urbanisation theory to the African context unquestioned for its suitability, hence, frequently results in a failure of existing explanation building for the processes encountered there (Coquery-Vidrovic 1991, Myers 1994, Watson 2002, Pieterse 2010, Myers 2011, Simone 2011, Berrisford 2011, Jenkins and Eskemose 2011). Yet, without a suitable concept of what is happening in the urbanisation processes, policy cannot improve living situations on the ground effectively and accompany the urbanisation. A qualitative approach for investigating these processes is argued for, following the discussions on "rapid urban growth" (Ministry of Works and Urban Development 2007: 2) or "rapid urbanization" (Daniel Weldegebriel 2011: 3), leading to differentiated needs for action in urban development of the different cities. Starting with the insights from quantitative descriptions, followed by results from qualitative work, the discussion from literature review will, therefore, be presented to give an overview of how far the discussion on the conceptualisation of urbanisation in African cities has so far advanced. 
Reliable data on urbanisation in Sub-Saharan Africa is still scarce, and estimates of the extent and nature of the phenomenon are consequently rather speculative. According to the available and most commonly quoted data, Sub-Saharan Africa's rate of urbanisation remains the lowest in the world (Boquier 2004: 135). Thus, Eastern, Middle and Western Africa are clearly lagging behind in urbanisation in comparison to Southern and Northern Africa (ibid: 137, Potts 2009: 254). In general, though, the growth rates of African cities are noted to be higher than in other world regions (Watson 2009: 161). The international organisations that take a lead role in the policy debate on urban policy worldwide, depict urbanisation in Africa as part of a large-scale process, whereby the majority of urban population growth on the continent can be found in secondary cities with fewer than 500,000 inhabitants (UN-Habitat 2008: ix). With a few exceptions, no regional studies on migration have been conducted in Africa, while poor statistical systems further complicate analyses based on secondary sources (Boquier 2004: 143). However, the pace of urban growth in Sub-Saharan Africa (SSA) has decreased considerably since the recent turn of the century (ibid: 135). The overall slowdown of the urbanisation rate is most probably not temporary (ibid). Moreover a large-scale analysis of francophone African cities suggests that the overall in-migration has slowed or halted in many large and middle size towns (Potts 2009: 257). Since the growth is mostly slowed and not inversed, however, the size of cities is still increasing considerably (Boquier 2004: 149).

Further differentiation of the phenomenon remains difficult, as the collection and comparison of quantitative data is often inconsistent due to varied definitions of "urban" from country to country; the lack of data, leading to the use of extrapolations instead of censuses for projections; the incongruent boundaries of the built-up area with the administrative city boundaries, leaving new urban neighbourhoods out of the equation; and the impacts of changing boundaries, which distort the growth rates based on migration and natural population growth ( $\mathrm{Ra}$ kodi 2002: 26-27). The picture drawn of the process is, hence, still characterised by accounts that are insufficiently differentiated. The UNPDF defines urbanisation as: "The process of transition from a rural to a more urban society. Statistically, urbanization reflects an increasing proportion of the population living in settlements defined as urban, primarily through net rural to urban migration." (UNPDF 2007: 6). This quantitative understanding of urbanisation is also reflected in the data informing many urbanisation policies: Referring to the situation on a continental level in Africa, the description of urbanisation is most commonly described as the shift of population proportions from rural districts to urban areas, expressed in a rural-urban population ratio. The description of demographic urbanisation, thus, assesses the contribution of in-migration to the growth of towns by comparing towns' growth to the national growth rate (cf. Potts 2009: 254).

Such a demographic description of urbanisation gives an outline of the general trends of urbanisation on the African continent in figures, but it also contains 
insufficiencies of a description limited to a rural-urban population ratio and its understandings of the consequences and requirements of the urbanisation process within the affected areas. These generalisations obscure the fact that there are strong regional, national and local differences in the patterns, speed and also the extent of urban growth across certain regions and between the individual cities (Potts 2009: 254). As described, there are two main reasons for this: insufficient quantitative data, and a lack of qualitative interpretation. The sparse quantitative data situation makes it difficult even to depict the extent of the progress and all prognoses are, therefore, subject to high relativity (Boquier 2004, Rakodi 2002).

Currently, demographic data cannot sufficiently provide an answer to the question of reasons for urbanisation. Due to the very general nature of quantitative data on a continental scale, qualitative interpretations of the phenomenon are consequently often general and speculative. Nevertheless, scholarly discussion is producing hypotheses to explain the phenomenon, which will be summarised in the following.

Reasons for urbanisation are derived from a wide range of aspects. The UNPDF generalises the qualities of urbanisation (beyond the quantitative extent and ratios) under the term "urban transition", which it has defined as: "The passage from a predominantly rural to a predominantly urban society." (ibid). It, thereby, seems to suggest that the societal aspects of the urbanisation process can be disconnected from the speed of population movement and describes a linear development pattern from rural to urban. Further assumptions are stated as marketisation, the growing significance of cities as a habitat due to overpopulation in the rural areas and changing external factors triggering more growth (Boquier 2004: 141). This hypothesis of rural-urban migration stands in contrast to Watson, who claims that growth rates in African cities are primarily due to natural increase (Watson 2009: 161). These hypotheses, however, are not mutually exclusive and reasons for urban growth in Ethiopia need to be established for the individual cities. It might be due to a combination of factors. Sources, further, state that urban fertility in African cities is currently lower, but lower death rates in the city due to lower infant and child mortality significantly impact and result in equal growth rates in urban areas and rural areas with high birth rates (Boquier 2004: 140, Potts 2009: 254). Slowing rates of in-migration might be due not to lower mobility, but to circular migration, which is not reflected in the population figures (Boquier 2004: 140, Potts 2009: 257). Boquier therefore predicts that future urbanisation in SSA will depend on migration, though the direct collection of migration data has been limited and prognoses are difficult (Boquier 2004: 149).

Meanwhile, the phenomenon also puts conventional theories of urbanisation as a result of industrialisation into question. It appears that macro-economic conditions do not favour African urban growth (rank in national and international economies), which is said to distinguish the urbanisation process in Africa from that of other world regions (Boquier 2004: 139). In most African cities across the 
scale, urban economies are not growing at the same rate as the influx of population that reaches the urban areas. Deborah Potts (2009: 254) elaborates on this and states that rises in urban-based employment as seen in the Asian contexts of urbanisation have generally not been observed in Africa. She points out that structural adjustments have lead to the decline or stagnation of formal employment since the 1980s, while informal jobs in the low-income ranges have gained massive significance for income generation (ibid). According to Potts, this is due to the structural conditions currently affecting urbanisation in Sub-Saharan Africa, which she names as "different" from those in other regions of the "developing world", leading to distinct forms of economic geographies to be shaped on the continent in the process (ibid). According to UN-Habitat (2008: 4), it seems that new strategies for survival are developed within these geographies. However, they might be putting the urban dwellers in constant "states of emergency", as AbdouMaliq Simone (2004: 4) puts it. As the spatially most visible phenomenon of rapid urban growth is informal settlements, these have been described as an outcome and visible product of the urbanisation process in various locations. Cattle in the street and practices of urban agriculture are omnipresent. However, a locally grounded analysis of the living conditions is mostly not available, or the areas are assessed by universal standards, resulting in the declaration of poverty-affected urban areas as slums (Ministry of Works and Urban Development 2007: 4) by purely technical and economic criteria. Such assessments term rapid urbanisation that does not result in urban structures conforming to standards as somewhat divergent from an implicit norm of urbanisation. It replicates dualistic thinking on the "developed" and the "undeveloped", in which African cities are regarded as something "other" than cities. The temptation to regard them as temporary phenomena in a transition phase is large. However, this again would rely on the explanation of theories that are "out of place" (Myers 1994: 209) instead of depicting the local context. Reducing the phenomenon of urbanisation to such - however critical - aspects, hence, does not do justice to the contingent complex realities of planning and everyday urbanisation that can be observed in individual cities. While this kind of incremental growth remains a planning challenge for various reasons, these new areas have been insufficiently studied to provide evidence for the patterns of in-migration (Potts 2009: 257 ) or the rationales behind the (self-) construction of new urban structures. The assumption is that the outcome of the general trend of population shift to the urban settlements is that a large proportion of the newly urbanised population is dependent on irregular income sources and, therefore, particularly prone to food insecurity and lacks access to basic amenities. However, what we can observe in Africa at the moment seems to suggest that industrialisation might act as a driver (as the example of Europe proves), but is not a pre-condition for urbanisation.

The reasons named for urbanisation indicate that either a variety of reasons contribute to urbanisation and/or that generalisation of the issue is not possible on a continental scale. There is a notion of deviance from existing development 
theories that describe industrialisation as the initiating driver of urbanisation, and an account for the current phenomena of urbanisation within African cities is missing. While, in consequence, descriptions of uni-directional migration processes need to be elaborated to portray the more complex migration patterns and diversification of livelihoods within the urban context (Boquier 2004: 149), suggestions that, due to the slowed urban growth rate, rural lifestyles could stay dominant in SSA with the exception of South Africa (ibid: 140) need interpretive discussion, as circular migration and diversified livelihoods with multiple sites and sources of residence and income generation would still include a higher number of people making use of the city's resources. Exploring this, the explanations given for the larger phenomenon of urbanisation need to be broken down and verified for the urban development of respective cities.

Generalisations are often obstructive to policy formulation within growing and emerging cities. Often only the size and speed of the population-shift towards urban settlements in combination with increasing poverty levels justifies the calls for action, mostly geared to the rising demand in housing and infrastructure, while qualifications of the needs resulting from urbanisation remain under-researched. It is, therefore, beneficial to look into the academic discussions that have addressed the shortcomings of research on cities in Africa and their theoretical output. As described in the following post-colonial urban studies will be looked into as a reference point for this purpose, as its criticism can serve to derive an analytical framework for describing contingent urbanisation processes in a specified location.

\subsection{Concepts from URBan Studies}

The lack of differentiated explanation for current urbanisation processes across the African continent marks a major research gap. Urbanisation needs to be described as a fundamental cultural and socio-economic transformation that requires academic investigation and recognition in policies and goes beyond demographic accounts. Trying to review from literature what frames the urbanisation processes in distinct cities in Africa and trace their exact qualities, it becomes evident that the social, cultural and economic aspects of urbanisation in their locations are understudied. So far the description of specific qualities of these settlements has been generalised or limited to narratives on the largest centres of urbanisation. International attention is focused on capitals and mega-cities, such as Lagos, Johannesburg and Nairobi to give some names. As Garth Myers describes, the lacking recognition of African cities as such resulted in a lack of study of them (Myers 2011). Acknowledging the idiosyncratic nature of place, there is hence a need for descriptions of spatial arrangements resulting from path-dependent development in cities from an extended range of location (Nijman 2007: 2). However, assuming 
a distinctly African urbanisation trajectory and a resulting general typology of an "African City" by structural or cultural criteria is thereby called into question. As Anderson and Rathborne (2000: 1) point out, the research on urban history of African towns has gained relevance in the face of amounting social and economic problems in today's African cities. Thereby, they can claim that the scale of current urbanisation is a modern phenomenon, but urbanisation as such can be observed on the continent as far back as 2000 years ago. The towns have their distinctive histories that need to be understood for catering to their specific problems (ibid). They, further, refer to the fact that Africa has largely been depicted as rural, and a history of cities and, thus, the contingent urbanisation processes in the different cities have not been contextualised or reviewed according to assumptions of path-dependency. This has consequences for the research on African cities: there is a rural bias, a focus on mega-cities and often a de-historisation of their accounts of foundation. Additionally Nijman explains that, while comparative urbanism produces "the systematic study of similarity and difference among cities or urban processes" (Nijman 2007: 1), the "continental" typologies of cities are proof of the undeveloped state of the comparative methods and lack of typologies based on empirical criteria and conceptual underpinnings applied in the discipline of urban geography (ibid: 2). He, therefore, calls for methodological self-consciousness in order to avoid the misleading notions of scientism, developmentalism and universalist categories in the comparative study of cities regarding their converging or diverging development under conditions of globalisation (ibid: 1). In effect, this also counters attempts to construct a generalising category of "African urbanisation" and calls for a diversification of the account across the variety of cities.

Countering this lack of locally grounded analyses, the discussion under the headword of "urbanization under poverty" (Scholz 2008: 5, Baumgart and Kreibich 2012) calls for differentiated engagement with the local realities created in the urbanising world regions. Thereby the aspect of poverty is relevant, as the poverty levels in the originating regions of migrants might play an important role in explaining the phenomenon of urban-rural migration and needs consideration in the data collection. As a reference to the resources of administration dealing with aspects of urbanisation, this claim to poverty might also be made. However, the conditions, under which a population prone to urban poverty makes its migration choice and under which the migrating individual evaluates chances for income generation and sustained livelihood are in question as explaining factors of urbanisation and conditions in the city can not be reduced to living in economic despair. Even if poverty is rising in the African cities, pairing urbanisation with economic wealth is highly debatable. The definition of the ongoing process of urbanisation is thereby linked to the absence of a somewhat generalised economic status. However, the informal building and economies characterising current urban growth in many urbanising cities in Africa are not only strategies of poverty or indicators 
for lacking state capital. Instead, there are indicators that many cities undergoing urbanisation processes are indeed facing processes of segregation through formal and informal rationales of urbanisation and thus struggle over the distribution of resources (Roy 2009). The questions therein are, thereby, not (only) the provision of resources, but rather the access to them and power relations responsible for their distribution. Having to deal with the living situations of urban poor is therefore not necessarily a result of "urbanization under poverty", but under circumstances the result of socio-economic segregation and the distribution of resources. The specific economic contexts of urbanisation hence need to be discussed for the individual national and local cases and attempts to uncouple the definition of urbanisation from conditions of economic development need to be undertaken.

A strong impulse to write new accounts of urbanisation in specific towns comes from the post-colonial strand of urban studies that has formulated the necessity to overcome historical patterns of thinking in order to describe local development trajectories in the former colonies. Post-colonial studies first arose as a branch of literary studies, but they have extended to other disciplines and expanded to urban studies from there (Göckede 2010: 52, Lindner 2011). Thus, post-colonialism should not be understood as a time period after the wave of (African) independence, but rather as an analytical approach which seeks to question and uncover power-relations developed in a colonial mindset and continued in the practice of a post-colonial environment (see Lindner 2011). The call for a thorough de-colonisation based on analytical findings is mostly inherent. However, their writing has relevance beyond the formerly colonised geographical contexts, as according to these discussions disciplinary thinking in urban studies needs to be reframed. For a long time, urban studies hardly took African cities into account as sites of study and sites of knowledge. The colonial and neo-imperial power relations are deemed responsible for this, are reflected in themes and analytical views in theoretical discourse and are meant to be questioned by the findings of post-colonial (urban) research (Robinson 2006: 2). The approach seeks to overcome developmentalism, conceptions that have led to an exclusion of traditional, informal or low-tech urbanisms from the recognition by urban studies. Urban development policy is thereby informed by the theory on urbanisation questioning these power-relations and relies on instruments for implementation that are effectively directed at addressing the aim of inclusiveness in policy formulation. This is mainly achieved by using dialectic approaches to interpreting the concepts of modernity and tradition, understanding them not as succeeding each other in a progressive development, but rather as parallel developments, which leave space for many ambiguities.

The theoretical discussion is fed from a discussion resulting from practitioners' insights. Since the 1990s, urban professionals increasingly started questioning the body of urban theory, which did not include, represent or explain the urban contexts of rapid urbanisation that they were working in. The point of criticism was thereby not that ideas might come from the West, but that cities with a poor data 
base and inventory have adopted policies that do not match their potential and have not undergone a local target formulation. In 1994, Garth Myers specified that a "Eurocentric 'imprint' as a sub-text" led to the dismissal of indigenous African ideas of the urban for the African cities (Myers 1994: 196). The dismissal of local urbanism is thereby described as a key issue in many failures of states in Africa (ibid), leaving the local planners and urbanists concerned with African cities to question the universality of the common urban theories in place. The discussion, thereby, identifies the planning discipline and key ideas linked to the popular understanding of cities as generally rooted in Europe and North America and as, thus, having a European cultural background (Robinson 2006, Watson 2009). Efforts to establish a universal account of urbanism on the basis of the experiences of cities limited to these "western" regions were consequently strongly contested (Robinson 2006: 41). Referring to this, the predominating "global" view on cities, which is almost exclusively fed by North American and European experience, strikes Roy as focused on flows connected to global economy, excluding large proportions of the world's cities from the research agenda and contributing to policy formulation (Roy 2011a: 406-08). As a result the normative ethic of current planning has to be considered an export product from the European and North American context and questioned as to its appropriateness to the (southern) application context. The resulting guiding principles for urban development spring from the models developed in the "western" context and are termed "regulating fictions" by Jennifer Robinson (2006: 11).

A critical discussion of prevailing planning approaches hence arose among scholars such as Abdumaliq Simone (2004), Jennifer Robinson (2006) and Vanessa Watson (2009), due to the dismissal of local cultures and informal realities and related to theories developed in the urbanising geographical contexts beyond those reflected widely in theory (Roy and AlSayyad 2004). From the starting point of "provincialising" the common "global" and "modern" urban theories as originating in Europe and North America by only granting them validity for their own geographical contexts (Chakrabarty 2008), authors have started to call for what Watson has named "seeing from the South" (Watson 2009). Watson, thereby, does not seek to establish a competing paradigm valid for the hemisphere, but argues that instruments of contemporary urban planning have to be re-evaluated according to their suitability to their implementation context. All in all, the discussion on "seeing from the South" reveals that the problem focus on the global economy and a lack of critical self-questioning regarding hegemonial implications of the urban planning profession have led to inadequate theories for practical application in the many local working contexts.

In the urban professional's quest for policy revision for the cities of the global South, the analytical approach of post-colonial studies has been looking to provide new approaches to some of the crucial questions in various African cities. According to Robinson, the theoretical body of urbanism, springing from western 
experience and claiming universality, should be complemented by urban theories based on the knowledge systems and experience of cities not characterised by strong connections to the global economy or subject to traditional urban planning (Robinson 2006). The acknowledgement that urbanisation processes might be subject to different path-dependencies and logics of organisation than is suggested by "western" urbanisation through industrialisation, signifies that new types of theory building need to be undertaken in cities of Latin America, Asia and Africa in order to describe the phenomena adequately (see Coquery-Vidrovitch 1991, Roy and AlSayyad 2004, Robinson 2006, Watson 2009). The aim is to question and critically reflect patterns and legacies of urban development and overcome universalist and developmentalist assumptions. Based on these insights, impacts of urbanisation in the various cities in and outside of Africa require to be looked at.

\subsection{Informing URBan Policy on URbanisation}

After the above description of the theoretical proposals from urban studies concerning the phenomenon of urbanisation, this chapter seeks to establish how policy formulation and planning address urbanisation following these implications. Thereby, a re-reading of historical urbanisation considering the uneven powerrelations in the urban planning profession and practice is also called for. It is along the lines of post-colonialism that Regina Göckede (2010) describes the necessity for a post-colonial reading of modern urban planning in her article on Ernst May's planning efforts in Kampala (Uganda) in the 1930s. While she notes a tendency by planners and architectural historians to evaluate the social and technical contents of modernist projects as progressive, she finds the African context is all too often reduced to climate and topography, fading out social and architectural history (ibid: 53). Göckede, further, points out that modernism and, hence, modern practices of urban design cannot claim to have developed outside a colonialist context. As she states, the first modernist ideas were developed in Europe in colonial times and with inherent colonial contents, meaning that an intertwinement of colonialism and modernism has to be assumed, beyond the adaption of "neues Bauen" ideas in the colonial territories (ibid: 52). She describes how, although modernism reached the global South with a delay, after it had become a symbol of progress and democracy in the USA, it was used as an instrument to consolidate racist spatial hierarchies and the modernisation of colonial exploitation structures by colonial powers in Africa (ibid: 52-53). She, further, argues that architecture and urban design are dependent on facts generated by the socio-political conditions of the location. So, although modern planning shapes the physical environment and, thereby, has a strong impact on society's everyday life, western historians claim that among all spatial references of globalising architectural modernity, the sovereign subject is only found in Europe's cultural reference. But unlike in the literary disciplines, 
the critical discussion of such racist and colonialist assumptions has bypassed the spatial and construction disciplines so far. She, therefore, calls on the spatial and architectural disciplines to abandon their denial of involvement in colonialism and imperialism and to uncover the origins of the planning epistemologies. The post-colonial approach from other disciplines tackles these issues and is, therefore, found to be a suitable reference point from which urban studies might depart (ibid: 54). In this regard, Robinson (2006: 172) argues that urban policy has - equally to urban theory - been divided into strategies for richer and for poorer cities. Thereby the poorer cities have been recommended to apply tools and interventions geared towards aims of developmentalism and global economics (ibid). Consequently, poorer cities are currently left "tossed" between ambitions to globalise and meeting the demands of the developmentalist agenda (Robinson 2006: 166). Meanwhile, ordinary, casual or everyday aspects of urbanisation also need to be described and conceptualised. Based on these insights, Amin and Graham (1997) as well as Robinson (2006) call for accounts of "ordinary cities" and Hall (2013) describes "ordinary streets". The impetus, practices and movements that construct spaces of operation, habitation and transaction in urbanisation beyond statutory provision need to be considered in the overall accounts. In order to acknowledge and address rationales of urbanisation outside of governmental planning, everyday urbanisation, therefore, needs to be added to the research agenda.

As described earlier, what is on the table in the African urban studies, is nothing less than the re-evaluation of underlying theories and ideas of urban planning in order to avoid replicating segregational patterns of development and power distribution. Thereby, the laws on which urban development is based and by which urban policy is executed need to be challenged for their legitimacy, if they rule out the majority. In this study of urbanisation practices, urban planning needs to be understood as "the management of resources, particularly land, through dynamic processes of informality” (Roy 2009: 80). Hence, understanding planning as inherently forecasting is disregarded, but the review of planning is also set as the crucial question on how to reform the sovereign's rationale on accompanying urbanisation. Unlike the more technically oriented disciplines, Healy (2012: 191f.) describes urban planning as driven by a "community of inquirers", leading to the idea of the planning field not being determined by the delimitations of formal planning parameters, but by "a continually open exploratory and evolving process", a "contingent universal". She, thereby, defines "planning" as "the effort to shape urban and regional development pathways through some deliberate, collective governance efforts" (ibid: 194). The idea of such governance can, thereby, emerge also outside of the formal and professional planning field (ibid: 199).

In the face of a largely unknown but assumed diversification of urban lifestyles, there is generally a need to address the widening range of city life, further referred to as "inclusiveness" (cf. Watson 2009: 188) by revised understandings of urban development and an expanded spectrum of actors contributing to improving living 
conditions in the growing urban settings. The legal constellations in place, though, are often protected by the ruling powers, who seek to protect their covert privileges relying on social exclusion and profit making (Watson 2009: 186). Nevertheless, re-describing the urbanisation process and establishing a theoretical base for current and anticipated urbanisation practice allows policies to be formulated that overcome established professional patterns and address the distinctive needs of the respective cities (Robinson 2006: 172).

A precondition for planning schemes that address the broadest possible range of citizen's interests in the sense of inclusiveness is the understanding of the systems of knowledge informing current planning decisions. To meet the actual local requirements of urbanisation, systems currently informing the planning decisions need to be questioned and revised. Thereby, the current dis-link between development standards and the development potential on the ground - described as "developmentalism" (Escobar cited in Robinson 2006: 4) - needs to be overcome not only in analytical categories but also the regarding the institutional memories, structures and practices of policy directed to current urbanisation. This thesis, thereby, suggests following three steps: data collection in the local context, analysis of the data and third strategy formulation grounded in the results of local findings.

Gathering information: Empirical investigations need to be undertaken to identify the constituting elements of urbanisation before policy aims and principles can be formulated on how to address the phenomenon. For data collection on issues of urban development, Jennifer Robinson (2011) and Patsy Healy (2012) have advocated the use of "case studies" for the purpose of filling in knowledge on urbanising cities but reveal that the question of how to delimit the unit of study, how to organise data collection and how to set up the analysis to adequately grasp the urbanisms of the cities that have so far been underrepresented in urban theory building is still at an experimental level. Even considering the wide range of local predicaments and variations of research project set-ups and resources, this has to be considered a research gap. To address this, they advocate thorough revision of the methodology of case studies and consideration of comparative approaches. While the field of urban studies is described as hitherto largely reluctant to pursue systematic comparative strategies, planning consultancy is noted to have been heavily engaged in almost random comparison by best-practice transfers across cities (Robinson 2011: 2). Not only has this practice failed to take into account failures and possible lessons (Roy 2005: 156), even correcting this omission would ignore the more crucial argumentation against "simplistic borrowing" (Watson 2009: 186). Instead of looking at the success of projects as a criterion for the transfer of planning systems and policy sets, Watson proposes reviewing new ideas regarding their potential to yield principles as opposed to models of development (ibid). 
Systematisation, identification of fields of action: Very few suggestions have been made on systemising data in analyses geared towards formulating policies for urban development that acknowledge current urbanisation. However, Watson identifies the current relationship of informal strategies for survival and the high requirements implied in formal planning and land-use management as "anti-poor" (Watson 2009: 187). Reviewing urban planning to make it stop excluding the poor is thus necessary, as it has not adapted to the changing conditions of urbanisation (Watson 2009). Her argumentation rules that, in order for urban policies not to be anti-poor, the high level requirements of conventional urban legislation need to be discussed in relation to survival strategies of low-income urban dwellers (Watson 2009: 187). Thereby, it is assumed that current urban policies stand in competition to other land-use interests that have so far not been the subject of urban studies. For this, Watson has coined the term "conflict of rationalities" (Watson 2009: 187) in which different governmental and non-governmental actors pursue their own agendas of urban establishment. As these relations are often dominated by their formal or informal legal statuses, remembering that it is the state's institutions that determine this status and questioning on what basis this is undertaken is central to the investigation on "competing rationales of urbanization" (Watson 2009: 187, Roy 2005: 156). However, in the course of this, it is necessary not only to document the questions of land use and possible struggles over it, but also the question of ownership, land-titles and rules of access to land use (Roy 2005: 155), including the parallel (informal) systems of land distribution and appropriation. The consequences of such simultaneous regulatory systems for resource management in urbanisation cannot be discussed without regard for their hierarchical dimension and need to be identified for each particular city affected by urbanisation.

Strategy formulation: While the planning practices guided by modernist understandings and ideals often supplied local elites with tools for promoting modernisation, they are often unsuited to addressing the living conditions of many informal settlements in conditions of rapid urbanisation (Healy 2012: 191, Watson 2009: 187). Therefore, the findings from the accounts of urbanisation of African cities need to serve as information bases for selecting adequate instruments and measures for their specific contexts. Here, a research gap has to be acknowledged, as there are few specifics on how to find adequate planning tools to accommodate the diversified rationales of urbanisation. Nevertheless, the spaces and practices of informal urbanisation are not beyond the control of planning. Since informality has been accounted for largely as a product of the state, it is within the realm of planning professionals to tackle the issues it raises (Roy 2005: 155). For planners in the African context this does not signify a way back to what Myers, referring to Foucault, describes as the „ideology of return“, where „myths“ about pre-colonial history tell of times when „African towns were bastions of equality and fine living for all“ (Myers 1994: 200). Such descriptions are ideals that cannot be re-installed 
or serve as a contextualised planning vision. In this sense, a way ahead needs to be found that addresses the current challenges and complexities of urbanisation in a locally grounded manner. Planning can address the current and anticipated urbanisation in its policies if it can increase its impact on distributive justice and inclusiveness of the urbanisation process.

While Parnell and Simon (2010) suggest tackling the phenomenon of urbanisation at the national level by formulating an "urbanisation policy", recommendations on planning strategies on a city scale are given by Watson (2009). She names different types of strategic planning and participatory budgeting and refers to a Brazilian planning instrument called ZEIS, which, in her mind, has the potential of being inclusive, as it might be adapted to local conditions of dealing with poverty (Watson 2009: 188). On this, a reverse perspective is given by Roy, who describes how existing informal urbanisation practice can feed into policy. Roy recommends four policy epistemologies that might be included in addressing the issues of urban informality (Roy 2005). The first she names as "Policies of Shit", in which the residents of underserviced locations are recognised as the experts in questions of upgrading (ibid: 150-152). Robinson, further, suggests exploring the economic relevance of such basic-infrastructure delivery, by which the provision could be turned into job-opportunities (Robinson 2006: 164-165). Roy's second suggestion is "Underwriting the Right to Participate in the Market", by which policymakers need to actively allow market access for the owners of self-constructed property (Roy 2005: 152-153). By "Strategically using the State of Exception", her third proposition, she propagates the use of the state of informality as a strategic planning tool that can open spaces of possibility (ibid: 153-154). In these, supportive infrastructure for informal activities could be inserted, instead of concentrating state investment on established economic ventures (Robinson 2006: 165). The fourth proposal is "Scale Jumping", by which decision-makers at higher policy levels should be addressed directly (Roy 2005: 154-155). It is assumed that this step would have the effect of making the needs not accommodated by formal regulatory conditions visible with the aim of entering a recognition process.

The urban policy agenda arising from the broadened array of urbanisation practice needs to be "situated" in the sense that it takes into account the distinct characteristics of the place for which it is formulated (Watson 2009: 187). While it seems efficient and legitimate to base policy formulation on experiences from other times or locations, Watson points out that the underlying assumptions on society, politics, economy or environment need to be made transparent in the any transfer of ideas, while it needs to be questioned if these can be upheld in the receiving context (ibid). The perils of a planning view disconnected from low-income urbanisation lie in the fact that the "aggregate impact" of local individual planning and building decisions might not be as clearly traceable as governmental or largescale interventions, while impacting strongly on everyday life (Myers 1994: 196). 
Reconsidering the notion of parallel rationales of urbanisation, Jenkins and Eskemose further propose that one has to assume there to be a governmental practice in place already that "engages with these largely endogenous social processes, while pretending to adhere to its generally exogenous normative principles" (Jenkins and Eskemose 2011: 14). Their advice is to support these practices as a "Realpraxis" in reference to a "Realpolitik" (ibid). The underlying rationales of political practice are so obscured for many locations in Sub-Saharan Africa, but need to be given consideration, when questioning the aims and effectiveness of the actual practice before the point at which it might reflexively feed into policy formulation and toolshaping.

The literature review has made evident that current policy re-conceptualisations not only aim at the legal status of urbanisation practices and resulting structures, but are also concerned with their consideration as "modern", as "urban" itself, and as seeing its inhabitants as "sovereign subjects". Roy's "idiom of urbanization" can, therefore, serve as a starting point and is supplemented by these topics to structure the account of urbanisation in a flexible and modular account. The discussion on these four aspects is summarised in the following accounts on the legal status of urbanisation practices and structures, the regulating principles and paradigms that underpin the urbanisation practices, the question of delimitations of the urban as well as the negotiation of citizenship in the rapidly growing cities.

\subsubsection{Beyond the Formal-Informal Dichotomy ${ }^{1}$}

Informal modes of urbanisation seem to account for a large proportion of current urbanisation but have so far largely been ignored in the accounts of urbanisation and as a basis of policy formulation (Roy 2005). Informal structures and practices come about in urbanisation, for the one part because obtaining the necessary building permissions, plans and land rights is tedious, expensive, and, therefore, demands are opaque (Watson 2009: 173). For the other, planning law is often merely seen as an irritation by project developers and is not in a position or willing to control the excessive developments of the private sector (Berrisford 2011: 210).

In the general European understanding, urban informality as described by Roy and Al Sayyad (2004) is still imagined as a phenomenon of poverty, existing in geographies of "the Global South", far beyond Europe's own urban realities. In the public debate, but also in parts of the academic discussion, urban informality as a structural phenomenon and practical rationale is, hence, attributed to the emergence of slums. According to some, the slum has, therefore, become synonymous with urban informality and is clearly distinguished from the formal city (Myers 2011: 76). In this binary understanding, the legal status of building structures

1 | An earlier version of this sub-chapter was published in German (Appelhans 2014). 
and urban practices is specified by the terms "formal" and "informal". Thereby, structures and processes abiding by the law are classified as formal, while actions outside of regulation are informal. The theoretical discussion on urban informality practised in everyday life of many urbanising cities is, thus, divided from the mainly European discussion centred around informal planning tools, such as master plans or participation processes beyond the requirements of local planning law.

Yet, the structures and practices produced informally are not necessarily illegal and the binary and static understanding needs to be countered by the acknowledgement of a dynamic dialectic between formal and informal, encompassing also the activities of state institutions. Viewing informality as a strategy of urbanisation that can be practised by the administration, as well as the population, thereby, serves as an analytical vantage point that allows to interpret the interplay of formal and informal practices constructing informal dwellings, as well as seeing formal urban structures as being produced by a range of formal and informal activities (Roy 2011a: 233). Informal urban development can therefore not be reduced to appear in squatter settlements, but rather needs to be understood as independent from poverty and as a wider phenomenon of urbanisation, that also includes wealthy agents and state actors. On this basis, formality and informality are integral components of urbanisation processes and can be found in all cities across the globe, while the qualification of city structures outside the formal regulatory framework as "informal" is not a fixed attribute and can be interpreted as a heuristic construction, as the sovereign himself variably determines the informal status (Roy 2011: 233). By holding the authority over appointing formality, the sovereign has the possibility of drawing lines between formal and informal. The legal status is therefore not a fixed condition, but rather subject to a dynamic of de- and re-formalisation. On the African continent control of this sanction and legitimisation is of particular sensitivity, as planning law has gained a bad reputation after being put into use by oppressive regimes to legitimise the repression of parts of the population (Berrisford 2011: 215).

Despite the clear definitions in documents and regulations, research observations show that formal and informal are not clearly distinguishable on the ground. Next to building activities, the informal urbanisation, thereby, may also include socio-economic strategies of survival that are not necessarily bound to a specific location and are of service also to residents of formal areas. Formal and informal spatial practices thereby intertwine. A study of governance in Mozambique by Jenkins and Eskemose (2011: 14) reveals how land and housing development as physical aspects of urban development materialise through a complex and hybrid set of interactions. Thereby, government agencies, which are generally considered formal agents, interact with social agents (such as households) that are considered informal actors in such hybrid manners. The resulting urban structures manifested in land-use and construction apply to socio-cultural norms of the households developing them, while adhering to the structures of economic and mainly local 
political concepts (ibid). On the basis of her research in India, Roy, meanwhile. describes how random and fluctuant the conditions of "legal/illegal, legitimate and illegitimate, authorized and unauthorized" are, while at the same time they are instruments for the execution of state power (Roy 2011: 233). She shows how different strategies of urbanisation that are undertaken by the state and by nongovernmental actors include formal as well as informal practices (Roy 2009: 86). As Meagher describes for the case of informal economies in Nigeria, if informal organisations have no means of holding public officials accountable regarding their needs, this results in a relation of neglect or conspiracy between the informal economies and the state (Meagher 2011: 68-69). According to Berrisford (2011: 211), the negotiation of formal and informal is thereby a deciding societal distinction, as in connection with enforcing land rights it can have re-directional or consolidating effects on land distribution. Structures mimicking formal appearances and practices, such as middle-income housing constructed on agricultural land or nature reserves, are not even recognised as informal and have good chances of being legitimised. The practice of informal urbanisation is thus not limited to activities of informal dwellers but is also practised by wealthy citizens and public officers (Roy 2011: 233). According to Roy, this meriting of "elite informality", paired with the criminalisation of poorer forms of informality, produces spatial inequality. In a development dynamic the announcement of acceptance or non-acceptance of structures thereby tends to render poorer areas illegal, while wealthier informal urbanisation is legalised and can continue accumulating wealth (Roy 2011: 233).

At the same time, traditional, colonial, modernist or neo-liberal practices coexist for land distribution and the access to settlement areas, limiting each other's reach and, under circumstances, leading to a dominance of de-facto rights (Jenkins 2004: 211f.). The competing formal and informal agency leads to the parallel existence of principles of regulation. It is, thereby, possible for different modes of land distribution and claims resulting from land practices to collide (ibid). Some urban researchers even doubt the legitimacy of formal regulatory systems and laws if they do not accommodate these complex social, economic and political realities of population majorities, ruling them out of formality (Jenkins 2004: 210, Watson 2009: 187, Jenkins and Eskemose 2011: 14).

Due to the recent insights, dissolving the dichotomy between formality and informality plays a central role in the re-conceptualisation of urbanisation. The binary understanding of formality and informality in the sense of "order and chaos" or "citizenry and labourers" cannot be upheld, although it could be questioned if the contrasting terms "formal" and "informal" adequately describe the urban structures and processes in which formal and informal conditions alternate and are overlaid, thus subjecting them to conditions of clear distinction of status. An investigation of these conditions is seen as particularly useful in the deconstructing the legitimising bases of state power and its use of planning instruments such as mapping, cadastres, land-use, surveying and foremost legislation to secure its 
status (Roy 2011: 233). Explicitly, this deconstruction means documenting how the determination of informality structures the urbanisation practices of different actors. For Roy, the crucial question in this context is "why some forms of informality are criminalized and thus rendered illegal while others enjoy state sanction or are even practises of the state" (Roy 2009: 83). There is a need to unveil these issues and question the corresponding interventions on behalf of distributive justice.

\subsubsection{Establishing Rural-Urban Linkages}

The distinction between "modern" and "traditional" is a fundamental regulating factor for the selection of building styles and adaptation of urban practices. The structures and actions considered modern will usually be selected as acceptable or desired in the course of urbanisation, while others that are not considered state of the art will fall into general disregard. The definition of modern and traditional is also grounded in the underlying paradigms of planning. Since ethical considerations should underlie all urban planning, their origin and suitability to the context of application must be considered in thought and practice of the profession (Roy 2011a: 412). However, what is modern is subject to negotiation. It has been recognised as a fundamental problem that modernity has, so far, not been attributed to artefacts and processes in what has been coined "the developing world".

According to Robinson, it is a theoretical manoeuvre that suggested a close tie between particular cities and the notion of modernity, which dominated the view on cities and resulted in hierarchical orders dividing the cities of the world into developed and undeveloped (Robinson 2011: 3). Cities embracing tradition were, thereby, rendered primitive or outdated and therefore un-modern (ibid). What results is a Eurocentric interpretation of modernity as "dynamic, individualising, rational", with a contrasting understanding of tradition as "static, communal, in thrall to the sacred" (Robinson 2006: 15). Thereby, the Western cities considered as modern were held to be particularly innovative if they adopted novelty, while those regarded as traditional were stigmatised as imitative if they embraced the new (ibid: 7).

Thus far, drawing on the assumption of a divided tradition and modernity among cities, those places not conforming to the assumed traits of contemporary urbanity have been deemed "in need of development" (Robinson 2011: 3). The practices and resulting structures are, consequently, negotiable based on such a declaration. This approach of institutional encouragement of "lifting" cities to a supposedly "higher" standard by mainly technical criteria has become known as "developmentalism" (Robinson 2006: 4). Modern buildings, designed according to technical and economic criteria, are thereby meant to replace structures with conditions of sub-standard sanitation. However, this fails to take into account the strengths of informally constructed settlements regarding the social, cultural and flexible (Robinson 2006). Thereby, fictive representations of other urban locations 
are used as benchmarks, a phenomenon Robinson (2006: 11) refers to as "regulating fiction". By using such de-contextualised best-practice examples and stereotyped images as guiding principles of urban development, the actual traits and potentials of the cities supposedly not conforming to modernity have fallen out of view and hence the perspectives of development are reduced to standardised imaginations (Robinson 2006: 4). However, there are limits to the power of travelling planning paradigms transported in best-practice examples and "regulating fictions". On the transfer of planning concepts, Healy points out that "travelling planning concepts" cannot be reduced to promoting new forms of colonisation, as the acknowledgement of the intricacy and contingency of their implementation within certain development pathways calls their universal validity into question (Healy 2012: 191). In fact, Robinson herself states that "we can generally predict an active cultural politics of engagement with circulating modernities - even when modernity is externally imposed" (Robinson 2006: 78) Cities thereby take the role of settings for the circulation and gathering of urbanisms, which acquire particular contextual meanings (Robinson 2006: 20). As a result, what remains undescribed is how paradigms are adapted to local contexts and form specific interpretations of modernity and tradition.

In order to qualify the current urbanisation process and gain insights into its aspects of transformation, the complex phenomenon of "urbanisation" needs to be conceptualised based on data from local experience. According to Robinson, poorer cities need to be released from "the imaginative straightjacket of imitative urbanism and the regulating fiction of catching up to wealthier, Western cities that categorising and hierarchical approaches to cities produce" (Robinson 2006: 11). Avoiding these pitfalls new approaches to urban development need to be explored. On these grounds, the understanding and transfer of planning ideas needs to be perpetually questioned and updated, in order to critically confront existing practices, which cannot claim to be planning on the grounds of having evaded the critical debate by the field (Healy 2012: 201-202). Just like the work by Roy mentioned above on the relation of formality and informality within urbanisation, Robinson (2006) suggests dissolving the binary view of modern and traditional as attributes of cities and put them into a dialectic relation. Robinson (2006: 4) therefore challenges the understanding of urban modernity and re-coins the term "urban modernity" to be understood as "cultural experience of contemporary city life and the associated cultural valorisation and celebration of innovation and novelty" . Thereby tradition is understood as an element of modernity, leaving African city dwellers that practise forms of reworking their traditions to be modern urbanites (ibid: 48f). 


\subsubsection{Countering the Rural-Urban Divide}

Current phenomena of urbanisation are calling into question what is conventionally understood as defining "cityness". Apparently, the commonplace ideas of the countryside being a site of village-life and agricultural economy and the city being the site of industrial development and progressive lifestyles can be attributed to modernist interpretations (Redepennig 2011: 86). These interpretations were based on a moral as well as a political geography that established a binary view on the two parts at the start of the 20th century (Redepennig 2011: 87). Despite the strong distinction between rural and urban practices, the Chicago school assumed that "urban culture could pop up almost anywhere", as it was not confined to the physical area of cities. This dualist distinction has eventually become relevant to everyday life in the Western nations (Redepennig 2011: 89).

The commonplace distinctions of rural and urban have been called into question by observations of recent urbanisation. The movement of people, goods and practices across the African countries seems to follow organisational patterns that are not congruent with the administrative distinction between rural and urban and questions the binary understanding of rural and urban. Two important phenomena are identified by Einhard Schmidt-Kallert that shape migration in the current rapid urbanisation of Africa and Asia: non-permanent migration and the reliance on multi-locational households (Schmidt-Kallert 2009: 323). The urbanisation processes in Asia and Africa, thus, do not follow uni-directional patterns of permanent migration (ibid: 320). Instead, one or several members of one household change their location for reasons of income generation or education for a seasonal or aim-specific period of time. This, for example, can be moving to the city during a bad harvest for alternative employment opportunities or accessing secondary education, but just as well be temporarily returning to the rural areas to re-invest capital gains from economic activities in the city in livestock. These movements can be assumed to serve as a strategy for households to deal with rising urban poverty (UN-Habitat 2007: 5) as they strive to minimise risks by spreading sources of income generation. The rural-urban divide is, hence, cross cut by mobility of practices and structures once allocated to rural or urban geographies, causing it to be blurred and dissolved in the course.

Yet, it is currently not well documented and quantified where the reception structures of rural-urban migration lie in the urban fabric and how the patterns function (Schmidt-Kallert 2009: 323). It can, however, be assumed that temporary migration is increasing in different parts of the world (ibid: 319). The discrepancy between housing needs as well as access to land use and the prospective delivery of shelter is particularly high under such fluctuant circumstances.

As ephemeral as the phenomena appear in descriptions, the assumed impact is, nevertheless, substantial: While it is suspected that migration is, at least seasonally, depriving rural and urban areas of their most educated labour force, there 
is a concentration of skills in the cities, as also external return migrants come to the cities rather than to the countryside (Boquier 2004:140). On this issue, Simone notes that, as yet, "not enough attention is placed in urban planning on making use of how movement continuously respatializes social positions and resources. Cities are mobile entities - oscillating relationalities that stretch and retract, include and exclude, filter and circulate." (Simone 2011: 390). The challenge posed is. hence. to integrate movement as a mode of urbanisation into frameworks directing urban development and fixed building structures. It is. thereby, assumed that building structures need to reflect and facilitate mobile livelihoods and are, therefore, directly linked to the occupant's lifestyle and income opportunity. For providing this, analyses with broader household concepts than those assuming living and eating under the same roof have to be utilised to allow the explanation of multilocational livelihood patterns (Schmidt-Kallert 2009: 324).

These issues and phenomena observed in the rural-urban interface need not only to be recognised but also to be translated into policies and projects (SchmidtKallert 2009: 331). So far, the longstanding history of movement on the African continent has rarely been considered in urban development policies (Simone 2012: 379). Simone suggests that "instead of trying to keep people in place, in newly democratic and decentralized localities, perhaps emphasis should be placed on how to make already existent movement more productive and convenient, and to accede to the possibility that urban residents "come to go and go to come" (ibid: 390). He calls this "making productive use of urbanities of movement as a formal resource" (ibid: 379). How, then, can rural and urban be defined in contexts of high-mobility creating fluctuant structures and constantly shifting boundaries to do so? Meanwhile urban studies researchers have countered binary and exclusionary assumptions of the "rural" and the "urban" and have declared that a range of social processes which had been declared un-urban by Chicago School scholars are actually shaping the nature of cities (Robinson 2006: 37). To clearly identify the impacts, the rural-urban divide in the analytical description of urbanisation needs to be overcome. It is suggested that complementary and differentiated urban and rural development strategies are developed, rather than abandoning one for the other (Parnell and Simon 2010: n.n.). Rural and urban should, hence, not be viewed as opposites, but as concepts that, in a dialectic understanding, spring from one another. To dissolve the predominant duality, Redepenning refers to the work of Luhmann, who points out that there are always interconnections between the divided (Redepennig 2011: 91). Using the image of the rural being a mirror to recognise the urban and vice versa, he states that "even if only one side of the distinction is picked out as a central theme, and therefore made present, the absent side is nevertheless present and necessary and silently shapes its other" (ibid: 97). There is, therefore, no sharp border between the concepts, but they rather serve as means of interpretation for social concepts. The idea of transition from a rural to an urban lifestyle within two generations, thus, has to be questioned, as it originates from 
Eurocentric views of observation and is not adequate to describe the rural-urban relations within the rapid urbanisation processes in the global regions mentioned (Schmidt-Kallert 2009: 319). Instead, "most of the studies from Africa and Asia [...] converge on the statement that forming multi-locational households, thereby spreading assets and risks across space, is not simply an interim phenomenon but a strategy which may be upheld for generations" (ibid: 330). Migration in these areas, therefore, has to be viewed not as a "once in a life-time decision to leave" rural areas and move into a city, but rather more complex and diverse than models based on industrialisation suggest (Schmidt-Kallert 2009: 319). While some migrants undergo a transgression from rural "traditional" lifestyles towards what is perceived as modern and urban lifestyles, others undergo more hybrid transitions. Bearing in mind the analogies of the socio-cultural interpretation of rural-urban and modern-traditional, the dichotomy of rural-urban can, thus, be dissolved by reading them as varied manners of livelihood that come in different varieties of being purely agricultural and rural based or urban and wage labour oriented, but also as a range of intermediate and mixed strategies of survival (Fereya and Terefe 2011: 223). While it is understood that a universal theory of urbanism can not be formulated, the differences between the livelihoods forming the practices of urbanism can be understood as diverse, without creating judgement by installing benchmarking or a hiearchical order among the variety (Robinson 2006: 41). The range of lifestyles currently viewed is, hence, not a mix of progressive developments at different stages but rather one of parallel coexistence and interaction of varieties, of which some will vanish and others might prevail. Which of the strategies is considered urban and which rural will be defined from the local rural and the local urban viewpoint, acting as the mirrors of self-identification. The "rural" is used to describe something that does not represent the idea of city-life. This local definition of what belongs in a city and what does not will lead to a local notion of urban deviating from what a developmentalist perspective would assume. One of the central understandings of the revised position is thereby, that modernity can occur in cities, but it is not a pre-condition for their definition as "urban" in relation to the „rural“.

\subsubsection{Re-Framing Local-Cosmopolitan Constellations}

The question what is termed as "ethnic" - or in the African context "tribal", "clan related" or "traditional" - and what is "cosmopolitan" is at the heart of the question on who is an urbanite. To local identities "connections and travels beyond the local are long-standing and constitutive" (Robinson 2006: 3). In a globalising world, these connections are assumed to become increasingly accessible to the individual. Connected to this question is the attribution of citizen's rights in the understanding of the term "citizen" as the culturally and socially "legitimate" or accepted urban dweller acting within such networks. According to Simone, the 
sovereign rationale of development "is also about capturing residents to a life aesthetic defined by the state so that they can be citizens. It is making ethical beings; about holding people in relations that makes them governable. As such, development is about assisting residents to meet their needs in a "good" way or a "moral" way." (Simone 2004: 7). Thereby, the state as the sovereign has an interest in subjecting individuals to its policies and disregarding competing power structures. However, ethnic ties and family structures are major configurators of African societies. Here the hierarchical construction of the primitive and the developed is often applied to draw boundaries between clan structures and the government. The assumptions regarding the uni-directional flow of ideas between the tribal and the cosmopolitan thus become relevant. The "primitive" is, thereby, implicitly assumed to be receptional and accommodating, while its agency is overlooked. Traditional forms of administration are then overlooked and community leadership unrecognised (cf. Berrisford 2011). However, evidence has been provided that the competition between indigenous law and international standards implemented in African cities cannot be assumed to be uni-directional, but an exchange embrace and adaptation of ideas takes place. An example for this is the adoption of modernist ideas by the African independence movements and the construction of new capitals with hybrid interpretations of modernist design principles to suit local socialities (Robinson 2006: 84). Other cases, such as the embrace of role models, changing identities and clashes of gender roles with globalised value systems as phenomena of how conformity to citizenship and, thus, access to rights can be seen as a struggle for power, identity and resources, have hardly been the subject of discussion in urban studies.

The description of formation of identities compatible or non-compatible with awarding citizenship consequently needs to be addressed in urban studies' accounts of urbanism. While Simone (2004: 17) argues that all African cities are subject to similar conditions of globalisation and are, thus, converging, the links between external factors such as globalisation and local configurations need to be examined and their respective roles as factors determining convergence or divergence in development paths established. It has to be established, how connected citizens are to a universal idea of the "urbanite" while in keeping with local contingencies. Therein, "we need a form of theorizing that can be as cosmopolitan as the cities we try to describe" (Robinson 2006: 3). Comparative urbanism, thereby, needs to aim for an analytical concept that reflects diversity regarding actors and systems of regulation of urban development (ibid: 9). The topic also needs to leave the realm of anthropological descriptions to enter policy formulation. In this respect, it needs to be identified who the sovereign subjects in urban contexts of postcolonial African cities are, how they are organised and governed. The question is: Who is a citizen? In order to overcome exclusionary perceptions of which criteria allow individuals to be viewed as citizens, the diversity of local identities needs to be placed into a global context. If the circulation of ideas formerly described as 
imitative in certain contexts is described as appropriation instead (ibid: 77), the role of the implementing society changes from being viewed as perceptive to being selective and adaptive. Thereby, ethnic identities can conform to cosmopolitan requirements. Hence, "there is a possibility for different kinds of urbanism and diverse ways of life" (ibid: 7) that give account "on a diversity of ways of living in the city" (ibid: 63). What was deemed primitive by colonial accounts, hence, has to be re-assumed to be tradition in the sense of being an "element of urban modernity, urban nature of ethnicities, specific form of urbanism, revising the ethnic identity" (ibid: 48), giving evidence of social innovation not only in the cosmopolitan, but also in the tribal. Spatially, this results in viewing places as a composite with connections to other locations and cultures (ibid: 3 ), while the citizens can be acknowledged as citizens with decision-making rights, regardless of their ethnic and cultural background.

\subsection{Assembling Narratives of Urbanisation in African Cities}

The literature review for this research project has confirmed that there is a lack of to-the-point descriptions of the processes and impacts of contemporary urbanisation in the African context. The variants of the phenomenon of urbanisation have not been identified between the different cities, and hypothetical urbanisation types resulting are not included in general urbanisation theory. Neither have differentiation processes within cities' urbanisation trajectories received adequate academic attention. Current urbanisation in Africa is not only a population shift from the rural to the urban, but also livelihood transformation leading to socioeconomic and cultural diversification. The process is multi-directional and irreversible, the sites of urbanisation are not only situated in the mega-cities, but rapid rates of urbanisation are observed especially in the small and medium-sized towns. However, according to the findings of current academic debate, the conceptualisation of urbanisation in Africa has been obstructed by the lack of adequate analytical tools. The lack of matching theory to describe the everyday reality in many African cities and its substitution by Eurocentric concepts has been named as "theories which are out of place" (Myers 1994: 209). Consequently urbanisation in Africa has not been systematically described and accounts of urban development are still scarce. There is need for African-centred research to verify the applicability of the existing theoretical concepts to the object of investigation (thus the respective city in question). There is, hence, a research gap on urbanisation in Africa and need for more nuanced local data that needs to be addressed. Within this account of urbanisation, location-specific typologies of urbanisation practices need to be portrayed and discussed. 
As a result of urbanisation, the incremental strategies and assumed diversification of urbanising trajectories among and lifestyles within the cities, form new challenges to urban planning that until now remain largely unspecified. Currently, the implementation of "universal" planning tools to address the most urgent or highly prioritised issues of development are bridging the gap of laying down informed policies to address such issues. On the basis of data collection, site-specific descriptions of the phenomena, impacts and arising needs of urbanisation within the towns can be given. Policy can, thereby, improve its role and impact to serve distributive justice and promote wider-scale improvement of living conditions. Choosing from the range of analytical approaches reviewed in this chapter, the focus on the relation of urbanisation will, therefore, be studied by following the proposals made by Ananya Roy's “idiom of urbanisation” (Roy 2009). Theorising on the case of India, Roy talks of an "idiom of urbanization", which is "antithetical to planning - indeed anti-planning - while it can and must be understood as a planning regime, with informality as a key feature" (Roy 2009: 82). Following the argumentation of Roy (2009: 86), governmental planning and the ordinary practices beyond it both include formal and informal actions. Together, they constitute the "idiom of urbanisation" that can be used to structure the account of urban development. (ibid) Based on the evidence from such an analytical approach, planning procedures and instruments can be reconsidered and revised, while also granting practices of everyday urbanisation legitimacy. Her experiences from India will be used as a framework to structure the investigation of Bahir Dar as a case of urbanisation practice in the Ethiopian context. Thereby the concept of "urbanisation as an idiom" is useful to structure the description of urbanisation for the use in planning, as it allows the complexities to be described instead of reducing the process to a linear transgression by questioning power relations and constellations of interests behind urbanisation. The idiom of urbanisation as Roy describes it will, thereby, be expanded to suit the purposes of this investigation, not only to include formal and informal aspects but rather to distinguish "planning" from other rationales of urbanisation that are either formal or informal but non-governmental, which will be termed "everyday urbanisation". Thereby the development path of urban planning and its relation to everyday urbanisation will be described as a variety of competing rationales forming a location-specific "idiom of urbanisation". The approach can, thereby, reflect not only the dialectic of urban formality and informality but also the dialectic in other topics such as those described in this chapter (2.2.2 to 2.2.4), including those that might arise from site-specific constellations. It is, hence, possible to value the contingencies rather than to judge by a set standard.

Although the set-up of the actors practising urbanisation is assumed to be dialectic and not binary, a focus on the relation of formal governmental and unspecified self-organised urbanisation in a specific location is necessary, as current policy transfers and concepts need to be questioned regarding their local suitability. So, in order to move away from the common de-contextualisation in planning 
programme development, local conditions in a relevant spatial area need to be studied. By applying and developing post-colonial research suggestions into methodological frameworks for policy formulation, dominant planning approaches like the "African City", developmentalism, economic ranking and best-practice are disregarded to avoid a planning practice that is not placed in the relevant urban context. Instead, the findings from investigating "everyday urbanisation" with its elements such as migration, auto-construction, traditional land-practices, investment-driven projects etc. and its relation to statutory planning as another rationale of urbanisation can be re-considered regarding their contribution to the ongoing urban transformation.

It is assumed, however, that the current generalisations on the urbanisation processes in Sub-Saharan African cities prevent the production of specific solutions to local demands and the consideration of locally available resources in the individual cities. The location should define what kind of practical development tools it requires in contrast to the way they are currently chosen. The subject of the thesis is hence to specify in what respect they need to be elaborated or adapted, in order to improve living conditions under the conditions of urbanisation. 



\section{Accounts of Ethiopian Urbanisation}

This chapter gives an overview of the research discussions on urbanisation in Ethiopia and current descriptions of urbanisation there. The limits of knowledge on the issue of urbanisation are pointed out. Material on the ancient history of urban Ethiopia is the starting point of the review, in order to clarify that the development of urban structures and urbanism is not a recent phenomenon in the country. Nevertheless, a new phase of rapid urban growth has to be acknowledged since the early 20th century, which needs to be conceptually framed. The chapter gives an account of the urban policies that have been developed so far at the national level in order to clarify the institutional framework under which urban development in Ethiopia is regulated. It, further, serves as a reference to which the specific case of Bahir Dar can be compared later in this thesis.

As $83.9 \%$ of the total population live in the rural areas, mainly as small-scale farmers (CSA 2008: 19), Ethiopia's levels of urbanised population are among the lowest in the world. The overall percentage of inhabitants living in Ethiopian cities was at $16.1 \%$ in 2007 (ibid). This is the result of the slow speed of urbanisation until the arrival of the Italians in the 1930s (Golini et al. 2001: 93). This low level of urban residence seems particularly surprising in the face of Ethiopia's ancient history of urban settlements and the foundation of cities in the Axumite empire as early as the fourth century BC (Fasil Giorghis 2010: 49). Nevertheless, prior to the 20th century, caravan trade, feudal residences and shifting capitals as well as military garrisons formed the bases for establishing towns in Ethiopia (Koehn 1979: 215, Solomon Mulugeta 1997: 190). However, as in other African countries, there has been a struggle for Ethiopian urban history to find acknowledgement, even within the scholarly Ethiopianist discourse. A common narrative on the early Ethiopian towns is that they were not permanent sites of settlement, and the only historical exceptions as sites of permanent residence are Axum and Gondar (Liyew Adamu 1994: 35, Golini et al. 2001: 94-96, Gebeyaw Walle 2003: 20-21). The royal camps are said not to have had the support of an urban citizenry and the artisans and traders following these travelling camps were focused on the supply to the camp (Liyew Adamu 1994: 35-36). Meanwhile, the remaining population is assumed to have been supplied by open-air field markets outside the settlements (ibid: 36-37). 
According to this line of argumentation, modern urban development with a hierarchical network of cities cannot be traced back further than the 19th century (Liyew Adamu 1994: 35). Donald Crummey (1987) challenged this account of absence of towns in Ethiopian history, as he believes a researcher's bias has led to a focus on the traversing royal camps and dismissed evidence of fixed settlements inhabited by the ordinary population. Thereby, Crummey (1987: 1) does not contest the basic proposition of the discourse that nucleated concentrations of population were not common in Ethiopian history. Crummey (1987: 12) notes that the establishment of a royal residence is not to be confused with the founding of a town on the same site. Instead, one has to assume that some nucleated concentrations of population did exist (ibid). According to him, a civil type of permanent town pertained before the 18th and 19th centuries (ibid: 2). These Ethiopian towns can be described as permanent, nucleated centres of settlement (ibid). They were found throughout the Amhara and Tigrinian speaking areas and constituted the upper end of a spectrum that ranged in size from hamlets of around one hundred residents to towns with as many as 6,000 to 10,000 inhabitants (ibid: 2). His opinion is supported by evidence from Richard Pankhurst, who notes that the establishment of settlements with small numbers of stone buildings, such as Emfraz, Gorgora and Danquaz in the Lake Tana area, marks the transition from royal camps to more settled capitals (as precursors of the well known site of Gondar) in the second half of the 16th century (Pankhurst 1979: 426). Pankhurst drew attention to these towns, but, due to methodological issues, his topic was dismissed by some other scholars (Crummey 1987: 2). However, other researchers have come to support his findings, and studies on varieties and frequencies of clustered settlements, particularly in the Amhara area, furthered the notion of a historical Ethiopian town (ibid: 2). Thereby, "towns were an intrinsic and significant feature of the physical and social geography of Christian Ethiopia in the eighteenth and nineteenth centuries" (ibid: 2) and have to be considered indigenous (ibid: 15). Crummey points this out, as the contingency of Ethiopian cities was repeatedly challenged and attributed to foreign influence in scholarly publications (cf. Koehn 1979: 217). This assumption has led to hypotheses that describe cities in Ethiopia as foreign installations and, hence, disconnected from historical roots (ibid). Contrary to this, however, also the smaller settlements of about 2,000 to 4,000 inhabitants are to be viewed as deeply interconnected with their rural surroundings, while functionally serving as a city to these surroundings, despite their comparatively small size (Crummey 1987: 2). Reducing them to having been installed as foreign outposts would, thus, disregard the fact of their emergence as products of their local societies (ibid: 2-3). So, even beyond the evident ancient sites of Axum and Gondar, small settlements have been historically verified in the meantime.

Largely lacking are descriptions of the historical settlements, as the sources are limited and not representative. The 18th and 19th century literature is largely restricted to the accounts of foreign travellers, as the written Ethiopian sources 
of the time are not descriptive of the localities' nature or appearances (Crummey 1987: 3). The travellers, in turn, apply their own urban nomenclature to structures foreign to them for which they might not have had more suitable vocabulary (ibid: 3). Within these accounts, Ethiopia is said to have had a specific role in the European imagination and in European geopolitics, shaped during the Portuguese Jesuit period starting at the beginning of the 16th century (Martínez d'Alós Moner 2003: 165 f.). Thereby, Ethiopia was reduced to a somewhat enclosed country with Christian customs, Semitic elements and a few other notions (ibid: 174).

Urbanisation in Ethiopia accelerated after the Italian occupation (Golini 2001: 93) and has not stagnated since. Between 1950 and 1965, it reached rates of 5.4 and $5.6 \%$ p.a., resulting in a doubling of urban population every 13 years (ibid: 93). In $1975,9.5 \%$ of the population lived in urban areas of at least 2,000 inhabitants (ibid: 92). The period of the largest urban growth in the time up to 1975 can be linked to the highest rate of rural-urban difference in population development, which signifies that the urban growth was triggered by rural-urban migration (ibid: 93). Urbanisation continued at a rapid pace in the final decades of the 20th century, with another peak of 5.93\% urban growth in 1985-1990 (ibid: 93). The low level of urbanised population is, thereby, about to change from a small minority into about a third of the total population, as the UN extrapolates figures of $10.4 \%$ in 1980 to a projected $27.4 \%$ in 2030 (UN-HABITAT 2008: 171). The total size of the urban population is, thus, expected to almost triple within a time span of five decades. Although rapid urban growth will continue, the coming of urbanisation in the towns has only received modest interest from the field of Ethiopian studies. The early settlements were repeatedly dismissed as exceptions in a largely rural society (Genet Alem 2011: 10). Given the current figures for urban development, this will have to change. However, the definition of what a town is in Ethiopia seems disputed, as the historical sites of urbanisation have not been sufficiently interrogated (Crummey 1987, Genet Alem 2011: 10). The statistical criteria of a "town" are limited to the quantitative point of having more than 2,000 inhabitants (Liyew Adamu 1994: 50). In fact, the average size of Ethiopian cities, excluding Addis Ababa, was not significantly bigger than this minimum figure in 1994, resulting in a mean of 5,670 inhabitants according to the CSA (Golini 2001: 101). Golini et al. dismiss the current urban network as "weak", as there are "urban deserts", in which no small and medium-sized towns exist to serve the surrounding area (Golini et al. 2001: 93). Meanwhile, just as the discussion on global urbanisation has focused on the existing and proclaimed mega-cities of 10 million inhabitants and more (see chapter 1), the discussion on rapidly growing Ethiopian cities is largely fixed to the national capital and primate city Addis Ababa, with an estimated population of 4-5 million. The population figures are also reflected in the number of cities with more than 50,000 inhabitants, which rose from just four in 1994 to more than 25 in the year 2005 (see figure 2). While the map shows that larger urban structures in 
Ethiopia are, indeed, a recent phenomenon, it also indicates a need for discussion on the phenomenon of urbanisation within the secondary cities.

Fig. 2: Urban Growth in Ethiopia

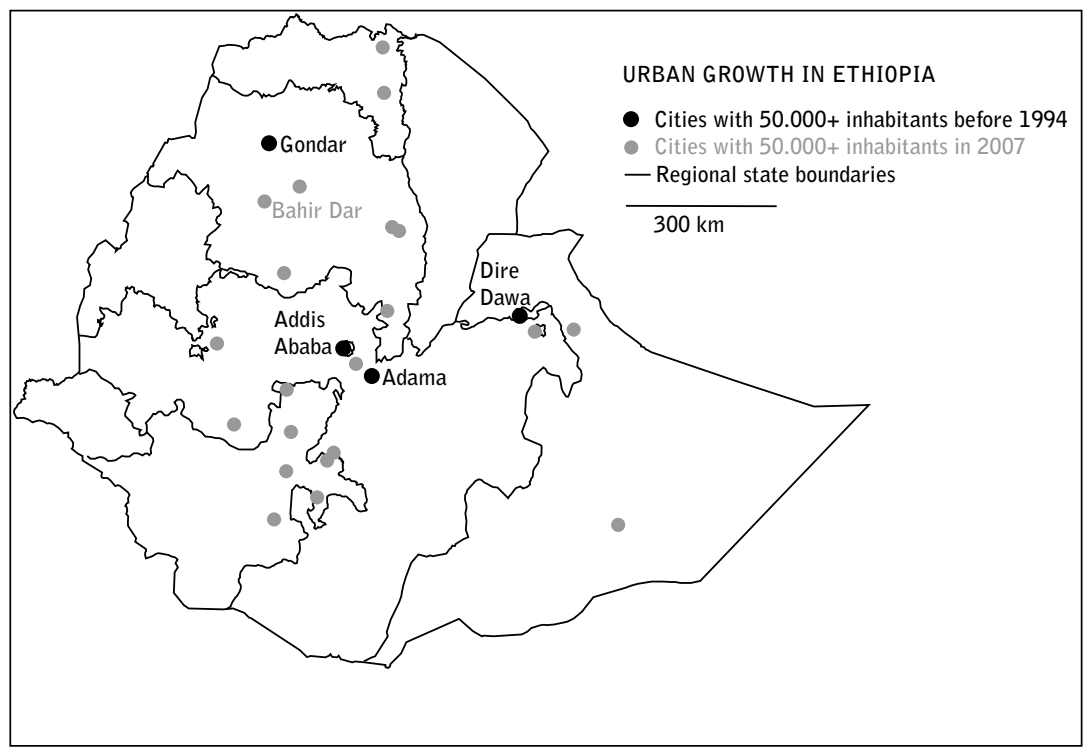

Image by the author with data from Golini et al. 2001 and CSA 2008.

Yet, the literature review for this thesis on the question of urbanisation in Ethiopia suggests that explanation building on the subject of urbanisation is highly speculative. The low level of urbanisation is described as due to the fact that the early growth of Ethiopian towns is irrelevant to development, as they were apparently shaped as a result of political factors, consumed and had no underlying economic system by which they could contribute to production by Gebeyaw Walle (2003: 2021). Other authors claim that the historically low rate of urbanisation still visible today is due to the self-sufficiency of the rural areas (Ofcansky and Berry 1991, Golini et al. 2001: 93). Crummey (1987: 11) concurrently assumes that the redistribution of surplus to large royal courts preventing the establishment of settlements may have been the main restrictive factor for urbanisation until the recent acceleration. Another attempt at an explanation refers to a historical contingency ascribed to the country. Thereby, the account of isolation mentioned above recurs in recent narratives on Ethiopian international relations (Gebeyaw Walle 2003: 20-21, Zegeye Cherenet 2010) as an attempt to explain the low level of urbanisation and coming about of the country's dispersed and culturally particular settlement structures. 
Accounts of urbanisation in Ethiopia have, further, been given as a processes of population concentration with non-agricultural income generation (Gebeyaw Walle 2003: 20-21). The recent rapid urbanisation is, then, commonly explained by natural population growth and movement of individuals from the rural areas to the towns (Golini et. al. 2001: 104, cf. Piguet and Dechassa 2004: 137, Gebeyaw Walle 2003: 19), paired with the opportunities through the concentration of infrastructure and social resources that are perceived as offering better chances for making a living in the city (Gebeyaw Walle 2003: 19) or as urban growth being the result of urban policy interventions (Liyew Adamu 1994, Gebeyaw Walle 2003: 20-21). At the same time, Liyew Adamu (1994: 49) claims that processes of urbanisation were due to industrialisation and bad conditions in the rural areas (ibid: 50 ). This account is similar to that of the UN, which views matters as being complicated by the fact that the urban economies are not growing at the same rate as the influx of population that reaches the urban areas (cf. UN-HABITAT 2008: 4). In contradiction to the theory of industrialisation triggering urbanisation, Koehn states that urbanisation in Ethiopia either has not been accompanied by industrialisation or has exceeded the economic growth rate of the few industrial centres (Koehn 1979: 215). The theoretical context in which "urbanisation" has, thereby, been placed is that of "over-urbanisation" in the capital and "under-urbanisation" for the rest of the country (Benti Getahun 1995, Golini 2001: 92). This model claims that the urban population is too large for the industrial sector of the city, or an absence of urban functions respectively (Benti Getahun 1995: 521). Benti Getahun (ibid) comes to the conclusion that this happened despite not conforming to dependency theory or colonial influence.

However, accounts of the reasons for the initial low-levels of urbanisation and the rapid urban growth in Ethiopia have generally not been placed in a historical context and systemisation, which is why the explanations stated are often derived from political programmes rather than empirical exploration. They are, therefore, somewhat contradictory to each other due to their mostly speculative nature and lack of reliable data. However, the rapid expansion of urban settlements is posing a challenge to organisation and construction and needs further investigation. The statements collected and the reasoning behind them will, therefore, be questioned in the following, to see which argumentation can be furnished with evidence from the existing empirical material but also through the findings of the case study research conducted in the course of this research project. Currently, few comprehensive compilations of empirical studies on recent urbanisation in Ethiopia are available - those that are tend to be quantitative descriptions. This chapter will, therefore, provide an overview of urban development according to the periods of Ethiopian rulership and discuss the data available. It attempts to merge and describe the state of knowledge on urbanisation in the different phases of rule to give a comprehensive overview of the topic of more recent urbanisation in Ethiopia. 


\subsection{0-1936: EARLY TOWNS}

As discussed above, widespread urbanisation and the formation of fixed settlements that shape the basis of today's towns, in the opinion of some scholars, has only been under way since the founding of Addis Ababa in 1887 in the period of Menelik II's reign (Liyew Adamu 1994: 38c, Gebeyaw Walle 2003: 20-21). The facts that lead them to this assumption are grounded in the occasion of Addis Ababa becoming the first permanent capital. The impact of Addis as a fixed capital changed the spatial organisation of the country. The permanent location became possible through the introduction of eucalyptus as fuel wood, the introduction of private-ownership of urban land through a proclamation from 1907, and, as this ended the notion of impermanence, a cultural turn towards embracing technological advances led to the completion of the construction of the Djibuti- Addis Ababa railway line in 1917 in a cooperation with the French and saw the introduction of modern social and technical infrastructure in the new capital Addis Ababa (Pankhurst 1985: 363, Solomon Mulugeta 1997: 191). Menelik II intended to set up a central traffic and communications network in his empire (Liyew Adamu 1994: 38) and is said to have laid the foundations for the modernisation of urban Ethiopia. This embrace of new technologies was taken up and accelerated by all his successors (Pankhurst 1985: 363).

Beyond the establishment and modernisation of the new capital city, Menelik II began founding military and administrative towns in which trade gained an increasing importance (Liyew Adamu 1994: 40). Their location was chosen on strategic grounds, often on hilltops in the malaria-free highlands (ibid). In 1880, around $11 \%$ of the population were counted as settled in places with more than 2,000 inhabitants (Ofcansky and Berry 1991). Meanwhile, forms of settlement such as the "ghebbi", reflecting the court, were taken into the cities and shaped their layouts (Genet Alem 2011: 97). Most of the 19th century towns served as administrative centres and provided seasonal residence for political figures (Crummey 1987: 5), while the pace of overall urbanisation remained slow (Ofcansky and Berry 1991). However, while northern Ethiopian regions have been noted for their urban life of at least 18 centuries, few permanent settlements could be found in the south of the country (Koehn 1979: 215).

The cities' economies were reliant on diverse fields. Crafts were modestly concentrated in the cities as well as other forms of specialisation, but craftsmanship was not a sufficient source of income and had to be combined with mostly agricultural subsistence activities (ibid, Gebeyaw Walle 2003: 20-21). The general absence of inns, restaurants, hostels or other kinds of hospitality services in these towns was noted at the time (Crummey 1987: 6). In various aspects, the towns functioned as connectors of interests and linked with their rural surroundings (ibid: 7). The monasteries, thereby, tended to preserve the natural surroundings in their original state and were not involved in transforming the sites outside of their compounds 
into urban areas (Persoon 2003: 680-81). Importantly, through the presence of the church and monastic schools, towns were centres of education (Crummey 1987: 6). The churches located there were provided with vast lands to support the clergy, which attracted clerical students in the absence of other educational facilities (ibid: 6). Some churches and monasteries had social and economic importance as destinations of pilgrimage (Persoon 2003: 681). The churches played further important structural roles, as they could provide personal sanctuary in the churchyard and amassed considerable surplus through "rist" tax collection from the surrounding agricultural land (Crummey 1987: 8). As the Ethiopian courts did not allow an urban class to feed on the agricultural surplus from the rural areas but rather entertained large courts on the produce, the settlements' population sizes had to remain comparatively small (ibid: 11). In this manner, the class structures of nobility and rural peasantry were reinforced and feudal militaristic endeavours supported in expense of urban development (ibid).

\subsection{6-1941: Italian Fascist Settlement Plans}

Ethiopia's self-image is that of an independent nation that has never been subject to colonial seizure of power (Benti Getahun 1995: 517). To some extent, Ethiopia is even considered a colonial power itself (Myers 2011: 56, Martínez d'Alós Moner 2003: 165). Thereby, the long-standing non-colonisation of Ethiopia is considered not purely a military achievement but also a result of the preceding contact and exchange with European rulers (Martínez d'Alós Moner 2003: 175). However, while a first attempt at colonisation by the Italians was successfully fought off in the "Battle of Adwa" in 1896, the country faced renewed and extended colonialist aggression during the five years of Italian occupation from 1936 to 1941. The initial motive for the Italian invasion of Ethiopia was a desire for commercial exploitation, later amplified to political and military aims (Sbacchi 1985: 229). This desire was paired with a strategic settlement programme for Italian nationals, known as “demographic colonisation" (Haile M. Larebo 1994: 138-76). Their intention was to further the self-sufficiency of various settlement areas, with the result that the Italian road networks that were installed to support this purpose departed from the exiled Emperor's line of centralist development in favour of a network (Liyew Adamu 1994: 40). Generally, urban growth increased with the Italian invasion and during the occupation (Ofcansky and Berry 1991). A number of settlements was established across the country during the occupation. The cities were often founded around transport infrastructure, in particular along the Addis Ababa Djibouti railway line, and also along the expansionist road-network the Italians were seeking to install (Koehn 1979: 215, Liyew Adamu 1994: 40). The effects are still visible today, as now the most industrialised region of Ethiopia is established along the railway line (Liyew Adamu 1994: 40). Many of these new or expanded 
"Italian" towns were garrisons, which also attracted local population through the new incorporation of markets (Liyew Adamu 1994: 40). Even though the Italians did not have any labour or housing policies to address urban growth or migration issues (Solomon Mulugeta 1997: 192-193), factors such as the land rights and land-use practice also have substantial significance for the change of meaning and importance of Ethiopian cities. A number of the settlements received a core of permanent buildings for the first time, in which mainly administrative functions were allocated (Liyew Adamu 1994: 40). The building legacy of the Italian occupation is largely found in the large cities, namely Addis Ababa, Dire Dawa, Gondar, Jimma and Harar (Liyew Adamu 1994: 87, Rifkind 2011: 508-09). No labour intensive industries were introduced, so industrial work places were only occasionally installed in small numbers (Liyew Adamu 1994: 40, Benti Getahun 1995: 521).

Overall, the discussion and evaluation of the colonial occupation on urban development in Ethiopia is controversial, as estimations of the nature and strength of its impact on the cities vary strongly. Regarding the spatial development, some authors like Künzel and Hebel (2007: 29) deny colonial impact, while Myers dismissively states, "Italy's brief occupation led only to a small transformation of Addis Ababa's central business district” (2011: 50). Contrastingly, Liyew Adamu (1994: 87) comes to the conclusion that urban planning in Ethiopia begins with the Italian occupation. Also Podestá (2013) claims a vast socio-economic impact of the Italian infrastructural endeavours. Like a number of Italian authors, he limits his description of impact to the colonial settlers themselves and does not offer any insight into the effect on the local population. In fact, many of the available papers looking at the larger urban scale focus on the formalistic discussion of master plans developed for these locations to enforce colonial rule (e.g. Solomon Mulugeta 1997, Perotti 2010). The draft of two master plans for Addis Ababa, once it was decided to keep it as the capital, are well documented (Solomon Mulugeta 1997: 193). The first was more of a sketch that was devised by LeCorbusier following an order of Mussolini, while the second is a more detailed plan designed by Valle and Guidi in 1937 (ibid). Yet, it is necessary to look beyond descriptive accounts of plans and move towards an evaluation of their significance for the cities they shape to this day. In this vein, Rifkind describes how Italy instrumentalised urban design as a key concept in reforming the everyday life of the Empire's public, based on the analyses of the re-constructionist master plans of Gondar, which served as Amhara Region's capital during occupation (ibid: 493 f.). In going beyond the identification of the Italian architectural legacy to look at the developmental practice, he shows how the design of the city impacts on identity formation and urban life. According to him, the Italians viewed their settlements in East Africa not only as military bastions but also as agricultural depots and sites of industrial production. The cities were nodes in a system in which the Italians aimed to subject the Ethiopian nation to their rule through the settlement of Italian agronomists (to be) in the fertile region under the slogan of "demographic colonisation" (Rifkind 2011: 
496). From the examples in North and East Africa as well as South and SouthEast Asia, the Italians adopted the approach of "translating political order into built form", the aspects of race and religion, thereby fell under the regulation of spatial administration within the cities (ibid). The Italians' planning philosophy was derived from the experiences of the British and the French in their respective occupied territories and becomes very evident in Gondar (ibid: 507). In a "civilising mission", the occupiers, thereby, substituted the tukuls of the historical city surrounding the castle and established structures on principles of modernisation targeted at the "technical deprivation" of the Ethiopians (ibid: 507). Technological modernisation, such as the installation of communications infrastructure, was to be synonymous with the act of "civilising colonisation" (ibid: 498). A master plan set up by Bosio in 1936 laid the principles that still implicitly guide the city's urban development to this day (ibid: 503). The plan intended to relocate many of the Ethiopian residents to the neighbourhood of Ghebbi, south of the city, clearing the site for the buildings to house the colonial administration in the centre (ibid: 504). It was only by the intervention of the viceroy Duke of Aosta that the Ethiopian building heritage (including the famous castle structure) was preserved and the master plan revised (for the third version;ibid: 505). The master plan included a zoning framework, a street network and design principles. In a second step, a racially segregating zoning plan was devised for the city, which had become a self-sufficient garrison town (ibid: 495-496).

In an effort to estimate the overall impact of the Italian occupation on cities in Ethiopia, Rifkind (2011) comes to the conclusion that the towns need to be analysed by placing them in the general context of Italian city building. He also notes that in a "disquieting compatibility between progressive planning practises and authoritarian politics cities built in Italian-occupied East Africa further demonstrate the extent to which the modern urban design could participate in the coercive project of constructing imperial identities, among both Italian settlers and African colonial subjects" (ibid: 493). This signifies that, as far as the architectural legacy of the period is concerned, the remainders of Italian building activities can undoubtedly be distinguished and identified as their artefacts influencing the construction practice. With the strongly increased use of concrete under Italian influence, new building standards were set (ibid: 502). Regarding the Italian influence on building practice, building contractors, who stayed on even after the period of occupation, had a great impact on Ethiopian architecture (ibid: 497). However, Liyew Adamu (1994: 87) notes that the Italians did not consider local aspects such as nature, climate, culture or social issues in their plans, which signifies a break with Ethiopian building traditions. Cultural identities and regional typicality of architecture was lost, in consequence. Yet, he evaluates the introduction of systematic urban planning and policy positively (ibid).

In summary, although the period of Italian occupation is brief placed in the longer history (Martínez d'Alós Moner 2003: 165), a review of the available ma- 
terial shows that the country was subject to racist and colonialist restructuring principles, and spatial development of this period is comparable to that of other colonised areas (Liyew Adamu 1994: 40). Yet, as Haile M. Larebo (1994) points out in the introduction to his book "The Building of an Empire", the academic description of the period of Italian occupation, overall, has a strong focus on the battles and violent oppression. He criticises that "Italy's colonisation per se is generally ignored or dismissed in a few perfunctory paragraphs" (ibid: vi). The introduction of wage labour by the Italians, for example, has so far not been discussed regarding how it changed the urban setting. This dismissal of critical encounter with the Italian colonial legacy is also noticeable regarding the poor availability of critical empirical material describing the colonisation practice in the urban centres of Ethiopia. What can be established is that Italian rule entwined modernism and authoritative rule. So, although the Italian presence in Ethiopia from 1936 to 1941 is generally acknowledged, the rhetoric of "free Ethiopia" has obstructed the account of how the colonialist agenda applied by the Italians has affected the current towns beyond an (aesthetic) architectural legacy and representational master planning.

\subsection{1-1974: IMPERIAL MODERNISM}

Emperor Haile Selassie returned to power in 1941, marking a period that was subject to conflicts arising from British attempts to dominate Ethiopia (Benti Getahun 1995: 518). Haile Selassie's reign experienced accelerated growth of many newly established urban centres with a growth rate of about $6.3 \%$ p.a. in the 1960 s (Ofcansky and Berry 1991, Golini et al. 2001: 93). The population size of the six settlements Akaki, Arba Minch, Awasa, Bahir Dar, Jijiga and Shashemene more than tripled, while eight other sites more than doubled (Ofcansky and Berry 1991, Golini et al. 2001: 93). Mostly, these were capitals of newly constituted regions and agricultural distribution centres (Golini et al. 2001: 93). These smaller, rapidly expanding southern towns (particularly Shashamene, Gore, Awasa and Dembi Dolo) experienced rapid economic growth, as they became major marketing centres where imported goods and local agricultural produce were loaded and unloaded, distributed and stored (Koehn 1979: 220). They experienced a diversification of tasks and profiles as sites of industry, educational institutes, communications or service centres (Golini et al. 2001: 93). Meanwhile, the railway-line from the harbour of Djibouti to Addis Ababa constructed under Menilik II by the French had made Addis the unchallenged distribution centre for imported goods in the country (Benti Getahun 1995: 518). It was, then, in the period from 1950 to 1965 that a network of towns developed closely around the capital, linking it more strongly to the surrounding regional capitals of the time (Golini 2001: 96). However, the longer established towns of Addis Ababa, Dire Dawa and Debre Zeyt experienced rather slowed population growth in this period (Ofcansky and Berry 1991), while 
overall urbanisation in the country continued at a rapid pace between 1967 and 1975 (Golini et al. 2001: 96). The rapid population growth of small and mediumsized towns during the later years of imperial rule is rooted in rural-urban migration, also to the smaller cities (Koehn 1979: 220, Golini et al. 2001: 96). The concentration of educational facilities in the cities is stated by Koehn (1979: 220) to have led to a brain-drain in the countryside, while the vast majority of migrants coming to Addis had been residents of other towns before arriving (ibid: 220-221). The population of the cities above 20,000 inhabitants is, thereby, most fluctuant (ibid: 215). Simultaneously, Addis Ababa concentrated 50\% of the urban population in 1950, but the percentage declined to $24 \%$ at the end of the century (Golini 2001: 93). From 1950 on, Addis Ababa even lost importance as the commercial centre (ibid). In the latter years of imperial rule, the commercial base of older northern centres (Gondar, Axum, Dessie) stagnated or declined, while town populations continued to increase at slow pace (Koehn 1979: 220, Ofcansky and Berry 1991). However, neither was the economic base of the cities reliant on industry, as employment was seldom to be found in manufacturing. Only $5 \%$ of the economically active population were employed here in 1969 (Koehn 1979: 220). Yet, in the years 1973/74, less than $40 \%$ of the Tigre, Gurage, Amhara and Oromo migrants in a survey intended returning to their place of origin or family home and seem to have made their livelihoods in the city (ibid: 221).

In the face of these developments, Haile Selassie pursued an active urban agen$\mathrm{da}$ and 47 of the 210 municipalities of the time were subjected to master planning (Koehn 1979: 224). His strategy largely abandoned the colonialist ideas; for example, the Italian road networks were often not maintained during Haile Selassie's reinstatement due to differing political agendas (Liyew Adamu 1994: 40). The Central Statistical Agency (CSA) was installed in 1960, since when the monitoring of urban population sizes has been possible in principle (Liyew Adamu 1994: 49). The Ministry of Interiors paid an Italian consulting firm to set up 40 master plans during the 1960s; a further seven were drafted by the Municipalities Department in the early 70s (Koehn 1979: 224, Liyew Adamu 1994: 88). Addis Ababa as the capital, thereby, received special attention. Overall, at least five master plans were set up for Addis in the post-liberation period (Solomon Mulugeta 1997: 193).

A number of assessments describe the royal planning as conducted according to the political interests of the sovereigns (emperor and local royalty), which did not lead to satisfactory results in urban design from a professional perspective, as building was undertaken for prestige (Liyew Adamu 1994: 88, Koehn 1979). During Haile Selassie's reign, master plans were prepared without consulting or regarding the majority of the urban population, neither in formulation nor in the planning stage (Koehn 1979: 224). Only in the larger cities were technical employees of the municipality included in devising the plans (ibid). The aims of the plans devised by the "Municipalities Department" of the Ministry of Interiors mainly proved too ambitious for the municipalities to implement with their limited set of 
legal authority (ibid). The plans were based on dubious data sets; yet, they introduced strict zoning controls and firm design objectives such as material-intensive paved roads (ibid). Social and economic requirements of the population majority are said to have been left out of consideration (ibid). All of these master plans resemble each other in the respect that, although they include widely formulated development aims and zoning regulations, public opinion and elected local officials were not consulted (ibid). Instead, they are seen by Koehn as administrative exercises with no chance of being implemented successfully (ibid: 224-225). They had no legal backing, lacked political support and could not rely on any administrative capacity for their realisation (ibid: 225). The municipalities were generally not equipped with a budget for plan execution (ibid). There was also no accordance with the legal code for the implementation through the municipalities, which left them grid-locked from action (ibid: 226). Voluntary compliance was expected from the developers, instead, who typically did not meet the requirements of the plan (ibid). Forty to sixty per cent of the buildings had been constructed without a building permit; yet, these were hardly ever demolished, while informal settlements were also not serviced or upgraded (ibid). Nevertheless, expropriations were almost randomly undertaken, as municipalities could legitimise them as being in the "public interest" (ibid: 227). Further, while a small wealthy group of $5 \%$ of the population owned 95\% of the land in private hands (Mesfin Wolde Mariam cited in Koehn 1979: 228), tough landownership disputes arose and obstructed the progress of plan implementation. ${ }^{1}$ In this struggle to secure royal land tenure, Haile Selassie forged alliances with the Orthodox Church, as the monasteries gave up some of their autonomy in order to (seemingly) take a share in political power and gain access to more material wealth (Persoon 2003: 681). The establishment of cities, however, was not accompanied by a devolution of power to the regional or municipal level. Although self-government was to be introduced on awraja (sub-province) level in 1966, the attempt failed and the centralist power structure remained (Tegegne Gebre-Egziabher 1997 694). Thus, while the Italian urban policies were based on racism, the monarchy under Haile Selassie can be titled a "meritrocracy" in which the gains would be shared among the Emperor's protégés in a non-racially based system of favouritism (Teshale Tibebu 1995: 170).

Beyond urban restructuring and securing royal land-claims, the post-occupational period also saw the first attempts at formulating housing policies. The first was drafted for the second five-year plan devised for the years 1963-1967 (Solomon Mulugeta 1997: 195). It was "aimed at launching large-scale moderate and low-cost housing programs, while at the same time calling for the formulation of legislation to define landlord-tenant relationships" (ibid). The third five-year plan (1963-1973) expanded the housing policy realm so it could build on the results of the first urban housing survey conducted by the Ministry of Public Works (ibid). It now specified

1 | For further reading see Koehn 1979: 227. 
the number of dwellings as 25,400 housing units to be constructed annually in large-scale government-sponsored projects throughout the country (Solomon $\mathrm{Mu}$ lugeta 1997: 195). Of this, 91\% were designated for low-income households (ibid). The fourth 1974-1979 five-year-plan then newly introduced the instrument of aided self-help housing programmes (ibid). However, hardly any housing was delivered (ibid: 195-196). Still, contrary to the account of Koehn (1979: 226), Solomon Mulugeta (1997: 197) claims that pre-revolutionary land-tenure was successful in preventing the development of informal housing.

\subsection{4 - 1994: TOWNS UNDER SOCIALISM}

Generally, there is a controversial discussion as to whether or not socialism favoured rural-urban migration (Mengistu and Sjöberg 1999: 28). According to Golini, the urban population growth between 1975 and 1984 can be attributed to natural population growth and differs from the urban expansion due to ruralurban migration seen in the foregoing periods (Golini 2001: 96). Many small towns emerged and by 1970 there were 171 towns with 2,000-20,000 inhabitants, increasing to 229 towns by 1980 (Ofcansky and Berry 1991). The towns largely emerged informally and, since the socialist period, are characteristically road-side villages that appeared about every 15-20 km (Liyew Adamu 1994: 43). They were not deliberately planned but rather spontaneously constructed (ibid). Unlike the former residential settlements, they are often located in the lowlands along transport and infrastructure routes and in fertile areas that have been appointed for agricultural development (ibid: 44). The cultures of these towns are not regionally differentiated or very sophisticated, due to the recent emergence of the urban structures (ibid). They are typically comprised of chicka (mud) buildings, either on an irregular layout or in circular or oval layouts in reference to the royal camps (ibid: 45). Even in socialist times, stone and concrete buildings were only found in the cities founded by the Italians (ibid: 46), and multi-storey buildings outside the capital Addis Ababa are a recent phenomenon. The economic basis of the small towns founded since the socialist period is trade and hospitality, with businesses mainly run by individuals or families (ibid). According to Liyew Adamu, these towns have an important function as connectors that accommodate innovative institutions in the sectors of education, health, trade with industrial goods and craft (ibid: 48).

The pace of urbanisation was reduced in this period, before it regained speed in the time from 1984 to 1994 (Ofcansky and Berry 1991, Golini 2001: 96). Much of Ethiopia's urbanisation increase took place between the late 1980s and the early 1990s, while before that time the level of urbanisation was fairly stable (Liyew Adamu 1994: 18-19, Mengistu and Sjöberg 1999: 28). About 35\% of Ethiopia's urban population was concentrated on Addis Ababa in 1987 (Ofcansky and Berry 1991). The second largest city, then, (before the secession of Eritrea) was Asmara, with 7\% 
of the urbanites residing there (ibid). The breakdown of the socialist government and the secession of Eritrea in 1994 left Addis Ababa in the position of a primate city. Asmara was succeeded by Dire Dawa as the second largest city, which was 14 times smaller than the capital of Addis Ababa, though (Liyew Adamu 1994: 22). During warfare from 1988 to 1991, all urban centres received refugees and migrants (Golini 2001: 94). Young people and children prevailed, and in 1990 more than 55\% of Addis Ababa's population was below 20 years of age (Golini 2001: 94).

At the same time, the socialist policies are said to have had a negative impact on urbanisation (Golini 2001: 93). In 1987, the Derg established autonomous administrative regions in Eritrea, Diredawa, Asseb and Tigray, while the rest of the country remained under centralist rule (Tegegne Gebre-Egziabher 1997: 694). The national government institutions were the only ones executing development planning (ibid). However, after the socialist revolution and the transfer of power to the socialist Derg regime in 1974, radical changes were undertaken in the formulation of policies concerning urban development. As one of the first measures, all land, non-owner occupied housing, firms and shops were nationalised in March 1975 (Koehn 1979: 229, Liyew Adamu 1994: 22, Solomon Mulugeta 1997, Crewett et al. 2008: 12). The land reform also included the expropriation of the church, and ecclesiastical land was lost to the government (Persoon 2003: 683). In effect, all private landownership was abolished and tenancy relations were forbidden, making state-owned rental housing and owner occupation the two sole tenure systems. (Gebeyaw Walle 2003: 31). The reasoning for the land reform was stated as wanting to overcome the historical injustices of the exploitative relation of the imperial system towards the countryside as well as aiming to create egalitarian access to land for all of the families dependent on farming (Crewett et al. 2008: 12). The traditional hereditary systems of landownership were dismissed and substituted by the state granting usufruct rights (ibid). The effect of this is said to have been stronger on the tenant cultivators in the south of the country than on the farmers in the rist system in Northern Ethiopia (ibid). The problems encountered with the implementation of master plans due to unclear ownership compensation were, thereby, resolved in the interest of the government (Koehn 1979: 229). However, regarding rental regulations, no differentiation was made between richer and poorer land-lords, the policy also led to a number of destitute residents renting out living space on their property for income being expropriated, while cramping into the remaining quarters (Solomon Mulugeta 1997: 198).

Although the focus of the new policies lay in the implementation of "agrarian socialism" (Crewett et al. 2008: 12), the new sovereigns also broke with the past urban development policies. Balanced urbanisation and development of regions was one objective of the Ten-Year Perspective Development Plan (Habtemariam Tesfaghiorghis1986: 165). Planning under the socialists was conducted according to ideas from the Eastern bloc (Liyew Adamu 1994: 88). On the premise of "social planning", urban and rural development was to be undertaken jointly (Koehn 1979: 
229). However, according to Koehn (1979: 220), the political focus on commercialised agriculture functioned as a "push factor" from the rural areas, as the agrarian population could not conform to the demands of such a changed approach to working the land. Coupled with unrealistic employment expectations towards the urban areas, this led them to leave their rural homes to live in the cities (ibid).

Urban planning regulations were drastically amended during the first year of power (Koehn 1979: 229). The renamed "Ministry of Urban Development and Housing" institutionalised regional planning and this institution centrally prepared regional development plans (ibid) for the 14 regions (Liyew Adamu 1994: 14). In the 1980s, a redefinition of the tasks of urban development was undertaken (Solomon Mulugeta 1997: 199). The National Urban Planning Institute (NUPI) was established (ibid: 200). From 1985 to 1988, this institute for urban planning set up urban plans for 79 of the 366 cities of the time, but these plans were not legally acknowledged at city level and therefore had no grounds for enforcement (Liyew Adamu 1994: 89). The sites for which the plans were devised were apparently randomly selected, and pre-studies had only been undertaken for 11 of these, resulting in the plans generally being insufficient for implementation (ibid). The scrutiny through which these policies now had to pass was so intense that the result was a freeze of housing production in the urban centres (Solomon Mulugeta 1997: 200). In combination with the nationalisation of the national housing stock in 1975, this proved fatal. Local and federal governments owned 37.92\% (Wendwosen 2007: 3), since between 1975 and 1980 each citizen was allowed to own one house only, irrespective of its size, while all others were confiscated (Liyew Adamu 1994: 22). The influence of this practice on private initiative is described as strikingly negative (ibid). By 1991, the figure of housing stock in the hands of the government was reduced to $34 \%$ of the country's total housing stock by sales. (Wendwosen 2007: 3). However, despite the acclaimed state ownership of housing, living space remained scarce. Despite a large need for housing, the imperial housing policy was disregarded under the socialists (Liyew Adamu 1994: 21-22). Instead, inconsistent and sometimes even contradictory proclamations and legal notices on housing issues were released between 1975 and 1990 (Solomon Mulugeta 1997: 199). The socialist government did not prepare a demand-based housing programme, and, although housing policies from other socialist countries were introduced from 1980 on, hardly any new dwelling units were constructed (Liyew Adamu 1994: 22). The rate of housing output in Addis Ababa from the late 1970s to the early 1980s, for example, was about 1.1 dwellings/1,000 inhabitants, against an estimated demand of 8-10 dwellings/1,000 inhabitants (Wendt cited in Solomon Mulugeta 1997: 204). During the period of the five-year-plan from 1984 to 1989, only 12,376 housing units were newly constructed across the country, of which $83 \%$ were located in Addis Ababa, leaving virtually none for the remaining Ethiopian cities (Liyew Adamu 1994: 27). The implementation lacked critical adaptation and the units produced were standardised architecture that was organised on the socialist principles of 
cooperatives (Liyew Adamu 1994: 22). The socialist reign deepened the problems caused by urbanisation in the areas of housing, technical infrastructure and urban design (ibid, Wendwosen 2007: 2c), and the negligence of urban issues under the socialist regime is still held responsible for the housing backlog of today (Wendwosen 2007: 2c).

A further significant impact on the administrative organisation of cities was made by the institution of "urban cooperatives", called "kebeles", for development aims (Koehn 1979: 230). Thereby, 300-500 neighbouring households formed one kebele and were to elect a kebele leader (ibid). The kebeles of certain areas were organised into "higher urban dwellers' associations" called "keftigegna", while these again formed "central urban dwellers' associations" in the largest cities (ibid, Solomon Mulugeta 1997: 199). According to Koehn, these "central urban dwellers' associations" were expected to perform typical duties of a municipality (Koehn 1979: 232), while Liyew Adamu states that the municipalities in question did not have authority to set up their own urban development plans, as this power was allocated centrally to the national ministry (Liyew Adamu 1994: 89). At first, in 1975, important development tasks were assigned to the kebeles, as their members were to be mobilised in the support of the government's urban development directives and in building activities such as the construction of schools, clinics, roads and other urban facilities (Koehn 1979: 230). Direct input from residents was not pursued when setting development aims (ibid: 234). In 1976, these capacities were expanded to forestation, beautifying the urban centre, property protection, cleaning duties, hygienic education, combating illiteracy and keeping a population registry (ibid: 230). For this purpose, the kebeles were granted access to all property revenues below $\mathrm{E} \$ 100$ of the nationalised rental housing (ibid, Solomon Mulugeta 1997: 198). The system of the cooperatives was untested and the expectations towards the kebeles were very high (Koehn 1979: 232). The system came into severe crisis when the Derg began to instrumentalise the kebele structures for oppressive measures, such as raids and physical violence against critical citizens (ibid: 233).

As explained earlier (see chapter 3), the churches historically held an important role as centres of power and education within the cities but also as structuring elements around which settlement organised (Genet Alem 2011: 19). Contrary to common assumption, monastic life was not undermined by the socialist revolution as far as the religious institutions were concerned (Persoon 2003: 679), even though it was reshaped to emphasise its civil nature and the withdrawal of political power (ibid: 681). Since then, the monasteries have no longer owned substantial amounts of urban property, as it was also expropriated in the nationalisation of land. They lost considerable direct influence on urban development. Despite the loss of material assets, this allowed for a concentration on the spiritual roles that can also be interpreted as liberating for the monasteries (ibid). Their influence on popular culture and political spheres, however, remains. 


\subsection{4 - Present: The Federalist Urban Network}

The ruling party EPRDF came to power in 1991, when the breakdown of the socialist regime resulted in a major influx of population into the cities (Mengistu and Sjöberg 1999: 28). With the secession of Asmara, Addis evolved to be the primate city of the country (Benti Getahun 1995: 518), making its connection to Djibouti's harbour all the more strategically important. Yet, the new government inherited certain administrative structures and structural assets from the socialist government it succeeded. The nationalisation of land undertaken under the socialists can be assumed to impact on urban development and settlement patterns to the present day, as almost all land is still owned by the state and use rights are granted on terms set by the government (Crewett et al. 2008: 15). The constitution set up in 1995 made some changes to the question of land rights, but private land ownership remained virtually impossible (ibid: 15-16). The lease of land, the hiring of labour and unlimited plot-sizes per individual are now allowed, and compensation for cases in which "the right to use expires" has been included in legislation (ibid 16). However, the duration of usufruct rights is not clearly regulated, leaving tenure-security in very uncertain conditions (ibid). Due to the growth of the formal economy on the basis of state-led development (Müller 2015, it has to be assumed that investment pressure on urban land has increased. Therefore, the demographic development marks the onset of "rapid urbanisation", which, in conjunction with the impediments on subsistence economy and limits on infrastructure provision, has led to a new quality of informal urbanisation in Ethiopian towns, to provide for the low-wage majority of the population.

Under these conditions, the government has been following a decentralisation strategy (Tegegne Gebre-Egziabher 1997: 691). The new decentralisation strategy has two major fields of intervention: regionalisation and modification of the urban hierarchy (ibid: 697-698). The decentralisation strategy is, thereby, not only seen as a reorganisation of the administration but actively aims to modify the urban hierarchy by installing regional capitals and sub-centres. The modification of urban hierarchies refers to the changes in status of cities in the administrative system, as new regional capitals were designated and assigned to serve as service nodes (ibid: 701). The cities rising in the functional ranking, thereby, are granted priority when it comes to infrastructure provision (ibid). Regionalisation, on the other hand, is described as the approach to development and disaggregating national plans to these new units (ibid: 698). Consequently, administrative reforms have installed new spatial governing units in the form of nine regional states, while the former "higher dwellers' associations" were partly restructured and are now known as woredas (ibid: 695, Solomon Mulugeta 1997: 199). Together with the national level, they form a three-tier hierarchical governance system (Tegegne Gebre-Egziabher 1997: 691). In this installation of the federal system, the monasteries were largely stripped of their former roles, since political, cultural and material flows were not 
transferred to the new institutional systems (Persoon 2003: 682). Further, a reorganisation of space-related responsibilities, leading to the devolution of power to the new administrative levels, resulted in the fact that urban development today is guided by a complex set of rules and policies in the hand of multiple authorities at various policy levels (Tegegne Gebre-Egziabher 1997: 697, Meheret Ayenew 2008). The intention is to install a planning system split into national, regional and zonal levels for all regions (Tegegne Gebre-Egziabher 1997: 701). However, the Ministry of Economic Development and Cooperation (MEDaC) at the national level is still authorised to "derive policy objectives, strategies, plan preparation, guidelines and parameters used by ministries and regions" (ibid: 702). Consequently, the national institution is the only administrative level that can determine the specific planning tools to be put into use by the cities. In controversial land issues concerning the transformation from rural to urban land, the Ministry of Federal Affairs also remains the deciding instance (MoFed 2005). Resource allocation, though, is officially in the hands of the regional government (Tegegne Gebre-Egziabher 1997: 710 ). The tasks of the regional planning offices were to identify the region's resource base, formulate strategies and objectives for regional development, set development priorities and prepare the regional plans and studies as framed by the ME$\mathrm{DaC}$ (ibid: 702-703). Actors involved in setting up the regional plan are the regional councils, the regional executive committees, zonal administrations, wereda councils, regional and zonal planning offices and sectoral planning offices of the woreda (ibid: 703). If the MEDaC approves the plans, the regional level guides their implementation (ibid: 702. This dependency of the regional planning institutions on the federal state calls the autonomy of the socio-economic development institutions at the lower administrative levels into question, as the regions are, hence, at risk of being no more than the facilitators of the central government's interests (ibid: 706).

Already with the shift of power, Liyew Adamu recommended a review of urban policies for Ethiopia towards "developing urban policies based on the profound analysis of the current local situation, the historical growth of structures and the demographic and ethnic particularities of places, while considering natural, economic and social factors" and further advises that "the theoretical and methodological foundations of planning formulated in the developed regions should be taken into account and checked for their suitability to be transferred" (Liyew Adamu 1994: 9). He, thereby, makes it explicit that Ethiopian planning is open to accepting planning models from elsewhere as state-of-the-art in the profession. This attitude was not followed up until 2005, by turning to international consultancy for setting up national planning documents, when the current Ethiopian government loosened its exclusive focus on rural development and a set of urban policies was newly formulated to address urban development (Interview Dirr 20.10.09). The federal government has put itself "in power of supporting capacity building for accelerating urban development" (MoFed 2005). It allocates and distributes the finances required for the implementation of urban development policy and issues 


\section{Box: Integrated Housing Development Programme}

An additional housing need of 2,230,831 units between 2005 and 2015 was officially calculated due to population growth and formation of new households in Ethiopia (Ministry of Works and Urban Development 2007: 30). To meet this demand a National Integrated Urban Housing Development Programme was included in the formulation of the National Urban Development Policy in 2005, (Wendwosen Demrew 2007: 4). The largescale housing programme has been developed in order to accommodate the strong demand for low-income housing space (ibid: 5-6). It is meant to drive the regeneration of "slum areas", the development of micro- and small enterprises, create a large amount of employment, promote cost-efficient housing construction technology, provide affordable housing and ensure tenure security through ownership (ibid).

Under the "Integrated Housing Development Programme" the construction of 360,000 low-cost housing units and 36,000 commercial units were to be realised between 2006 and 2010 (Ministry of Works and Urban Development 2007: 30). In Amhara Region 48 cities were selected for the first realisation phase, in which a total of 49,654 units were to be constructed (Ministry of Works and Urban Development 2007: 31).

The Housing Programme is meant to address housing problems; however, its concept claims not only to provide housing space, but also to cater for economic livelihoods (Ministry of Works and Urban Development 2007: 32; Künzel, Hebel 2007: 27). The programme incorporates the development of micro- and small enterprises, employment generation, capacity building in the construction industry and regeneration of inner urban areas (Wendwosen Demrew 2007: 4). However, the division of work and housing space in the low-income sector is enforced by this programme and needs to be noted as a reorganisation of spatial practice in Ethiopian towns.

regulations on this implementation (ibid). In the face of increasing numbers of urban dwellers, the core documents devised are the framing PASDEP (Plan for Accelerated and Sustained Development to End Poverty), under which the Ministry of Works and Urban Development formulated the National Urban Development Policy in 2005 (Meheret Ayenew 2008: 456c). The policy intends to tackle the issues of urban poverty and infrastructure deficits in connection with rapid urban growth (ibid). Concerning cities, this is the policy formulating all aims to take place on urban ground (ibid). The seven priority areas of urban development it names are, therefore: (i) fighting urban unemployment and poverty, (ii) improving urban governance, (iii) building institutional capacity, (iv) infrastructure development, (v) housing upgrading, (vi) tackling urban environmental issues and (vii) 
the mobilisation of urban civil society (ibid). The Ministry of Federal Affairs is appointed to coordinate the policy transfer and undertakes the monitoring of the implementation (MoFed 2005). The policy hands down the responsibility for setting up an urban plan to the administration of the towns, obliging them to stay in line with the national and regional urban development plans. They are, thereby, allowed to issue rules and regulations for the implementation of the National Urban Policy, set up and strengthen institutions for its execution, ensure public participation and carry out development activities. The formulation of the implementation strategy is handed to the regions, which are also responsible for allocating subsidies and permitting loans to the towns. One of the problems acknowledged by recent policies, such as the "Plan for Accelerated and Sustained Development to End Poverty" (PASDEP) is the necessity of overcoming the rural-urban dichotomy. PASDEP, therefore, seeks to adopt rural-urban linkage mechanisms (MoFed 2006, Aynalem and Assefa 2011: 173). At the same time, there is a sharp division of power concerning rural and urban land use issues between the Ministries of Works and Urban Development and the Ministry of Rural Development at a national level, which is repeated at the regional administrative level (MoFed 2005).

The set-up of the National Urban Policy in 2005 (Meheret Ayanew 2008: 456c, Ministry of Works and Urban Development 2007: 20) marks a significant change in approach towards urban questions. Despite the indicated conflict between the federal and regional decision levels, this is the first time that urban planning has been supported by regional administration and has had a legal base. However, the impacts of implementation are still to be evaluated. The government's assumption is that decentralisation will further popular participation in planning and development, that it will generate additional resources and improve their distribution, and that it will facilitate coordinated and integrated planning by the preparation of local plans (Tegegne Gebre-Egziabher 1997: 691). Whether this has been achieved will be discussed in the findings of this thesis.

\subsection{MisSing AcCOUNTS OF URBANISM}

The phenomenon of urbanisation in Ethiopia can be described as a research gap, as such. Not much is known about common towns in early Ethiopian history. We do not know when exactly ordinary towns first emerged in Ethiopia, as there is scant record of them. However, it is established that the early emergence of cities is distributed unevenly across the country, as cities are a much more recent phenomenon in the South than in the North. What can be dismissed is the claim that early towns in Ethiopia are relevant politically but not economically or culturally, due to their lack of contribution to development. Evidence for this claim has not been provided and the growth of historical settlement sites suggests otherwise. Although it is still disputed whether the early towns shaped a distinctly urban 
economy entailing trade, crafts, communication services, hospitality industry etc., in a combination with subsistence practices, the question is not whether there is innovation at these sites but rather what kind and with which effect. Accordingly, the definition of "development" needs to be challenged and set in relation to the local context. Thus, while the assumption by which Ethiopia did not experience true urbanisation after the Aksumite period is speculative and improbable, the early course and nature of urbanisation in Ethiopian cities in the early periods is still under-researched.

Starting from this low level of urban population, urban growth in Ethiopia has been described as a fairly slow process until the reign of Menelik II in 1880, followed by a rapid movement of population towards the cities since the late 19th century. Whether this leap was due to the low percentage of urban residents and the dispersed situation of towns, "isolating" the wider population from the urbanisation process of other countries, whether it was a result of the self-sufficiency of the agricultural society or whether it stemmed from the agricultural surplus accumulating in the court and not in the settlements is hard to verify at this point due to lack of empirical material on the subject. What is known on the phase first considered as modern city building in Ethiopia can be summarised as follows: Ethiopia's overall percentage of urban population until the 20th century is very low, even in comparison to the low figures of other African states. Yet, this is changing, as low urbanisation has since been followed by rapid urban growth, which is due to natural population growth but also to movement of individuals from rural to urban areas. From the data available, it is evident that most of today's towns in Ethiopia and, thus, their stock of housing were founded within the past 140 years, and large proportions of the urban population can be classified as newly urbanised. The review of the material taken together seems to suggest that there are multiple factors relevant for the migration decisions leading to urban growth. Under royal reign and under the Italians, an active urban development policy was pursued and implemented and, overall, the new centres grew much faster than the old centres from 1967 to 1994 (Golini 2001: 96). Reasons for this are, hence, seen in the opportunities provided by the concentration of infrastructure and social resources in the city or as a result of policy intervention (e.g. induced industrialisation policies), at times under the pressure of foreign interests. Thereby, their urban policies are stated to have attracted people to the new urban centres.

Meanwhile, Ethiopia has, so far, not been the focus subject of study by progressive planning theorisations. Repeatedly insisting on uninterrupted national independence, contemporary urban studies in Ethiopia have hardly been in touch with post-colonial critique. Instead, urban policies and plans are well documented and heatedly discussed. However, the urban fabric in which the majority of the population lives has not been produced through these policies. Cities have seldom been the focus of political and academic discussion. When they have, it can be noted that academic descriptions of practices of urbanisation, such as construction, 
housing provision, foundation of towns and population movement, rely heavily on evaluations of official policies towards towns. This chapter displays that, in the accounts that largely stick to political periodism, there is contradictory assessment of the extent and significance of urbanisation in Ethiopia from author to author. The most common phasing of recent urbanisation, producing urban structures that are still in use today, is as follows:

- vernacular towns and imperial capitals

- Italian garrisons

- $\quad$ socialist resettlement activities

- decentralisation and regional capitals in the Federal National State

It seems plausible that the different phases of growth and waves of population influx into the city have different causes of coming about and need further investigation. Yet, unlike the material available on Ethiopian folklore and traditions, the data available on life in Ethiopia's cities is often not grounded in primary data collection and are rather conducted as implementation monitoring. Thereby, policy documents are available and valuable written sources, giving an account on the historical views and aims geared at urbanisation. Yet, the resulting discussions are somewhat focused on the effectiveness of the directives. However, the current size of cities is expanding beyond natural population growth by migration that cannot be explained by any of the described policy directives. This urbanisation indicates that forces beyond the policy initiatives must be at work, leading the population to move into the cities. How these entire neighbourhoods were constructed remains largely undescribed. Beyond systematic descriptions of traditional regional building typologies, there is little account of mundane practices of urbanisation as a collective societal endeavour available within Ethiopian cities. The material that is available mostly concentrates on the capital city and the historically acclaimed sites such as Aksum, Gondar and Harar. The information on the other cities, their dependencies, interrelations and specialisations in the functional urban network, have largely been left out of academic accounts so far. Given this pre-condition, the tendency to idealise pre-colonial conditions needs to be avoided (Myers 1994: 200). Instead, qualitative research on the issue of urbanisation in Ethiopia is, therefore, necessary to question the status of knowledge on the subject through inductive reasoning.

At the same time, unaccounted urban growth will continue. The high rise in population figures and relatively low levels of economic production suggest that a large proportion of the newly urbanised population is increasingly dependent on irregular forms of income and is, therefore, particularly prone to food insecurity and lacking access to basic amenities. The stream of population into the city without a formal economic basis for survival needs to be addressed, as the standards of living are often inadequate by humanitarian standards. This fact has 
been recognised politically, and, by introducing decentralisation in the realm of urban planning, politics are currently trying to expand their reach and facilitate their governance. In alliance with leading international institutions, they have taken on the task of reshaping Ethiopia's urban face. The formal legitimisation to restructure is, thereby, supported by the international organisations rhetoric of declaring 98\% of Ethiopia's urban fabric slum areas (see UN-Habitat 2007: 22, Ministry of Works and Urban Development 2007:4). In doing so, the description of everyday urbanisation practices is obstructed and qualitative empirical accounts on its relation to planning has been reduced to the viewpoint of compliance or non-compliance with introduced building standards and land-use zoning. This is seconded by Tegegne's verdict on the overall situation of governmental urban development practices: “The planning process thus far practised has no role for popular participation in which local people are involved in decision-making and problem identification" (Tegegne Gebre-Egziabher 1997: 704). Despite dispersed recent efforts to change the situation, this leads to the question whether we are at all looking at how the majority of people live when we devise urban plans. While it is, yet, to be empirically identified where the socio-economic reception structures of rural-urban migration lie in the urban fabric and what roles the cities take in a larger urban network, the meaning of urbanisation for the development of Ethiopia's cities has seldom been the subject of discussion. There, consequently, is a need to reconceptualise this description and give a more holistic account, in which everyday urbanisation is granted a review of its agency and contribution towards urban structures, modernity, urbanity and identity. The interactions between planning and urbanisation, to date, need to be accounted for in more detail, so that, on the basis of qualified accounts, everyday urbanisation can be re-evaluated and adjusted to suit local requirements. Data on the practices of the ordinary population need to be gathered and systemised to function as an informative foundation and reference for statutory urban planning. The qualities of the process and the resulting built fabric, going beyond the technical criteria of urban policies, need description. For this, narratives of individual cities' urbanisation are necessary. 



\section{Research Design}

The review of material presented in chapter 3 reveals that Ethiopian cities lack adequate description and conceptualisation of local practices of urbanisation to serve local planning strategies addressing the quality of urban livelihoods in conditions of urban growth. Based on the research gaps identified in the proceeding chapters, the topic of study is the relation of planning and urbanisation practice and rationales in Bahir Dar as one of the fast growing secondary Ethiopian cities. The chapter describes the methods selected to conduct the empirical work on this topic. Here, the propositions of the research, the research questions and the unit of analysis are introduced as the conceptual framework, while the criteria for interpreting the findings are described as the analytical framework.

\subsection{Applying a Case Study Methodology}

Due to the need for empirical data on the pre-defined question of rapid urbanisation in Bahir Dar, an adequate research methodology had to be chosen for this thesis. As the thematic field of study is open and unstructured meaning that the issue of urbanisation is not a clearly delimited topic, while reliable quantitative and qualitative data on Ethiopian urbanisation are scarce (see chapter 3), and no qualitative research has been done on the relation of urbanisation and planning for this context or location, the methodology should allow for a mix of qualitative methods to gather empirical material. This investigation on urbanisation and planning has few references to build on from African cities and needs to take an explorative approach. Since the presence of urbanisation in Africa's history for more than two thousand years has led to a wide variety of urban histories and urban practices (Anderson and Rathborne 2000: 1), it is plausible that conceptions of these should be "derived from the historical record and local frame of awareness" (Myers 1994: 208). According to Robinson, the historical comparative analysis that is committed and long-term avoids the danger of entering "a new round of imperialist appropriation of international urban experiences to service Western and other well-resourced centres of scholarship" (Robinson 2011: 19). In order to do 
so, the interrogation of the historical urban development must try to recollect the pre-colonial accounts and go beyond questioning the plans of the colonial era. This holds especially true, as a thorough re-evaluation of modern urban development often did not take place neither in the former colonies in the course of regained independence, nor in Ethiopia as a country included in generalised accounts of "urban Africa". From a historical view, patterns and urbanisation practices can be described as originating from multiple sources of action (Robinson 2011: 7).

A common stance to suit the above-mentioned requirements is to conduct a case study. To this understanding of urban development, the case study approach is suitable to generate local accounts and place them into the wider context of discussion. The case study methodology is sometimes described as an unsystematic approach but is elaborately defined as a research method by Robert Yin (2009). Yin (2009: 27) states that the research design of case studies requires a set of research questions, propositions of the research, a unit of analysis, a logic to link the data to the propositions and criteria for interpreting the findings. Following him, it is "an empirical investigation, that investigates a contemporary phenomenon in depth and within its real-life context, especially when the boundaries between phenomenon and context are not clearly evident", while it also "copes with the technically distinctive situation in which there will be many more variables of interest than data points and as one result relies on multiple sources of evidence, with data needing to converge in a triangulating fashion, and as another result benefits from the prior development of theoretical propositions to guide data collection and analysis" (ibid: 18). In other words, the case study methodology is suited to research on complex processes, in which the phenomenon and context are intertwined, which applies to the phenomenon of "urbanisation", the subject of this research. The overall aim of the case study approach is for the selected case to contribute towards a more complex and differentiated theoretical conception (Janowicz 2008: 270). In contrast to other ethnographic approaches or grounded theory, the case study explicitly relies on a theoretical background and propositions which are tested by empirical evidence (Yin 2009: 35). Consequently, however incomplete or generalised the theories related to planning and urbanisation in secondary African cities (chapters 2 and 3) present themselves, they can serve to discuss the findings of this research, which in turn can expand and nuance the theoretical accounts. Case studies have regained acceptance as a relevant research method in urban studies, despite some criticism of the approach. In quantitative research their importance is, indeed, low (Lamnek 2005: 302). While post-modernism did not engage in comparison, as categories of comparison could not be formed, case studies have recently regained popularity as a special form of conducting comparative urbanism in urban geography (Nijman 2007).

In order to extend the reach of the case-study findings to the needs of urban planning, the findings from the empirical work on urban development and urbanism are generally used to feed into theoretical discussions from which advice 
for urban policy formulation can be developed. Thereby, the research faces the same dangers of fallacy regarding "scientism, developmentalism and universalist categories" (Nijman 2007: 1) as research in the field of urban geography. However, drawing from the critical theoretical proposals from post-colonial urban studies (see chapter 2.1), these can be identified and overcome in conceptualisations. The case study is, hence, meant to bridge the gap between theoretical discourse of urban studies and implementation of the new ideas in urban planning. The implicit comparison between site of best-practice realisation and implementation destination in policy transfer and urban planning can be exposed, as it currently does not rely on comparison of context and path-dependency, but rather on the similarity of problems and issues irrespective of the reason for their occurrence. This needs to change in order to make urban policy more effective and context specific.

However, the reach and restrictions of case studies have been discussed controversially. Yin traces the existing reservations towards the validity of case studies to the lack of rigor in past examples of case studies, the confusion of case study research with case study teaching and misconceptions on the questions of bias and generalisation. In response to the doubts, Yin (2009: 14-15) points out that the question of bias is inherent of other methods as well, while the question of generalisation can be answered in short, by declaring that the aim of qualitative case studies is "to expand and generalise theories (analytical generalisation) and not to enumerate (statistical generalisation)". Bearing this possibility of bias in mind, the method can prove fruitful. As Robinson (2011: 5) states, the single case study is implicit, displays causality assumptions that are historic and specific but is not always comparative or theory-building. However, following the argumentation of Lijphart, she notes that the case study strategy "has the potential to be relatively unproductive for social science research, unless it consciously involves theory building", but "when it does, it is an important part of a broader suite of comparative methodologies." (Robinson 2011: 6).

For this research, the large uncertainty due to the lack of data has to be considered in the question of theory building in the sense that an exploratory case study approach has to be favoured. Despite the figures indicating a rapidly growing population, there was little material available on the issue of urbanisation so far. This thesis, therefore, marks a substantial contribution to the literature on the city. Since the set-up of this research aims to contribute to knowledge on urbanisation in secondary African cities by studying one case, the peril of theoretical unproductiveness can be avoided by substantially contributing to a discussion base for the location and allowing for the place to be set in the larger context of urbanising cities. This is named as a "revelatory case study" by Yin (2009: 49). The aim of the case study is to identify structures and typical processes that were previously not described and are manifested in the data, distinguishing the single case. Comparing the results of this single case study with the body of theory might produce new insights at the general descriptive level as also explained by Robinson (2011: 6). 
This way, the case study can give "geographical explanations for path-dependency" (Nijman 2007: 2). This feedback into general theory requires openness towards the theoretical framework for the suggested modifications resulting from the empirical case study evidence (Janowicz 2008: 270).

For this thesis, criteria of describing the relation between different rationales of urbanisation consequently have to be specified. In order to describe this relation, the proposals made by Roy's idiom of urbanisation are used as a theoretical reference point (see chapter 2.2), as well as the topics considered relevant in the same chapter. It is established how urbanisation practice is contextualised locally in Bahir Dar. To do so, the state of knowledge on the topic is retrieved and systemised, while data on typologies of everyday urbanisation is gathered to widen the account. The "idiom of urbanisation" is thereby considered aware of multiple accounts of urbanisation under the same conceptual framework and can account for competing rationales and interpretations in the sense of an assemblage. Also Patsy Healy advocates that the rich narratives of in-depth cases are most useful to promote trans-national reflection on planning ideas, more so than other common approaches in urban planning, such as best-case or systemised matching of context and planning experience (Healy 2012: 196). I consider this observation as crucial for the revision of the planning discipline's constituting habitus of formulating policy recommendations and implementing designs. Only by moving away from looking at the success or failure of certain interventions in best-practice or bad-practice analyses and directing the view to the underpinning rationales and path-dependency related pre-conditions for the success of certain interventions, can adequate means of intervention be identified and policy transfer be successful. The case study directed towards these underpinning rationales and pre-conditions can contribute to a new system of urban typology as required by Nijman (2007: 2), which would be grounded in the specific attribute and not in the stipulated geographical category or developmental status of a city. This aspect concerning the normative consequences regarding institutional planning and everyday practices, their interrelations and competition forms a focus of investigation for this thesis. It seeks to shed light on issues regarding the multiplicity of state intervention and contradicting interests between different non-state actors. Nevertheless, Nijman states that "there is no single comparative method, but rather a plurality of comparative approaches, it is equally clear, that there are no universal or permanently fixed categories, but rather contextually variable and temporally dynamic typologies" (ibid: 5).

\subsection{The Case Study Site}

According to Yin (2009: 91), the selection of the case and, thus, the unit of analysis needs to be systematic. The case study on urbanisation requires a location, which 
should be bounded and in which these questions can be investigated. While, of course, its geographical and administrative delimitations change over time, this unit of analysis also includes the community of the settlement as a non-spatial aspect and the administration and other organisational powers of urbanisation in the location, even if they might be geographically situated elsewhere. From the case and its findings, abstractions can be made. With its own contingent and idiosyncratic development, the case study can serve as one of many cases to diversify the knowledge we have on the Ethiopian cities experiencing urbanisation and challenge generalisations made on African cities.

Due to the limited human resources available in a doctorate project, I had to abandon initial ideas of conducting comparative research with a multi-sited approach and decided on a single case study. Thereby, it has to be acknowledged that the comparative element of a single case study to general theory and national policy is implicit rather than the explicit comparative nature of multiple-case studies. The single case study is also limited in its capacity to establish typologies due to a lack of comparative material. For this a comparison with other case studies on urbanisation from the literature or future research would have to reveal particularities of the location and contribute to forming categories and typologies of urbanising cities. This is not possible within a single case. Neither can the general theory be expanded through the single case should the findings from the case affirm what is already known. However, a feedback into theories is possible, if the case can challenge the existing body of knowledge or make differentiations on the prevailing assumptions as a "revelatory case study" (see chapter 4.1.; Yin 2009: 49).

The criteria for the selection of the case study site have to be connected to the research theme (Yin 2009: 28). Wanting to contribute to questions of urban development under conditions of rapid urbanisation, the case study site should display a high development dynamic. From various possible locations in Ethiopia, Bahir Dar - the capital of Amhara National Regional State with a population of around 230,000 inhabitants, situated on the southern shore of Lake Tana - was chosen as the unit of analysis. Bahir Dar is located within an area around Lake Tana that has been selected by the Ethiopian Government to promote the formation of new settlement structures (RUPI 2000), and the settling activities in the area are thus expected to stay a political focus. Bahir Dar has a high rate of population growth, a high number of rural-urban migrants and a vast extent of spatial growth. Overall, the city is currently affected by a strong development dynamic. Bahir Dar's size expanded from 297 ha in 1957 to 4,830 ha in 2009, an average growth rate of $31 \%$ p.a. (Nigussie Haregeweyn et al. 2012: 155). The built-up areas have increased almost tenfold from 80 ha in 1957 to 848 ha in 1994 (ibid), while intensely built-up land on the urban area of 1957 doubled in the period until 1994 from 80ha to 155 ha (ibid). The parallel rate of population growth in Bahir Dar between 1967 and 1994 was, at 7.57\%, among the highest in the country (Golini 2001: 97). According to census data from 1994, 54.1\% of the city's population were migrants (Gebeyaw 
Walle 2003: 97). An evaluation of the same census data shows that the rates of wellestablished population in Bahir Dar were lower than that of Ethiopia's city mean, which was 52.1\% (Golini et al. 2001: 177) and indicates a relatively higher influx of people into Bahir Dar. The proportion of new in-migrants (less than five years of residence) in the population by sex was $24 \%$ of males and $23 \%$ of females. This is higher than the national average (20.7\% for males and $18.7 \%$ for females, ibid). Thus there was a high share of recent arrivals. The influx of population into the city continued after this, if also at a slower pace. On the basis of data from the CSA, Gebeyaw Walle (2003: 39) calculated the urban growth rate of Bahir Dar to be $4.8 \%$ per year between 1994 and 2003. Bahir Dar's urban area is expected to double from 2012 to 2024, based on a linear population development and areal expansion projected into the future (Nigussie Haregeweyn et al. 2012: 153-154).

\subsection{Research Questions}

The research presented here aims to gather data describing the constituting practices of urban development as a local result of a larger urbanisation process. The data is evaluated and directed at formulating a local concept for urban development based on the theoretical insights into the relation of urbanisation and the possible realm of planning in Bahir Dar. To define the scope of data collection and frame the outcome, a set of research questions was formulated to guide the investigation. A main research question is, thereby, broken into general research questions, which again are broken down into specific research questions. By means of this operationalisation, the fieldwork was conducted.

Exploring the urbanisation process in Bahir Dar bearing in mind the theoretical proposals discussed in chapter 2.2, the case study seeks to clarify the contingencies of urban development under conditions of urbanisation in Bahir Dar. To structure the account, a special focus is given on the relation between urban planning and different practices of everyday urbanisation to be identified in the course of the research. The thesis intends to describe how urbanity and urban structures are produced in the city as the result of the larger contextual conditions of population shifts to the city. It seeks to outline the implications for urban development encompassing actors from non-institutional and institutional backgrounds in the understanding of a "collective governance effort" (Healy 2012: 191; see chapter 2.2). The main research question to guide the investigation is formulated as follows:

How do statutory and everyday practices constitute urbanisation in Bahir Dar and what are the implications for future urban development?

The main research question is broken down into a set of four general research questions: 
1. Which are the site-specific rationales of statutory planning in Bahir Dar and how do they produce and organise city structures?

2. Which are the site-specific rationales of everyday urbanisation in Bahir Dar and how do they produce and organise city structures?

3. How do the different rationales relate to each other?

4. What are the implications for future urban development?

The first two general research questions cover the aspects of "statutory planning" and "everyday urbanisation". These first two general research questions guided the collection of empirical data from the case study site. These questions were in turn broken down into specific research questions. The field tools were selected by attributing the specific research questions to data/variables for which suitable field tools were identified to retrieve the corresponding material. The results are presented in the tables below:

Fig. 3: First General Research Question Broken Down into Specific Research Questions

Which are the site-specific rationales of statutory planning in Bahir Dar and how do they produce and organise city structures?

\begin{tabular}{|c|c|c|}
\hline Specific research question & Data/Variable & Field tools \\
\hline $\begin{array}{l}\text { How has the urban expansion been } \\
\text { monitored? }\end{array}$ & $\begin{array}{l}\text { Expansion/densification of built up } \\
\text { area at the city-scale over time }\end{array}$ & Review of maps and aerial photography \\
\hline $\begin{array}{l}\text { Which planning documents have been } \\
\text { issued and put to implementation in } \\
\text { the past? }\end{array}$ & $\begin{array}{l}\text { Evidence for planning strategies, } \\
\text { projects }\end{array}$ & $\begin{array}{l}\text { Review of archive material, expert } \\
\text { interviews }\end{array}$ \\
\hline $\begin{array}{l}\text { Which planning documents are } \\
\text { currently valid? }\end{array}$ & $\begin{array}{l}\text { Evidence for planning strategies, } \\
\text { projects }\end{array}$ & $\begin{array}{l}\text { Review of archive material, } \\
\text { expert interviews }\end{array}$ \\
\hline $\begin{array}{l}\text { Which phases of urban development } \\
\text { can be identified in Bahir Dar? }\end{array}$ & $\begin{array}{l}\text { Time periods, guiding principles } \\
\text { of urban development }\end{array}$ & $\begin{array}{l}\text { Literature and document review, } \\
\text { expert interviews }\end{array}$ \\
\hline $\begin{array}{l}\text { Who is involved in formulating the } \\
\text { valid planning policies? }\end{array}$ & Actors & $\begin{array}{l}\text { Literature and document review, } \\
\text { expert interviews }\end{array}$ \\
\hline $\begin{array}{l}\text { Which infrastructure projects } \\
\text { and technologies have an impact on } \\
\text { urban development? }\end{array}$ & $\begin{array}{l}\text { Project impact, infrastructure } \\
\text { contribution }\end{array}$ & $\begin{array}{l}\text { Expert interviews, key-informant } \\
\text { interviews }\end{array}$ \\
\hline $\begin{array}{l}\text { Are there clearances and/or } \\
\text { resettlements? }\end{array}$ & $\begin{array}{l}\text { Land-use conflict, relation between } \\
\text { formal and informal regulators }\end{array}$ & Expert interviews \\
\hline
\end{tabular}

Image by the author. 
Fig. 4: Second General Research Question Broken Down into Specific Research Questions

Which are the site-specific rationales of everyday urbanisation in Bahir Dar and how do they produce and organise city structures?

\begin{tabular}{|c|c|c|}
\hline Specific research question & Data/Variable & Field tools \\
\hline $\begin{array}{l}\text { Are there clearances and/or } \\
\text { resettlements? }\end{array}$ & $\begin{array}{l}\text { Land-use conflicts, relation between } \\
\text { formal and informal regulators }\end{array}$ & Expert interviews \\
\hline $\begin{array}{l}\text { What are the benefits and options } \\
\text { of choosing an urban lifestyle? }\end{array}$ & $\begin{array}{l}\text { Evidence of changing living } \\
\text { arrangements, identification of } \\
\text { benefits and assets gained through } \\
\text { individual urbanisation }\end{array}$ & $\begin{array}{l}\text { Review of population data, } \\
\text { in-depth interviews }\end{array}$ \\
\hline $\begin{array}{l}\text { Which are the livelihood strategies of } \\
\text { newly arriving migrants? }\end{array}$ & $\begin{array}{l}\text { Evidence for socio-economic } \\
\text { diversification through urbanisation, } \\
\text { forms of establishing in the city }\end{array}$ & In-depth interviews \\
\hline $\begin{array}{l}\text { What are the ethnic, cultural and } \\
\text { religious distributions of population } \\
\text { at the city scale? }\end{array}$ & $\begin{array}{l}\text { Evidence for cultural diversification/ } \\
\text { clustering over time }\end{array}$ & $\begin{array}{l}\text { Linking population data with spatial } \\
\text { information from observation/mapping } \\
\text { and historical sources }\end{array}$ \\
\hline $\begin{array}{l}\text { Who/what are the mundane regulators } \\
\text { of urban development? }\end{array}$ & $\begin{array}{l}\text { Data on actors (NGOs, churches, } \\
\text { community leaders, party structures) }\end{array}$ & In-depth interviews, document reviews \\
\hline
\end{tabular}

Image by the author.

The analysis of the data collected was guided by the general research questions 3 . "How do the different rationales relate to each other?" and 4. "What are the implications for future urban development?", for which policy advice was then formulated in chapter 9 (see chapter 4.5)

\subsection{Data Collection}

As can be seen from the tables above, various sources of evidence were consulted for the case study according to the multi-tool approach suggested by Yin (2009: 102). The multi-tool approach for the data collection through fieldwork supports the display of various aspects of the selected case, while it increases the reliability of the results. Using the case study methodology, data is collected through documentation, review of archival records, interviews, direct observations, participant observation and/or physical artefacts (ibid).

As already mentioned in chapter 1.2, the data collection began in 2009 with two short exploratory visits to Ethiopia. Consequently archive work produced the original designs for the first master plans for Bahir Dar from 1962 in the University Archive Darmstadt (Germany). In a three-and-a-half-month period of fieldwork in Bahir Dar in 2010, a systematic mapping exercise was undertaken with research assistants to understand the city's layout and neighbourhood structure. Conducting a workshop on the question of regional development in the larger city network on 
Lake Tana, organised jointly with the Bahir Dar University, Addis Ababa University and the ETH Zurich, established access to the network of professional planners. As a result of a contact made at the conference, there was an opportunity to sit-in at an expert hearing for the development of the Bahir Dar Waterfront Development Plan, organised on February 24th 2011 by the Canadian Urban Institute in Bahir Dar. A last round of fieldwork, in which in-depth interviews were conducted with residents in the sub-case sites, was undertaken in January and February 2013. The period of data collection, hence, spans from March 2009 to February 2013.

As described above, sources of secondary data were initially consulted. A fist review of literature on urbanisation in Ethiopia revealed that information on the phenomenon of urbanisation is only starting to be gathered. Already working in a context of scarce secondary data, it turned out that a lot of the data has to be regarded as unreliable by academic standards. A lot of the material consulted contains incomplete, contradictory or unreliable data. Given a lack of alternatives, it can serve to give impressions of general sizes, even though it has to be questioned due to insufficient independence of coverage. This is not necessarily caused by bad methodology in data collection, but rather due to cultural and political interpretations of what statistics and mapping should cover. Thereby, the results can be presented to project certain aims rather than reflect a status quo. Moreover, the data available is very difficult to access. Where academic concepts assume institutionalised access to libraries, archives, statistical offices, etc., access to knowledge in Ethiopia is controlled socially to a very high degree. And even with good personal contacts, permission for access can change due to the daily constellation of gate keeping. Although the feasibility studies set up by various English companies in the 1950s, and the personal documentation of Guther's engagement to design a new city in Bahir Dar from 1962 (see chapter 5.3) could be obtained and were sighted in various visits to the archive of the Technical University of Darmstadt, and random material such as policy documents, statistical data from the administration and academic literature on the case study site were reviewed, the insights from the secondary data on the issue of urbanisation in Bahir Dar were limited.

The material would, therefore, have to be complemented by the collection of primary data from the field gathered under consideration of the local circumstances. As most material on African urbanisation comes in the shape of policy recommendations, references for field studies in urban development were not available. As such, the conventional approaches to data collection for urban planning projects quickly reached their limit:

Data collection was strongly limited by the political restrictions exercised concerning the work of NGOs, the press, publishing on the internet, freedom of speech and the reoccurring destruction of historical archive records in the realm of understanding knowledge as a power instrument. Under such conditions, access to decision-making networks proved difficult. Additionally, contact information on institutional members is difficult to retrieve for an outsider. 
The cultural differences revealed certain implications academia makes towards the role of the researcher in society. Coming into conversation situations as a female "ferenji" from a university background occasionally triggered intense reactions and often prevented the distance necessary to permit gathering and describing information. On two occasions I was accused of spying for Egypt; on one occasion I was regarded as a spiritual being; there were various marriage proposals, and I was the subject of tourist scams solicited in supposed interview set-ups. Face to face with conversation partners, even from the professional field, certain anticipated patterns of rational professional behaviour were hence deviated from, questioning the feasibility of data collection in accordance with academic standards. Further, due to linguistic and cultural contexts, passing on knowledge is often conducted in an oral tradition, which has little in common with the communication assumed by empirical interview techniques. In Amhara culture, the word "no" does not exist and questions are not negated on the grounds of true or false. The concept of "Wax and Gold" as an Ethiopian hermeneutic ${ }^{1}$, as well as certain emotional or spiritual argumentation, clashes with western academic conduct of conversations, sometimes rendering communication in scientifically approved form (such as interviews) impossible.

In this sense, the acceptance of the concept of the researcher determines the quality of the primary data available. Under these circumstances, empirical work had to adapt to local conventions. Primary data collection, thus, proved timeconsuming and had to rely on coincidence and opportunity to a strong degree. Readings of the built environment were conducted by systematically walking and mapping the entire built-up area. For the purpose of these cross-section walks, the built structure of Bahir Dar was sectioned into 26 areas on a satellite map, irrespective of the administrative boundaries of the city, so the peripheral growth and de-facto boundaries of dense urban fabric are included in the data collection. With the help of three research assistants - in this case students from Germany - information on the prevailing type of business activities, particularities of the neighbourhood's residents, sites of interest and the building structure were documented. Conversations with locals during these cross-section walks helped gather information on the characteristics of the city's individual neighbourhoods and were used to complete the notes.

Since obtaining information from experts in the field of building proved difficult due to their limited accessibility (see above), but also due to the custom of long waits for appointments and unavailability as a symbol of professional status, a lot of effort went into making contact with the professional networks to find expert interviewees willing to respond beyond politeness. In order to gain information on the projects of urban development, obtain plans and learn about planning practice, the possibility of organising a conference with the joint participation of Bahir Dar

1 | For further reading on the concept see Levine 2014 and Girma 2010. 
University, the ETH Zurich, the EiABC of Addis Ababa University, the Technical University of Dortmund and the HafenCity University promised to gather experts in the field by creating a discussion platform under the academic roof. For the thesis, this workshop helped build trust in my work and added contacts that were before not visible to me. As a result, seven semi-structured interviews with specific sets of questions for the respective interviewees were eventually conducted. The experts were interviewed in a random manner according to their willingness to openly voice their opinions on urban development issues.

For the description of variants of everyday practice, four specific neighbourhoods were identified as sub-cases and are illustrated in dense descriptions (see chapter 6). A final phase of fieldwork was conducted in the sub-case sites to conduct interviews with residents on their biographies of urban residence and their current living situations. The sites were selected to represent the planning periods identified in chapter 3. Information on periods before the arrival of the Italians is difficult to trace, due to the advanced age of informants from the time period up to 1935. Therefore, there is no sub-case selected specifically for this time period. For each of the following four phases from the arrival of the Italians, "imperial modernism", through the "socialist period" to "decentralisation" under the current government, a corresponding settlement area is identified. Within the sub-case sites, in-depth interviews with residents were conducted with 22 inhabitants of the sub-case sites. The interviews were semi-structured in-depth interviews, in which all respondents were questioned on the same range of topics related to their urban life. Candidates were identified according to stratified sampling criteria. Four categories were set-up: male under 30 years of age, male over 30 years of age, female under 30 years of age, female over 30 years of age. The age-line is derived from the average age of migration, the most recent data available being from the 1990s. An orientation to the overall average age did not seem sensible, as this was as low as 14.1 years for the male population in 1994. The average age for migrants from the rural areas, however, was 31.7, while the migrants from urban areas were exactly 30 years old on average (Golini et al. 2001: 180). As no information could be obtained on the average age of the female migrant population, their age groups for the interview selection are based on the figures for the males. With these criteria applied, the range of interviewees is expected to span individuals of both sexes before and after the frequent age of migration decision. With both sexes questioned in equal number, different gender perspectives are expected to be represented in the indepth accounts. In the areas with an evident mix of religions, it was attempted to interview representatives of the diverse religions as much as possible. They were contacted on the doorstep and interviewed in their homes, mostly over a cup of coffee. 


\subsection{Analytical Framework}

The material collected during the fieldwork and reviews forms the database of the case study (Yin 2009: 119). The criteria for interpreting the findings from the data collection are set by the analytical framework and form the case study report (ibid). In this thesis, the analysis is guided by the general research questions (see chapter 4.3). Therein, the multiple sources of data mentioned in chapter 4.4 serve to increase the reliability of results in the analysis. For this purpose, the data is triangulated and converged to support the facts by multiple sources of evidence (ibid: 116) throughout the thesis. The data from secondary sources, such as the archive work and policy review, is contrasted by the accounts from primary sources like the interviews, mapping and observations and vice versa, to establish if they are congruent in their argumentation or if contradictions arise. Contradicting accounts are noted in the case study report. To answer the research questions on the site-specific rationales of statutory planning and everyday urbanisation in Bahir Dar and how do they produce and organise city structures, the data collected in fieldwork is linked to the findings through the analytical approach of explanation building. This is guided by the first two general research questions "How do the different rationales relate to each other?" and "What are the implications for future urban development?".

The aim is to set up a focused description of the relation between planning and urbanisation in order to find out, how the two can be integrated. According to Robert Yin, explanation building can be described as a particular type of pattern matching, where the aim is to analyse the case study data by building an explanation about the processes and relations examined in the case (Yin 2009: 141). The explanation of a phenomenon is thereby defined as the stipulation of "a presumed set of causal links about it or how/why something happened" (ibid). This proposal is followed in this investigation. For this purpose the data is collected and coded in categories according to the propositions of the material. The explanation building analysis has a narrative form, but should reflect theoretically significant propositions for the case and the general theory (ibid). Where applicable, rival explanations are discussed in this approach, intended to be ruled out by argumentation and meant to increase the probability that the case study is exemplary (ibid: 187). The nature of explanation building is iterative and the final explanation may not have been fully stipulated at the beginning of the study. It, therefore, differs from the other pattern-matching approaches. Instead, the evidence is examined, the theoretical positions revised and the evidence is examined once again in this iterative mode (ibid: 143-44). This procedure has similarities with the analytical method of open coding, but refers to theoretical propositions to build the explanations, rather than being a topic-generating venture (ibid: 35). Explanation building regarding the research questions, therefore, is conducted in the manner of assembling a temporary, dynamic and incomplete account of functional organisation 
on a neighbourhood scale using sub-case sites that can be expanded and revised by future research findings. The outcome is a re-conceptualisation of current understandings concerning the phenomenon of urbanisation in Bahir Dar and the discussion of current theoretical proposals in the light of the empirical findings.

Using the second general research question on how to adjust the normative underpinnings of planning to suit the local conditions and requirements of urbanisation, the results from the empirical chapters are used to expand and adapt the existing theories to form new paradigms for local planning and to suggest instruments to adequately accompany processes of urbanisation in Bahir Dar. The insights identified in case-study research are, hence, linked to the objective of policy revision and a revised toolbox for intervention. The policy advice is, thereby, formulated as an extension and result of the discussion of empirical evidence in the case study report. 



\section{Urban Planning in Bahir Dar}

This chapter reviews the literature available on urban development in Bahir Dar. Thereby, an earlier review of material (cf Appelhans 2011) is thoroughly revised and expanded, while the data is contrasted with insights from everyday practice in order to compile a comprehensive account on the topic. Bahir Dar's urban development history is described beginning with the earliest assumptions about the 14 th century to give an impression of the context into which formal planning was established. The account of statutory urban development planning and practice continues until the present day and is described here to current knowledge. Thereby, the material has been organised into phases of urban development that are in line with the periods of national government. The phases of urban development identified in the chapter on urban development in Ethiopia (chapter 3) are, hence, utilised to structure the material on urban development in Bahir Dar, as they also coincide with local planning undertakings. The account spans the urban development of Bahir Dar from its beginning as a site of dwelling of the Wayto tribe and Orthodox monastic settlement on the lake shore, through the Italian occupation, the era of expansion under Emperor Haile Selassie, up to the recent decentralisation period, now making it the regional capital of Amhara National State. It ends with a description of the contemporary planning practice in Bahir Dar. The aim of the chapter is to establish the qualities of urban planning and contributions to local urbanity from a longitudinal perspective.

\subsection{TRADITIONAL LAND-AdMinISTRATION AND Settling Practices}

The early history of Bahir Dar is not well documented. The size of the town before the 20th century can only be roughly estimated, as sources give varying figures but remain within a certain size category: Bahir Dar is listed as one of the Christian towns with a permanent population of at least 2,000 inhabitants in the 1810 s to 1850s by Crummey (1987: 4). In 1891, a different population count estimated the city's size as between 1,200 and 1,600 residents (Seltene Seyoum 2003: 442). Un- 
like what Seltene Seyoum (2000) proposes, the evidence reviewed in this thesis suggests that the town seems not only to have a monastic founding history, but to have multiple constituting origins: an ethnic tribe living on the resources of the river Nile, a monastery and its function as a trading hub. These three nuclei constitute the first forms of settlement in today's city location and the historical centre. The first accounts of the population, hence, describe a majority of Amhara, the indigenous Wayto and number of traders (Darmon 2010; Consociazione Turistica Italiana 1938: 383). The first buildings were the traditional "tukuls" made of reed from the lake shore (ibid). What is known about the origins will be described in the following, as it has to be understood that the founding period of settlement did not distinguish between urban and rural land and was subject to a single administration under which a variety of livelihoods were practised in a growing density of settlement.

The Wayto are an ethnic group that formed part of the original population living on the shores of Lake Tana. It is not documented since when they have been settling here. The Wayto had their own language, which was last documented in 1928 by Griaule before it disappeared and was replaced by Amharic (Darmon 2010). The traditional Wayto lifestyle was strongly dependent on the Lake, fishing and hunting of hippopotamus (Gamst 1979: 233-235, Freeman 2003: 316-317). They were organised autonomously and had egalitarian rules of dividing the kill (Freeman 2003: 316). Their religion was traditionally water related. They worshipped "Abinas", the God of the Blue Nile, from whom they believed to receive wealth, health and resources, and from whom they tried to ensure this by sacrificing animals in his name (Oestigaard 2011: 27). Only with the introduction of rifles and a demand for ivory tusks did the hippo population decrease to the extent that by the 1930s the Wayto had to turn to fishing and agriculture (Freeman 2003: 316-317). The diversification of income sources proceeded with picking up crafts such as stone grinding and reed boat production as well as small-scale trade, when the availability of fish decreased by the 1960s (ibid). However, these economic extensions to other population groups in the form of trade and land lease from the Amhara did not lead to bridging the social gap between the Wayto and other settlers (ibid). The Wayto are considered "fundamentally distinct" from all of their ethnic neighbours in various respects (Gamst 1979: 253). Their Amhara neighbours traditionally see the Wayto as impure, as their practices of eating hippopotamus meat and catfish do not comply with their food rites, leading the community itself to be considered impure (Freeman 2003: 316-317). This has marginalised the Wayto population ever since the Amhara first settled the area. According to Seltene Seyoum, the Wayto quarter appeared as new settlement patterns within the town along with the Italian military camp in the 1936 (Seltene Seyoum 2003: 443, Seltene Seyoum 2000: 237c), by which he contradicts all other evidence. His argumentation can be countered with the account from the "Guida Turistica", which describes the 
indigenous village of Bahir Dar as consisting of "abyssinian" and "Uoito" (sic) huts, suggesting that the Wayto were well established there long before the time of publication in 1938 (Consociazione Turistica Italiana 1938: 383). In my opinion this scholarly disregard reflects the dismissal the Wayto culture faces from other ethnic groups in everyday culture. Although their surroundings have drastically changed through urbanisation in the past century, the indigenous Wayto population still remains as a community in Bahir Dar today. They continue to be marginalised on the basis of their traditional lifestyle, which is considered impure by the Ethiopian Orthodox Church's rites (Darmon 2010: 2). The Wayto have converted to Islam, but because they continue worshipping the Nile, Bahir Dar's Muslim community does not acknowledge them as true to the religion (Oestigaard 2011: 27, Interview Zerai Mesfin 2013). The tribe members therefore still face strong marginalisation by the Christian Amhara and the Muslim population, and the majority of the population in Bahir Dar remains wary of the community members (Darmon 2010: 2; Interview Zufan Sodru 2010). This is why, in an attempt to destigmatise the community, it has now been re-named "Negede", an Amharic term for "tribe", by the government (ibid).

However, power relations in the early constitution of the Bahir Dar as a town have led to a situation in which the marginalisation of the Wayto was institutionalised. Access to the city's facilities, including education and health care, remain out of reach based on stigmata. They are largely excluded from access to educational facilities, health facilities, transport, clean drinking water, electricity and modern communication (Interview Zufan Sodru 2010, Ajala 2008: 25). Beyond that they rely on the lake for drinking water, which due to its contamination has severe effects on the health of the community (Darmon 2010: 2). They are consequently described as still relying on their network of traditional and social capital to support each other in times of crisis and for larger efforts such as housing construction. They are settled in three different villages within the city boundaries (Interview Zufan Sodru 2010). Their buildings are still traditionally made of clay with grass roofs and have a lifespan of about five years before they have to be rebuilt (ibid). As in the past, they rely on the lake for fish, papyrus grass and small-scale agriculture on the flood plains. (Ajala 2008: 25) From this, the men produce Tankwa (reed) boats for sale, while women are engaged in basketry (Darmon 2010: 2). Apart from fishing and farming, petty trade is their only source of income (ibid: 25 , Interview Zufan Sodru 2010).

Bahir Dar's monasteries can be traced back to the 16th century, when Khidanemihret was the main church (Seltene Seyoum 2000: 235). The present name of the settlement originates from an Ethiopian Orthodox monastery named Bahir Dar Giyorgis (ibid). The time of the foundation of the monastery is attributed to the reign of the Gondarine King Iyassu I between 1682 and 1706 (ibid). With the strengthening of the Orthodox Church, the monastery gradually extended its administra- 
tive reach over the surrounding farmlands (ibid). The administration at the time was a complex system composed of locally and periodically differing systems, which are difficult to outline in a comprehensive manner but in which the church is repeatedly emphasised to have played a key role. The dominant traditional landholding systems in Amhara were based on communal ownership (ibid). According to traditional land-holding systems such as "rist"1, all descendants of land-holders were entitled to a share in the use of the family plot (ibid: 235-236). The immediate use of the agricultural land secured and determined the landowners' wealth and the management was entrusted to the elders of the community (ibid: 235). This land tenure system therefore determined a wide set of social relationships. Those foreign to the area or members of religious minorities (Muslim, Falasha, Wayto), could not gain land rights (Crummey 1987: 8, Seltene Seyoum 2000: 236). Occasionally, they rented from the local landowners (balabats), thus securing the land-holders an additional source of income (ibid: $235 \mathrm{c}$ ). The land rented out to the tenants is called rim land and is said to have made up only around $2 \%$ of the holdings in the region (Ofcansky and Berry 1991). As a result of landlessness, nonChristians worked on much of the church-owned land (Crummey 1987: 8-9).

Although access to land is often claimed to be purely hereditary, research by Allen Hoben (1973) was able to prove that the size of landownership changes during the lifespans of Amharic landholders. Land sales or bartering must, therefore, have been possible under some circumstances (Hoben 1973: 7). The monastery was entitled to gather taxes from the local landowners on the surrounding farmlands (Seltene Seyoum 2000: 235). Land use was mainly for subsistence farming (ibid: 235-36). As described above, $10 \%$ of all production on rist land was granted to the Ethiopian imperial state through the Ethiopian Orthodox Church, while all taxes on land and from trade were due to the monastery itself (Seltene Seyoum 2000: 236). A distinction between rural and urban land within the administrative zone of the Bahir Dar Giyorgis monastery was not undertaken at the time (Seltene Seyoum 2000: 236).

The settlement was subject to Portuguese missionary activity from the early 17th century until the expulsion of the Jesuits from the country in 1634 (Meinardus 1965: 283). However, the only relict known of this time is an altar on the grounds of today's Kidus Ghiorghis Church in the town centre (ibid) and the relevance for urban development is assumed to be negligible.

Bahir Dar has to be considered a market town as early as the 19th century (Crummey 1987: 4). It was located on a long-distance trading route, as well as converging local trading routes connected to the productive areas in the hinterland (Gebeyaw Walle 2003: 26). According to the descriptions of Grottanelli from 1935, the majority of market space in the towns in the Lake Tana basin was given over to

1 | For further reading on traditional land tenure, see Hoben 1973. 
small-scale, local or regional level exchange of agrarian commodities and utensils (Crummey 1987: 4). This is the scene of reference one has to imagine for Bahir Dar at the time. The trading population is, thereby, said to have come from interior regions, as well as the ports around Lake Tana (Seltene Seyoum 2003: 443), while many artisans were members of religious minorities (Muslim, Falasha, Wayto), as these population groups could not gain land rights (Crummey 1987: 8). However, even landowners are said to have supplemented their income with short-distance trade across Lake Tana, and on land or by transporting goods on reed boats along the Nile (Seltene Seyoum 2000: 236).

Although Seltene Seyoum (2000: 236) claims that the market turned into a trading post for long-distance merchants arriving in caravans, based on other evidence, its significance to the region, however, has to be evaluated as modest. In the regional network of cities around Lake Tana of the time, Ifag as a slave market was a much more important centre for long-distance trade and played a predominant economic and institutional role in the area (Crummey 1987: 4). Crummey generally also concludes that the transit of caravans was occasional and seasonal and, accordingly, did not have a permanent impact on the towns' character (ibid: 5).

\subsection{ITALIAN LEGACY}

The Lake Tana Region was recognised as a water-rich and, therefore, strategically important area even before the First World War. A narrative of a fruitful and agriculturally rich region was developed and spread to Europe, which sparked the interest of the Italian regime in gaining power over this area (Abdussammad $\mathrm{H}$. Ahmad 1994: 621-622). The control over the area was strongly contested, as other foreign political powers also developed their interests on the Lake Tana watershed, the main source of the Nile. So it came to pass that, at the beginning of the 20th century and throughout the First World War, the Lake Tana region was subject to a power struggle between the Italians and the British, in which the latter were interested in the water resources, while the former wanted to build their own colony at the location (Abdussammad H. Ahmad 1994: 622-624, Tvedt 2004: 122). The ambitions for this region, however, were of greater strategic relevance within the wider aim of establishing an Italian colonial empire, as by seizing control over the headwaters of the Nile, Italy speculated on a dominant role in North-East Africa (Tvedt 2004: 122). Meanwhile the Italians were not the only foreign party with interests in the Ethiopian territory on Lake Tana: "Great Britain had as well a grandiose project of building a storage dam at the mouth of Lake Tana. The dam idea in turn triggered Britain's interest in north-west Ethiopia and brought this part of Ethiopia within the imperialist geopolitics of the Middle East and North-Eastern Africa. [...] To ensure the prosperity of the Gezira (Sudan), Britain envisaged to build a storage dam at the mouth of Lake Tana. However, Britain unlike Italy had 
an anti-annexionist policy which went along with her goal of exercising control over the waters of Lake Tana and the Blue Nile. The British felt that their interests were best served through diplomatic exchanges with the Ethiopian government" (Abdussammad H. Ahmad 1994: 621-622). Following the dispute of powers, the Italians invaded Ethiopia in 1936 (Haile M. Larebo 1994: 263). As part of the images created of a resourceful region with the idea of irrigation and hydropower projects, the rural areas around Lake Tana were designated as cotton-growing areas to supply the Italian textile industry in 1938 (ibid). The administration of the cotton-growing area was established in Gorgora (ibid), and large-scale expropriations of land were undertaken around Lake Tana (ibid: 81).

Situated within this cotton-growing district was the settlement of Bahir Dar, which was taken by the Italians on their advance southwards in April 1936 (Consociazione Turistica Italiana 1938: 383) and turned into a local garrison (Seltene Seyoum 2000: 237). In the contemporary travel guide, the settlement is described as a village made up of Abyssinian and Wayto huts, accommodating small-scale trade, a post-office, a clinic and a telegraph office (Consociazione Turistica Italiana 1938: 383). The Italians took to actively restructuring land holding and settlement organisation. In the occupation, the "Residenzia del Tána Meridionale" was installed, replacing the traditional administration, and the settlement now served as an administrative sub-centre for the occupied region south of Lake Tana with approximately 25,000 inhabitants (ibid). These measures strongly raised its political importance in the region. Economic activities in the city were taxed by the Italian administration from this point (Seltene Seyoum 2000: 238). This resulted in a redirection of taxes from the imperial Ethiopian government and the Ethiopian Orthodox Church to the Italian regime, accompanied by the loss of administrative power to the occupiers. The act signified the establishment of a separate urban administration, rendering the surrounding area rural.

For new uses projected in the town, additional space was provided by draining surrounding swamp lands and making them fit for construction but also by forcefully removing local inhabitants from their dwellings (Seltene Seyoum 2000: 237). With the arrival of the Italians, the traditional land rights were overridden by the Italian planning advancements with far-reaching implications: the Italian occupation has left a legacy of divided rural-urban administration in Bahir Dar. The land was reallocated to new residential and commercial owners (ibid: 238). New residential and commercial zones were established for development (Seltene Seyoum 2003: 443, Seltene Seyoum 2000: 237c). Further, public land was allocated for administration, the military, an airfield near the centre and port facilities on Lake Tana (ibid). The connections to Gondar and Addis Ababa by aeroplane were first introduced, and the town was connected to Gorgora by motorboat via other ports on Lake Tana (ibid). The reorganisation of socio-economic configurations accompanied the physical changes and altered connectivity: The communal family ownership of land was abolished and individual landownership was instituted 
instead. The balabats from the settlement faced a loss of income and wealth, as the tax formerly collected from the tenants by the landowners themselves was now also due directly to the Italian occupants (Seltene Seyoum 2000: 238). Nevertheless, there were no means of compensation for the former land-holders, neither for this loss of income, nor for the land expropriated in the construction process (ibid). By re-appropriating the land, a new class of urban land-holders arose (Seltene Seyoum 2003: 443, Seltene Seyoum 2000: 237c).

By the time the Italians had constructed a motor road including a wooden bridge across the Nile, to make the city accessible for car traffic from Gondar and Addis Ababa (Consociazione Turistica Italiana 1938: 379, Tvedt 2004: 178), a number of box-shaped chicka (mud) houses with corrugated iron-sheet roofing were erected along the road to contain a number of tiny shops (Boden 1962: 4a). According to Seltene Seyoum (2000: 237), a Muslim community appeared as a new settlement pattern within the town along with the Italian military camp. Meanwhile the existing tanners' quarter is described as having remained largely unchanged by the surrounding construction activities (Seltene Seyoum 2003: 443, Seltene Seyoum 2000: 237c). As the town's economy grew steadily, artisan, clerk, and labourer occupations evolved (Seltene Seyoum 2000: 237). A cultural mix of peoples is reported to have been observed in the town, and different kinds of shops, tea-rooms, tailors' shops, bars and restaurants, run by Italians, Arabs, Somalis, and Sudanese (ibid). The Ethiopian participation in these enterprises first appearing in the commercial zone is described as insignificant at the time (Seltene Seyoum 2003: 443, Seltene Seyoum 2000: 237 c).

The period of Italian occupation ended when the Italian troops fled from Bahir Dar after a battle with the Emperor's army in April 1941 (Haile Selassie et al. 1994: 156). Their legacy regarding urban development is, thereby, wide, although the Italian's architectural output in Bahir Dar was relatively small. Apparently, it consisted only of three single-storey masonry buildings (Boden 1962: 6). One was later occupied by Getachew Bekelle, the governor of the sub-region, the other by the harbour authority and a third was put into use as a hotel (ibid). Despite the ambitions regarding cotton production and the need for manufacturing centres, the Italians' exact intentions for Bahir Dar's future, beyond serving as a garrison in time of battle, remain unclear. The settlement is described as an emerging centre in the Italian tourist guide from 1938 (Consociazione Turistica Italiana 1938: 383), but in the region, Gorgora and Gondar have to be considered far more influential towns at the time.

Yet the assumption that the impact of colonialism on Ethiopia's towns is small and limited to the business district in Addis Ababa can be rendered false, based on the evidence from the case. In my opinion, the findings from Bahir Dar demonstrate that there is a colonial legacy even in Ethiopian cities without a large architectural colonial heritage or an implemented colonial master plan. The legacies of the Italian occupiers are visible in built structures, but can also be found in urbanisati- 
on practice, including urban planning. The impacts of the revised land tenureship and the introduction of urban administrations, such as in Bahir Dar, are extensive.

The division between rural and urban administration, and, thus, the introduction of a dichotomy that is reflected in the division of rural and urban ministries to this day, is proving problematic in the current questions of rapid population growth and urban expansion. The implications of abolishing the traditional landholding system have to be seen in the split of de facto land rights exercised in continuation of traditions by occupants who were never confronted with other claims and new de jure regulations installed by the occupiers, resulting in potentially competing land management systems (see chapter 2.2).

The Italians can also be said to have introduced the implementation of industrialised agriculture in their cotton-planting scheme. Although cotton planting was not overly successful and the district on Lake Tana remained the only productive cotton district after the occupation (Haile M. Larebo 1994: 282), the "regulating fiction" of a cotton industry was introduced so successfully that the Emperor Haile Selassie later appropriated the idea. When demanding reparations for the Italian damage, a textile mill was claimed by the Emperor and constructed with Italian funding and expertise in Bahir Dar (Guther [around 1962]: A5 and J3; see chapter 5.3). The Italian rhetoric claimed that industrialised cotton production would benefit the indigenous population, but it seems that, in effect, the crop was exported to the Italian cities, leaving no surplus in Ethiopia (Haile M. Larebo 1994: 263). However, the model was adopted and expanded to install a textile industry in Ethiopia itself, thus disregarding a "commercial colonisation" (Göckede 2010: 56 ), in which this step of the value chain would lie outside the country for a local production industry. It seems that the transfer of certain Italian urban practices like industrial labour division to the system of reinstated monarchy is due to its symbolism of modernity and development. This period, therefore, marks the beginning of project-related developmental interests on the water resources of the Lake Tana watershed basin, leading to the industrialisation policies described in the next sub-chapter.

\subsection{The Modernist Layout}

Emperor Haile Selassie's government was reinstated after the Italian Occupation ended in 1941. At first, a temporary administration was set up to govern the town (Seltene Seyoum 2000: 238). In the early phase of the Emperor's reinstatement, the Italian military legacies in the urban core of Bahir Dar as well as the colonialist land practice based on expropriation of traditional land holders, were transferred to the rule of the new administrative system and thus legitimised without compensation (Seltene Seyoum 2000: 239). As a result Bahir Dar's urban land stayed in the hand of the sovereign. At the time, the settlement is described to have had 
around 4,000 inhabitants, most of whom resided in round huts known as tukuls (Boden 1962: 4a, Guther [about 1962]). The mayor's office was accommodated in a stone house only in 1961 (Boden 1962: 6). The Italian legacy mixed with monastic and trading activities, plus the indigenous (Wayto) settling activities, formed the settlement pattern. The Orthodox Amhara formed the majority population and depended largely on farming, while the Muslim community was responsible for most of the trading activity in the location, making up about $40 \%$ of the population in 1960 (Guther [1962]). Despite an agreeable climate, the living conditions in Bahir Dar of the time are said to have been devastating, the average life-span being 35-40 years, due to a high rate of malaria, bilharzia, yellow fever, typhoid, leprosy and polio in absence of any sort of sanitary and medical facilities (Boden 1962: 4d). From 1945 on, Bahir Dar was officially considered a municipality (ibid: 239). The Italian institutions and administration were reformed, and various administrative offices, as well as public services, were set up during this period. The city's governor Aemiro proceeded with the construction of many new streets to house administrative offices, such as a courthouse, a police station, and a prison. Commercial facilities such as small shops, restaurants, and a hotel were newly constructed (Seltene Seyoum 2000: 238 c).

Fig. 5: Max Guther's Master Plan with the Built-Up Area in 1957 (red) and the Current Administrative Boundary (yellow).

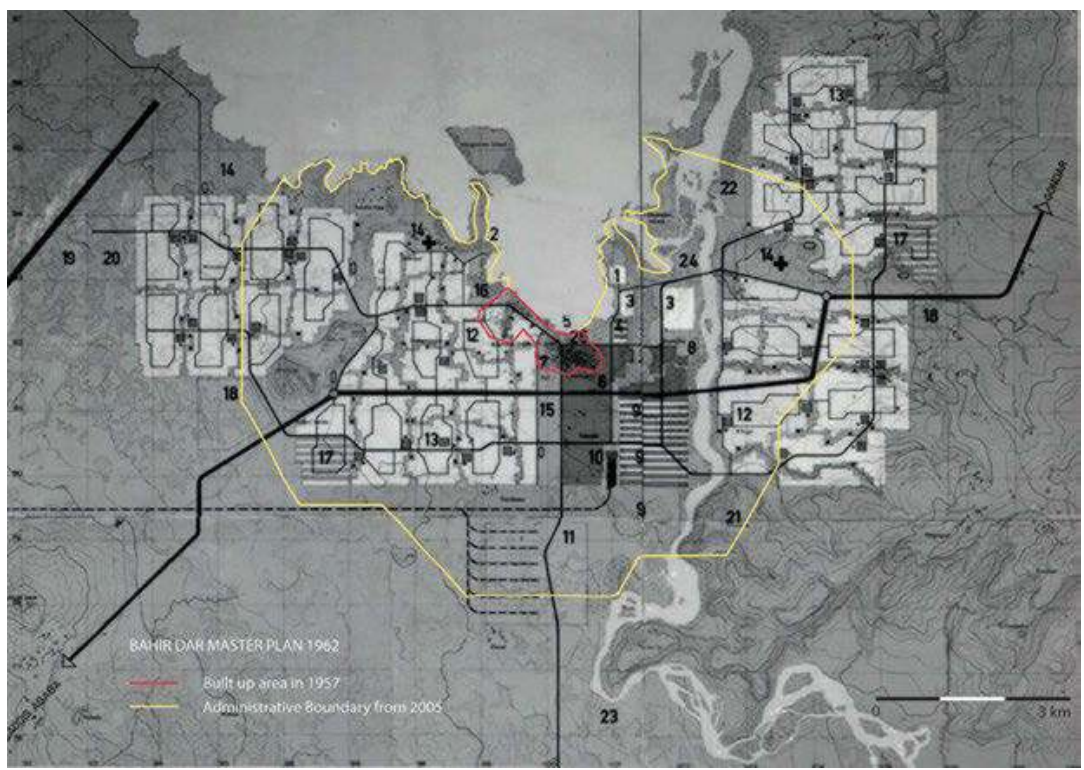

Master Plan by Max Guther (Guther et al. 1961), with data from Haimanot (2009: 52) and RUPI [date unknown c]. 
In the course of his reign, however, Emperor Haile Selassie developed a strategy of industrialisation for the country, which eventually led to the initiation of expanding the settlement of Bahir Dar Giorgis on the banks of Lake Tana. In a continuation of the power struggles between the Italians and the British over the water resources of the Blue Nile, the British pressured the Emperor for an area on Lake Tana on which they were keen to establish hydropower works in the early 1940s (Bahru Zewde 1988: 279). As a result of this, and with the Italian irrigation plans having been devised, but not realised, the Emperor explicitly acknowledged the strategic importance of the resources in the Lake Tana Region. According to Terje Tvedt, it was at the beginning of the 1950s that Emperor Haile Selassie began developing an industrial development plan for Lake Tana (Tvedt 2004: 237). Following his quest for "development" (Haile Selassie et al. 1994), Haile Selassie decided to give the order to design a new city on the site of the rather modestly sized Bahir Dar, which would make use of the hydropower potentials of the location (Tvedt 2004: 255-57). Tvedt states that:

"Independent Ethiopia under the leadership of Haile Selassie gradually became, [...] more and more bent on using the Nile for generating hydropower. So committed was the Emperor to this idea at the beginning of the 1950s, that he thought of moving the capital from Addis Ababa to the new town of Bahir Dar, planned as a center for hydropower and development, on the shores of Lake Tana. But most of all he wanted Eritrea to be part of Ethiopia, and he hoped to use the plans for the dam as a leverage to achieve this regional, imperial dream." (Tvedt, 2004: 237)

The Emperor received three different drafts from different European architects, before the plan finally executed was drafted by German architect Max Guther from Darmstadt and his team (Guther [around 1962], Boden 1962, Egli 1967).

Although it cannot be established how serious the Emperor's ambitions to relocate the capital were, various sources state that this was his plan and that the order Guther received was to design a capital city (Guther [around 1962], Egli 1967, Tvedt, 2004: 255). The contents of the plan were discussed between Guther's team and Haile Selassie, who designated his Minister of Public Works and Transport to be responsible for the project (Guther [around 1962]: A1). The establishment of the new urban development project would drastically change the urban scenario in spite of its adverse implications for human habitation. The master plan Guther set up in 1962 was based on a concept of industrialisation and consisted of various elements, which were organised on an infrastructural grid structure. The newly devised zoning of the plan included both banks of the Nile, linking them by a concrete bridge. The zoning suggested cultural and business areas, industrial zones, small-scale industry, administration, services, military and a definition of subcentres with commerce (see image of the plan). The final stage of the master plan 
projected up to 300,000 inhabitants (Egli 1967: 393). This meant a projected tenfold expansion of the figure of 25,000 inhabitants estimated in 1938 (see above). The plan included architectural designs for three model houses (Boden 1962: 1). When starting to devise the plan, certain building projects had already been decided on and had to be incorporated into the master plan. Among these projects was the textile factory that was in construction due to a reparations agreement the Emperor had settled on with the Italians (Guther [around 1962]: A5 and J3). Guther himself drafted and executed the Felege Hiwot hospital project (Guther [around 1962]).

Meanwhile, the master plan did not take into consideration the existing settlement nor did it look at social, cultural and economic structures in place. The tukuls were disregarded as not worthy of consideration in the progressing construction and were designated for removal (Guther [1962]: J1). Beyond that, no enquiries on local living were made, although Guther stated that he wanted the design to be of "Ethiopian-African nature" and model it on Gondar (Guther [around 1962]: A8). Guther, instead, applied the principles of universal modernisms in his plan, making references to Chandigarh and criticising the rigid formality of Brasilia's urban layout. In terms of racial questions, Guther remained very neutral. The plan did not contain any kind of racial segregation, nor did it acknowledge the multi-ethnicity of Bahir Dar's population (Guther [around 1962]). The abolition of traditional land rights in the urban location was not discussed and the Emperor's landownership in Bahir Dar was not questioned. On the contrary, Guther expresses his relief that royal landownership meant easy implementation (Guther [around 1962]: E7).

The idea of establishing a new city on the site on the southern shore of Lake Tana was eventually put into practice. The estimated annual growth rates for the period from 1966 to 1979 and the period from 1970 to 1978 are given as $10.0 \%$ and 11.3\% respectively (Habtemariam Tesfaghiorghis 1984: 163). From the start of implementation, the Ministry of Public Works and Communications was responsible for working on putting the master plan into practice on the part of the Ethiopians. This ministry sought municipal administration expertise from Germany, and at their request Hans Boden arrived in Ethiopia in March 1962 to function as an advisor to the Ethiopian government (Boden 1962: 3). Boden claims to have had a strong influence on keeping the order of the plan during his presence in Bahir Dar. He assumes his presence to have prevented building activities on sites not designated for construction as well as pointing out suited locations within the urban plan for building requests by a Shell petrol station, a large motel built by the oil company AGIP, a building for the State Bank of Ethiopia, student housing for the technical college and a commercial building for the Besse import-export company (Boden 1962: 10).

Initially the progress of implementation is described as good. Backed up by foreign development aid, a concrete bridge across the Nile (funded by the USA), a technical college (funded by the USSR), a hospital (funded by the Federal Republic of Germany), water provision (funded by the USA) and a school (also funded by 
the USA) had already been constructed or were due for completion in 1962 (Boden 1962: 4c). Thereby construction seems to have started ahead of the master plan, as the final draft was only completed and presented that same year. In addition, the Italians had agreed to pay reparations in form of a textile factory on the bank of the Nile, which was in realisation, while the Ethiopian Electrical Association had built a hydro-power station at the Blue Nile Falls (Boden 1962: 4c). Boden heard of further plans, including the construction of an airport at a designated location for which the technical equipment had already been ordered. Meanwhile the improvement of the road from Addis to Gondar was due to reach Bahir Dar from both directions within one year. (Boden 1962: 10)

However, after the initial period of progress, financial difficulties arose, prohibiting further development (Boden 1962: 4d). Guther also expressed disappointment at the fact that the architecture filling his design did not sufficiently live up to his expected standard (Guther [around 1962]). The state budget of the year was E\$ 280 million (one E\$ being equivalent to DM 1,50 at the time), while the Governor only had E\$ 500 and the municipality no more than E\$30,000 to spend, overall (Boden 1962: 4d). According to Boden, who was present in Bahir Dar attempting to give advice on administrative issues, neither the state budget for the coming year (1963) nor the second five-year plan for the years 1962-67 included a budget for the further development of Bahir Dar (ibid). This lack of financial means for the project is a possible explanation why substantial elements of the plan, such as the sewerage system, were never executed.

There also seem to have been issues concerning the project being ordered from the highest instance of power in Addis Ababa. Boden describes how, on a return visit to Addis, he discovered that the responsible Minister had left his post and with him the knowledge of the experts present for the city project and possibly even the project itself (Boden 1962: 4b). He, further, describes an unwillingness on the part of the Governor and the Mayor to support the implementation of the plan. Boden speculates that they might have felt threatened by the plans and feared for their positions. As for the Governor, he assumes that a feud with the Emperor, resulting in degradation to this post from a former more responsible position, and personal resignation added to his suspicion towards the project (Boden 1962: 5-7).

The modernist ideas and ideology shaping the development of Bahir Dar through urban planning have been traced and need to be discussed. The material presented here reveals that today's city location was chosen on the basis of strategic international interests in its water-related potential, to which Ethiopia eventually made its own claim. By establishing a textile factory in Bahir Dar, the production was changed to overcome colonialist agricultural exploitation. Instead, an attempt was made to create a value chain and establish Bahir Dar as a site of industrial manufacturing. A link to the cotton plantations that were planned by the Italians but never materialised to the extent intended, can clearly be established. However, the manufacturing industry, from fashion design to final production and market 
demand, did not have the equivalent features as the Italian set-up on which the colonial cotton production was modelled. The further expansion of the city was in fact the result of a developmental view of the country that the Emperor had adopted. The city plan he received from Guther followed a modernist approach, claiming universality for the standards it supplied. The positive side of this is the attempt to lift the living standards of the population. However, the focus on technical aspects and neglect of social, economic and cultural conditions, as well as the exclusion of the population from the planning procedure also prevented the rise of an urbanisation practice more rooted in the local culture. In this respect Bahir Dar is not a representative case for Ethiopian cites, being the centre of an international power discourse and designated site for a new capital. However, it shows the ideas to which the Emperor was open and the modernist mindset of the time. Unlike the colonialist Italian urban planning approach, Ethiopia's imperial modernism made no differentiation of development standards according to racial zoning. The basic attitude towards the project, however, was an assumed developmental gap between the Ethiopians and the Europeans. The point lies in the fact that there was no racial division but also no acknowledgement of ethnic and religious diversity within the city in Guther's master plan. Based on the construction of this developmental gap, the Europeans are, therefore, legitimised to come in as experts on behalf of the Emperor and subject the local Ethiopian population to the plans of settlement improvements, disregarding the existing settlement structures. A democratic ideal was not exercised in devising the master plan; a paternalistic planning approach was followed, instead, while the content serves to spatially support the royal power structures. The planning process was neither participatory nor considerate of local settlement culture, as described by Genet Alem (2011) in her book on traditional northern Ethiopian highland towns. The population was completely left out of the planning process on decisions concerning their own habitat. Bahir Dar's population was hence not conceptualised as responsible individuals to be considered in the planning process. Yet, the multi-directionality of flows needs to be addressed: What Guther interprets as architecture not suited to standards can also be viewed as an appropriation of the structures with locally available means. The plan was, therefore, flexible enough to allow filling-in and the street layouts practical enough to withstand being overwritten by other patterns.

\subsection{Introducing the Kebele Administration}

In the time of the Derg, Bahir Dar and its surroundings formed an administrative unit called Awraja, which was between the provincial and the woreda levels (see map in Liyew Adamu 1994: 15). After the 1974 revolution and the coming to power of the socialist Derg regime, relatively little attention was paid to Bahir Dar's urban development. The political focus was on agricultural development and farming as 
an industry, and there is a gap in academic literature of the period as far as Bahir Dar is concerned. It can only be assumed that the Master Plan by Guther continued to be the planning reference for the location, as no evidence for the existence of other plans was encountered in the review.

Since the urban land in Bahir Dar had been expropriated in the course of the construction of the projected capital (see 5.3), it, further, has to be assumed that the land reform put in place at the time was not as significant for Bahir Dar as it might have been for other towns. Land ownership was already in the hands of the state, leaving the former royal claims to the new socialist rulers. What has to be considered being of larger importance is the expropriation of rental housing. Despite the property reform, $61.1 \%$ of Bahir Dar's residents continued to live in owner-occupied housing in 1984 (Gebeyaw Walle 2003: 44).

Those houses expropriated fell to the newly established Kebele administrations, to rent out the acquired houses. The establishment of these administrative units has survived the socialist regime and still forms the smallest administrative basis within the city of Bahir Dar today. However, the data obtained for this thesis could not reveal whether the spatial boundaries of these units have remained unchanged since that time.

The attempts at establishing industries also continued under the socialist government. The textile mill gained the Derg's attention and industrial production was supported by the installation of sports facilities (a tennis court and a public swimming pool), as well as a library, a restaurant and a cafeteria in convenient reach for the housing and plots provided for a growing base of textile workers. It can, thereby, be said that the colonial ,schemes of production were appropriated not only by Emperor Haile Selassie but also by the socialist rule.

Despite the lack of evidence of further formal urbanisation efforts, the city continued to grow, even though the estimated average urban growth rate of $2.2 \%$ p.a. in the period from 1978 to 1984 was significantly slower than the double-digit growth under Haile Selassie's expansion plans (Habtemariam Tesfaghiorghis 1984: 163).

Whether the (seeming) lack of urban policy signified a chance for everyday urbanisation, including informal and traditional building practices, cannot be established from the literature review. In policy terms, this change does signify a switch from inducing, forecasting and managing growth to a management of resources in place (see chapter 2). 


\subsection{Contemporary Planning}

Fig. 6: Towns in Amhara Region

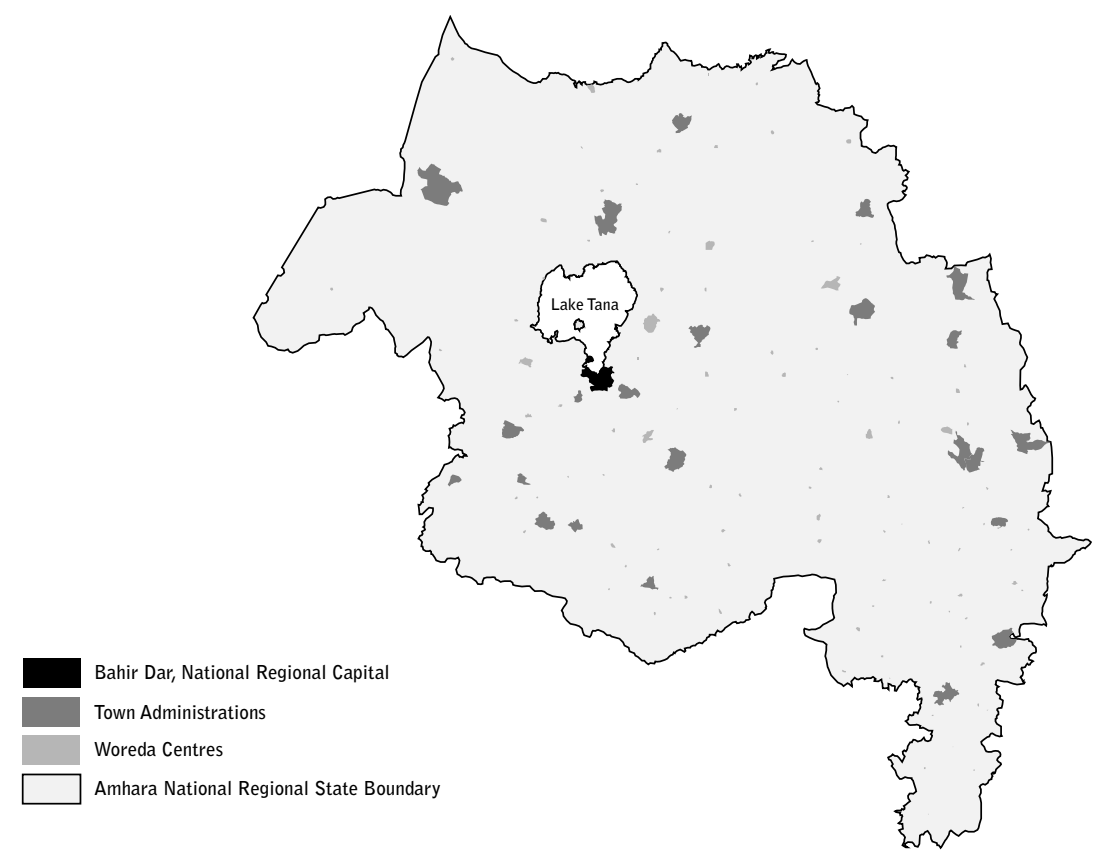

Image by the author with data from RUPI [date unknow].

Following the instalment of the current government in 1994, Bahir Dar was chosen as a seat of the Amhara National Regional State (Nigussie Haregeweyn et al. 2012: 150). Despite the city's high growth rates in its time of establishment under Emperor Haile Selassie and the Derg (see 4.2), Bahir Dar turned into a destination for a new type of population influx from the rural areas with the end of socialist rule (see 3.5). In 2003, the city was still dealing with growth rates of $4.8 \%$ per year and was expected to double in size between the years 2012 and 2014 (Nigussie Haregeweyn et al. 2012: 153-154; see 4.2). While development pressure increased on the land in this period and issues faced in the city are unserviced settlement sites, overcrowding, food security and ecological issues (Interview Endegena Ejigayehu 2011). Under the new government, urban development was put back on the political agenda in order to address the situation (see chapter 3.5). The EPRDF sought to decentralise the tasks formerly concentrated in the National Urban Planning Institute (NUPI) in various steps. So far, this process has reached down to the establishment of "Regional Urban Planning Institutes" (RUPI) in four of the "National Regional States" that form the Ethiopian Federation (Ministry of Works 
and Urban Development 2008). The Amhara National Regional State's RUPI was established in 2008 and is responsible for setting up plans for all urban settlements in the region, including Bahir Dar (ibid). According to Tegegne Gebre-Egziabher (1997: 704), the sectoral planning approach stayed dominant in the overall planning framework. Since there was no adequate methodology for regional planning in place, inconsistencies across the zones allowed sectoral planning to pertain (ibid: 705). Often the planning offices stayed passive and did not take the initiative to devise development plans (ibid: 704). With the exception of the offices in Addis Ababa and Amhara, they were understaffed and not well equipped regarding logistics and budget (ibid: 705). As one of the more populous regions, Amhara has a relatively higher tax-base, but external sources are still needed for state expenditure (ibid: 706). Other monetary sources for the local administration are national government transactions and funds from donors (Tilahun 04.09.10). Despite this overall situation, Bahir Dar's master plan was first revised in 1996. Thereby, the revision incorporated the old plan's grid structure into an expanded radial one (see fig. 11 and 13). As a result of these planning efforts, Bahir Dar Municipality was awarded a "Peace Prize" by the UNESCO in 2002 for addressing the challenges of rapid urbanisation (United Nations Educational Scientific and Cultural Organisation: 2002; Daniel Weldegebriel 2011: 13).

With the installation of the new government, the tenure situation in Bahir Dar did not substantially change policies on ownership and rental laws (Daniel Weldegebriel 2011: 5). The tenure system is regulated under federal law and cannot be changed by the Amhara National Regional State (ibid). The cities are encouraged to make proposals for the land use (ibid). However, plan making and land administration are operationally on the same administrative level in Amhara region. Different ownership models apply for the real estate on rural and urban land. In Bahir Dar, people interested in acquiring plots for residential or business purposes may do so by negotiation or by putting in a bid (ibid). Meanwhile the municipality's rates base relies on the land tax and the land-transaction tax, which go directly to the municipality. The taxation rate on land is at about $2 \$$ per plot, irrespective of the size (Interview Endegena Ejigayehu 2011). The land-use rights within the city of Bahir Dar are granted for a fixed period of five to 15 years (ibid). In case of demand, the municipality can then reclaim the plot.

The amount of owner occupied-housing, Kebele and housing rented-out by the administration fell in 1994 in comparison to 1984 (Gebeyaw Walle 2003: 44). In reverse, the quantity of rental housing from private owners rose, following permission for subletting and the new national policy on the right to ownership including rental relations (ibid). According to data from 2011, 30\% of the city's approximate 30.000 housing units were located in informal settlements on state owned land or designated farm land (Daniel Weldegebriel 2011: 13).

Meanwhile, the overall living conditions in the city at the time have to be described as dire. In 1994 , about $54.7 \%$ of dwellings were in good physical condition, 
$35.7 \%$ required maintenance and $6.6 \%$ were derelict (ibid: 37$)$. Almost all of the building stock was single storey (99.16\%, ibid: $43-44)$. In 1995 , about $81 \%$ of all houses had floors of mud, $87 \%$ had mud and wood walls, $85.4 \%$ an iron sheet roof, while $86 \%$ of all buildings had no ceiling according to data from the Central Statistical Authority (ibid). Despite a percentage of $94.91 \%$ of the entire building stock considered to be permanent buildings with a life-span of more than ten years, the mud buildings are considered to be sub-standard housing by the government (ibid). Also due to the population growth, a severe shortage of housing was documented in Bahir Dar in the formal sector in 1998 (Gebeyaw Walle 2003: 34). Reasons for the shortage were stated as high-interest rates, low earnings, increasing prices in construction material and scarcity of rental houses (ibid). Between 1994 and 2002 , about 5,365 housing units were constructed. However, this is only about $37.04 \%$ of the estimated housing need (ibid: 35 ). At stable construction speed, this backlog would be addressed only over a period of 15 years (ibid: 39 ).

Also, the provision of basic infrastructure did not meet minimal sanitary requirements. Until today no sewerage system has been installed in Bahir Dar. The city relies on a septic tank system, while there is an open disposal site for solid waste outside the city to which the septic waste is taken. An assignment to treat the solid waste has been made, but a plot of land on the outskirts of the city needs to be allocated for a treatment plant. Further, there is a problem of litter, as not all the households participate in waste collection. The municipality controls the waste collection system, but it has been outsourced to a private company since 2009 (Tilahun 04.09.10).

Bahir Dar's poverty levels remain high and further efforts to address the situation are being undertaken. A study on poverty incidence from the UNDP issued in 2003 in ten major Ethiopian towns is quoted by Philippa Bevan and Alula Pankhurst and shows higher than average percentages of poverty in Bahir Dar in 1995 (Bevan et al. 2008: 12). Due to this, the "informal sector" is considered an issue according to a survey by the Central Statistical Agency (2003) and has to be considered relevant to Bahir Dar's further urban development. Ethiopian government institutions currently still describe informal economy as a "sector", in which a large proportion of the population is economically active (CSA 2003: 15). The Central Statistical Agency survey states that all the informal sector establishments in Bahir Dar were found to be in sole-trader ownership, with only a few operators in a position to employ further workers. Of these most are found in the manufacturing sector and a few more in trade, hotels or restaurants. (CSA 2003: 33) Due to their informal nature, they are said in the survey to be "beyond social protection, labour legislation and protective measures at the workplace”. (ibid: 9) The survey was, therefore, undertaken with the focus of identifying the scale of unregistered economic activities that are not paying licenses and tax, or are avoiding the labour regulations; the methodology by which the "sector" was monitored is questionable, as certain activities were not documented at all. Taking the absolute figures of the 
CSA survey, calculations on the proportions show that, even together, the transport and construction sectors apparently only accommodate around 3\% of individuals in informal labour. Instead, according to the state sources, the majority is active in manufacturing (63\%), while a further $20 \%$ work in trade, hotels or restaurants and $14 \%$ deliver community and personal services (CSA 2003: 33). However, a survey by Woldie Assaw et al. (2010) among seasonal migrants in Bahir Dar revealed quite a different picture of the entering modes on the labour market for rural-urban migrants than the data from the Central Statistical Agency suggest. According to his survey, many of the migrants seeking short-term employment engage in informal, unskilled manual labour. Among seasonal migrants in Bahir Dar, 94.2\% are stated to have worked in construction, $56.9 \%$ had dug wells, $30.4 \%$ engaged in cultivating chat, $10.1 \%$ in loading and unloading, $8.7 \%$ in domestic work and $4.3 \%$ in other activities (Woldie Assaw et al. 2010: 67). Considering the number of these seasonal migrants, their labour ought to have appeared in the CSA's statistics as informal activities. Overall, knowledge of the informal sector has, therefore, to be considered as fragmentary and hardly documents the role of informal employment for urbanisation practice. It, furthermore, does not serve to document the intertwinement of formal and informal production in certain locations, legal work status or the dynamics of informal work practice. The investigation even excluded larger enterprises in advance. This lack of data points to the fact that informality is understood as a problem related to smallholder enterprises, subsistence and poverty by the governmental and administrative institutions. This gives an insight into the state's divisional understanding of formal and informal urbanism.

Against this background, the Ethiopian government decided to adopt the Integrated Development Plan (IDP) in the national "Urban Plan Proclamation 574/2008". The instrument was transferred from South Africa, where it was developed (Interview Berrisford 2012). Bahir Dar was one of the first sites in Ethiopia to go ahead with the implementation of an IDP, and the question of the extent to which the transfer requires the tool to be carefully adapted to the context will be explored.

\subsubsection{The BDIDP}

A number of pilot sites were chosen for IDP implementation. Bahir Dar was among the selected cities and an IDP was drafted, replacing the previous master plan (Ministry of Works and Urban Development 2008). Feasibility studies at a local level were not conducted before the implementation of the IDP in the pilot locations in Ethiopia (Interview Berrisford 2012). The federal government's Ministry of Works and Urban Development developed the general policy framework for the National Urban Planning Bureau (Ministry of Works and Urban Development 2007: 7). In 2012, the Amhara National Regional State was busy establishing a regional urban planning regulation to recognise "Structural Plans" and "Inte- 
grated Development Plans” only (Genet GebreEgziabher 2011). Tourism sites are preferred in the upgrading through structural plans and are treated with priority in their set-up. The tourism sites are currently not serviced and there is a high government interest in promoting this economy. Urban planning, therefore, seeks to further expand tourism. However, the Regional Urban Planning Institute has no data on tourism-related issues (Tilahun 04.09.10).

\section{Box: IDP SOUth AfricA}

IDPs were first developed as a planning concept for municipalities in South Africa in the process of replacing the apartheid planning system with a democratic spatial policy (Harrison 2006). The IDP was a contextual response to challenges arising in the transition from apartheid planning to democracy. It reacted in particular to the issue of getting a new system of local government installed after apartheid had induced a fragmentation of local governing. The country hence faces the challenge of having to overcome strong socio-economic disparities, which were institutionalised by apartheid rule and spatially manifested in urban structures (Interview Gorgens 2012). A need for planning instruments became evident in the mid-1990s, which could direct the local authorities' newly acquired governance responsibilities. (Harrison 2006:195). At the same time its early development was strongly circumscribed by international planning discourse and practice. (ibid: 186) Under the influence of the GIZ (formerly GTZ) and with the joint effort of various international institutions, such as the UN and the World Bank, the content determination for the IDPs got under way. Harrison therefore argues that the IDP is the outcome of a process of international policy convergence in the 1990s (ibid: 188).

The IDP was introduced with a legislative act in 1996. At the outset, it stood in direct competition with other planning instruments and its purpose as well as it's contents had not been clearly drafted. Its objectives were only clarified in an accompanying "white paper" issued by the government in 1998 (Harrison 2006: 186). Consequently, the IDP in South Africa is more an instrument for directing and coordinating the municipality's policies through spatialisation and serves the purpose of allocating legislative budgeting (ibid: 190). With this aim it integrates sectoral plans and promotes cross-disciplinary spatial planning. The IDP is prepared for the duration of the five-year legislature of the elected council. As a coordinating tool, rather than a programmatic plan, the underlying principles are part of a negotiation process for each location, which is guided and made transparent by the IDP, and meant to be cross-sectional, participatory and spatialised. For this purpose the IDP is accompanied by a Spatial Development Framework (SDF) (Interview Gorgens 2012). 
Lately, a new emphasis was set on multi-level planning, in which the IDP is now no longer just local but joined up with higher-level provincial and national planning, modelled on the regional plans set-up by the European Union, in an attempt to align policy, planning and budgeting throughout the different governance levels (Harrison 2006: 200). It is the first time in the course of this post-apartheid restructuring process that substantial power has been devolved to the local level from the strong provincial level (Interview Gorgens 2012).

The emphasis on integration and the multi-sector approach are strengths, while other aspects fall short. For South Africa, one can therefore say that the IDP has meanwhile developed into a comprehensive plan due to practical implications (Interview Berrisford 2012). Environmental aspects and the insufficient recognition of social, economic and political dynamics do not have enough emphasis (Harrison 2006: 202). This is reflected in the IDP's inherent incapacity to speak to informal contexts (Interview Gorgens 2012). The existing urban structures, participation of residents and integration of upgrading approaches remain to be addressed and solutions, such as the introduction of modified building regulations to incrementally upgrade housing areas in Cape Town, are being developed under the roof of the IDP. So, while the IDP has contributed to the shift in expenditure towards the historically disadvantaged communities, the shifted expenditure might not be reflected in the spatial and social patterns of inequality. The new spatial policy making involves responding to a paradigmatic shift in geographical imaginations and involves processes of dialogue and negotiation (Harrison 2006: 195). However, though the drafters might have found the plans coherent, the role of the IDP was not always understandable to all actors due to its complexity (ibid: 196). The tool, with its multi-level approach, was introduced to an administrative structure with an institutional memory of preventive apartheid planning. Considering the lack of data in many of the formerly systematically disadvantaged areas, the performance of the IDP is also limited to the extent of the material that can be fed into the process (Interview Gorgens 2012).

The Federal Government and the city administration jointly prepared the Integrated Development Plan that is in implementation now (FUPI 2008). At first the regional administrations were not involved in the process of setting up the IDP as an instrument in Ethiopia (Interview Yirsaw 2013). Following the pilot phase, the responsibility for setting up the IDPs was passed on from the national level to the regional planning institutes in about 2010 (ibid). The responsibility was then handed to the newly established regional planning bureaus (Ministry of Works and Urban Development 2007: 5). The regional administrations can either devise the plans themselves or initiate a bidding procedure, in which urban planning professionals with licences can put in their offers, with the lowest bidder then preparing the IDP (Interview Yirsaw 2013). After the general framework for Bahir Dar 
had been drafted, it was the Amhara Regional Urban Development Bureau under the Ministry of Urban Development that then related the different sectoral policies to the IDP (ibid). With this concentrated responsibility and a non-obligation for the sectoral offices to participate, the IDP has a problem of reach across the sectoral institutions. An example of this is the drinking water provision managed by the Water Authority. Utility maps are prepared to avoid use conflict. However, the sectoral offices may implement their own plans and do not have to coordinate their action (Tilahun 04.09.10).

The regional "Industry and Development Bureau" supports the implementation process of the IDP and controls how the implementation is conducted. It acts as a consultant to the municipalities in the implementation and gives advice (Interview Yirsaw 2013). In the case of projects being of regional or national interest, the responsibility for implementation can be taken from the city. Implementation then goes ahead contrary to what has been agreed on in the plan. The responsibilities for urban development projects in the national interest thus leave the city administration and move to the regional or national administrative level. In these cases, construction goes ahead regardless of the zoning indicated in the plan. This procedure has been followed, for example, on the site of the new Amhara National Regional State Parliament building on the banks of the Nile. The site was originally zoned as a forest, while on the ground it had been in use as an informal settlement. With the choice of this site as the building ground, the settlement was cleared and the zoning will be changed in order to legitimise administrative use. At the time of conducting the fieldwork for this thesis, the parliament was being erected on the site of what, up to its clearance for the project, used to be an informal settlement. According to residents in the expansion areas on the eastern side of the Nile, they were moved there in the course of clearance of that site. In the immediate vicinity of the regional parliament building-site, another neighbourhood will be cleared), although it is marked as a residential area in the IDP. The neighbourhood is made up largely of single-storey clay buildings and seems to be inhabited by lowincome families. The most common reason for using this mechanism, however, is the prospect of attracting "high investment", thus serving as a legitimisation for transferring responsibility back to a higher administrative decision level. The environmental bureau, which is responsible for the environmental impact assessment, will be consulted, but has no statutory rights to reject construction. The Regional Development Bureau can revise and make zoning changes after the realisation of the projects in the national interest (Interview Yirsaw 2013) thereby not considering contrary local interests.

For the future revision of the IDP in Bahir Dar, the responsibility will be with the Amhara Regional Urban Planning Institute. The city administration will ask for this kind of service, if there is an interest in changing the zoning or land-use functions. In this case the Regional Urban Development Bureau will view the plan, send professionals to check the situation on the ground and conduct the zoning 
change. A criterion for the evaluation of this would be the improvement of public services through the amendment of the zoning (Interview Yirsaw 2013). Bahir Dar's plan is soon to be revised (Interview Yirsaw 2013).

The BDIDP, thereby, contains a plan responsible for allocating the projects into the urban structure, called "Spatial Development Framework" (SDF). The SDF was developed on the basis of previous master plans (FUPI 2008: 398) and consists of a land-use plan and a set of strategic projects called "action area plans" (Genet GebreEgziabher 2011).

In contrast to the South African plans that are tied to the legislative period of five years, the Ethiopian IDPs are valid for a period of ten years. The planning practice in all towns in the region will be exclusively organised in projects conducted under the Integrated Development Plan (IDP). They will substitute all master plans or other forms of plan in place.

The BDIDP document states that the land-use plans were assessed and revised to suit the BDIDP's aims (FUPI 2008: 398). Consequently, the previous land-use plan has largely been adopted. Although fragmentation of the city structure has been reduced since the formulation of the last master plan, the SDF names this as its main objective (FUPI 2008: 398). This can be supported by a survey of the landuse/land-cover change in the city of Bahir Dar which exposes a mainly horizontal expansion of the city in the years between 1957 and 1994 (Nigussie Haregeweyn et al. 2012: 155). It, thereby, proposes that urban structures are growing in the form of sprawl and growth on the fringes rather than densification in the centre (ibid).

According to the RUPI, the urban design furthered by the IDP is intended for poverty alleviation (Tilahun 04.09.10). A further set of sub-aims is related to the land-use categories. Besides residential areas, commerce and trade, services, culture, cemeteries, manufacturing and storage, transport, recreation, agricultural use and forest, its land-use map also indicates areas designated for special functions (Genet GebreEgziabher 2011, FUPI 2008: 398):

- Residential areas: Housing is declared a priority issue. Therefore serviced land is provided, based on population projections. Although only 700 ha would be needed according to the figures, 1,381 ha of residential zoning is provided: nearly double the amount. Reasons given for this are difficulties with swamps and an anticipated increased in investment in residences by the Amharic diaspora. (FUPI 2008: 398).

- Administration: The sole aim is the relocation of the prison from its current location to a peripheral site near the airport (FUPI 2008: 399).

- Commerce and trade: Active nodes and corridors are determined by this use in addition to the city centre reserved for this purpose. Market areas are newly devised outside the current central location, by which investment into the cleared inner-city space is meant to be furthered (FUPI 2008: 400).

- Services: Services, which are specified as education and health facilities, are 
assumed to be largely provided by the private sector, and a portion of the residential area will be reserved for this purpose (FUPI 2008: 400).

- Culture: This is limited to the space needed by religious institutions (FUPI 2008: 401).

- Cemeteries: A redistribution of the use is planned and an expansion of the existing area size necessary (FUPI 2008: 401).

- Manufacturing and storage: Without giving evidence for demand in the BDIDP document, the development of this sector is assumed to be fast, therefore 339.4 ha of development space is proposed for manufacturing and storage purposes. Thereby, manufacturing, which is currently located in the centre of the city, is assigned land on the relocation sites, as it is considered unsuitable for its current location (FUPI 2008: 401).

- Transport: Two new freight terminals for road transport will be installed in addition to the existing bus-station. City and marine transport facilities will be expanded. (FUPI 2008: 401).

- Recreation: The land use will be determined in a two-stage plan preparation, as six large-scale areas are designated in addition to flexible neighbourhood public open spaces (FUPI 2008: 402).

- Agriculture: The wetlands in the city and vacant land in marginal locations are assigned for urban agriculture in the form of animal husbandry and horticulture. (FUPI 2008: 402). The SDF includes possibilities for organised associations to engage in urban agriculture as an acknowledgement of subsistencebased livelihoods in the city (Tilahun 04.09.10). The scale of this is unclear.

- Forest: $13 \%$ of the urban area is reserved for forests. The locations are on hills, the buffer area from the lake and hazardous areas. However, feasibility studies are to determine whether the locations can be converted into parks (FUPI 2008: 402).

- Special function: Anything that does not fit into any of the aforementioned land-use categories is subsumed under "special function". The description itself lists water bodies, buffer and marshy areas (FUPI 2008: 402).

The mixed use of the informal and historic structures within small-scale structures is compensated for by single-use residences, as there is also no "mixed-use" designation in the land-use plans.

At the project level, the SDF proposes four major development directions in which the city is to expand in a time span of ten years (FUPI 2008: 398, Bahir Dar City Administration 2011). It is proposed that the road network should serve to reduce fragmentation in the urban morphology (FUPI 2008: 403). Therefore, "geometric standards" for a hierarchical road system are introduced (ibid). The expansions are to follow the direction of the major access roads to the city from Gondar, Mota and Debre Marcos. Additionally the document proposes a range of projects that are not explicitly located, plus a redevelopment of the inner city (FUPI 
2008: 398, Bahir Dar City Administration 2011). The inner-city development is, thereby, composed of:

- an action plan for lakeshore development,

- upgrading projects for Kebeles 04, 05 and 06 and

- detail plans and designs for the market area, stadiums and the martyrdom monument

(FUPI 2008: 398, Bahir Dar Metropolitan City Administration 2011).

For this purpose, "action area plans" are devised for the projects that the SDF will incorporate as strategic components (FUPI 2008: 398). The implementation of the SDF projects is within the responsibility of the city administration. For this, it uses the lease system policy, which allows it to allocate land to the uses and projects that it feels suit the development plan. The decision on building permits for development projects is either undertaken by tender of the city administration on the grounds of the land-use function, the height of the buildings, the size and the lease period or by an investor proposal. The latter will then be negotiated between the developer and the city administration. If the site chosen for "development" has already been occupied, e.g. by informal settlers, or the existing housing is not deemed to suit the development aims, the settlers will be resettled on grounds of not fulfilling the building standards for the site. All residents are offered an alternative site for self-construction. Additionally, compensation is offered if the residents are the lawful owners of their buildings (Genet GebreEgziabher 2011).

The IDP is still a new approach, which, according to the regional administration, has an advantage over the two-sectioned approach of strategic plan and master plan. It is considered more participatory than former approaches. Stakeholders are invited to participate in an open discussion for the set-up of the plans. In the participation, different sectoral experts, government officials and kebele residents are invited to contribute; the form of approach differs according to each group in consultation (Interview Yirsaw 2013). The planning has been decentralised and is described as "close to the public" by the administration. However, problems are solved from case to case (Tilahun 04.09.10). This view of decentralisation being participatory is thus not supported by evidence.

Changes in the IDP's concept were undertaken in the transfer process of the IDP from the South African framework into an Ethiopian adaptation. Overall, the IDP can, hence, be deemed not to be a one-on-one copy of the South African version. In the course of the policy transfer, conscious, implicit and practical changes have shaped a contingent Bahir Dar version of the IDP as a policy instrument. It has largely lost its character of being an instrument of participatory budgeting, but rather turned into a revision of the last master plan with additional strategic elements represented by the included projects. One of the changes is the extended period of validity from five to ten years, benefiting the strategic components. In my 
opinion, this comes much closer to the concept of comprehensive planning than that of participatory budgeting. This might be called a simplification of an overly sophisticated tool that has been made operable while retaining its potential to be elaborated. The four main projects of the SDF will be reviewed in the following, in order to describe how planning relates to its own plan in practice.

\subsubsection{Urban Development Practice}

By introducing the IDP, Bahir Dar has opened up an experimental approach to urban development, due to the promising potential of the instrument. In the regional administration there is an acknowledgement of the ongoing urbanisation process and a general notion that there is a need to act on this. The IDP as an instrument is intended to serve as a tool to coordinate the competing interests on spatial use, regarding formal solutions. The "action area plans" are geared towards formalisation of urban structures, which is the scope the IDP is actually drafted to address. The strengths, therefore, lie in housing-provision for the middle-income groups, construction of institutions and provision of standardised infrastructure. In the following it will be described how the projects included in the IDPs strategic document are put into place.

\section{Action plan for lakeshore development}

In the original master plan from 1962, the northern waterfront area of Bahir Dar, stretching right from the western side over to the eastern edge of the city, was intended as a public green area for recreational purposes. A public walkway was planned, which has been realised and is still maintained today. Large trees house a wide variety of bird life. The eastern part of the area is a landing site for the timber trade and provides working and living space for tanners. Large parts of the land on this shore are in the hands of the church. Towards the centre, the area with its walkway is currently strongly frequented by the city youth for various purposes. The cafés are meeting points (consumption is usually not obligatory), it is a hideout for young couples, petty trade and tourist boats run their business. Access to the lake is important to a large number of people washing laundry and doing their personal hygiene in the lake, despite the inlet of sewage. In the very centre of the city the commercial port with its ferry jetties and warehouses is functional. The western area between the city centre and the mouth of the Nile is very swampy and therefore remains untouched. Large parts of the shore are used for subsistence agriculture.

In recent years, the waterfront has become a focal point of building activities in the city. The area on the lakeshore faces high land-use competition between development and public open space interests. There has been a paradigm shift in planning, away from industrialisation towards building up a tourism sector. With 
this shift, commercial pressure on the lakeshore has risen. The 1996 land-use plan allowed the allocation by designating the area as "special use", leaving space for interpretation. Under the aim of encouraging tourism, land use on the waterfront is, thus, privatised and handed over for the development of hotels, while representative administrative buildings are also placed in these prestigious locations.

The IDP declares the waterfront a "special planning area". From 2011 on, the further planning and implementation process for the waterfront is guided by a "Sustainable Vision and Waterfront Plan". The elements of its vision are formulated as: "public access to the waterfront and its natural areas", "green, beautified and sanitary infrastructure and design", "mixed use corridors", "appropriate housing and jobs for all", as well as "access to rural-urban linkages" (Canadian Urban Institute 2011). The City Administration, the RUPI and the NGO "Canadian Urban Institute" set up this plan in a joint effort. It will be valid for a period of ten years and will be accompanied by stakeholder participation.

Beyond these intentions for participative development however, the site is especially popular among investors, and the city administration and the regional government have been pressured by private developers to allow construction in the area. The regional government and the national government have taken decision control and are overseeing the implementation for this site because of its investment potential. Projects that have been realised in recent years are the redesign of the ferry jetties and the building of international-standard hotels, such as the "Kuriftu Resort". According to the RUPI, hotels are now seen as having employ potential and are foreigner oriented. They have major importance for Bahir Dar City, as foreign currencies can be taken advantage of. It is seen as a driving force of the city's development and there is a high political interest in promoting it. The area on the lakeshore is being actively promoted as an investment opportunity to foreign and national investors and has received positive response from both (Tilahun 2010). Political pressure has also been passed on to the Port Authority, which occupies and administers the central area of the lake shore, including the operation of the ferry, the landing, sand extraction, boat tours and hotel enterprises. On the demand of generating higher profits from its ventures, investment and "development" on the central spot was demanded. A project plan was developed to construct a building with further hotel accommodation, a kindergarten and further tourist facilities for recreation, while maintaining the port operations such as the ferry service and logistics. The plans were discussed in a closed meeting with experts in the Taitu Café in October 2009. They were already executed in the following year.

By the time the "Sustainable Vision and Waterfront Plan" started its participation scheme in 2012, many important decisions on the land-use of the lakeshore had therefore already been taken outside of the plan. Nevertheless, the plan proceeded with a number of public hearings to address different stake-holder groups. The participants were invited to give their opinion on the future development of 
the lakeshore. How these actually influenced the further planning decisions could not be established during research. Interests conflicting with the development priorities however did not get a chance to enter an open-ended negotiation.

\section{Kebele upgrading projects}

The implementation of the IDP is facilitating the "development" of the inner-city land by encouraging financial investment and business activities. Within the frame of the IDP, the Canadian Urban Institute is developing an "upgrading and urban design strategy" for the downtown area (Canadian Urban Institute 24.02.2011; Interview Yirsaw 2013). The plan is intended for setting up commercial areas and residential areas for different income levels. The aims of this upgrading initiative are based on the aspirations of the city administration. They are focused on giving the impression of modernity and renewal. At the outset, a detailed socio-economic survey was conducted, including all existing houses in the area. Data on housing typology, household income, and personal experiences were retrieved. These data were handed to private consultants who are now devising an "upgrading plan", which at the time of data collection was still being prepared. In the face of this upgrading aim, the residents were asked about their relocation needs. However, according to the regional planning administration, this plan is also still in preparation. The planning initiative, though, is expected to have a leverage effect in the sense that a number of residents is assumed to abide by the new regulations and to voluntarily upgrade their dwellings within this larger process, making resettlement unnecessary (Interview Yirsaw 2013). In effect, the modernisation scheme forces the residents to leave the area by declaring their houses unsuitable to the building standard. The modernisation vision is dependent on attracting investment and does not consider incremental upgrading strategies based on existing structures. Single-storey buildings are to be replaced by multi-storey buildings. The current occupants can bid and propose enlarged structures in order to secure their plots. The uses of the new buildings will be partly the same as at present, as apartments and bars are established, but the price range and target groups will clearly differ. If the land-holding residents or shopkeepers do not have the financial means to rebuild and comply with the new standard, they will have to move from the location. Details of refunding for displacement were not available at the time of observation. 
Fig. 7: Street Corner in Downtown Bahir Dar with Kebele Housing in 2009

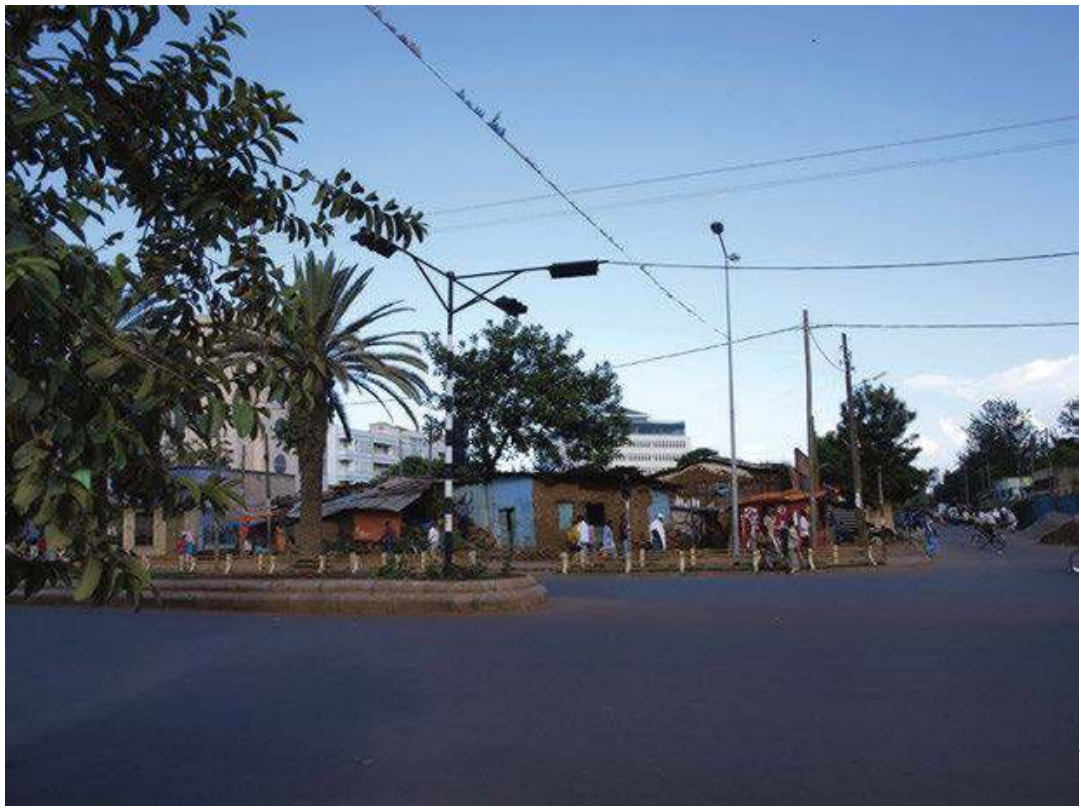

Image by the author.

Fig. 8: The Same Street Corner with Commercial Development in the year 2013

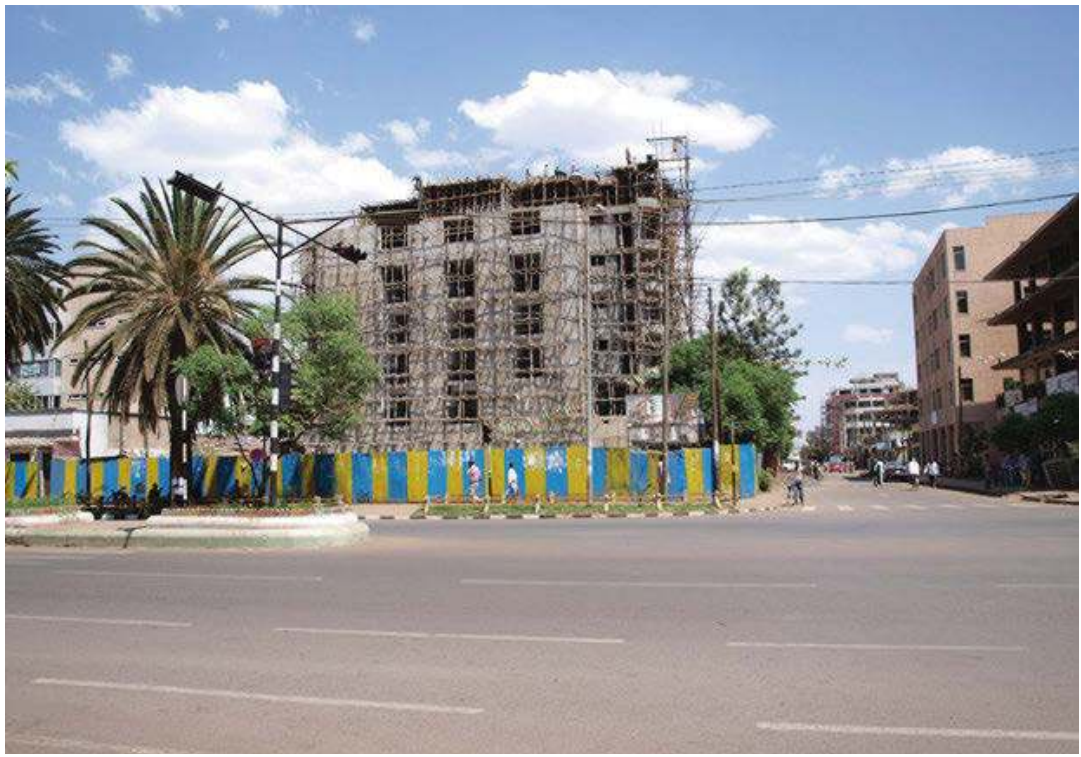

Image by the author. 


\section{Detail plan for shifting the market}

The market will be decentralised and moved indoors to two new sites, so that its current inner-city site can be cleared and developed. Market activities incompatible with the modernisation are to be shifted from the city centre to the two new market areas in the east and the southwest of the city (Bahir Dar Metropolitan City Administration 2011). The proposal for the shift is made in the development plan, where most of the area has been qualified as commercial zones (Interview Yirsaw 2013). The new market areas are situated in less central situations and are both surrounded by residential areas. Market halls and defined market stalls are already provided in the new locations. In the southwest, a lot of trading activity is currently taking place outside the provided structure, as the smallest stalls have continued their sales on canvas sheets on the ground. Yet the two new markets will provide mainly roofed vending space, thus replacing current informally accessible vending space for small-scale agricultural producers in the near future (Interview Yirsaw 2013). This leaves the question of how long these decentralised market structures might remain as open farmers' markets before being turned into shop spaces. The idea behind this is that farmers will no longer trade themselves, but sell their produce to whole-sellers, who will take over the distribution (Interview Yirsaw 2013).

\section{Expansion areas}

On behalf of governmental urbanisation practise, the city's growth is being addressed by designating expansion areas in the IDP. These areas are located in a ring-shaped structure around the existing built up area in the south, east and west of Bahir Dar. All in all, the expansion-sites offer accommodation for all uses driven outside of the centre and the additional growth. The expansion on the eastern shore of the Nile forms a new sub-centre. The formal expansions of the city are undertaken on land parcels provided with basic infrastructure. While all types of land-use are included in these expansions to cater for a variety of demands, residential use is most dominant in the peripheral areas (Gebeyaw Walle 2003: 48-49).

The expansions cater for a variety of uses and the housing standard and typology is varied. It includes privately erected housing, many of them using the standard designs, which are available from the municipality. Thereby, the size of plots provided by the Land Registration Office for single-unit residence has decreased from $250 \mathrm{~m}^{2}$ in the 1990 s to currently $100 \mathrm{~m}^{2}$ (Nigussie Haregeweyn et al. 2012: 154). Further government housing is provided in the shape densely built up condominiums, private and public education facilities, trade and all scale industries.

The usual approach to find a plot for construction, involves fulfilling certain criteria of residence, which the town administration validates. Together 20-30 people apply for a development parcel. They already have to be residents in Bahir Dar and not owners of a house, yet. The town will then find a location to build. This procedure was the norm from the previous socialist regime, to the introduction of the condominiums in 2008 eth. calendar (Daniel Weldegebriel 2011: 5). Now, the 
condominiums housing programme in Bahir Dar offers an alternative access to housing (Zelalem Yirga 2012). However, with the housing provision through plots and condominiums, the expansion areas do not target recent migrants, as plots can only be requested from the municipality if there has been a two-year period of residence in the city (ibid).

Industrial investment has priority over agricultural use in the expansion areas. Two industrial sites were allotted, in which more than 100 investors received plots, sized between a half and one ha. The municipality prepared and serviced more than 100ha of land, but at the time there was no further investment interest. The expansion sites for industrial investment have faced difficulty in realisation. According to the RUPI, , more than 100 investors gained plots on two industrial sites that were provided in the municipality of Bahir Dar, but many investments failed. In these cases there was no progress in the construction for more than three or four years. (Tilahun 04.09.10)

Nigussie Haregeweyn et al. (2012: 150) describe the urban expansion as posing a serious threat to the livelihoods of small-scale farmers on the urban fringe, who earn their living by farming the productive agricultural lands under urbanisation pressure. The expansion of Bahir Dar's urban area follows the conversion model of Addis Ababa, where a strategy for the conversion of rural to urban land has been piloted. This involves the relocation of farmers around Bahir Dar for urban expansion. The urban expansion is described as having serious threats on the livelihoods of the surrounding small scale farmers in subsistence agriculture. (ibid). Farmers practising subsistence agriculture are, thus, facing a decrease in agricultural land in the region around Bahir Dar, as it is consumed by urban expansion and other non-agricultural uses (ibid). The urban expansion and substitution of rural land specifications are decided by the government (Genet GebreEgziabher 18.02.2011). In the progress of expansion, 2878 households were compensated for having to move due to development projects between the years 2004 and 2009 alone (Nigussie Haregeweyn et al. 2012: 154). Some $12 \%$ of these farmers lost all of their land in the course of the expropriation (ibid). The compensation is most often delivered in monetary form. Other offers, such as access to credit or access to training and advisory services were promised to the dispossessed farmers, instead, but had a very low rate of delivery. The study, further, describes how the majority of recipients store this monetary compensation in the bank, because they lack ideas for investment (ibid: 155). Smaller proportions use it for home consumption, another small fraction for renting land or draught animals and another fraction has invested in houses in the urban areas (ibid). A major problem in putting the monetary compensation to use is the illiteracy of the farmers losing their land (ibid) and, therefore, the failure to integrate them into the changing circumstances of income generation in the face of urbanisation in their settlement areas. 
The process is described to have created a shortage of farmland and is accused of having brought social problems such as increasing territorial conflicts among farmers and migration of people from their rural homesteads to communities living on the urban fringe. The young population on the urban fringe is described as being increasingly without occupation due to a lack of access to land (ibid). Additionally, environmental impacts are identified, but these were described as of lesser importance to the residents. However, positive effects of the urban expansion are also described: Access to education, health services and infrastructure, electricity and clean water were facilitated due to the approximation of urban services (ibid). These have led to the development of a strategic settlement in hope of receiving either income opportunities or compensation. Since compensating plots are also offered to informal settlers under certain conditions, building and development sites, such as the new "Legal Campus" of Bahir Dar University, trigger the informal sub-division and undocumented sale of land by the resident farmers to newly arriving settlers, who self-construct on the site in the hope of making a business or even in direct expectation of compensation (Achamyele Gashu 2014). This issue can only be tackled partly, as the responsibilities for rural and urban are divided between different ministries.

In practice, the implementation of the IDP in Bahir Dar does not differ distinctly from operating with a comprehensive plan. Its intention to integrate sectoral planning is countered by the fact that there are no means of coordinating the sectoral responsibilities across the regional ministries. Processes of dialogue and negotiation are part of the IDPs concept and have been initiated. For participatory budgeting as a form of decision-making, however, a high level of data input would be necessary. However, experience with participatory formats in Ethiopia is rare, data for Bahir Dar are scarce and the processes have to be viewed as a first step to establish participation in planning. Current decision-making comes in form of public hearings, serves to inform the population and does not include decisionmaking on public budgets. The IDP in Bahir Dar has, hence, developed into a comprehensive plan for practical reasons.

Being a planning instrument developed for the transition to democracy, the processes designed for the IDP originally have an impetus of transparency and are meant to visualise political priority setting. The democratic decision making of the planning process which is guided by the regional planning office, however, is countered by a proviso enabling the national state to intervene to benefit national interest, which has been used for administrative use and business investment. This national state intervention undermines the power of the IDP, as the plan is not binding, while criteria for the exceptions are unclear (see 5.5). The devolution of power in urban planning has, thereby, been undertaken with substantial subtractions. The possibility to override lower-level decisions also questions the plan's original purpose, by which planning is to be aligned throughout the different governance 
levels. It is due to this that there are occasions in which the plan is changed to suit the construction projects already realised through higher interest legitimation.

An original intention of the IDP from its background in South Africa was the integration of spatially fragmented and economically and racially segregated structures to overcome disparities and distributive injustice. The situation encountered in Bahir Dar is different from the context in South African cities, as the income levels are low overall, and the income disparities are not as large (Ministry of Works and Urban Development 2007: 12). The aim in development in the city, therefore, needs to be to maintain equality while raising the overall standard of living. Currently Amhara's tax-base does not cover its expenditures (see 5.5), and so financing is reliant on external funding. For the IDP, which was originally conceptualised for redistribution through participatory budgeting, this proves problematic, as there is high political pressure to draw investment into the region's cities. Laying the development priority on the tourism sites (see 5.5), which do not benefit the underserviced residential areas and does not address population influx, reflects this. Further, resettlement practices continue to benefit business development and are favoured over upgrading strategies. The impact of this on those affected by resettlement will be looked into in the following chapter (see chapter 6.1.1 and chapter 6.1.3).

Beyond the topics actually addressed by the plan, the IDP as a planning instrument does not address the informal practices of urbanisation in Bahir Dar, which make up a large part of the city's development. Planning, therefore, regularly comes into conflict with traditional and informal settlement practices, which are considered neither in existing land use, nor in the projected zoning.

\subsection{Ruptures, Continuities and Parallels in BaHiR Dar's URBan PlanNing}

The urban development of Bahir Dar has been shaped by a number of principles over time. Urban planning in Ethiopia has colonial and modernist elements, while also the planning discipline itself is rooted in modernism. Planning in Bahir Dar is influenced by a multitude of sources, reaching from the Italian introduction of an urban administration via the first master plan for the city by Max Guther, through influences of socialist industrialisation policies to the current conceptions introduced by multi-lateral aid-agreements. All of these have, thereby, left their distinctive spatial marks on the city. From this perspective, Ethiopia has not been isolated but has been subject to receiving urban development plans and has been a site of urban construction on the basis of non-Ethiopian theories, named as "models-in-circulation" (Roy 2011b: 410). The findings suggest that, in Bahir Dar, urban development history shapes the setting for current planning practice. However, the data indicates that the relation of the guiding principles is not one of succession but 
rather one of ruptures, continuities and parallels that can still be traced in today's city. The phenomenon of changing guiding principles is hence not a historical sequence, but rather one of an accumulation that is legible in today's urban fabric. The paradigms brought into this context can be linked to five periods of political influence at a national level in Ethiopia, which acted as sovereign powers also over the local development of Bahir Dar. However, due to its strategic location on the source of the Nile, Bahir Dar became politically relevant over the international dispute on the use of water resources.

The first phase is that of traditional land practice. Bahir Dar can be considered one of the fairly young cities. Practices of everyday urbanisation, leading to the establishment of an early dense settlement on the site of today's city of Bahir Dar, began before "planning" as a professional concept arrived. In contrast to other Ethiopian cities that were long-standing royal residences such as Addis or Gondar, urban planning as a statutory task arrived in Bahir Dar much later, for instance. It was introduced into what had already been a fishing village, trading post and monastic centre, where the land administration was in the hands of the Ethiopian Orthodox Church and followed a hereditary system. However, there is little evidence on life in the settlement from the founding period of Bahir Dar, and the development of a larger city was apparently prevented by malaria.

The second phase is that of the five-year occupation of the Ethiopian territory by the Italians with colonial spatial policies. With the arrival of the occupiers in 1936, a military camp was installed and the first permanent buildings erected. The colonial interests that determined spatial use were rooted in the Italian textile industry, which was to be provided with cotton from the region (Consociazione Turistica Italiana 1938: 383). The Italians and their installation of a military garrison subjected Bahir Dar to restructuring measures during the occupation. An urban administration and land taxation levied by the occupiers were introduced. Modern urban planning was, hence, introduced to Bahir Dar later than other Ethiopian cities such as the capital Addis Ababa and Gondar. Compared to other cities, the Italian impact on the urban layout of Bahir Dar was relatively minor, and segregated living areas such as in Gondar were not introduced. Consequently, the occupiers did not systematically reshape the local building tradition. However, their presence impacted on the building standards. It also stands against the traditional land-administration of the area and induced the parallel existence of land-administration systems that endure to this day.

With the reinstitution of Haile Selassie as Emperor in 1941, the third phase of development for Bahir Dar commenced. Bahir Dar was, thereby, one of many locations that were subjected to master planning under Emperor Haile Selassie after his return from exile. Before the establishment of the master plan, urban development 
in Bahir Dar was largely an issue of local negotiation. From then on, however, urban planning for Bahir Dar was a centralistic task. However, its speculative status as future capital put it in a particular position among the other 46 cities with restructuring activities. To decide disputes over the water resources in the region, the Emperor gave the order for a master plan to be devised, designing a city for more than 200,000 inhabitants. The continuities between the periods of Italian rule and the modernist master plan for the city based on industrialisation, including cotton production, need to be made the subject of further academic discussion.

Structurally, whatever had existed as a settlement was dismissed by a new modernist vision of what a city is and was projected to be a centre of power over water resources. With the introduction of modernist planning and its technocratic belief system, the expansion of a settlement into a town was decided on, laying the foundations of the transformation from a small-scale settlement to a larger city structure. The master plan not only intended to reshape all existing structures, it also marked a fundamental change in how everyday urbanisation is viewed. In relation to the plan's modernist proposals, traditional building and local practice was now considered backwards and inadequate. New building standards were introduced to which local building practice henceforth had to comply. This is, thus, a turning point after which administrative aims and local interests developed in significantly different directions, as existing settlement structures were no longer regarded as a reference or even an asset.

The urban expansion triggered by the plans for industry and use of hydropower guided by the master plan were the start of a rapid phase of urban growth in Bahir Dar that has continued to this day. The movement of individuals from the surrounding countryside into the newly expanded urban area was triggered by their search for work in the newly installed textile mill and large construction projects. Bahir Dar can, thereby, be considered one of a number of rather recently established small industrial centres that had especially high rates of urban growth during the past decades. The loss of regional typicality in the course of urbanisation might have been triggered by the Italians in some locations, but the evidence from Bahir Dar shows that modern principles of planning were only introduced to certain Ethiopian cities long after the occupation. Emperor Haile Selassie favoured stone and square clay buildings for construction, and these structures increasingly replaced the local tukul. Introducing the Guther plan thus means a division into formal and informal urban structures. However, there is not only a traditionalist movement that was forced to modernise, but also an Ethiopian progressive movement that believed in the merits of the modern standards and introduced them voluntarily. Implementation of the general layout proposed by Guther began in 1962 (Egli 1967, Tvedt 2004). Nevertheless, here was no comprehensive modernisation of the city due to lack of funds. Bahir Dar was never able to systematically supply water and sanitation to the inhabitants, as grid service was not established alongside the expansion of streets, industry and housing. Today's water and sanita- 
tion crisis can also be seen as the result of a failure to install the 1962 master plan's infrastructure components.

Although Guther's master plan was not underpinned by sufficient political and legal support and could never be implemented to its full intention, from now on it coexisted with the local urbanisation practice. While it marks the introduction urban administration to Bahir Dar in the modernist understanding, existing building structures were only partly replaced and many remained, building techniques with local material persisted and traditional practices of land-distribution continued. As generally described by Berrisford (2011) for former colonial states, this introduction of tenure, taxation and building technology on the premises of Italian intervention and by German development aid resulted in the installation of parallel institutional and traditional systems of land-administration, settling and building practise also in Bahir Dar.

The phase of master planning is followed by the fourth period of socialist doctrine, in which urban development was virtually abandoned in favour of rural development by the government (Gebeyaw Walle 2003: 31) but still experienced population growth and a number of influential administrative changes. While the socialists displayed a negligent attitude towards housing and quality of infrastructure on a larger scale, their instalment of infrastructure for the textile production site emphasised their idea of building an industrial labour force, thereby shaping spatial configurations into the present. Although socialism did not develop plans for individual cities, their general (anti-urban) policies, and also their buildings and industrial projects, have left significant structures in the city and triggered the establishment of urban neighbourhoods. The impact of socialist policies on urban development in Bahir Dar is substantial and cannot be dismissed as inactivity. The impacts of administrative reform and nationalisation of land are felt to this day, but they are overshadowed by the rule's arbitrary violence against the population. What this has done to the population's trust in state institutions - also those of urban planning - is not discussed openly in Ethiopian society. The cost of these policies could, thus, not be established, but there are still population groups that have lost from resisting or following socialist policy as well as others that have profited.

In the fifth phase under current EPRDF rule, Ethiopia set up its first official Urban Policy in 2005. The framework to guide urban development and, hence, address the process of urbanisation is conducted with the instrument of the IDP, which was largely developed in South Africa for the redistribution of land and assets in a highly racially and economically segregated country. The BDBIDP has, since, replaced the master plan as a planning instrument. In order to introduce this planning instrument to Bahir Dar's context, it has been adapted from its original form. The planning document consists of a Spatial Development Framework, and a set of "action area plans". By allocating the responsibility for the IDP to the RUPI, 
the power for setting up the plan is centralised on the regional level and the municipality is, in fact, not in charge of setting up the plan (even if it is consulted in the process). Paradoxically, for this critical moment in time, the municipality has lost formal authority over its urban development to the RUPI as the higher regional authority, under the process of devolution in "decentralisation". Instead of developing local solutions this set-up can be criticised as creating new political power structures that reach beyond the capital and are in line with what has been criticised as "governability" (see 2.2.4).

While the RUPI has the authority to set up the plan, it faces difficulties in the sectoral participation. Issues widely acknowledged as fundamental tasks in need of systematic planning, such as providing for basic infrastructure, have not been considered in the BDIDPs content. Not only is there no leverage to bind the other offices to participate in the set-up and implementation of the BDIDP, the institutional set-up in Ethiopia also differs strongly from the fragmented and strongly sectoral background the IDP was developed for in South Africa. South African cities come from a history of self-governed provinces with a weak national directory, while Ethiopian cities face a history of a centralistic socialist system. The IDP cannot foot on a sectoral planning tradition in Ethiopia, which are the institutional grounds of colonial and apartheid legacy, on which the instrument was developed on in South Africa. In Bahir Dar, infrastructure plans, rural development, economic development, cadastres etc. are now set up under the responsibility of their own regional offices and are mostly still in the beginning stages. Here it is not mainly the question to overcome rifts of non-cooperation of a fragmented institutional landscape but rather the reverse general question of decentralisation and responsibility for sectoral planning issues that have to be addressed in feeding the decision-making tools for urban development. In order to function as an integrated plan and negotiate planning and trade-offs, the IDP will have to be equipped with systematic contributions from all sectoral offices.

At the outset, it seems that the transfer of the IDP from the South African context to Ethiopia implies a congruency or at least a convergence of the underlying realities of South African and Ethiopian cities, or even an underlying typology of "African City", which has no empirical proof. However, while the instrument has been introduced into the statutory planning structures and serves as an instrument, the guiding principles were not transferred unquestioned. The assumptions, ideals and underlying guiding principles of urban development in South Africa were partly transferred as they are inscribed in the aim of avoiding fragmentation but do not function as a larger guiding principle for the urban strategies for Bahir Dar. Yet, unlike the instrument originally requested, the local negotiation of normatives by which the IDP as an instrument is meant to spatialise budget allocation and design interventions, has not been undertaken transparently and in public consultation but rather in a tacit endeavour as they were implicitly replaced by the Ethiopian government rhetoric of "development". Priorities are set on tourism 
and government development projects, while the IDP does not cater for informal, agricultural and ethnic urban structures and processes in practice. Placed within the government strategy of development, the BDIDP continues to operate on a strong technical planning ideal. Here, past paradigms continue and persist in the administrative practice that has appropriated the idea of the IDP and assimilated it to its own mode of operation. As illustrated, the instrument currently faces a lack of sufficient data and information on internal migration, housing needs formulated by the population and analyses of emerging livelihood structures to base its decisions on. A key-problem is that, due to lack of data and adequate local problem descriptions (Tilahun 04.09.10), the IDP as a "data hungry" instrument can not be fed with the information it needs for the decision making processes to allocate budgets. On issues of migration, e.g. sample data and field observations are used for planning purposes due to lack of more specific figures (ibid). To fill this gap, the planners look at conventional understandings of urbanisation and conceptualise the dynamic as growth that will lead the inhabitants to adopt middle-income life-styles. This adoption of ideas bears dangers, as the underpinning rationales of urban development do not find sufficient recognition in the transfer process. As for Bahir Dar, it has to be assumed that a diversification of urbanisation rationales was induced. While there is not much data available on population movement, it should be assumed that the rural-urban migration patterns include circular and temporary movements like in other African states. However, no accounts of this non-governmental practice of rapid urbanisation were established, as research has largely limited its accounts to the evaluation and description of policy documents. This sets predispositions for false assumptions: Based on speculations, the actual needs of the population are, hence, difficult to target with urban planning measures. While the plan includes explicit anti-discriminatory passages regarding the rights of ethnic minorities, the informal practices of the poorest, the recent arrivals, those outside of traditional family structures and those unable to find rental accommodation (for example for religious reasons), are not tolerated by administrative practice, despite its claim to contribute to poverty-reduction. Instead, the plan aims at formalising, based on implicit assumptions of fordistic lifestyles that are assumed to gradually be embraced by increasing numbers of the local population in the course of urbanisation. These assumptions are reflected in the zoning proposals that know no mixed-use and differentiate between residential areas and commercial and industrial zones. It is also indicated by the building regulations, perpetually changed to increase density and determine the building materials allowed in favour of imported goods, just as the building typologies and standard designs available from the administration, that are drafted to meet these building regulations. In favour of these, the aforementioned settlement types (traditional, historical and informal) are declared slum areas or are not mapped as a result of their informal status. The inhabitants are dislocated and subjected to "resettlement" schemes. The plan's contents are, therefore, in effect exclusionary and 
demand a high level of conformity from the urban population to standards that were not developed from the local situation. It, hence, appears that the BDIDP has to be seen in continuation of a master-plan tradition, which has been transformed into a new shape of document to suit the categories proposed by the IDP manual.

The original idea of the IDP in South Africa was to further socio-democratic outcomes in a liberal economy by establishing an incentive system of participation (Interview Gorgens 2012). To make it perform, the original proposal of the IDP requires a high level of data input for decision-making. In Ethiopia however, the overall data base on which planning is executed is very thin due to lack of empirical material. To facilitate decision making, the BDIDP has, hence, largely been stripped of the function of participative budgeting and moved public discussion to the end of the planning process, at which the projects (see chapter 5.5.2) have already been decided. In Bahir Dar the decision making process on priority land-use, infrastructure provision and action areas in the BDIDP is intransparent.

Beyond that, the decision short-cuts from national level further undermine the IDP's purpose of introducing transparency into the decision process of determining spatial use. The plan's contents are devised mainly in a supposed public interest, but since the plan can be overridden easily, it is not considered all that important by actors with diverging interest. Projects of national interest can override the plan's contents that were negotiated with stake-holder participation and might rely on consistent obedience (nature reserves as protected areas etc.). These negotiations of the state and third party interests, are based on opportunities in the economic realm. As a general rule, economic value of a development will give the lead on priority changes with any other interests (Interview Yirsaw 2013). National government, thereby, even supports commercial development against the regionally set-up plan. And as changes to the plan can be decided on negotiation of investors and the administration, with questioning coming only from experts, there is no public eye on the keeping of the plan. Here, the government acts informally and the different levels of administration can intervene against each other. In this case, the plan as devised has little power to be enforced on the implementation level, where another sort of negotiation between higher policy officials and investors can evade the intentions of the region and the municipal level in favour of national interest. Here, statutory planning can therefore not be seen as forecasting, but rather as a practise of ad-hoc negotiation.

Despite operating on the normative of "development" and in the tradition of master-planning, the IDP does expand the range of instruments to statutory planning in Bahir Dar by including public hearings for the action plans. Although participation might actually stand in competition with other political interests and is therefore limited under the political pre-conditions, it was not granted in the negotiation of the planning paradigm nor is the public involved in budget-allocation, the action plans do, however, involve some sort of public hearings. These hearings are devised to address various stake-holder groups and can be assumed 
to address a wide range of interests. While the BDIDP guides the spatialisation of investments, a negotiation of trade-offs and the setting of aims, as the original purpose of the IDP intends, takes place in this limited realm. Yet, taking the IDP's intention of generating transparency in the decision making processes seriously, it needs to be analysed carefully, which of the actors and stake-holders are actually in a position to negotiate, due to the existing power-balances among sectoral inputs, participation thresholds and the confusion around the relationship of the IDP to other planning practices (sectoral and higher level planning as well as traditional settling regimes). Despite these first efforts, transparency in decision-making on urban development issues in Bahir Dar can well be improved.

The IDP is described as a good planning tool by the local administrative officers but, referring to the urban structures visible and obviously not conforming to the modern standards inherent in the regulations, an "implementation problem" was deplored repeatedly. The plan is, thereby, not considered powerful enough by urban planners of the Regional Urban Planning Institute. This mismatch between aspirational planning and reality on the ground needs to be acknowledged, but should be questioned regarding the adequacy of the planning instrument towards its context of implementation. Transferring the IDP from foreign context and political aspirations of development have lead the plan to function on outside experience, not on local realities. The ideas Bahir Dar has about its own urban development are very limited and developed from images, rather than local needs, available assets and experience. Lack in research on existing social, economic and built structures renders the existing to be non-conformant to plan and thus marginalises urban elements that do not suit the developmental interests. In an attempt to formalise, these outside influences have gradually taken a stance against local practices and have taken on local practice as adverse to their own endeavours. Instead of addressing and cooperating with local practices of settling, the IDP is called to deregulate former interventions of the state and render existing housing and commercial structures on the micro-scale illegal on the grounds of new standards. The arising disputes on building regulation and land-use issues between regional and municipal planning level and stake-holders are even furthered by the fact that a non-compliance with the agreements reached within the planning process and depicted in the plan currently has no sanctions. The municipality is not penalised, if it does not implement the ideas provided in the plan by the RUPI, which has lead planning officials to call for more power to the plan. Yet, the IDP and its measures insufficiently question the land-use and building structures proposed by development and technical standardisation. The example of failed industrial allocation shows, that the implementation of the plan's set priorities is not geared towards a factually existing demand. The Ethiopian condition of a strong dependency on subsistence farming by an overwhelming $85 \%$ of the population is meanwhile only poorly considered as a relevant context for urbanisation. 
While there might be a problem of implementation of the plan due to an intransparent political agenda, which is not publicly and openly discussed in the set-up of the planning instrument, there are further issues with the IDP. It has to be questioned, whether its implementation should actually be furthered in its current form. What is perceived here as an implementation problem of urban policies by the regional administration, might actually be related to the negotiation of the underlying planning paradigms, which was conducted in lack of data on local urbanisation processes. The needs of the population have not been analysed sufficiently. The planning approaches claim to be inclusive regarding the low economic status of the majority of population, but none of them has actually made a conceptual study of the urbanisation process and the needs emerging in it. Instead, the dualistic understandings of formal and informal as well as urban-rural that are inherent in the current urban policies become evident in the implementation practise and have to be considered obstacles for guiding urbanisation. Against its own assumptions, planning is, thus, not a coherent effort through the scales and intervention levels and has many loopholes leading to inconsistencies, tactical and informal practices, that go along with the formal set-up of plans and administration of resources. It, therefore, has to be questioned to what extent the plan's paradigms have been subjected to professional and public discussion (see chapter 2.3) and in whose interest the BDIDP functions. 


\section{Everyday Urbanisation in Bahir Dar}

This chapter aims to give an insight into local urbanisation at a neighbourhood scale. It presents local practices of "everyday urbanisation" in which the popular (inter-)actions of place-making are documented as rationales of urbanisation alongside urban planning. What has become evident is that there is a discrepancy between the accounts of formal urbanisation and the urban structures that can frequently be observed in town. Hence, it has to be asked which ordinary practices of urbanisation are responsible for large proportions of urban development in Bahir Dar. However, these everyday practices go beyond what has been termed as “informal” urbanisation in Ananya Roy's “idiom of urbanization" (Roy 2009) and encompasses livelihoods and building strategies by a large variety of actors in the form of traditional housing, various set-ups of single unit family homes, small scale mixed-use and multi-storey buildings. In the course of this work they will be named as "ordinary", "mundane" or "everyday" practice, all synonyms referring to a wide spectrum of urbanisation rationales that shaped the city outside of the government's housing and investment programmes. The literature review on the urban policies and literature on urban development shows that little is known about the everyday practices of urbanisation throughout history. Nor have the impacts of formal planning on the ways and habits of the residents in the neighbourhoods been investigated. It has, yet, to be answered how a distinctly local composition of urban practice for Bahir Dar has been shaped and how the urbanisms vary between the neighbourhoods established at different time periods and under varied paradigms. Since historical accounts on development and everyday life in Bahir Dar's neighbourhoods are scarce, today's urbanism can be reviewed to establish whether the different founding paradigms have led to diverse trajectories of urbanisation in the neighbourhoods.

As the preceding chapters illustrated, these everyday urbanisation practices have not been documented systematically in Bahir Dar on the grounds of being rendered informal or insignificant by legal or economic criteria (see chapter 5.5). As a consequence, it has to be questioned to what degree current urban development approaches consider these realities in their assumptions of living environments, working and income opportunities and modes of establishment in the course of 
arrivals in the city. However, knowledge on these factors impacts on the spatial arrangements of planning proposals and the regulation of access to the city's resources. Since this description has been lacking as a basis of policy information, the aim is to open a spectrum of diverse rationales of urbanisation beyond statutory planning by describing the different context-specific local urbanities and, thus, trajectories of development in the four different sub-case sites. Thereby, the subject of this research is the practices of the "ordinary" population, as their contribution to urban growth has not yet been described. While the major transformative power and ambivalent relation to politics of capital-intensive private developments has to be acknowledged, the majority of the population in Bahir Dar comes from low-income groups. However, the visible phenomena of urban life connected to these ordinary lifestyles and ways of income generation outside employment work are not sufficiently reflected in the accounts of urbanisation.

Currently, urban life in Bahir Dar is portrayed as a result of involuntary migration, as the focus is on the push factors in the countryside. The most common of the explanations given for the population influx (see chapter 5) is landlessness among the rural young, resulting in incapability to feed themselves and prospective families (Woldie Assaw et al. 2010: 63, Mekibib Kassa et al. 2013: 298, Gebeyaw Walle 2003: 19). There is, it seems, a shortage of land for the young generation and the Amhara Region Land Administration and Use Authority will not revise the current land-distribution scheme to make any land accessible for the younger population groups in Amhara's rural areas (Woldie Assaw et al. 2010: 63). They will continue to be excluded from the ongoing land certification processes in order to prevent a further fragmentation of land leading to unproductive land units (ibid). At the city scale, this narrative seems to be reflected in the general profile of migrants into Bahir Dar. Abeje Berhanu (2012: 39) identifies 67\% of all migrants in Bahir Dar being first-time migrants (coming directly from their area of origin), while he identifies a wide range of areas of origin - from the surrounding rural areas as well as from other cities all over the country. Abeje Berhanu states that $62 \%$ of his respondents worked on farms before coming to the city, while the vast majority of these did not own the land they were formerly working on (ibid). About $69 \%$ of his respondents were not married when they migrated and came from families with about 5-7 members, which is above the national average household size (Abeje Berhanu 2012: 37). The overall level of education is relatively low, and for those migrants of school age it has to be assumed that their schooling was discontinued with the migration (ibid: 49). 


\section{Subsistence Activities and Income Generation in Bahir Dar}

\begin{tabular}{|c|c|}
\hline Education & $\begin{array}{l}\text { High school education, university education (private and public), training courses } \\
\text { (diplomas and licences), clerical education... }\end{array}$ \\
\hline Trade & $\begin{array}{l}\text { Domestic trade, delivery services (supply for larger businesses), sale of farm } \\
\text { produce (market and street vending), petty trade (lottery, sweets, food leftovers), } \\
\text { shops, fixed market stalls, trade with fabricated (imported) goods (supermarkets, } \\
\text { technical stores etc.), chat dealing, second hand goods, street food (corn on the } \\
\text { cob, potatoes)... }\end{array}$ \\
\hline Services & $\begin{array}{l}\text { Domestic work, goods transport (road and boat), people transport (bajaj and min } \\
\text { bus), guard, "agent", waste collection (household) and recycling (scrap metal, } \\
\text { plastic bottles etc.), shoe shining, public scales, internet and telecom services, } \\
\text { tour guides, bicycle maintenance, porter services, rag-picking, catering/waiting, } \\
\text { health workers, sex workers, repairs (watches, radios etc.), car wash, coffee } \\
\text { ceremonies, financial services... }\end{array}$ \\
\hline Foraging, mining and gathering & $\begin{array}{l}\text { Stone excavation, grass cutting and vending, fishing, reed collection, wood cutting, } \\
\text { sand excavation... }\end{array}$ \\
\hline Production and processing & $\begin{array}{l}\text { Masonry, grass mats and baskets, tanning, welding, carpentry, building (daily } \\
\text { labour), textile production (weaving), urban gardening, cattle and poultry } \\
\text { husbandry, production of household goods (pottery, stoves...), bee-keeping, } \\
\text { tanqua boat building, food and drink production (injera, tej, araki..), souvenir } \\
\text { production (painting, carving...)... }\end{array}$ \\
\hline Third party support & Begging, remittances, family income... \\
\hline Revenues & Property investment, business ventures, land-holdings in rural areas... \\
\hline Administration & Ministerial work, sectoral offices, NGO work... \\
\hline
\end{tabular}

Image by the author.

However, this interpretation of landlessness has to be challenged in this context. Overall, only $11.5 \%$ and $4.3 \%$ respectively gave landlessness as a reason for leaving their area of origin and coming to the city (Abeje Berhanu 2012: 41). Instead, about $56.9 \%$ of first-time migrants and $81.4 \%$ of migrants with previous migration experience stated that their main cause of migration to Bahir Dar was to pursue job advantages (ibid). At $38.65 \%$ the proportion of illiterates is higher among the new in-migrants than among residents, where $29.62 \%$ are illiterate in the population aged 5 and over (Golini et al. 2001: 182). Accordingly, migrants will form a higher proportion of the unskilled labour force (Woldie Assaw et al. 2010: 67). The modes of entering informal labour are not well documented. Abeje Berhanu finds, though, that acquired skills can be used to seek jobs that promise to generate a relatively regular income (Abeje Berhanu 2012: 48). Thereby, the frequent use of opportunity in coming to the city and acquiring an urban livelihood is reflected in the fact that about half of the migrants questioned for his survey (ibid) accounted for having acquired at least one new skill, such as construction skills, mechanical skills, a driving licence, etc., since having arrived in Bahir Dar. As one of the first studies on Bahir Dar, Abeje Berhanu (2012), hence, brings together the topics of migration and informal work opportunities. He postulates that migration has to be understood as the opportunity to engage in income-generating activities, particularly for first-time migrants (ibid: 40). Thereby, many urban residents have to 
make an income that is not based on employment work. In the course of exploratory visits to Bahir Dar, a range of income generating and subsistence practices were observed in the public space and within homes that relied on individual or informal agency. Fig. 21 shows a collection of income sources and subsistence practices that were documented during fieldwork in Bahir Dar in 2012 through observation and interviews. These practices appropriate vacant public space or private homes, often in multi-use set-ups. In the case of the brokers, they occasionally even invade other entrepreneurs' business space to exercise their business-model of (uncalled for) brokerage. These practices, hence, produce and depend on spatial arrangements that need to be made the subject of documentation. Thereby, Abeje Berhanu's line of argumentation can be taken further by specifying that the act of involvement in these opportunities comprises rationales of urbanisation, as they are performed only in the city. For the migrants, engagement in the urban labour market results in overall higher incomes than those of their rural origins (ibid: 49). Their earnings are reported to be reinvested in property, furniture, bicycles, livestock and horse carts - or are deposited in the bank (ibid). The role of the microeconomy in urbanisation, hence, needs to be looked into.

Abeje Berhanu further explains that the respondents formulated the hope that the income from the jobs in the city would open opportunities for personal development such as finishing school, going to college, aiming for better jobs or establishing a family (ibid). This points to a second group of migrants, which is backed by the fact that the proportion of population with grade 12 education and above is significantly higher among the very recent in-migrants than with the residents born in the city: $10.76 \%$ of the population resident for no more than five years at the time of the survey completed high school, while only $0.94 \%$ of the resident population aged 5 and over did (Golini et al. 2001: 182). This means that the number of recent in-migrants that have a grade 12 level education is ten-fold higher than the number of those holding equal qualifications among the resident since birth. This is mirrored in the main sectors of formal employment, which in 1999 were manufacturing (30\%) and administration (43\%) (Gebeyaw Walle 2003: 29). Qualified job opportunities as well as possibilities for schooling and studying, were mainly lacking in the migrants' areas of origin (Abeje Berhanu 2012: 46) and, therefore, attract not only the unskilled, but also highly qualified migrants to Bahir Dar.

The diversity of everyday urbanisation practices, as well as the phenomenon of well-resourced migrants, has not yet been researched in Bahir Dar. How and whether Bahir Dar serves as an entry point to urban life, due to its proximity and accessibility for the people from the surrounding rural areas (Woldie Assaw et al. 2010: 63) and what makes it attractive for highly skilled migrants needs to be investigated. However, it has to be assumed that the attraction of employment work or micro-business with an urban lifestyle is a more important factor for migration than the alternative offer of making land available in the countryside can promise. 
It, further, seems that the city accommodates special gender-specific forms of labour migration. Women in Bahir Dar tend to migrate permanently and do not return to their home areas once they have arrived in the city (Woldie Assaw et al. 2010: 62). The share of already resident population (stable population) out of total population by sex shows that $47.6 \%$ of males were firmly established, while this only held true for $44.1 \%$ of females (Golini et al. 2001: 177). In reverse, this means that $56.9 \%$ of females of Bahir Dar's population did not live in permanent household arrangements, $3.5 \%$ more than among men. One of the reasons that might be made out for such unestablished arrival in the city is that of conflict in the area of origin (Mekibib Kassa et al. 2013: 298). In the conservative rural societies of Amhara, marriage still has to be considered a form of securing a livelihood for females. However, the marriages are mostly arranged and in case of rupture, the elders of the village decide on how to solve the conflicts. Banning the wife from the village in order to rehabilitate the husband is thereby commonly practised and accepted. In 1994 the in-migrant females in Bahir Dar were almost 8.5 times more likely to be widowed or divorced than those females resident in Bahir Dar since birth (Golini et al. 2001: 180). The city hence has to serve as a refuge and offers alternative lifestyles to the traditional set-ups. How these can be described has so far also not been sufficiently questioned, while, due to under-representation, women are often not considered in decision-making for urban development.

However, all the new arrivals in Bahir Dar are confronted with a housingbacklog: with a calculated need of an additional 2,739 housing units per year between 2003 and 2012, the city would have had to almost double the housing stock within ten years to accommodate population growth and compensate for dilapidated houses. Thereby, effective demand cannot be expected to be met by formal housing arrangements, as only $27.36 \%$ of the city's entire population were in the financial position to obtain a loan that would allow them to construct the simplest possible officially acceptable housing unit (Gebeyaw Walle 2003: 42). So, despite Ethiopia's economic growth, the number of low-income households dependent on self-organisational housing arrangements will still have to be considered substantial. They have to seek cheaper forms of accommodation - rental houses, sub-letting, informal construction, etc. This proposes that while the growth of population caused a housing shortage, the critical points are the resulting overcrowded units and informal settlements in the centre and on the periphery of the city (ibid: 97) that cannot be reached by formal housing provision. It, hence, needs to be questioned how the low-income households are accommodated in urban development.

\subsection{THE SUB-CASES}

The history of urban development was traced and phased in order to contextualise the data on present urbanisation practice (see chapter 3 ). 
Fig. 10: Sub-Case Selection according to Historical Phases of Urban Development

\section{Sub-case selection}

\begin{tabular}{|c|c|c|}
\hline Period & Site & Specifics \\
\hline Italian Occupation & Downtown & $\begin{array}{l}\text { Historical centre: Harbour, road to Gondar, } \\
\text { airfield (now Meskal Square), etc. De facto } \\
\text { mixed use. Partly declared informal according } \\
\text { to recent building regulations; redevelopment } \\
\text { projects on the way (market, centre and } \\
\text { waterfront). }\end{array}$ \\
\hline Imperial Modernity & Textile worker's settlement & $\begin{array}{l}\text { One of the oldest neighbourhoods, constructed } \\
\text { along with the textile mill. }\end{array}$ \\
\hline Socialist Rural Development & Informal settlements & $\begin{array}{l}\text { Auto-construction of village-like structures with } \\
\text { agriculture and subsistence activities on vacant } \\
\text { land. }\end{array}$ \\
\hline Decentralisation & University campus & $\begin{array}{l}\text { The two university campuses house several } \\
\text { thousand students and provide for almost all } \\
\text { their needs. Although the technical college is } \\
\text { older (from socialist times) the main campus } \\
\text { can be considered more typical for the } \\
\text { university programme conducted by the } \\
\text { national government and GIZ. }\end{array}$ \\
\hline
\end{tabular}

Image by the author.

According to these phases, four sub-case sites were identified (see chapter 4.4). These four sub-cases (see map Fig.11) will be described in dense descriptions to account for the mundane urbanisation practices.

Fig. 11: Sub-Case Locations

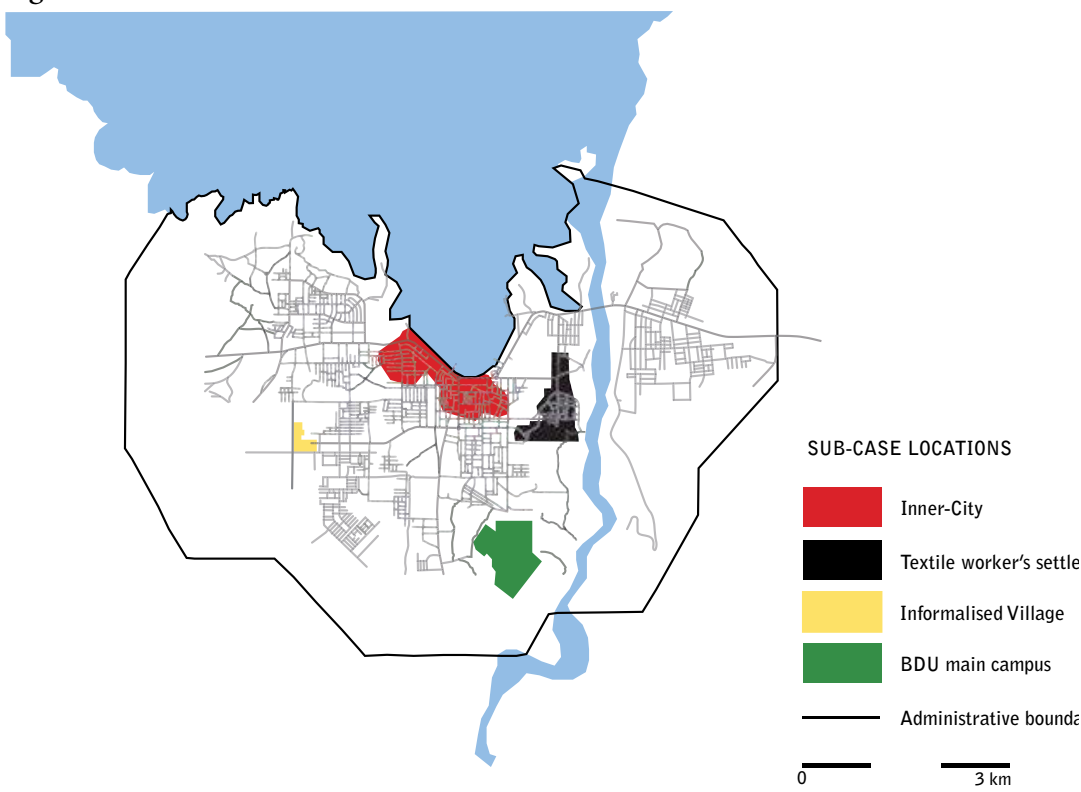

Image by the author. 
The four sites were determined as sub-cases, which were selected and studied to give an account of everyday urbanisation practice. The four different neighbourhoods that were chosen are: the inner city area, the textile workers' settlement, an informalised village and Bahir Dar University's main campus. The areas were chosen according to the different development phases of the city that were identified and described in chapter 5 (see fig 11). The sources for the description of the neighbourhoods and their everyday rationales of urbanisation are mainly the 22 in-depth interviews conducted on the sites, observations and material from the cross section walks and occasional complementation with material available from literature review. Biographical accounts of responding residents in regard to urbanisation in the different neighbourhoods is presented to give account on everyday life and access to the city. For each of the sub-cases, the material has been collected, systemised and will be presented as dense descriptions. Due to the exploratory nature of this approach, the results are incomplete because of the unstructured nature of the topic, which aims to identify whether there are general differences between the neighbourhoods but not attempting a comparison between the sub-cases. Based on the different historical planning rationales and local urbanisation practice on the different sites, the contingent urbanisation practices in the particular areas are meant to be revealed.

\subsubsection{Inner City Area}

The inner city is the oldest area of settlement in Bahir Dar and was the location of the first urban administration under Italian occupation (see chapter 5.2). Public spaces important for gathering and rituals (such as the old stadium and the former airfield, now known as Meskal Square) and the seats of various regional head offices, internationally frequented hotels as well as the close by market and bus station underline its central importance to the city. It was chosen as a sub-case site on the grounds of being the original node of settlement of Bahir Dar. The residential and commercial area are the historical core of the city. They were established long before the 1930s and have been subject to various waves and types of cultural and population influx. The area comprises what was the expansion of the entire town up to 1957, as described in chapter 5.1 and chapter 5.2.

The Kebeles in the town centre host a significant percentage of deteriorated housing stock. Overall, the living conditions in the inner city are often bad, and there is a lack of basic infrastructure (Tilahun 04.09.10). There are not many toilets in Kebele 05 and 06 . These are provided by NGOs, which select the sites according to their own criteria (ibid). Much of these dilapidated housing structures are owned by the Kebele itself and rented out to private households (Gebeyaw Walle 2003: 32). One of these houses is occupied by F, a 26 -year-old housewife and her family (see interview F). The Kebele owned houses currently have formal status. 


\section{INTERVIEW F}

F is 26 years old and gained access to her Kebele house by a municipal scheme supporting HIV-positive people, through which her mother acquired the right to rent the house from the Kebele. At first, she lived there with her children, not having any furniture at all. After her mother died, F married and started her own family. Completing school up to grade nine, she took on a job as a cashier, making 300 Birr a month. Paired with the family's main income from her husband's work as a builder on construction sites, this allowed them to gradually acquire beds, a sofa, a table, chairs and eventually a TV. When she had her child she gave up working and describes the focus on tending to her child as the main difference in her life today to that of her mother's in the same location. She describes the community life as good and she takes an active role in a savings group. Thereby, the area has an "older" group and a "younger" group that differ in that the younger members rather use the funds for gifts and the group as a social platform, while the older members distribute money. There is, therefore, somewhat of a differentiation of socialising styles within the area. While F sees her life as improving over the years, the house has undergone no structural alterations and they have made no additions. All investments into the Kebele's house they made were for essential repairs such as leaks in the tin roof. F knows that she and her family will have to move soon. She assumes that all households in her community of 20 people will be moved together into Kebele 14 , where they will receive plots of $105 \mathrm{~m}^{2}$. As she does not own the house she lives in currently, she will only receive land and is still trying to organise a way of obtaining materials for the construction of a new home. For her, the prospect of gaining ownership of this new house is something very positive and fits into her narrative of self-improvement regarding living conditions.

Apart from Kebele houses, there are also up to 50-year-old chicka mud-houses remaining that belong to the residents. One of these is owned by $\mathrm{H}$, a 67-year-old widow (see interview $\mathrm{H}$ ).

\section{INTERVIEW H}

$\mathrm{H}$ moved to the city centre more than 51 years ago, when she married. Her husband's house that she first arrived to was a traditional tukul situated on the plot where she still lives. With the land reforms of the socialist government, 
she and her husband lost their land and were expropriated. Clay buildings were constructed to house more people, of which $\mathrm{H}$ now owns only the one she lives in. Due to illness she cannot leave her bed and is dependent on support from her son and help of her neighbours.

Not all houses in the city centre are residential, as trade, catering and small-scale manufacturing are located here traditionally as well (see interview D).

\section{INTERVIEW D}

D's parents arrived in Bahir Dar as labourers in the textile factory but moved out of the centre when he was one year old. Today, he works at a carpentry workshop in the centre that he co-owns with another woman. This lady also owns the building that the workshop is housed in. D has a degree in accounting but decided to go into carpentry, as the work is better paid. He is living what he himself calls a "planned life". His fiancée is in Egypt as a labour migrant, and he himself can see himself marrying and following her, to make a better living abroad. Meanwhile, he spends his social time at the Protestant church close to his home in the condominiums of Kebele 14. D knows that the workshop will be relocated. He and his business partner will receive not only new land but also compensation for their loss of house ownership. He believes the move might be carried through together in the community and has heard the destination is Kebele 16. Here ,they will have to construct a new workshop themselves. D also sees the move as critical, mainly because the carpentry business will lose proximity to its customer base and has to re-establish.

In recent years, the inner city has come under large pressure to change and the formal status of the described houses are at threat by plans for new development. The centre is increasingly concentrating on commercial use, which is of regional importance and does not cater directly to the local population. Parts of the existing mixed-use structure have been declared informal according to recent building regulations; currently, redevelopment projects are on the way for the market area and the business district, as well as the waterfront. The impact of this can easily be seen in the location of the road lining the lakeshore park. It concentrates a number of large institutions and businesses. Yet, these are fairly recent and the small chicka structures containing private housing and cafés (bunna bet) are occasionally sandwiched in between. This can be graphically illustrated on the block from the corner of St. George to the east, where a commercial centre is set next to a tourist shop, a large insurance company building with commercial use on the ground floor, three 
adjacent chicka betocc, the electrical company's regional headquarter and Abbay Bank branch, the Dib Anbessa Hotel, a tourist stall, a building site, green area, Summerland Hotel, two souvenir shops and a café. At the same time, residential uses are changing quality. The long-term residents are all unlinked to this change of economic structure, but have made their income from local production. They are now being removed in favour of living space in the form of rental apartments that cater to employees with regular income. How these moves will take place is not always completely clear to the residents, and their prospects differ. F is expecting house ownership through the resettlement and sees the event positively. Her neighbour D with the carpentry workshop has a different view and different information. D sees the move rather critically, as he is aware that in a new neighbourhood, he will have to rebuild his business's customer base. Whether H knows about the move is unclear, but due to her ill health it seems certain that she is not in a position to re-build a house for herself.

Bahir Dar's inner-city hosts opportunities for subsistence activities. Most fallow land on the lake is occupied by subsistence agriculture. Beyond that, the natural resources of the city are exploited to generate income. In the city's forest areas, stones are excavated frequently and sold as building material, freshly caught fish are sold directly from tanqwa boats in the harbour and grass is collected to produce mats and to be sold for coffee ceremonies.

However, the inner city's concentration of various facilities, among them the central bus station, thereby furthers its central functions as the destination hub for in-migration. Various types of brokerage that await the arrivals and guide them to a variety of legal, illegal and informal businesses are connected to this. While the earlier population influx was often sustained by subsistence, the economic basis for many residents has shifted to making money on house ownership and sub-letting from current in-migration and a rental market has formed. According to Woldie Assaw et al. (2010: 67) the labour migrants coming into the city are desperate to find accommodation and are dependent on the sub-letting offers despite the bad hygienic conditions. Migrants arriving in Bahir Dar cannot enter the distribution programme for condominiums and housing plots by the city administration, as they have to be resident in the city for at least two years to do so (Interview Yirsaw 2013). This means that individuals and families migrating to Bahir Dar either need to be able to buy a house formally on the private market, have to enter the rental housing market or find sub-let accommodation. This situation has led to quite a number of the houses in the inner city being overcrowded, due to sub-letting or use as informal taverns and hostels. In the city centre new arrivals find such temporary accommodation easily accessible. Access to housing is often not made through formal markets and housing provision, but rather through personal arrangements in which one person takes in another. The results from Abeje Berhanu's study (2012: 46) show that $46 \%$ of the responding migrants owed their initial support to relatives that had already been resident in Bahir Dar. However, an interview in an 
informal hostel reveals that these "supporting" structures for incoming migrants are not necessarily only family relations, but are also found in sub-letting arrangements and pick-up locations for informal work. One of these hostels is run by interviewee $\mathrm{C}$ and his wife (see interview $\mathrm{C}$ ). The rural migrants $\mathrm{C}$ accommodates commonly face harassment by settled urban residents who consider them inferior (cf. Woldie Assaw et al. 2010: 67). As other informants also claimed, there is a distinction among the labour migrants between old and new arrivals. Conflicts between older waves of migration that came permanently and new waves that include seasonal migrants and non-permanent migration become noticeable in the form of hassle. The earlier settled migrants are said to spend more money in town than the recent seasonal ones who save on eating, drinking and accommodation in order to take what they earn back home to the countryside (Woldie Assaw et al. 2010: 68).

\section{INTERVIEW C}

C is 76 years old and living in a Kebele house made of mud with a tin roof near to the bus-station. He came to town about five years ago from the rural area near Gondar. He does not know the neighbourhood well but attends the Orthodox church and is a member in an Iqub and an Iddir. He left his farm, as he was on his own, because his cows got sick and his house there was deteriorating. He now lives in his new wife's house with a daughter. His other children have remained in the countryside, but there is no mutual support. At the beginning of our conversation, he claims to be a guard on another property, but after a while of questioning it turns out that a major source of income comes from the rural people who are crowding in the single room around us. They are travellers, who have to stay in the city overnight and have come from the nearby bus-station, or stay in the city as daily labourers and rent beds by the day. Many carry produce or large baggage. For staying overnight in the house's only room they pay 3-4 Birr. At the time of our visit, there were about eight additional people crowding into the house.

Further, downtown Kebeles 05 and 06 are especially known for their red-light district. Slipping into sex work sometimes happens casually and unplanned by the young females arriving via the bus-station, as they are escorted by brokers to older women, who sub-let Kebele houses to prostitutes and to whom they then pay half of the daily income (Abeje Berhanu 2012: 51). Earnings are about 150-200 Birr a day (ibid). Among the migrant sex-workers interviewed by Abeje Berhanu, a particularly high rate of illiterates was found (ibid: 36). They also tended to come from distant locations more often than other migrant groups (ibid: 39 ). 
The access to infrastructure and sharing of resources makes downtown a home to many street children, whose main sources of income are carrying goods, pettytrade, vending of lottery tickets, shoe shining, begging and washing cars (Amare Sahile and Sinkinesh Takleargay 2008: 76). Many of the street children seem to have come into the city due to difficult family constellations. According to Amare Sahile and Sinkinesh Takleargay (ibid: 64), there are around 5,000 street children in Bahir Dar. Most of the children come from large families with poor economic backgrounds and many of the children come from homes that lost at least one parent to death, while only $20 \%$ had their parents still living together (ibid: 72 ). For almost $80 \%$ of the street children, the street is their only living place (ibid: 74 ). About two thirds of the children come from the rural areas surrounding Bahir Dar, while another third was brought up in Bahir Dar Town (ibid: 69). The typical street children in Bahir Dar are Orthodox Amhara boys aged between 11 and 15 (ibid: 68). Most of the street children are self-dependent and have to make their own living. About $40 \%$ of them attend school, while about $40 \%$ have never attended and the remaining proportion of children dropped out (ibid: 70). The street children face various forms of physical, economic and psychological abuse.

Due to the different times and modes of settlement in the centre, the population in the oldest part of town is very heterogeneous and, despite Amhara region being considered Christian Orthodox, Bahir Dar's inner city hosts a large diversity of religions. All of the respondents stressed their positive view on living together with Muslims and Christians. One of the Muslims of the area is A (see interview A). According to Golini et al., 47.7\% of Muslim in-migrants in Bahir Dar are of urban origin, while $52.3 \%$ are of rural origin (Golini et al. 2001: 181).

\section{INTERVIEW A}

A is 21 years old and at his parents' house in downtown Bahir Dar for his course break at Arba Minch University, where he is a third-year student of computer sciences. He had to leave to study, due to the government's policy of sending Ethiopian students outside their regional states. He says meeting students from other parts of the country has taught him love and tolerance. Meanwhile, seven or eight people from three generations share his parents' house. The front room also houses a very tidy coffee house. It is a large Kebele-owned mud-house, for which they pay monthly rent since the parents came from Gondar and moved in more than 40 years ago. The house they moved into, and in which they still live, had only two rooms then, but the family added a third room, which now houses the kitchen. They have also painted the building's inside walls in lively colours. They keep contact with their family in Gondar City and unite for ceremonies, including weddings. There is no land in the family or other kind of subsistence 
agriculture they practise, so all groceries for the household are bought on the market. According to A, the family is doing well financially and derives their income from various sources. Apart from the coffee house, they are also homemanufacturing a special kind of local drink called "kapchua", which they sell. A wide range of customers pass by the house because of this specialised offer. The oldest brother is employed by the Commercial Bank, another one works for the administration. When A finishes his course, he wants to come back and find work in Bahir Dar, where he hopes to be able to support his family. Overall, the family has a good relation to the neighbourhood. A notes that there are certain persons there who contact the government authorities in the event of crime or other incidents. It is unclear to A, however, how these people come to "control" the neighbourhood, as he puts it, although he suspects it has to do with government issues. He, further, says on should be "tolerantof these people". As Muslims, religion is important to their everyday life in the sense that they follow the rules of the Koran. But A maintains a good relationship with his Christian neighbours and schoolmates. He states that they are not defined by difference.

Bahir Dar's centre is the main trading location and gathers the largest diversity of occupations and skills in the city. Apart from traditional trade, the large market with agricultural produce and diverse skilled workers also sees changes in views on certain types of labour, such as craftsmanship. Craftsmanship has a very difficult social standing in Ethiopian society and negative attitudes towards manual labour are widely spread. With regional variation, tasks such as welding and pottery are completed only by social groups that are marginalised even to the point of spatial segregation (Freeman and Pankhurst 2003). We see this change, in the inner city as $\mathrm{D}$ has gone into the crafts despite having completed a university degree (see interview D). He is, thereby, rejecting traditional Ethiopian stigmatisation of manual labour and M's life choices are progressive and pragmatic. Such self-determined careers are mostly not available to recent migrants and a lot of the current influx of population depends on job opportunities in wage labour as a first entry point. These are available on the building sites of the city. Many migrants find employment work in the expanding construction sector in Bahir Dar. A survey among construction workers of large-scale enterprises in Bahir Dar revealed that $60.1 \%$ of them had migrated to the city (Mekibib Kassa et al. 2013: 298). These building sites are all over town, including the inner-city but since cheap residence for the daily labourers is found in the city, and the bus station serves as a central arrival point, here their presence can frequently be observed beyond their places of work. On the building sites, the recent arrivals among the migrants are often more competitive than settled workers, because of the lower wages they demand (Woldie Assaw et al. 2010: 68). Fourteen dead workers in an accident on the university's new administration building site in 2012 suggest that the protective measures at 
the workplace are not the focus of attention in the building industry, and that work is generally hard. Women earn half of a man's wage on building sites. Enterprises hiring these daily labourers come to pick up the workforce by truck outside of the area in groups far bigger than the limit of ten workers stated in the CSA survey's restrictive definition of what is monitored as informal labour (CSA 2003: 9). The work engagements are infrequent and, for those who earn nothing for a period, lack of income sometimes means sleeping in the street, as the hostels require daily payment.

\subsubsection{Textile Settlement}

At first sight, the settlement surrounding the textile factory resembles the classical set-up of an industrial workers' settlement and was, thus, chosen as the second sub-case site. The area around the textile factory is probably the first of Bahir Dar's settlements to have been constructed after Guther's master plan was devised. It surrounds the textile mill, which was installed with the help of Italian reparations (see chapter 5.2) and was opened in 1961 (Abeje Berhanu 2012: 29). At first, the workers of the factory came mainly from the surrounding rural regions, as the local population was uncomfortable working with the large machines and refused the work. In 1995 the textyile mill had 1,604 workers employed in eight-hour shifts in its spinning, weaving and finishing departments (Y. Abebe and M. Fantahun 1999: 407). In 2006 it is reported to have had a work force of about 1,700 (Abeje Berhanu 2012: 29), indicating an increase. A further 450 jobs have been created since, due to a process of expansion that the factory has undergone (ibid). Connected to the textile fabrication, a "Textile Institute" has been installed at Bahir Dar University with a professorship connected to the Bahir Dar University, funded by the GIZ. The diversity of employees and employment opportunities connected to textile manufacturing is, thus, relatively high. However, it must be assumed that the main source of labour comes from migrants from the surrounding rural areas of Bahir Dar and around 74\% of the workforce have completed less than 12 years of school (ibid). Most of the positions they fill in the factory are thereby found in loading activities, as guards, gardeners and cleaners (ibid). Based on this, Abeje identified the textile factory as a site of destination for rural migrants mostly (ibid: 30). The factory workers are older than the average migrants to Bahir Dar (ibid: 36).

The area of the settlement is, thereby, divided into two parts: a residential compound on the fenced-off grounds of the textile mill, with official housing for employees and a surrounding area, where textile workers constructed houses in ownership and for their own residence, over time.

The enclosed housing compound officially in the hands of the factory has 63 houses and is divided into five sections named alphabetically from A to E. The factory's own area is fenced off and secured by guards. The high-ranking employees live in the large detached single-family homes in section A, the lower officials 
in row houses in the following sections, accordingly. Some of the lower ranked areas have vegetable patches, on which the families grow for their own needs. Apart from religious activities pursued by the individuals outside of the compound, social life within the official residence is organised by associations, iqubs and iddirs (saving groups). There is a women's association, which has social gatherings, while the mixed association is limited to taking responsibility for members in need, in case of sickness or other (personal) problems. Not all residents are married, so there are only about 38 women in the compound. As access to the residences is gained through qualifications and the position at the factory, the compound is religiously mixed. A café was installed in 1975 (European calendar) according to the inscription. The facilities of the enclosed residence include a tennis court, swimming pool, a restaurant and a library. The library is not open to the general public, however the other facilities are not only used by the direct neighbours, but by also by residents from all over the city. Despite this comfortable set-up, the well-educated residents of this area are aware of their chances elsewhere and do not feel tied to the location (see interview M).

\section{INTERVIEW M}

$\mathrm{M}$ is a 22 year-old female health professional. She came to live in the area with her husband, who works in the textile factory, and her two children four years ago. They came from Dire Dawa, where her husband completed a master's degree in textile engineering and where their families remain. After graduating, he was offered a position at the textile factory in Bahir Dar, which was what made them decide to move here. $M$ stays at home and does the housekeeping, while also studying for a further university degree. They buy their food at the market in town from her husband's salary. He has been promoted since he first started, which also allowed them to move into a bigger home within the compound. $\mathrm{M}$ is a member of a neighbourhood association and she describes her life in Bahir Dar as good. However, she and her husband are planning to move to Addis Ababa. They are just waiting for her to finish her degree, and then her husband will start searching for a job there.

The area surrounding the factory homes differs from the settlement, yet it is still closely connected to the factory historically. The land outside of the factory was subdivided and land-titles were given to the workers of the factory by the government more than 40 years ago. The workers were, thereby, enabled to build their own homes for themselves and their families in close proximity to their work place. This is why the ownership for the houses here is often in the hand of the occupants. The local population of Bahir Dar was largely afraid to work with the 
large machines in the factory, which is why the labour force was constituted mainly from migrants from the surrounding areas and other towns, seeking work in the city. These were mainly Orthodox Christians so that many families resident here belong to this religion. The overall middle-income population of the neighbourhood is involved in upgrading and people own their houses. The textile settlement is, overall, much more homogeneous in its appearance and range of urbanisation practices, which are still strongly linked to the ideas of industrialisation. However, the diversification strategies within the households of the textile settlement are spatially and culturally very wide reaching. With the regular income from the textile factory, the households' networks now rely on higher education, costly skills such as driving licences and trans-continental migration practices of family members. The second generation living in the area can clearly be described as middle class. This will be illustrated by the narrative of $\mathrm{K}$ (see interview $\mathrm{K}$ ), whose family partly draws its social status from the labour opportunities their father had in the factory, as well as their house ownership. By regarding the house not only as a home but also as an asset, the people owning their property outside of the compound have much more invested in their houses and, thus, the location than those provided with official housing.

\section{INTERVIEW K}

$\mathrm{K}$ is 25 and a driver for Bahir Dar University. He was born in the house in the neighbourhood of the textile factory, where his parents had built their home. His parents had come from villages some $40 \mathrm{~km}$ away from Bahir Dar, after his father had been told he would only be allowed to marry his mother if he could prove sufficient economic wealth. On his gaining a job at the textile factory, her family consented to the marriage and the couple moved to Bahir Dar more than 40 years ago. The family still keeps contact to their rural kin and, with the sons and daughters now having taken over the role of breadwinners from their deceased father, they also support their relatives. Thereby, the emigration of one of the elder sons to the United States of America is the family's main financial back-up. There is no engagement of any household members in trading or farming, nor do they sublet space. Over the years, they have continued to extend their home and added an extra room and an outside kitchen. According to K's description, the house forms an asset that the family wants to hold onto and protect.

Outside of lifestyles connected to the factory, there are few households that have no connection to the textile industry but still live in the area (see interview L). 


\section{INTERVIEW L}

L came to the area 22 years ago and is originally from Eritrea. She is now 45 and lives in one of the few Kebele houses in the area, a building once used as a school. She has four children and makes her living from home production. She collects grass at the shore of Lake Tana and produces place mats that she is well known for in the neighbourhood. She also offers laundry services and bakes injera for sale. She has made a few alterations to her home. Most significantly, she added a shed from bamboo mats that now accommodates her kitchen. Despite her uprooted past, she feels comfortable in the two-room house, which for her is clean and large enough. By making the alterations she has, therefore, appropriated it for herself.

\subsubsection{Informalised Village}

Site number three is named the "informalised village" here, as it appears to be a "rural" structure with many traditional features, while having been declared an informal structure quite recently, due to competing land-use interests of the encroaching city. The growth of the village that will be described in the following can be attributed to a period of socialist rule in which urban development was not the focus of attention and traditional land practice was continued, as other land claims were not enforced.

Urban expansion is not purely a radial phenomenon occurring only on the fringes of the built up-area and administrative boundaries. On some inner-city plots, villages have been forming enclaves and are now situated almost in the centre of what is currently Bahir Dar. One of them has been chosen as a sub-case and will be portrayed here. While the city has expanded over former agricultural land, its low density has allowed the remains or formation of ethnic and cultural clustering into villages where the lifestyle can hardly be distinguished from that of rural communities. However, they do form a clear contrast to their surrounding neighbourhoods of concrete single-family units and multi-storey buildings, which is how the delimitation of the sub-case boundary was chosen. However, also these communities are densifying. Compared to the satellite image from 2004, the number of houses here had increased by 2013; a densification is especially visible along the street leading to the private clinic in the vicinity. The style of buildings is dependent on local materials and resembles that of the rural villages. Communal toilets are run as a private commercial enterprise in a mud-house, while the site is not otherwise serviced officially with water or electricity. The houses have stables for chickens; sometimes there are even cow stables between the houses. The cows are sent to graze during the day with cow herders collectively in the areas surroun- 
ding the city and return in the evening. Many houses keep a dog for protection or donkeys to run transport businesses. Small fields are planted in the open spaces, spinach and cabbage being the vegetables in season at the time of the site visit. Below a small eucalyptus forest, there is even a coffee plantation. Some residents own fruit trees and, occasionally, there are private wells. Many of the homes have signboards indicating that they sell produce such as milk or injera.

The interviews in the location reveal that until about 70 years ago, the land on which the sub-case neighbourhood stands was bare and visited by cow herders with their cattle. Eventually some of the cow herders unofficially claimed the land and made their homes. The families occupying the land are all Orthodox Christians. The first houses in the location were made of grass and were later developed into steel sheet houses and expanded in size. Still today, the families whose children marry parcel-off land to them to build their own houses and live close to but independently from their parents. Due to this practice, the elders hold special importance for the communities, as they as first settlers are considered the owners of the land by the younger generations. The elders exercise influence by deciding who is granted a partition of the land. Currently, the fourth generation of settlers is resident on the site, still building their homes in auto-construction. Further outsiders were taken in by parcelling off areas over time as well. Community life is therefore mainly based on family ties, although the wider community is organised in iqubs and iddirs. These organisations offer support in times of crises to their members to a certain extent. However the families describe themselves largely as self-reliant. This can be illustrated by looking at the household of Q, one of the elders on the land (see interview Q).

\section{INTERVIEW Q}

Q is 66 years old and living on a small compound with three tukuls with his wife and his daughter. Their property has its own well. Q was born in Bahir Dar, and, after living in Kebele 03 with his mother, he was given this plot of land of 40 by 50 metres on the site by his brother. At the time, the monarchy was still in place and he remembers most areas of Bahir Dar as bare land, on which nomads grazed cows. The only fixed buildings were the Felege Hiwot Hospital, the palace and the Primary English School. Housing was eventually erected under the Derg Regime, while the area just around his village was only recently given to settlers by the current government. Q himself did not go to school, and all he can write is his signature. In the old time, he says, there was no need for education. They could live comfortably within their social network. Today, he says, learning has become more important, as things have become more complicated. He used to farm on his land and sell part of the produce. However, at the age of 
40 , he was chosen by the government to go to war alongside some other men. He caught a gunshot in his leg and could not work anymore after this injury. When he came back, he started selling his things, all the material and resources, until everything had gone. He then started collecting and selling wood to survive this way somehow, he says. He considers himself as very poor. The people settling around him are mostly his relatives, gradually having arrived after him. Q is an Orthodox Christian and goes to church regularly on Sundays. He used to be a member of iqubs and iddirs but stopped participation after losing his wealth. In times of crisis, in case his daughter cannot afford the money, the neighbourhood will collect and help with survival. Due to their precarious situation, his daughter could not continue to go to school, and at the moment his daughter's work is his only source of income. She is the only one who can regularly support him. She left school after grade eight to take up work on a construction site to help support her parents with the income. The family also practises subsistence farming, with modest success. They try to grow fruit on their compound, but

Also the younger generation describes receiving plots through subdivision from family members (see interview $\mathrm{P}$ and interview $\mathrm{R}$ ). However, the sources of income have diversified from the initial cow-herder society.

\section{INTERVIEW P}

$\mathrm{P}$ is a 35-year-old Orthodox Christian who was born and raised in the location, following his family traditions. His grandparents came as cow-herders from a pastoralist life-style and resumed to stay. He lives here with his wife and one-year-old son. His parent's subdivided their land to allow him to construct his own house. His house has two rooms. His parents' house has grown over time and now numbers seven rooms, which he himself considers very spacious. The extra space allows them to sub-let and make some money, in addition to their cattle trade. P makes his living driving his own bajaj, since his grades were not that good when he left school after grade ten. His wife is a housewife and neither of them is involved in any trading activities. Additionally, the family owns farmlands outside of the city, meaning that he has a share of agricultural assets as well. The family hires a farm labourer to work on the field and obtains a proportion of the harvest from him. The amount is just supplementary, though, and the regular source of food for P and his family is the market, where they go shopping. They are members of the local savings groups, iqub and iddir. Despite his long working hours, $\mathrm{P}$ says he has a comfortable life in the location and has no plans to leave. 


\section{INTERVIEW R}

$\mathrm{R}$ is a young female of 25 years who received the plot of land from her grandfather when she married. She built a house together with her husband. Due to her good grades at school she has managed to become a site engineer, meaning that she has to travel to the town of Shinti to work and spends lots of time there. Her husband is a bajaj driver in Bahir Dar, and, when she is home, she does the housekeeping for both of them. Additionally, they used to support themselves on food from agricultural land that they used to own. Now, the government has expulsed them and taken the land for other purposes.

Unlike the agriculturally dependent older generation, the younger, more educated generation is profiting from the institutions and educational facilities of the city. The two examples from interview $\mathrm{P}$ and interview $\mathrm{R}$ show how the households and their extended families have diversified their sources of income and livelihood strategies. Although agricultural practices remain a strong feature of the village, in the course of urbanisation, other income strategies have been adopted, and all the households interviewed rely on multiple sources of income. The younger households, thereby, described themselves as in comfortable situations. However, as resilient as these practices appear, the investment pressure and state-led development initiative will lead to eviction. While Q and P have heard rumours of conversion plans for the site and know that it will be obligatory to leave, $\mathrm{R}$ has actually already received notice from the government. This is all the more surprising, as it turns out that the houses directly neighbouring the sub-case delimitation do not fall under this qualification of informality. These newer mud houses were actually constructed after the government designated this place as a destination for resettlement from other inner-city sites. In contrast to the rental arrangements they came from, the relocated household interviewed claimed that it is now in a good situation being a house owner, as the construction of additional living space has enabled them to make an income from renting out space themselves now. What remains unclear is whether there is a clear policy on the type of building structure desired in the sub-case area, since although the old village and new resettlement communities might be divided, their building structures hardly differ. After decades of unexercised land rights on behalf of the government, criteria for resettling those designated to make room for a projected multi-storey commercial development therefore simply seem to lie in the differing legal status of the land title. 


\subsubsection{University Campus}

The fourth sub-case site is the university's main campus, which was instituted under the current EPRDF rule. The site was chosen, as the university functions not only as an institution of academic training but as a venue of cultural learning and urban living for the many students attending from all parts of the country. It can be viewed as a city within the city.

In 1963, on what is now the technical campus of Bahir Dar University, a Polytechnic Institute was founded with funding from the Soviet Union (Boden 1962: 4c). In 1999 it was merged with the "Academy of Pedagogy" (founded in 1972) to form Bahir Dar University (BDU; Abeje Berhanu 2012: 30). Overall there were about 45,000 students enrolled at Bahir Dar University in 2012 (ibid). To enter, the prospective students have to gain good marks at school, allowing them to ask for a placement by the government. The courses they are assigned to and the city they will have to move to are, thereby, selected by a central national institution and announced shortly before the beginning of the first semester.

Today, Bahir Dar University is distributed across several campuses and single institutions across and even outside the city. The main campus is on the southern urban fringe and connected to the city by a main road. Most of the buildings are recent, as the university was fully established in the course of the TVET Programme, which saw the installation of 13 campus universities across Ethiopia in an attempt to decentralise higher education and promote technical education for development purposes (GIZ 2015).

The university campuses house several thousand students and provide for almost all their needs. The students get loans from the state, which cover food, board and tuition fees. Every student (even those from Bahir Dar) is provided with a bed in the dormitory. These dorms are shared by 6-8 students each, with communal bathrooms and toilets. The loans have to be paid back after the education from a future salary. For everyday expenses - such as clothes - it is often the families that step in. Only few students resume a job while studying. Religious activities are not permitted, however, which is why going to church or the mosque is an occasion to leave the campus.

The main campus forms the delimitation of the sub-case area that will be studied here. A further reason for choosing the site as a sub-case was because, as part of the greater decentralisation efforts of the current government and the installation of higher education facilities in the regional capitals, the university as an institution also acts as a project developer in Bahir Dar. When there was a necessity to expand and the idea for a legal campus arose, the university leadership spoke to the city administration. The city administration negotiated with the Regional Industry and Urban Development Bureau, after which a partial plan was devised for the site of the new campus on the road to Addis Ababa. At the time of fieldwork in 2013, BDU had its administrative headquarters on the main campus. A new high- 
rise administrative headquarters was being constructed two blocks away from the campus, signalling that the university is still in the process of expansion and manifesting itself in the urban fabric.

However, there is a non-physical aspect of urbanisation that is strongly inherent in the concept of universities, too. Through the education acquired there, making a living in urban lifestyles becomes attainable. For students coming from the rural areas, getting a place to study at university is a big opportunity, as the case of W illustrates (see interview W).

\section{INTERVIEW W}

$\mathrm{W}$ is a 25-year-old third year student in the English department. He chose education to escape the hardship of life in his home in the Simian Mountains, 35 $\mathrm{km}$ from Debark. He is the firstborn of eight children on a farm. His family lives off their land, which provides enough to feed them. Their main produce is barley. To earn any small amount of cash, part of this produce would have to be sold. His parents are illiterate, like most in his village. As a child of about 10 years, W was meant to look after the sheep and cows. He says of himself, though, that he was a bad shepherd. He kept losing his animals and attracted his father's anger. In hindsight he says he was burdened with a lot of responsibility to perform as a good farmer, being his parents' firstborn, and compared to the children he now sees in town he views his own treatment as a child as inhuman. He was beaten, but he was not able to improve and recognise the lost sheep. His father eventually decided to send him to church school instead, so he could study to be a priest. He stayed for a year, and being a good student he says he was on the way to becoming a deacon. But he decided to switch to modern education instead. The primary school he visited from grade one to four was in his village. At the age of $12, \mathrm{~W}$ was engaged by his father to a girl from another village for an arranged marriage. They were meant to marry a year or two later. Seeing his teachers with their relatively good income, however, gave $\mathrm{W}$ the idea that he, too, could achieve this. He suggested to his father to postpone the marriage and to allow him to pursue education. He told him he would be able to support his parents only as a teacher, but not as a young husband trying to feed a family of his own on farming. His father seemed quite impressed with the idea and left his son W to it. He completed the 10th grade at his local school, but his father insisted that the engagement should stand. When he switched to high school, he had to walk to another village, between two and three hours' walk from home. He used to bring his own food from home, spend the week there and walk back home to his parents' at the end of the week. W had to become financially independent from grade five on, as his parents were neither willing nor able to support his further education. He made just enough money by car- 
rying other people's groceries from the market to buy bread and pay for the dormitory. He says of himself that he suffered a lot during this time, with many ups and downs. According to him, it was his love for education and the wish not to return to farm life in the mountains that kept him going. For grade 7 to 12 , he then moved to Debark. In grade 8 he took the exam to be a mountain guide. Out of 150 candidates, 16 passed, he being one. When $\mathrm{W}$ then first came to have coffee with a group of tourists at his parents' house, they were fundamentally confused. They had never heard human beings speaking English, and hearing W speak another language made his father question even whether he was his own son. W realised that the skills he acquired were earning him respect. With the tourists, he learned to speak better English even than his teachers. The job guiding tourists from all over the world paid him well, but he did not want to remain a guide in the mountains. While the other guides dropped out of education at grade 10 and now make their living in the mountains with tourists, he kept on rotating between guiding and studying for his university entry exam. He eventually passed with very good grades, allowing him to get English as his first choice of course and Bahir Dar as his first choice of university. He chose English for the respect it had earned him at school and how it made him a sought-after expert in the mountains. When he speaks Amharic with his mountain village accent in the city, he does not earn the same kind of admiration as he does for his English, where locals consider him knowledgeable. He chose Bahir Dar as it was reasonably close to his home and he would be able to pay for trips to see his family, but it is further than Gondar, which seemed to him too close to be something undiscovered.

Coming to Bahir Dar was a new world to W. He had not seen a television until he was 15 or 16 . He had not seen a roof made of tin in the mountains. When he first arrived in Bahir Dar for university, he came by bus, did not know anyone in town and had difficulty in finding the campus. He took a room in the centre for a couple of days and took time to ask people where he was meant to go. He then moved to the campus. On arrival, he says, he had a good reception, which was organised by the second-year students. He thinks there were about 1,000 students starting fresh with him that year. It was the first year that the university received students from all over the country, rather than just the regional state. Many of them, though, have left the course in the meantime, as they were not considered fit to study. He enjoys life on campus, where he meets people his age from all over the country. It is his way of getting to know Ethiopia without travelling, just as he gets to know the world by guiding the tourists in the mountains. His friends are from the campus, from different faculties, but nearly all of them are his neighbours in the dorm. They like to stay on campus for consumption, for the low prices, rather than going into town. W finds the campus well managed. He told me he enjoys the learning environment there and that he 
can engage with well-educated people, advancing his own progress. Coming to Bahir Dar, seeing the houses, starting to study and getting access to the internet he says was a good thing for him. In his vacation, W continues to travel home to the mountains to earn money as a tour guide. As a licensed guide $\mathrm{W}$ has earned a well-respected position there. Still he comes to Bahir Dar to study to get an even better education. Also, he now pays for his brother and sister to live in a dormitory in Debark, so that they can study in grade 10 in high school with the money he earns from being a guide. They are fed off the family's produce from the farm. Going home, he claims, it is difficult communicating with the other guides, as his world view has become so different, although the guides are doing relatively better than the farmers, such as the friends he knew when he was a shepherd. They are now married, have children and cannot read or write their names. W would not like that kind of life and jokes that he is happy he was a bad shepherd. When W completes his studies in a few months' time, he will have no more reason to stay in Bahir Dar. He will look for a job close to his home area, instead, or continue as a tour guide. In his hometown, doors will be opened for him. In Bahir Dar, he knows few people outside of the campus and there is no one to offer him a job. W wants to be an example to the people in his home area and says that, apart from missing some of the technology he got to know in town, it will not be difficult to return to the mountains for him. He wants to return to help improve the situation there, which reflects his awareness for the changing situation in tourism entering the mountains that were so far a "world of their own". W says of himself, that in his home village, he is special. Coming to Bahir Dar improved his position at home. Through his contacts to tourists he now receives requests by recommendation on the internet, making him an important gate-keeper. He is the only one to have made it out of his home village so far. For him, the harsh conditions he came out of helped him not to be spoilt and to know himself. Because of his education, his father is now highly respected for being the only one who sent his children to school. This respect has made him very proud of his son in the end. His fiancée's father still asks W's father from time to time about marrying his daughter. He is now an attractive match. But $\mathrm{W}$ is not willing. His choice for education has enabled his fiancée to pursue school up to grade 10 to keep up with him, but he rather sees himself marrying an even more educated woman.

As W's example illustrates, students from rural areas adapt certain "urban" lifestyles, when coming to Bahir Dar, while maintaining their family ties in the countryside as well as possible. To do this, they have to take on a variety of identities. Students from other rural areas have similar stories to tell. For many students coming from rural areas, this is the first time they have experienced city life. The university contributes to this by creating a specific academic living environment. 
As $\mathrm{W}$ described, the campus is an entry point into the city and a location determined to be clearly distinguished from any rural practices. On the other hand, it is viewed as a refuge from "dangers" of the city. Thereby the campus is described not only as a gateway to city life, as W put it, but as a sanctuary of learning for others (see interview U). As children from other urban contexts are pursuing education as a means of entering or staying in the newly forming middle class, which is largely urban, their stay on the BDU campus is often their first stay away from home or outside the family.

\section{INTERVIEW U}

One of the first things $\mathrm{U}$, an 18-year-old female student from Dila, mentioned when I spoke to her, were the dangers she expected outside the campus, especially after dark. She describes the campus as a place where there is female participation and organisation in associations, support for problems by student unions, and where she can live what she calls a "harmonious type of life". She describes her best friend as similar to herself and also the other relationships she has formed seem to be based on principles of sharing. She points out this perspective on her fellow students, even though she has an aunt in the city on whom she can rely on for support in times of crisis. Besides that and her regular visits to church, she has little other contact to the city and spends most of her time on campus with her friends from university. As soon as she has obtained her degree in management, she wants to return to her hometown and start her own enterprise. Staying in Bahir Dar is not an option for her, as she says it is due to the support of her village that she got where she is now, and she feels she wants to repay this support by going back.

This way, the stay on the campus is considered temporary by staff and students, as the largest magnet of population influx is de facto disconnected from the surrounding city and has developed its own set of practices.

The university campus, which houses several thousand students and should actually be contributing to a cultural urbanisation process through its educational programme and the differentiated origin of the students, is extremely regulated and a closed system. As university entry is highly selective and random at the same time, many students find themselves studying subjects that they struggle with personally or professionally. This has led to a flourishing landscape of private universities attracting students from all parts of the country as well. Studying outside the BDU campus also illustrates how the state university functions in creating an integrative environment (see interview X). 


\section{INTERVIEW X}

$\mathrm{X}$, a 24-year-old nursing student at a private university, moved into the city to follow her sister, who initially came to study and was now able to support her younger sibling with a job as a secretary at an international NGO. As they did not qualify to live on the BDU's campus (any longer), the two of them had to find private accommodation by knocking on the doors of houses in several neighbourhoods. When doing so, they were faced with severe discrimination on the grounds of being of Protestant faith. They eventually found two rooms in a converted servant's quarter in Kebele 13, but did not disclose their faith on arrival, leaving the landlord to believe they were Orthodox. They were threatened with eviction, since he found out, and eventually moved away to sub-let with a more liberal foreigner.

The protectionist living environment of the BDU campus is also expanded to the teaching staff, which is partly accommodated on the campus in special staff residences (see interview $\mathrm{T}$ ). All in all, there are four apartment buildings and a number of row houses to accommodate the staff.

\section{INTERVIEW T}

Lecturer $\mathrm{T}$ comes from a place $30 \mathrm{~km}$ outside of Bahir Dar, where his parents still live. He lives with his wife in a 1.5-bedroom apartment on campus that the university management provided on the basis of a one-off evaluation. The criteria for getting into the residences are based on several factors such as qualifications, academic output and publications, social engagement and evaluation of the teaching performance by students. If a better house is vacated, a competition is undertaken in the same manner to access the available house. $\mathrm{T}$ considers this living arrangement a privilege, as all in all not more than 100 members of the staff live in these facilities. The community on the campus is good he says, he has social contacts with his neighbours. He is an Orthodox Christian, but he does not have any friends based on his religion. He is very assertive saying that his friends are of all faiths, including Muslims. He considers the homogenous status of residents as teaching staff a good influence and environment for those raising children. They are also in the good situation of being able to use the facilities, such as a play-ground, on campus. He can also use the other campus facilities, such as the lounges, but generally he and his wife buy and prepare their own food, like in regular neighbourhoods. The staff on campus are soci- 
ally and economically organised in iqubs and iddirs, although he himself is not a member. However, just as the students pass through living on the campus, the protected environment is not a permanent set-up for $\mathrm{T}$ and other staff. With the help of an architect, he has started building his own home in Kebele 11 and plans to leave the campus. He considers housing in the cities as a very difficult issue in the urban areas, especially in Addis, but also in Bahir Dar. According to him, if you get the chance to move to your own house, you do it. He says that relocation within the city is not a common phenomenon, but building your own house, finding a better home or disagreements with the landlord are reasons to move. He found the plot because of connections he has within the city and avoided the common application process. To construct his house, he himself hires craftsmen personally and makes the pay arrangements. He has no general contractor. He says the speed of construction depends "on the pocket". For such undertakings, generally a step-by-step process of up to 10 years is expected. However, this investment does not mean that he is no longer mobile. $\mathrm{T}$ would like to stay in Bahir Dar, but would leave at any time for a better job. As he puts it, "I would even go to Dafur, depending on what they pay me".

Despite these provisions, T's account reflects the high mobility and low social ties of the very educated population group towards Bahir Dar as a city. The criteria for choosing the site of living remain almost solely in the job. Overall, living conditions on the campus are somewhat isolated from life in the town. There is hardly any exchange of the students with the rest of the city, because all meals, sports and leisure activities can be found on campus. However, the workers catering in the cafés do not live on the campus, but rather come in for their daylong shift every second day (see interview V).

\section{INTERVIEW V}

As the coordinator of one of the shifts, $\mathrm{V}$ says the income from her job has allowed her to incrementally construct additional rooms to her house. But entering these stable jobs at BDU has become more difficult than her informal entry 35 years ago. Today, a formal qualification is also required for BDU workers.

Meanwhile, the newly arising influx of students that have qualified for university arrives in Bahir Dar on account of a national distribution system. Through education, they are entering and will contribute to the political development agenda. 
Many of these students will work in the cities as experts in their fields of education and as government officials. The probability that they will return to live in the countryside is low, unless they can find or create adequate working opportunities. Those with urban backgrounds and those accepting the novelties of city life even try to distance themselves from what they perceive as rural backwardness by expressing their open hostility towards it or distancing themselves from the predetermined path their families expect them to follow. Other than that, those students coming from well off backgrounds show little connection to Bahir Dar as a city and seek to return to their family networks. For staff, the focus is on questions of pay and work content when deciding to move, rather than on aspects of living quality in the city. The campus is, thus, relatively disconnected from city life; there is little exchange with the population not linked to the university. Yet, there is a cultural process of urbanisation through the educational programme that the students undergo here (rather than one of physical construction).

\subsection{Ordinary Practices of Making the City}

Urban life in Bahir Dar can be portrayed as highly diverse, and urbanism reaches far beyond the account of marginalisation due to landlessness. The accounts show that urbanisation as growth but also as a cultural and socio-economic transformation is triggered by more than just push-factors in the countryside. Thereby, the results from this chapter show that a diverse spectrum of distinct urban development trajectories is found across the neighbourhoods. The differing constellations dependent on the changing planning paradigms and resulting structures, as well as their mutual shaping of and with urbanisation practices, are reflected in the findings from the sub-case studies. They show how the contemporary neighbourhoods have developed specific practices of the everyday and relations between varieties of everyday urbanisation, according to their specific drivers of urbanisation and path-dependencies. These have to be considered as contextual realities in the course of further urbanisation.

The empirical findings of this chapter, further, display the significance of everyday practices in urban development under rapid urbanisation. These practices provide a range of accommodation and are responsible for a wide range of building activities and income generation within the city. Thereby, the different structural outcomes and networks of local urbanisms are created in interchange between and among the statutory and everyday practices. While even within the normative ethic of the "developed" city found in statutory planning (see chapter 5), local understandings of adequate infrastructure provision vary according to context and are subjective; the empirical data suggests that civil society has an even more diverse understanding of normative ethics guiding urban development. Beyond the neighbourhood typologies focused on by statutory planning (see chapter 5.6), eve- 
ryday practices of urbanisation have formed neighbourhoods with distinct properties, dependent on the local constellations of formal and informal urban practice and co-producing urban structures. A majority of the urban population depend on incremental practices of urbanisation that are compatible with low incomes or irregular availability of building material. Thereby, the material gathered for this research shows that urban villages, historical mixed-use, industrial dormitory towns (as the forerunners of today's expansion areas) and informal shacks form typologies of neighbourhoods in Bahir Dar. And while some ideas inherent in these sites reach beyond the proposals of the "developed" city and guide citizens' understandings of improving the urban systems, these might not be explicitly formulated and have so far not been considered the status quo from which to inform policy and take on further development. Until now, everyday practices of urbanisation, including informal housing and traditional living arrangements, are poorly documented. Their guiding ideas, however, are not a simple "anti- position" to the idea of the "developed" city, just as all actions rendered informal by statutory planning cannot be reduced to an understanding of "anti-planning". The narrative of the interviewees suggests that the engagement with local space and materials is strongly defined by the desire to secure the household's livelihood and improve the living situation for the immediate family. While urban residence offers an opportunity to engage in income generation and constitutes a strong and recurring motive in the interviews for having moved to the city, the different neighbourhoods the residents live in offer different types of opportunity for income generation and differ in their accessibility to newcomers. Consequently, the amendments, appropriations, exploitation of resources and installation of building structures strongly depend on the neighbourhood's location and the existing facilities in the area. These are, however, mostly not the opportunities of formal employment labour anticipated by ideas of a "modern" city.

\section{Historical diversity}

The historical centre is prominently located and under strong land-use pressure. Despite the zoning as "commercial", downtown Bahir Dar is historically a mixeduse area in which a large variety of building styles has accumulated. The shoreline with the ferry harbour and tourism facilities, the markets, retail, ritual spaces and large religious buildings, regional head offices, the entertainment and red-light district and the bus station with its related activities are some of the most defining features of the area.

The area displays a wide array of social, ethnic and religious groups and income typologies across all scales. While some families have been residing here for several generations and live in municipal houses or their own property, the recent arrivals are dependent on other living arrangements. With the bus stop nearby and the ferry landing in its centre, it is also the arrival point for many rural-urban migrants and students coming into town. While the latter move on to campus, the 
former find shelter here in a number of informal hostels and add to the strain on infrastructure and space. These informal arrangements substitute for the lack of formal accommodation for the urban poor.

However, from the viewpoint of all kinds of migration, the inner city can be simultaneously viewed as a dense historic structure with a high frequency and diversity of opportunities and, also as a hub, thus a highly fluctuant space of temporary residence. Beyond formal work for the highly skilled and business opportunities for traders and investors, the area provides opportunity for ambulant business (vending and service) and daily labourers, as well as small-scale workshops and catering businesses. Often working and living are thereby conducted within the same space. Hence, the household members are often engaged in multiple activities of income generation and combine formal work (as employees or shop owners) with informal income generation (e.g. in home production). However, existing micro-economic practices are due to change on the impetus of development through larger investment. The diversity of urban livelihoods and dwellings is to be succeeded by developments suited to new development criteria. Thereby, the long-standing neighbourhood ties forming social bonds are in danger of losing out on relocation. The grown community is in threat of being dispersed, and traditional building practice will be discontinued in favour of intensified commercial use.

\section{Housing area}

The textile village is still a residence for many textile workers and their offspring. In its purely residential function, it can be seen as a forerunner of the housing areas in today's expansion areas. However, it is a dormitory town connected to an industrial development with a history. As a workers' settlement, the design of the city structures is based on assumptions of employed wage labour. The residents can enjoy the various learning and leisure facilities of the area and the single or twostorey family homes are constructed from quality material (stone foundations, clay or concrete structures). The main wave of migration to this area was connected to the establishment of the factory and the neighbourhood has since been in a process of consolidation. It has remained relatively unchanged since its erection and lacks the material development dynamic that can be observed, for example, in the inner city.

The settlers' structure is rather homogenous with a majority of middle-income Amhara Orthodox residents and qualified workers of other ethnicities. The residents' status is legally sound and long established. The long-term residents, however, are socially and economically established through work in the factory, are well engaged with their location and have appropriated their living space. For this group of residents, the site can be seen as the destination of permanent residence in town. The (relatively few) new arrivals to the area are often highly skilled experts for the textile mill and their families. Rental housing is accessible for these factoryrelated new arrivals, but the residents see this as a temporary set-up and aim for 
their own houses. However, entering the ownership model for new arrivals - even highly educated employees of the textile factory itself - is difficult, as the historical arrangements of access to plots have been discontinued in this area and there is no present equivalent to the former worker's privilege to housing. However, this does not seem to be a large problem in the context of highly qualified career paths in the industrial sector, as the stays for career purposes are considered temporary and the well trained professionals are willing to move on to other cities in pursuit of work.

\section{Urban village}

Traditional building structures and layouts are mixed with more recent chicka and eucalyptus houses, forming small scale settlement structures that are still governed by the traditional rules of land sub-division. Thereby the system relies on the decision of elders that are recognised as community leaders by the residents. While this neighbourhood is an Amhara structure, there are also variants of the typology as Wayto villages in other locations.

Although land is sometimes temporarily granted formally (as in the case of the Wayto), by standards of the current law, the land is mostly informally occupied. While traditional livelihoods and family-related settlement patterns continue in these locations, the high permeability of these structures due to the low cost of living also makes it receptive to urban arrivals with low financial backing. They settle in vacant houses or find space to insert new informal structures. However, settlement here was sometimes undertaken more than four generations ago. The older occupants mainly use the land for subsistence activities, which are complemented by incomes from trade, services, foraging/mining and gathering, home production or revenues from agricultural land held in the countryside. The continuous traditions are, thereby, complemented by and receptive to modernity. The younger generation has diversified its livelihood strategy and also engages in formal and qualified wage labour outside the village-like neighbourhood.

In comparison to the modern developments, the urban villages display a high flexibility towards changing environmental conditions. They are not dependent on imported material such as concrete and rely largely on renewable resources. However, the sites where these villages are located are increasingly attractive to rationales of commercial investment that also have to be counted as everyday practices of urbanisation. There is, hence, not only competition for the land use between subsistence strategies, but also an encroachment of formal development on the village location considered prime land by developers.

\section{Academic compound}

Next to the informal labour market, the schools, universities and churches have to be seen as important reception structures for incoming migrants. Thereby, the university is rapidly expanding and can itself be seen as one of the major project developers in Bahir Dar. 
The students come to Bahir Dar as temporary residents, with the fixed idea of completing a task (a degree, a qualification, a career step) and then moving either back to their places of origin or to places considered to offer even better opportunities and which are accessible with the qualifications gained in Bahir Dar. While the students are homogenous in their age group as recent high-school graduates, their cultural and economic backgrounds are highly diverse, covering all status groups and regions of the country. During their stay, students spend most of their time on campus and are fed and housed on the compound. Teaching staff members are highly qualified and can also live on campus. Residence on campus is, hence, geared towards achieving a certain aim or taking advantage of an employment or education opportunity currently provided here. The opportunity could have just as well arisen in another urban location within or outside Ethiopia, and the engagement with the city as such is, thus, low for many students and academic university employees. Exceptions can be found among students who either come from Bahir Dar and have family ties in the city, where they spend their free time, or who have a particular agency, seeking additional income or exchange with people off campus. Due to the lack of off-campus relationships, explicit statements that they would limit their stay in the city to a defined period of time were, consequently, made by students and academics at BDU.

The university campus, hence, stands for an enclosed neighbourhood typology for which the building practice does not form an everyday practice. Instead, urbanisation here is practised through cohabitation, as well as cultural and formal education. The campus, thus functions as a sanctuary. It is, thereby, not dissimilar to the compounds of churches, which house significant numbers of novices, even if the underlying ideology cannot be compared. Thereby, entering the programmes and being awarded a place on the compound - each by its own standards - is highly selective. The stay is, by definition, temporary. However, consecutive residence in the town is not actively encouraged and, thus, the BDU campus especially, as a compound typology, remains somewhat isolated from the rest of Bahir Dar City, also restricting the diffusion of knowledge.

The settlement strategies found in the neighbourhoods are not linear patterns of movement from the rural to the urban but rather recursive and "messy". Different reasons for coming to the city are followed by a range of actions that are partly formal, partly informal. The motives for coming to the city and also the opportunities taken up are very heterogeneous - they are somewhat diffuse in their formulation as aspirations and depend on context-specific opportunity. While there was a time when the textile mill provided a lot of formal employment, the opportunities to arrive in Bahir Dar are now mainly accessible through higher education and skilled labour or informal arrival systems.

For those who qualified in school or have completed their studies, establishment in Bahir Dar is formally regulated. The students of BDU are housed on cam- 
pus and are considered temporary residents in town, while the administration and industry workers often have access to company housing, can afford rental housing and have the possibility to apply for a building plot after two years of residence. Meanwhile, informal networking and illegal bribes are also common here, although they have rarely been accounted for as success factors in processes of sociocultural urbanisation until now. These are not practices on the margin of society: Even those coming into the city as a result of formal job recruitment make use of these actions to improve their own and their family's living situation, for example for gaining access to preferred building plots. Such ambivalent approaches were found in all of the accounts and, thus, range across the various status groups and locations included in the data collection.

Those without formal qualifications and economic resources have to depend on chances given in the city without much pre-knowledge. While access to housing is often not made through formal markets and housing provision but rather through personal arrangements in which one takes in another person, these are not necessarily only family relations but also business relations in sub-letting. Work opportunities are often a mixture of (temporary) employment in the micro-economy and subsistence activities. Further, learning and qualification (even certificates) depend on circumstance. Hence the opportunities actually taken are not concentrated on opportunities available in formal employment but are rather widely diverse in the range of finding incomes and subsistence strategies. The decision to move to the city is, thus, also influenced by unanticipated, irrational choice. These individual rationales might not be strategic due to the high uncertainty of environmental and economic set-ups, but based on chances and opportunities they are highly tactical in aiming for improved living-conditions for the person and often for household or family members.

Overall, data from the sub-cases, hence, show that a combination of formal and informal actions constitutes the rationales of the civil population. The outcomes vary between meeting formal requirements, remaining informal and anticipating legalisation. Looking at the practices in the location of Bahir Dar reveals that random opportunities, risk-taking, uninformed decisions and acting on impulse are important factors that open opportunities for establishment in the city. Thereby, the micro-economy with its low-thresholds for employment plays a crucial role as an integrator into city life for the population majority. However, there is competition between everyday practices, and, while some strategies are favoured by statutory planning, other rationales are disregarded and sanctioned, raising questions of injustice. Based on the findings presented in this chapter and the previous chapter 5, the next chapter (7) will discuss in what relation practices of everyday urbanisation stand in relation to urban policies within the described neighbourhood typologies. 



\section{The Relation of Planning and Everyday Urbanisation}

This chapter functions as a synthesis of the empirical evidence collected in the literature review and fieldwork, which was presented in the foregoing chapters. The findings from the preceding chapters on urban planning in Bahir Dar (see chapter 5) and practices of everyday urbanisation (see chapter 6) are jointly discussed here. The material is questioned in order to contribute to explanation building on urbanisation in Bahir Dar. With the purpose of describing the qualitative aspects of urbanisation in the Ethiopian context, the relation of planning and everyday urbanisation in the case-study site of Bahir Dar will be described as regulating systems in a location on which urbanisation impacts and urban growth has to be managed. The findings, thereby, contribute to the larger understanding of urbanity as assembled by a range of accounts of urbanisation. Chapter 5 proposes that the relation of the succeeding guiding principles of planning is not one of succession in practice but rather one of ruptures, continuities and parallels that can still be traced in today's city. Ruptures have, at times, left the relation of planning and other urbanisation practice unclear, while some practices were continued over the periods of time. At the same time, the changes in paradigms of planning do not mark a break from one period to another and cannot generally be interpreted as contradictions. Certain continuities within Bahir Dar's urban development throughout the changing political agenda have to be assumed. Especially under conditions of limited economic and material resources, the physical constructions and investment in infrastructure following prevailing paradigms of a time are not as flexible to change as the guiding ideas of urban development themselves. The phases of political urban development do not necessarily coincide with periods and fashions of the everyday practices of urbanisation. As a consequence, the phases of urbanisation cannot actually be distinguished as clearly as the clear-cut nature of changing rules suggests, and urban development has to be viewed as a continuum through the phases of government. Therein, the relationship between planning and urbanisation is dynamic and develops in its own time-frame, allowing for fluctuation, fall-backs and ephemeral constellations.

Here, it will be established in what relation the planning principles and practices stand to the distinctive local urbanities found across the sub-case neighbour- 
hoods (see chapter 6.2). The inner city area, the textile workers' settlement, an informalised village and the BDU campus have all developed local specificities based on the visions under which they were constituted. They continue to shape the urban practice based on their design principles, while the practices related to different visions and ideals exist simultaneously. The chapter discusses whether the existing local structures and practices are addressed by urban policy and which modes of urbanisation have been put out of focus. What the reverse focus of planning on the short-term political agenda, national economic interest and investment means to efforts of ordinary citizens building the city in terms of access to housing, equal rights for ethnic and religious groups, opportunities of income generation and social configurations will have to be conceptualised. It has to be questioned whether there are segregational tendencies in urban development and in which way planning is at all grounded in ordinary city life. To establish this, the relations between planning and local realities will be specified for the study's neighbourhoods in the following. They can, thereby, be considered spaces of negotiation. From the specific constellations of negotiation in the neighbourhoods (see chapter 7.1), the topics of negotiation (see chapter 7.2) that make up the discussion and relevant themes of urbanisation in Bahir Dar will be named. They are related to the systematic of topics derived from the literature review (see chapter 2.2) and presented as "spheres of negotiation".

\subsection{Constellations in the Neighbourhoods}

Through the study of the relation of planning to urbanisation over time, it has become evident that the relations between planning and everyday practices constituting urbanisation in Bahir Dar are complex and cannot be described in absolute terms for the city as an entity. Urban policies in Ethiopia did not succeed one another entirely, but have shaped and left practices on the ground that have gone into competition with the revised urban policies drawn up by the following regimes. Just as "different types of cultural traditions form different types of cities" (Robinson 2006: 60), the date and the dominating planning paradigm in relation to everyday urbanisation at the time of construction is also relevant for shaping particular urbanities. The findings show that everyday urbanisation practice in Bahir Dar varies according to a neighbourhood's historical and geographical underpinnings. Distinct differences in urbanisation rationales among the sub-case sites reveal that the urbanisation practices are tied to planning rationales of certain time phases. As they have produced distinct socio-spatial arrangements that might have undergone change over time, the resulting neighbourhood settings do not resemble each other in crucial aspects of urbanisation. These can be named as ties to rural areas and access to cheap accommodation, as well as employment opportunities, type of formal access to housing, the housing typology and access to means of subsistence 
(land and resources). These structures are far less dynamic than the changes in policy that are applied on the city-scale. Based on the shaping and simultaneous dependence of urbanisation rationales on these spatial structures, the neighbourhoods, therefore, display practices of urbanisation that reflect not only cultural and social diversity but also historic contingencies. Thereby, the engagement with the neighbourhood as a concept of building the city, establishing and, hence, urbanising in a mutual process of the individual with the neighbourhood can be summarised as typically distinct for the four sub-cases. The sub-cases demonstrate how at the time of establishment of the neighbourhoods the different contexts and composures of materialities, cultures and planning paradigms triggered processes that have resulted in locally varied expressions of citizen engagement with their parts of the city. The situation of engagement between a population and its site of dwelling (and livelihood) described as "everyday urbanisation" has to be considered contingent due to the historical settings. The basic local parameters according to which the settlements were first installed hence have a defining impact on the space and material-related practices within the neighbourhoods to this day. Thereby, the construction activities, etc., forming everyday urbanisation are directed at the structures that are already in place and strongly shaped by the underlying guiding principles of construction of the urban structures. Path-dependent urbanisation in Bahir Dar is, hence, guided by formal projects of planning, but mostly by opportunities that are created by what is termed as particular for the "urban": density, economic activity, access to infrastructure, learning opportunities, exposure to innovation, etc. The relations between the different rationales of urbanisation at the neighbourhood scale will, thereby, be examined in the following.

\subsubsection{Historical Diversity}

The city centre is one of the oldest parts of Bahir Dar (see chapters 5.1 and 6.1.1). The city centre's characteristics make it a location of opportunity. Its high density requires a high level of social interaction, the mix of building typologies caters for a large range of housing requirements across all income groups and the historical set-up as well as the permeability and connectivity of the area, result in a high diversity of population. Construction was often conducted according to the standards and material availability of different time periods and dependent on the individual capacities of the owners, leading to a historical mix of building typologies and building traditions. The livelihood strategies of the residents are also extremely diverse and go far beyond the conventions of formal employment in all income groups. The opportunities of income generation available in trade, the tourism industry, transport services, vending and small-scale production in combination with the offers of cheap accommodation further the influx of recent migrants. Despite its density, the neighbourhood therefore has to be considered particularly permeable and receptive for arrivals with limited resources. This is 
also reflected in the high visibility of street children and establishment of individuals whose biographies move away from traditional roles of gender or profession. It is here that the entertainment district absorbs females escaping from their roles of wives, or where the stigma of working in craft can be overcome by men and women of the middle class.

Of course, these properties of the neighbourhood come with a reverse side of clashing interests such as a high land-use competition between dwellers, established livelihoods and current investment interest. The increasing density up to the point of overcrowding paired with a lack of investment in the Kebele housing stock has also led to an overall critical state of sanitation. Yet, these clashes and the information from the interviews reflect that there is a high level of engagement by neighbours with their neighbourhood. Despite the fact that many dwellers live in Kebele housing, these buildings are modified within the possibilities, and despite lack of tenure security, they are interpreted as family homes by their occupants. Since residence has been assumed more than two generations ago for many of the current young population, long-standing neighbourhood ties have been established. These social networks define the use of public space outside the houses, which function as semi-public spaces for socialising and have important roles in the preparation of food and subsistence practices. The small-scale craft workshops have established customer bases in the area and operate on these networks. They share the same public space for production, storage and showcasing. The residents are, hence, in continuous negotiation over the local space and flexibly appropriate it to suit their acute requirements. It can, thereby, be described as an extension of their dwellings and workshops. However, the large-scale investments in the shape of business centres, hotels and shopping facilities recently constructed in the inner city have distinctly different requirements from their environment than the established small-scale economies and residents. The economic interests of the new hotels with foreign guests, for example, clash with the established structures. The soundscape created by the local entertainment district (paradoxically promoted as a point of interest to tourists) is considered a disturbance to the economic interests of the travelling industry (Evans 19.02.2011). Here, however, the negotiation over the use of public space and the configuration and construction of urban spaces is no longer conducted between equals. With national interest standing behind the tourist industry, social, economic and political networks ensure that questions of urban development benefit the larger businesses and relocate opposing interests. The residents can, therefore, currently not be considered drivers of the development dynamic in the inner city.

Currently, newly erected international standard hotels clash with noisy nightlife of the red-light district in corrugated iron shacks, which at the same time houses one of the oldest residential neighbourhoods. Looking from the main street, these smaller structures are hidden behind a line of multi-storey enterprise buildings, such as small shopping centres, representative buildings for NGOs, banks 
or bars. Due to their age and the limited economic resources of the residents, some of the residential inner-city buildings are in a neglected condition. The provision of basic infrastructure is not secured for the Kebeles 05 and 06 (Tilahun 2010). De facto, the centre hosts mixed use that has been developing without major planning regulation for more than two decades. In the land-use plan of 1996, just as in the IDP land-use plan, plots are either reserved for residential or commercial activities (Genet GebreEgziabher 2011). Beyond that, the area is an "upgrading area" and subject to the set-up of detail plans, involving fundamental restructuring. The IDP declares the waterfront a "special planning area" for which the "Sustainable Vision and Waterfront Plan" is put in place (see chapter 5.5) and the market place will be moved. Because of the government's priority on investment, a new landuse plan is being devised for the inner city, by which the residents of small-scale structures and of the production spaces are resettled into the expansion areas on the city's outskirts, section by section. The Kebele houses showing the described signs of deterioration will be demolished and the occupiers relocated. There is not actually an issue with planning regulations, rather existing structures are informalised in order to legitimise their destruction and substitution. The development of the city centre is steered not through land-use proposals but through building specifications and tenure redistribution. The nationalisation of land, initially meant to secure the land for agricultural purposes, now gives state institutions a free hand in allocating the use-rights to occupants suiting their criteria. In the contested inner-city spaces, where land-use pressure is high, economically powerful pressure groups are advantaged in offering technical improvement. Housing and commercial activities in one of the oldest areas of town are substituted by the same use but in a more investment intensive, representative multi-storey structure. In this location with high development pressure, a multitude of land-use interests have to be negotiated. The current situation in the city centre sees a collision of interests between residents, the entertainment district (including the red-light district), commercial development and a booming tourist industry. Here, this has led to a situation in which planning and everyday urbanisation have distinct relations from plot to plot.

To recapitulate on the lakeshore development, the elements of its vision are formulated as: "Public access to the waterfront and its natural areas", "green, beautified and sanitary infrastructure and design", "mixed use corridors", "appropriate housing and jobs for all" as well as "access to rural-urban linkages" (Canadian Urban Institute 2011). But how does the special sensitivity of the special planning area on the lakeshore comply with the "action-plan" for development and the heavy building activities in this zone? It seems, that the water-front as part of the innercity has been taken over by an investment driven development agenda. The recent development along the waterfront show foreign tourists and medium to high income groups as target users. These are very different from prevailing groups of young people and low-skilled income generation currently present. Their activities 
are likely to be displaced to unknown locations, as alternative sites for washing, bathing or recreational space are scarce. A balance of interests, therefore, needs to be undertaken. Although the public has a chance to participate in the redevelopment process of the waterfront, the social capital necessary to attend and barriers of actively taking part in stakeholder participation need to be acknowledged. Against this setting, the developments undertaken under the IDP are in tight competition with public interests and with agricultural and informal economic use of the lakeshore. Conflicting interests of economic driven plans for tourism and the longterm perspectives for the lake-based livelihoods also need to be carefully looked into. The region around Lake Tana is a designated UNESCO Biosphere Reserve (zur Heide 2012). This status includes the opportunity to establish economic gains through sustainable tourism. However, tourism in the area relies on the ancient heritage of the island monasteries as well as the natural potential of the lake. It is a hugely popular spot for bird watching. If capitalising on tourism is to advance, maximising the immediate facilities by building on the lakeshore will have to step back behind the actual reason of visiting an intact natural habitat. Decisions for building - especially on the waterfront - should strongly consider these interests and consider moving construction activities to less environmentally sensitive areas.

Currently, the market is placed in the immediate central business district of the city. The variety of sales goods includes all types of farming produce, household goods and clothing items. The vendors are either seated in simple stalls or sell their goods on the ground from canvas. The vendors of farming produce are usually the farming families themselves. Other sources of income are derived from the trading activities. Young boys offer their services as carriers or try to make a percentage on advising foreign shoppers. Other trading activities, such as that of processed food, cultural goods such as crafts, lottery vending and sweet selling by children, the wood merchants or tourist geared trade, seek their trading locations outside of markets. They either chose to be close to their customers, to gather their trade in specific locations or to place themselves, where they are tolerated in the public space across the town. However, the market space is gradually sectioned into plots by the city administration and given to investors that build "high-rising" buildings in the central area. The remaining market in this location is thereby to be turned into a closed (in-door) vending space.

At the time of the observations, many pre-provided stalls still remained vacant in the two new market locations, although substantial trading activity could be observed. Many of the traders were farmers selling their own produce (vegetables and staple foods like lentils) and, thus, evading the regulated market structure. However, in the new larger stalls, crafts are sold by professional traders. Goods include blankets from imported material, local pottery, and imported Chinese house ware. Limited amounts of clothes are also available. The markets also have sections with services, where radios and watches are repaired or second hand items refurbished. 
In the case of shifting the market to two other locations, the evaluation of benefits and disadvantages is complex. It seems there is no specific preference towards supporting "rural" or "urban" lifestyles in the relocation decision, although all types of livelihood are affected. The new locations are more accessible to farmers coming from the rural outskirts. They are close to the residential areas of the urban consumers and hygiene can be improved in the city centre as well as the more spacious new markets. Formalisation, however, always bears the risk of excluding the smallest scale traders, as these subsistence farmers come irregularly and cannot afford additional fees for their stands. In the new locations they currently have enough space to place themselves on blankets around the formal structures, but of course are dependent on their activities being tolerated by the authorities. In terms of poverty eradication, the support of this income (for rural and urban farmers) lacks planning security. Just like the traders that are not present at the market but have their own informal allocation system of trade in public areas, they can continue their income generation activities, unless a change in policy towards the informal occurs. The interests of informal traders and farmers not resident in the city but supplying the city's demands, will have to be considered more carefully in the future planning implementation.

The individual practices of everyday urbanisation in the inner-city stand in very variated relations to the paradigms of statutory planning and the practices conducted under their "regulating fictions" (Robinson 2006: 11, see chapter 2.1). The historical centre has a great diversity of building typologies and standards, a highly mixed-use structure and dense occupation. As the commercial centre, it is the focus location for investment and population influx under the conditions of urban growth. A plan for urban-upgrading in the sense of urban renewal was in the process of set-up at the time of fieldwork. In effect, the current single storey building will be cleared to make way for multi-storey construction, with a focus on commercial development. Thereby, the recent redevelopment plans (see chapter 5.5) and hotel allocations along the waterfront show foreign tourists and medium- to high-income groups as target users in the design of public space. These diverge from groups of young people and low skilled income generation currently prevailing. The current user's activities are likely to be displaced to unknown locations, as alternative sites for non-commercial use, such as washing, bathing or recreational space, are scarce and not replicated in urban planning. Beyond securing the land for agricultural purposes, the nationalisation of land now gives state institutions a free hand in allocating the use-rights to occupants suited to their own criteria. Thereby, the "development" of the city centre is steered not through land-use proposals but through urban design, building specifications and tenure redistribution. In the contested inner-city spaces, where land-use pressure is high, economically powerful pressure groups are advantaged in provision of technical improvement. Housing and commercial activities in one of the oldest areas of town 
are replaced by the same use but in a more investment-intensive, representative multi-storey structure.

Some dwellers and business owners are offered the chance to conform to the newly imposed building standards. In order to stay in place, they have to be flexible and resourceful enough to comply with changing building standards in this area with high development pressure. If they cannot fulfil the requirements of changing building standards or adding significant floor space (in the form of additional storeys) to their buildings, they are given notice and their land-use permits are not extended. Some residents and businesses can comply with the changing requirements and stay in place, others cannot and have to shift to other locations. Thereby, the areas of destination do not necessarily display lesser land-use competition but rather more favourable power relations and easier access to land from the government perspective (see chapter 6.1.3).

Other neighbours are not given the opportunity to stay. The dwellers of Kebele houses are directly referred to relocation schemes as soon as their plots are due for redevelopment, just as small-scale businesses have to move to locations away from their customer base. Here, the current government breaks with the previous socialist line of nationalisation. The Kebele-owned structures will be replaced by private development as a spatial expression of the liberalisations for economic investment. The needs created by this turn in paradigms are predominantly designated to be accommodated in the symbolic city centre. With the resettlement of population on plots with land-use rights and house ownership, the stock of municipal real estate in housing is reduced and the state controlled rental market for housing is drastically transformed. The occupants do not have an awareness of these structural changes and assess the measures according to the impact they will have on their own living situations. Granting house ownership is, thereby, considered a major asset. The sites they are relocated to are less crowded, but the sites are often not fully serviced with basic infrastructure by the government.

By uprooting the existing economic and social structures in the city centre, the expected urban upgrading scheme will make the inner city less permeable for incoming population groups. When entering the city, the most pressing problem stated by the labour migrants is the lack and quality of housing that is accessible to them (Woldie Assaw et al. 2010: 67). Although changes in quantity and quality of the housing stock are likely since the last available documentation (Gebeyaw Walle 2003), the rather large group of migrant workers is generally not addressed by current urban policy. They do not have enough negotiation power to stand up for their interests, as the investors do in negotiations with local politics. With the increase of formal living arrangements and a rise of the economic threshold for access to housing in the city centre, it will become even more evident that only long-term dwellers can enter formal housing systems and all other status groups have to rely on informal arrangements. 
With the mobilisation of investment for an "upgrading" of the city centre to a dense multi-storey inner-city commercial district with apartment living and tourist facilities, a major turn-over process has been initiated by the authorities, of which the limits have not been defined. Within this process, the behaviour of the state is tactical and decisions of land distribution are based on the best prospects of fulfilling the promises of a "regulating fiction" (Robinson 2006: 11) of modernity. Well-resourced locals are faced with the choice of complying or relocating. Those structurally affected by implementation are the urban poor, as they are marginalised and systematically dislocated. Thereby, the bad living conditions, hygiene and sanitation issues only play a minor role in the state's reasoning for resettlement. Instead, the small-scale mixed-use dwellings are not deemed fit to represent a regional capital. There are no upgrading strategies for informal areas or long-settled residents in place to accompany the programme. The substitution of small-scale structures by the "modern" vision of a commercial centre applied, therefore, fails to consider the relations and dependencies between housing and location for income generation of the lower income groups and leaves them uprooted.

The development dynamic of the highly heterogeneous everyday urbanisation established in the centre is not the basis of statutory planning. The structures have been subject to continuous adaptation. Not all structures were conserved in their original state and have undergone various modifications to suit changing needs and been appropriated for living and income generation. While the existing buildings and establishments are now being inventoried instead of using the information for in-situ upgrading strategies, the information serves for compensation and relocation in favour of redevelopment. Despite some cases of individual gain through compensation, overall, the long-standing neighbourhood ties and social and business bonds on the micro-scale are in danger of losing out on the relocation in favour of larger-scale investment. Thereby, the technical assessment of living conditions in the formulation of government housing programmes justifies the practice and furthers tendencies of marginalisation of low-income groups by moving them out of the city centre.

\subsubsection{Housing Area}

Following the establishment of the textile mill from Italian reparations under Emperor Haile Selassie, the development of this area as a sub-centre was suggested by the 1962 master plan. The actual urban development has conformed to this proposal, even if Guther's ideas for architectural standards might have been left out of focus. As a layout, this type of urbanisation fits with the modernist vision that the Guther plan devised for the city. However, as a continuation of the imperial plan, the socialist government of the time provided plots for the factory's work force for household establishment and granted house ownership. The idea that industrial production with attached urban residence is an adequate spatial expression of ur- 
banity and serves national interests, is continuous throughout the changing rulerships and a strong continuity in the changing government's positive assessment of such structures has to be assumed. Although socialist politics were undoubtedly anti-urban (see chapter 3.4), the idea that socialism did not engage in urbanisation cannot be upheld when studying this neighbourhood. The high standard of public facilities provided exclusively for this area (swimming, tennis, library) in the socialist era remains high-level in comparison to other neighbourhoods to this day. The facilities find wide appreciation and are in good use also by residents from other parts of town.

The neighbourhood established in the realm of the textile mill drew a large number of workers from the regions surrounding Bahir Dar. As the urban population was initially reluctant to work with the large machines, these rural-urban migrants came into the city in the classic sense of industrially driven urbanisation. The factory, thereby, functioned as one of the original pull-factors into the city. This complementary relation with formal employment in the factory explains the strong residential qualities of the neighbourhood. The establishment of housing in the neighbourhood is specific to the area, however. In order to support the industrial endeavours, the workers were rewarded with rights to stay in company housing or were given tenure rights to land on which they could become house owners. While the tenants of company property see their dwelling there as temporary, those resident in their own homes are strongly engaged in their area of residence. This property attributed by the former socialist government has resulted in high personal investment in these plots. The occupants consider the houses family assets. Thereby the set-up of the neighbourhood is designed in a way that grants each house (also the Kebele houses in this area) a private outside space. These spaces are often used to construct outdoor kitchens and offer opportunity to engage in food preparation and subsistence activities. However, they do not require negotiations over the use of this space with the neighbours.

In the textile village, industrial development has respatialised social positions and resources. Following an active recruitment campaign to work in the factory and settle in Bahir Dar by the government of the time, social roles have shifted from tradition, and new social statuses were attained in the course of urbanisation. They emerge through self-invention and negotiation of new social standards in the forming urban society. Inhabitants who were attracted by work opportunities in the textile factory were enabled to establish their own households and families with their earnings. The further support granted by providing plots on which houses could be constructed secured settled ownership status and long-term land-use regulations. Granting residents land-use rights in connection with ownership to the buildings has led to secure investment conditions that furthered a sense of belonging and establishment of the local community. It has also resulted in a high conformity to formal building regulations by the residents' construction activities. Those that chose to grasp the chances that the establishment of the factory offered 
have often made a good life for themselves and their families as a result. They can now be considered part of Ethiopia's middle class.

In combination with housing provided for highly skilled staff, the location can attract (young) professionals from distant locations and compete with other employers located in places such as Dire Dawa or even Addis Ababa. However, the model mainly functions for satisfying an existing need for housing in a formally employed population group. The relative wealth of the population results in the fact that sub-letting is not that common in the area and the rental market is small. Those not in contracts with the factory can enter through the relatively small amount of Kebele housing or do so informally. Obtaining plots here through the official land-distribution system today is unlikely, as it is quite a consolidated neighbourhood. Thereby, the middle class is served and other population groups are left out, resulting in a homogeneity of the population structure. While the older residents and their families are mostly Orthodox who came from the surrounding rural areas, some Muslims have come as qualified workers from other areas of the country and moved into the neighbourhood recently.

Despite the strong synergies between the governmental and administrative efforts to establish a residential area around the textile mill and the appropriation by the incoming workers of the structures provided, it is evident that in other locations the employment structure and spatial ideals of modernity do not coincide in the way they do in this neighbourhood. The example of the textile village illustrates that there have been synergies between planned urban extension and everyday practices of building and appropriation. However, the extent to which these can serve as examples for future urban development has to be questioned. The historical background shows that the development experienced here was only possible on the grounds of the reparation payment received from Italy. Such a factor cannot be foreseen in forecasting urban structures and is not replicable. For further planning, the idea of synergy, therefore, has to be conceptualised and grounded in the given economic circumstances.

\subsubsection{Urban Village}

The third constellation between planning and everyday urbanisation that could be observed in the course of the study in Bahir Dar is that of competing systems of land-tenure. The expansion of the city over former agricultural lands has led to the formation of villages in the city, in which lifestyles can superficially hardly be distinguished from those of rural communities. The style of building is dependent on local materials and resembles that of the rural villages. Agriculture for subsistence is carried on land surrounding the homes.

The site on which the village-like structure chosen as a sub-case developed was already part of the area designated for urban development in Guther's master plan but it remained untouched pasture ground for a long period. Several governments 
ignored the settlement practice that formed on what used to be the urban fringe. Their land-use on administratively urban land can basically be described as agricultural - usually considered a uniquely rural feature. Through practice, urban agriculture can, thus, be considered a constituting element of the city. The practices and the structures and spaces produced for their purposes rely on self-sustaining principles and community support, yet have become practices of urbanisation over time. The settlement practices on the sub-case site seem to follow traditional practices of land-subdivision within growing clans. Simultaneously the traditional lifestyles are updated by the proximity of the location to the city centre. Although some residents are completely self-reliant in terms of consumption, especially the younger people can profit from the opportunities of education and employment the city brings. Thereby, these are gradually taken up as add-ons to the traditional lifestyle, with a slow shift away from subsistence practices. The living arrangements are extremely diversified but also grounded in the free availability of natural resources. While these practices allow flexibility and, therefore, strong resilience to periods of uncertain economic development, as well as displaying a strong degree of sustainability, they require a strong labour investment in the construction of the location. Since the social ties are very strong, the self-reliant building of housing and stables as well as agricultural activities, are tackled within the closely-knit community. The lifestyle is thereby highly dependent on the specific features of the location, as a lot of building material is produced on site, food is cultivated on the land and even clothes are produced from cotton shrubs in the gardens.

The accounts show that, until now, there has been something of a peaceful coexistence of traditional land-holding and de jure state ownership. While it has to be acknowledged that there is a tradition for new-comers to settle on the urban periphery, some of these actions were meanwhile undertaken three generations ago. In traditional manners, they have sub-divided land according to family requirements, self-constructed their dwellings and rely on social organisation by elders. The densification and the emergence of the village-like structure evolved through further partition of the land according to custom, by which the relatives are given partitions to settle on. Despite the nationalisation of land under socialist rule, the small settlement thrived to include what are today several hundred inhabitants.

With the change of power to the current government and the arrival of a new urban agenda for investment and economic development in 2005 (Ministry of Works and Urban Development 2007: 20; see chapter 3.5), the site - no longer on the geographical sidelines - has been identified as a potential site of investment in relative proximity to the city centre and located on the city's main regional connection road. An investor has made a proposition to the municipality and declared interest in developing the site. While the village, as a product of continuing Ethiopian building traditions, has survived several political reforms of urban policy and development approaches, it has now been rendered informal by the administration. Although state ownership of the land has not been enacted till now, the 
residents' claims are not acknowledged as customary rights to their dwellings but are rather rendered illegal and their settlements named informal in the course of increased land-use competition. Against government argumentation, in which this use of the plot on the former urban fringe is unsuited to what is now part of the inner-urban fabric, and despite maintaining habits of subsistence to support their livelihoods, the residents are urban dwellers and have taken advantage of the opportunities the city has given them in terms of education and income diversification. Despite its traditional appearance, the village can, therefore, not be considered a place of standstill. The practices there are not archaic, but rather assume adaptation and are questioned as to their practicability concerning the question of securing the inhabitants' livelihoods. This innovation, therefore, contrasts the narrative of backwardness used to legitimise their eradication in favour of developmental ideas of urban planning.

The settlers are given no opportunity to engage with the development designated for the site by investment and formal planning. With the recent proposals for "development", the structures of the village and its inhabitants have been marginalised in the sense that the practised de facto land-use and land-rights systems are being overturned in the state-lead development endeavours in favour of capitalintensive commercial development. Some of the residents know about their own resettlement, others have not been officially informed and are in a state of limbo. They will receive no compensation for their houses as they are not legal owners, only new plots for reestablishment will be provided in an undisclosed location.

The set-up of subsistence, which is highly dependent on local assets (trees, fields, wells), is, thereby, undermined with insecure outlooks on its reestablishment. By resettlement, one of the most resilient of all (urban) settlement types is being destroyed. Those members of the community who are heavily reliant on subsistence will face severe challenges in the course of relocation. The households unsuccessful in acquiring new skills suited to urban lifestyles in education (driving, technical or school) are those that will prove most vulnerable in the face of losing their agricultural assets in the course of resettlement. Overall, the situation has to be described as a dominance of a developmental planning agenda over existing settlement structures.

\subsubsection{Academic Compound}

The Bahir Dar University Campus is a spatial expression of the government policy of "development" through an education programme focused on business and engineering. As such a structure, the state takes patronage of it. The university administration, thereby, acts as a project developer, as it is responsible for carrying out various building projects on the large campus areas. The national government provides the buildings and facilities of the university through the university programme executed with the GIZ. This construction endeavour constitutes an 
enclosed entity physically and, to a large degree, also socially. Among all the arrivals to Bahir Dar, those seeing education in the government institutions are privileged through an expanded system of subsidised study. However crowded, BDU is providing living space for a large number of students that is considered modern by governmental standards and in the perception of the students that live in the rooms. They are exposed to an experience of cultural exchange among a student body from across the country and engage in practices of communal learning and shared routines. The university campus can be considered a "city within the city". Entering this education system secures a livelihood within the city for those selected to join and prescribes daily routines within the campus facilities and environment. By design, most of the space here is attributed a specific function in this routine. As a result, the residents - the majority of them students - do not actually have much opportunity (nor the desire) to actively shape their surroundings. Appropriation is limited to the practices conforming to the campus rules, for which decision power is in the hand of administration and government. The students view themselves as privileged to be on campus, however, and mostly value the facilities. Thereby, they remain among their peers and dissociate from the rest of the city. In this regard the students of "modern" education differ strongly from those found in the traditional education systems of the churches, who live on the church grounds but take the freedom to connect to the neighbourhoods. The university, therefore, has to be considered somewhat isolated from the urbanisation processes that target the other neighbourhoods, but it also does not take an active role in influencing these processes by encouraging the students to form networks in urban society. Instead, the focus lies on inter-ethnic exchange among the students and the education. The campus, in its rather static state of design, is attractive as a site for its purpose. However, it does not create a long-term commitment by the incoming students or staff to the campus nor does it further the attachment by supporting interactions and connections to the outside city.

The practice of housing students on campus is, thereby, a critical issue that has been in discussion for several decades as the evaluation is ambiguous. While providing comparatively modern living facilities for a large number of students that would not be available in the town's neighbourhoods in this quality, there is also criticism that the closed campus set-ups are not actually favourable to academic advancements regarding society. From the perspective of societal benefit, the UNESCO Conference on Higher Education in Africa "called for residential universities to consider becoming 'non-residential or partly residential establishments" in 1962 (Livsey 2014: 682). As Livsey (ibid) further states, "it argued residence removed students 'from that sense of one-ness with their societies without which they cannot effectively serve their societies"'. In reverse, this can be seen to confirm that the university campus in Bahir Dar has been designed for achieving academic results, not to function as part of the city. Conventional rules of land-use rights acquisition are invalid, as the rules for entering rely on scholarly 
merit. Students unsuited to their government-assigned careers have to drop out. Those with insufficient marks turn to the private education sector if they can afford to. Entering the facilities is only possible by qualifying and conforming to the government's education system, leading to the assignment of a course and thus the city of residence for the students prescribed by the administration. By conforming to the rules and high standards set for entering, the students and staff members enjoy privileges distinct to the academic living environment. Outside of campus students from private universities recount that Protestants face difficulties in finding accommodation in the city's neighbourhoods, due to their religion and accounts of harassment of women in the streets is common. Meanwhile, questions of religion, ethnicity and gender are explicitly required to be handled in an egalitarian manner on the Bahir Dar University campus. The conditions of living here are described positively by those able to conform and are considered a merit. This phenomenon of modern space lending students (and staff) distinction, thereby, also has a history in modernist planning (cf. Livsey 2014: 683).

The dual benefit of keeping the university functional as an education facility by letting the students escape the dysfunctional private rental market through provision of campus accommodation while setting students and members of staff apart from the "rest" of the city's population is described by Livsey (2014: 684) as an "entanglement of practical and symbolic considerations". While this might be true from the university administration's perspective, the resulting low engagement and identification with the city of Bahir Dar and the remaining society can also be seen as a wasted potential for the city's progress. If personal ties in the city cannot be established and a local professional network entered, the potential of educated young residents will move to other attractive working locations in their home areas, in Addis Ababa and abroad. Regarding the university as a closed institution exempts it from functioning as a facility for the city and neglects the opportunity of seeing the students not as subjects but as agents of urbanisation.

\subsection{Spheres of Negotiation}

As it turns out, there are four very distinct relations between planning and urbanisation found across the four sub-cases. Within these neighbourhoods, the topics identified from the theoretical debate on urbanisation are recurring issues, however, they are discussed in variations in the different sites. The issues of legal status, modernity, urbanity and citizenship identified as conceptual dialectics on which rapid urbanisation has been negotiated in other geographical contexts are, hence, mirrored in the negotiations undertaken in Bahir Dar's urbanisation process. Thereby, the location's specific constellations lead to a locally specific negotiation outcome that will be described in the following by moving the insights from the empirical case study into the thematic realms termed as "spheres of negotiation". 
Hereby, the discussions are reflected regarding their site-specific understandings and dialectic realities to conceptualise the rationales that are at work in urbanisation and to uncover the mechanisms they rely on in argumentation.

\subsubsection{Negotiations of Legal Status}

In Bahir Dar, statutory urban planning considers informality as opposing the formal plans and arrangements that it has set-up itself (see chapter 5). However, these plans often do not consider the factual developments on the ground, but rather rely on projections of an ideal urban development. This repeatedly leads to clashes between existing structures, everyday building practice with plan and projects. Thereby, the concept of informality is central in the negotiations that are undertaken in the realms of local economy, land administration and the erection or sanction of building structures, as the determination or non-determination decides in the case of competing urbanisation interests.

\section{Local Economy}

Looking at the textile area, the empirical findings suggest that, while industrialisation is a driver of urbanisation, the situations in the other sub-cases show that it is only one economic factor underlying the urbanisation process among others. In fact, urbanisation in Bahir Dar is happening outside the political-economy frameworks based on models of urbanisation through industrialisation and is creating a distinct heterogeneous type of urbanity beyond conventional descriptions. The economy, therein, is an important driver, not so much in the form of industrialisation but rather in form of formal and informal services in the local economy as well as in construction as a present phenomenon of the growth dynamic. Most job opportunities described by the interviewees can be found in the micro-economy, administration, hospitality and in building. The attempt at statistical description of informal labour in Bahir Dar undertaken by the Central Statistical Agency of Ethiopia (CSA 2003), meanwhile, does not connect the population influx with informal work opportunities and thus processes of urbanisation. While the strong development of a service sector can be observed by studying the services available, the "informal" organisation of these economic structures supporting a wide range of urban dwellers is considered a failure within the regulated system, rather than the prevalent economic system itself. The National Urban Policy does not address the population movement and increasing informal modes of seeking livelihoods. Instead, the binary of formal and informal economic sectors is upheld by Ethiopian politics and administration, which is reflected in the land-use categories of the IDP and spatial segregation of labour and housing (see chapter 5.5). The activities monitored are, thereby, limited to those of income generation, while building and appropriation practices are ignored in the surveys. Distinguishing between formal and informal is declared as relevant by the official surveys because informal 
working conditions are rendered as exploitative by the government. There is also a concern for tax evasion that justifies the investigation. There is, hence, an implicit understanding that the question of formality and informality is linked to that of legal status of practices and structures, while this is not actually transferred into a more complex conceptual understanding of the relation of formal and informal. Meanwhile, subsistence activities, domestic labour, home production, foraging, informal employment and other modes of informal work beyond criminal activities of drug trafficking, blackmail, etc., are common occupations in Bahir Dar. They are not evenly distributed across the neighbourhoods. As the results from the empirical data show, the inner city and the informal village host far more opportunities to engage in small-scale income generation. Thereby, the city centre provides a wide range of occupations, opportunities of subsistence are particularly found in the urban village. While formal wage labour can gain from strict enforcement of labour regulations, undifferentiated exertion of such would lead to the eradiation of both low-threshold income opportunities for the low-skilled workforce and cheap labour for the cities' economic and physical expansion. As Meagher (2011: 69) described for Nigeria, this disregard of informal and smallscale economy leaves those in informal operations with the choice of neglect or conspiracy towards the state. This is particularly difficult, as the findings from this case study suggest that informal income opportunities are a major factor of reliance for a large proportion of the urban population and should be investigated as a driving force of urbanisation. Therefore, those neighbourhoods providing such opportunities act as arrival destinations and are attractive to urban migrants with lower education levels, their structures are neglected in the distribution of resources for upgrading and development. It has to be assumed that lifestyles based on local economies of opportunity rely on different city structures than those proposed by plans assuming Fordistic production and income generation in the city. The economies anticipated by urban planning, thus, need thorough questioning. The focus on industrialisation has resulted in waiting for investment in vain. Meanwhile, existing business models in crafts, repairs, local production and services that might be less capital strong are not regarded as relevant and are overlooked or disregarded in spatial planning in favour of economically promising but also capital-concentrating ventures, for example in tourism. That the formal developments rely on cheap labour from the informal sector (hotels obtaining bread from home production, grass harvested from the lake for coffee ceremonies, informal domestic labour in the wealthy households, building material from informal excavations, etc.) is, thereby, paradoxically taken for granted. While formal status is occasionally disregarded and withdrawn, these are examples where is there an interest (on the part of politics or investors/citizens) in maintaining structures and services in an informal state. 


\section{Building structures}

The assumption stands that slow housing delivery is the reason for the construction of informal dwellings (cf. Achamyeleh Gashu 2014), which the government counters by an urban expansion programme providing more formal dwellings. This "myth of delivery" has to be questioned on the grounds of findings by Gebeyaw Walle (2003), who shows that the housing problem is more persistent, due to the fact that the majority of the population could not fulfil formal building requirements (see chapter 6), and has to be assumed to continue to do so. Assuming less than $30 \%$ of the population can manage to comply with government building standards and limited condominium provision, the majority of Bahir Dar's population is beyond the reach of the formal housing market. In fact, there is a danger of criminalising these informal livelihood practices by implementing slum-upgrading or public housing programmes, especially when housing is not sufficiently accompanied by the provision of social, economic and technical infrastructure as well as spatial arrangements that allow for survival. Thereby, building regulations are instrumentalised to legitimise eviction and destruction on the basis of noncompliance with changed building standards. Meanwhile, the affected local building culture in Bahir Dar is not well documented and there is a lack of description of the population's practices. The Ethiopian building structures resulting from everyday practices rooted in history have more recently been declared slums by international organisations (UN-Habitat 2007: 22), but also by national politics (Ministry of Works and Urban Development 2007: 4). Thereby, the qualities of these areas regarding social structures, subsistence and other factors contributing to sustainability and resilience of the cities' populations are neglected. Instead, the existing structures are legally informalised by a change of building regulations, given notice of the change and made subject to clearance if they cannot comply. There are no upgrading strategies for informal areas or long-settled residents in place.

The success of negotiation for legal status is dependent on the type of building or enterprise that it is negotiated for. Just as in the cases of informally erected settlement structures, the substitution of existing buildings by projects fulfilling new standards of building material, height, density and land use are a recurring planning principle, also exercised in the latest implementation of the IDP. Rendering settlements informal is, therein, limited to sites of poverty while building conforming to understandings of "development" can be legalised. The informal status legitimises state sanction, such as tearing down and resettling. Regulation, here, is undertaken by the sovereign changing the regulations to disregard existing structures for ones that are designed to fulfil new standards of "development". To what extent personal influence plays a role in the negotiations could not be established, but it is a relevant factor, as the individual promise of "development", of being able to override the rules of a plan in the "national interest", is a game-changer. The powerful have mechanisms to legalise their projects against local public interest (such as in the case of construction of the Kuriftu hotel on former public-use land, and 
the construction of the regional parliament in a forest zoning occupied by informal settlers). For fulfilling these promises, however, one needs to promise capitalintense measures. The system offers possibilities of negotiation and bribery to pursue personal interests in questions of urban development. Less wealthy residents, in turn, have no negotiation power. For them, hurdles to enter the formal housing system are unequally higher. Everyday urban structures are, hence, disadvantaged in the planning procedure and, thus, do not hold a strong basis of negotiation for the expansion or future development of the city.

Those affected by planning implementation and dislocation are those not able to comply for economic reasons. Thereby, the resettlement is evaluated differently among the affected. For some it is the chance of accessing a plot for home-ownership or gaining formal resident status, for others it means losing customers or poses an effort of establishment unable to be met due to age or sickness. Beyond that, there are issues with the land offered as compensation: Mixed-use informal and historic structures are compensated with single-use residences, as there is also no "mixed-use" designation in the land-use plans. Planning, therefore, does not consider the relations and dependencies between housing and space for income generation.

\section{Land use}

Formal land administration in Bahir Dar is undertaken in competition with community-regulated practices, as well as being challenged by national intervention. In the absence of state interest in land-use of certain plots, a dominance of de facto rights could prevail. There are practices of urbanisation that do not refer to statutory planning as the regulating institution but rather rely on traditional reference systems to divide the resources, including the sub-division of land. While formal growth is mainly situated in the expansion areas (see chapter 5.5), informal urban growth is not only assumed on the urban fringe but also through densification or crowding into existing structures in the city centre. Reasons that contribute to this lie in the fact that either relatives or contact persons from the rural areas serve as first references when entering the cities, cheap sub-letting is available or land can easily be appropriated. In the sub-cases reviewed, these practices of land distribution were not conducted for profit. So, although there is a system of informal brokerage for other sites which capitalises on the informal subdivision of land (Achamyele Gashu 2014, see chapter 6.1.3), the socio-cultural norms play a big role in a number of locations that can be seen as "enclaves" from the perspective of the city but are actually rather quite dominant Ethiopian settling practices on the national scale. Resulting from this, there are discrepancies between the IDP's proposals and the interests of present (informal) land use. The continuation of these traditionally rooted but constantly reinterpreted family practices led to a coexistence of traditional land holding and constitutional state landownership. At the same time, the implementation of the plan's proposals is subject to a separate set of balancing 
interests. Viewing the results of these procedures, the small scale and poor "informal" is disregarded by formalist planning and put into a disadvantaged position in relation to investment interest of local or even national importance. Informal settling structures such as traditional housing are not considered in the execution of planning and, thus, do not form a basis of negotiation for the expansion or future development of the city. Meanwhile, investors can directly negotiate with the municipality on allocating their project proposals and are treated favourably in the hope of economic gain for the city. Of course such tactical behaviour calls the plan into question, since plots that are required in prime locations can be occupied plots, public space, or nature conservation areas, in which land-use specifications are then overridden. Some of these ventures are, thereby, initially informal, but can rely on their power to change the land-use regulations according to their requirements and, thus, obtain legalisation. This has been done by various hotels on the shoreline or in the case of the building for the regional government (see chapter 5.5). Those informal(ised) structures that do not conform to the government's ideas of the urban, however, are dislocated on the grounds of non-compliance with the standard. This is particularly critical, as it has earlier been described that the building standard is fluctuant and set by the sovereign, by whose legitimisation the land can be cleared and transferred to new land-use proposals. At the time of data collection this applied to a number of buildings in the downtown entertainment district, which were faced with clearance on the grounds of non-compliance with new multi-storey building regulations (see chapter 5.5). There is, therefore, an unequal power situation in the negotiation of access to urban land and land-use issues between the occupants, possible developers and the municipal and national levels of governance. In these constellations, the wealthy have contacts and money to avoid the formal system and find illegal/informal ways of accessing legal plots. Those who cannot comply with the two-year rule of residence before accessing a building plot or do not have the money to construct either have to succumb to insecure rental arrangements or have to build informally and rely on a chance of formalisation (for example by compensation in resettlement schemes).

In mutual contribution, the competing land regulating systems of traditional practice and development through investment limit each other's reach and have led to a temporary dominance of de facto rights in some areas. However, under increased development pressure, government-supported projects eventually gain the upper hand over everyday practices due to the unequal power-relations. Planning law in Bahir Dar, therefore, currently has to be considered to have a consolidating effect regarding the inequalities of land access in favour of the wealthy.

It can currently be observed that urban policy does not clearly correspond to the formation of livelihood strategies connected to the process of urbanisation. The current (informal) development of urban structures, operational and economic practice is often not anticipated. On behalf of the residents, this is resulting in 
avoidance of regulations rather than demanding their stronger enforcement. In these hybrid rationales of urbanisation, the findings show that, in practice, formal and informal cannot be clearly distinguished, as they are based on shifting understandings of what is lawful and are practised by all income groups as well as practices of the state itself. Informality as a sector is, thereby, not suited to conceptualising the modes of moving into the city and culturally dominant forms of urbanisation beyond formal planning. The government's description of informal economic activities needs revision. Instead, principles of agency (formal and informal), thereby, lead to parallel existence of principles of regulation (e.g. housing access, land, and building permits). Just as Jenkins and Eskemose (2011: 14) have described for the land and housing in Maputo, Bahir Dar's physical aspects, but also the negotiation of labour, is undertaken in a "complex hybrid interaction" (ibid) between formal and informal agents and operations. Thereby, the coexistence of formal and informal urbanisation is not only due to differing demands that are provided for but came about due to historical constellations and incidents, as well as a continuing socio-cultural practice. Different informal arrangements are, hence, used to access limited resources more easily. Informal practices can facilitate life in conditions of uncertainty, thus frequently making it socially or economically profitable to disregard law-abidance in questions of urbanisation.

Roy's (2009) observations that legal status is negotiated differently in contexts of poverty and wealth also apply to the situation in Bahir Dar. In this negotiation, legal status does not guarantee an equal attitude on behalf of the state towards structures and practices of the status quo. Urban development producing smallscale informal structures has been in danger of being subsumed under the label of "slum", leaving no space for differentiated analysis of practice and needs assessment related to the solution-finding expressed in such technically low-standard accommodation. Thus, the informal structures in the poverty-prone areas are not ignored but rather required to change at the random convenience of the state. The engagement that the residents have invested in urbanising the space and making it functional for their purposes is, thereby, overturned in favour of competing interests. Meanwhile, socio-economically potent stakeholders are able to negotiate on the legalisation of their practices. Larger investments can, thereby, be declared as in the national interest, while politics and administration itself builds contrary to the plans the urban development divisions have set up. The instruments are, hence, factually not acknowledged when other deals can be struck. So, although the instruments are supposedly universal, planning, in practice, takes differing approaches towards legal status according to the outcome it is negotiating for. The term "informality" is, thereby, used by the regional and municipal planning authorities to stigmatise undesired structures and practices; the formal and informal division is de-facto made along the income divide. The changing building regulations affect the poor who cannot conform to new standards and, therefore, have (involuntarily) distributive character regarding socio-economic segregation. The 
current system of urban development, hence, has the potential to consolidate or further segregation in access to the city.

\subsubsection{Disputed Modernity}

What can be deduced from the literature available is that Bahir Dar's origins, with their implications for today's living, have a history of several centuries. The urban development process is largely evolutionary and continuous. The influential rationales of urbanisation of the phases of urban development have left various layers of material structure in Bahir Dar. Structurally, Bahir Dar, hence, needs to be described as an aggregation of different elements that are partly overwritten, but partly integrated into the present-day appearance in the sense of a palimpsest. It is even possible to identify the neighbourhoods according to their period of construction. Thereby, it integrates elements of exchange with foreign cultures, European understanding of towns and construction on the firm basis of local urbanism. Bahir Dar differs from other "traditional" Amharic cities such as Gondar, for example, in the sense that it was the subject of a major expansion project in the master plan from 1962, which significantly changed the existing core with an infrastructural grid, demanded the substitution of existing tukuls and projected for an industrial economic basis. It is, therefore, perceived as a "modern" or even "new" town in popular understanding, and even in the local population it is falsely assumed that there is an urban history reaching further back.

While the understanding of what is considered "modern" has changed over time, Bahir Dar has since continuously been subjected to restructuring and expansion to maintain its status as "modern". Urban policy frames the issue of urbanisation in a rhetoric of "development" and sees this as a positive expression of progress. Thereby, the idea of "development" is a guiding theme in questions of urban growth, resulting in an agenda for "delivery" of housing units and infrastructure provision. In official narratives, Bahir Dar's urban identity is determined by its function as a seat of administration and distinction of the city's structures from the traditional. Bahir Dar is portrayed as a planned city and known for its grid structure. Industrialisation, still, is a major factor that policies rely on and assume that it is a process that can be politically induced.

Bahir Dar's statutory urban development has formulated a range of development aims it wants to address in the BDIDP (see chapter 5.5). The origins of the guiding principles of Bahir Dar's current urban development are not officially documented but lie in the origin of the planning instruments and are openly complemented by ideas of progress derived from images of Dubai, from China and facilities of consumption from the West. These include fast food chains, shopping centres and leisure facilities. Trying to comply with such imaginaries is, thereby, highly conflictive and leads to controversies on the aims of urban development 
in the face of a large proportion of the population that is struggling with meeting their basic needs.

\section{Urban Design}

Urban design in Bahir Dar is currently focused on avoiding urban sprawl in formal development by aiming to avoid fragmentation. It does not assume responsibility for informal urban construction and is not suited to the actual needs of housing even below the standards of the "low-income" condominiums. It has no in situ upgrading schemes by which density could also be reached in incremental steps but rather tries to substitute what is not considered dense and modern enough by an idea of "the urban" of undefined origin. Even though residents are allocated alternative sites and might be compensated if they are the lawful owners of their houses, and though there are chances for some in the relocation, it is unclear how this claim of poverty alleviating planning is compatible with the priority given to high-level investments and the practice of "slum" clearance-induced displacement.

What can be established from the "travelling plans" having reached Bahir Dar, as well as the ideas that have circulated to the city is that current planning in $\mathrm{Ba}$ hir Dar is grounded in a developmentalist understanding. The development aims have been transferred from a foreign context and universalist planning paradigms. Implementing planning concepts such as the IDP contains an implicit comparison, which in this case is not sufficiently justified by data suggesting a similarity between the context of origin and the context of implementation. Siding of the government with private developers in the hope of economic gain for the larger good further defines new building standards on the basis of new economic possibilities but has to make deals with private investment (in tourism) to fulfil these visions and standards. The offers politics makes are not always attractive. Building commercial structures in the city centre is successful with investors, while the industrial park could not attract enterprises. Therefore, suggestions for projects by the developers are taken on directly. Adjunct to this, aesthetic visions are consulted, by which ideas of modernity are linked to appearance. Dubai is a frequent reference on which stakeholders would like to model Bahir Dar's physical structures. The underlying economic models of the oil business are, thereby, dismissed. Due to the gap between need and "regulating fiction" (s.a., Robinson 2006: 11), these standards are not very useful for progress in the Ethiopian context and run the risk of increasing disparities. They have led the Ethiopian state to set urbanity in the sense of modernism as the standard in its practice of urban expansion.

The modernisation scheme based on political imaginaries forces the residents to leave the area on the grounds of declaring their houses unsuited to the building standard. To reach the standards of urban development set by the modernisation vision, it is dependent on attracting investment and cannot consider upgrading strategies based on existing structures, as these would not be economically powerful enough. This strategy is extremely risky, as the anticipated investment is highly 
volatile and dependent on external factors, leaving it beyond national political control. It relies on foreign investment, imported goods and external expertise as well as making local resources available to outside interests in the hope of economic gain. The question arises of how people are to make a livelihood in the condominiums and other mono-functional designs if the industrial set-up underlying this spatial division of residence and labour does not accompany the planning?

\section{Basic needs}

The current development of urban structures (formal and informal) is often not sufficiently accompanied by provision of social, economic and technical infrastructure or spatial arrangements that allow for survival. The distribution of infrastructure provision, thereby, mirrors uneven socio-economic development in the different neighbourhoods. Thereby, lack of basic infrastructure largely affects the urban livelihoods of low-income households and rural-urban migrants and, therefore, large proportions of the urban population that rely on inconsistent incomes. These parts of the urban population are currently particularly vulnerable to economic instabilities and food insecurity, in addition to sanitary issues caused by lack of access to water and sanitary infrastructure. Bahir Dar's high levels of poverty lead large parts of the population to face issues of food security, health, impermanent shelter, or difficulty in accessing education. Unequal access to basic infrastructure, therefore, furthers social inequality.

Urban planning, thereby, does not acknowledge these issues sufficiently when solutions for "upgrading" are sought. As urban agriculture is promoted and the provision of fallow land is cheap, it is easier to provide than costlier facilities such as clinics, which remain an unresolved issue. Bahir Dar's hospital, hence, is the only public hospital for an area of 1.5 million inhabitants (Mulugeta Tadesse et al. 2006: 32). However, it is not only the physical access to basic infrastructure that proves difficult for certain population groups; access to education, which is widely available in the city and often the reason for moving into its proximity, is difficult to attend on a regular basis if basic needs (food, water, clothes, shelter) are not secured.

While individual proximity to infrastructure is considered progressive in Bahir Dar, by international standards it is considered a basic right. Within the city, there are disparities created by unequal service provision and planning. The provision of infrastructure in the city is not systematic and partly delegated to NGOs (water) and private companies (waste collection). While waste collection and recycling can be viewed as income generating, other basic services are in a fundamentally critical state and create disparities among areas that are serviced and serviceable and those that are not. Sanitation, for example, relies on a tank system and is only available to those who can pay for these installations and services and only in areas that are accessible to the sewage trucks. All other residents resort to the bush, and public urinating has become a major issue. As even the Felege Hiwot 
Hospital only recently started treating its sewage before disposing of it into Lake Tana, the hygienic conditions are dire and have to be expected to worsen in the course of urbanisation, if efforts to improve them are not drastically increased.

In the realm of basic infrastructure provision for the incoming population, many responsibilities are tacitly delegated by the state to the private sphere. The BDIDP thus informally assumes the public will take charge of issues that should actually lie in the public sphere of responsibility (provision of infrastructure, social resources). Yet, the priorities need to be further revised: In the provision of basic services, the tourism sites currently have a high government priority for receiving infrastructure. Meanwhile the inadequate service provision in other areas is used as legitimisation for "slum removal". Those most prone to poverty and in dire living conditions are, further, excluded when their shelters are deemed inadequate. While some profit from resettlement, for others the requirements made by this are too high (e.g. elderly and sick people). The concern for service provision should therefore be reconsidered and addressed by in-situ upgrading instead of resettlement.

Generally, there are mutual influences of planning paradigms, policy aims and everyday practices. The contents of the BDIDP and the administrative practices to realise it as well as governmental practices beyond the plan have very nuanced effects on the reality of everyday practices dependent on the neighbourhood context. At the same time, the practices shape the structures introduced by statutory planning through appropriation and develop the city without regard to the land use designated by the plan. Thereby the high level of conformity that urban planning demands of the urban population stands in contrast to the diversity of biographies and lifestyles that can be found in the city. The conformity that is demanded can often not be lived up to, and so the system makes excuses for exceptions it welcomes, while strongly sanctioning exceptions that it deems irrelevant. As traditional accommodation is considered inferior, informal practices are rendered illegal and practices of foraging are not at all acknowledged institutionally, the plan dismisses these local interpretations of the urban that reach beyond its own definitions of urban livelihoods. Meanwhile, investment-intensive development projects on the lakeshore can be executed by negotiating the plan's terms. And, although planning now has a legal and political base, non-compliance with the plan is not sanctioned and is tolerated for economic gain. The impacts of this negotiation practice on the individual urbanites are substantial, as traditional accommodation is not granted permanent legal status and the resources on which the urban livelihoods depend informally are not considered in the plans for urban development. Since these practices and urban lifestyles that do not conform to the plan's understandings of industrially underpinned urbanity are largely those of the urban poor, it has to be acknowledged that the implementation of the BDIDP systematically jeopardises 
the material livelihoods of the urban majority in favour of what are considered "modern" developments by the administration.

\subsubsection{Understandings of Urbanity}

While statutory planning aims at furthering rural-urban linkages in the sense of attempting to connect rural and urban geographies and economies, urban planning remains largely unaware of the blurred conceptions of rural and urban for which the city is and will stay a melting ground. The administration is strictly divided into rural and urban responsibilities and a lot of effort is put into trying to keep the population in the countryside as well as reshaping the urban economy to suit ideas of urbanity. Infrastructure is meant to make the countryside more attractive, while wholesalers are supported in the re-conceptualising of the market with the aim of replacing the current practice of direct vending by the farmers. This binary understanding of rural and urban as well as the common stereotyping of the farmer as backwards and slow, thereby clashes with realities on the ground. There is an adaptation of subsistence activities to the urban context, blurring the practical distinction between agricultural farmland and urban land use of residence, industry and service. There is a reciprocity and links to the rural areas, reflected in circular, temporary and seasonal migration, etc. Informal land subdivision on the urban fringe and a fleeting population of temporary migrants as well as entangled economies challenge the common understanding of what a city is. The descriptions of urbanisation from the "Western" or European context are insufficient to serve as criteria for the qualification of phenomena and structures we are currently observing in Africa as urban, although they clearly belong to the city. If urban planning is to address and accompany the rapid urbanisation adequately, these knowledge gaps and assumptions need to be overcome. To do so, the question of what the urban is can most coherently be answered by looking through the "rural".

\section{Natural Resources}

The urban development strategy of substituting subsistence strategies based on natural resources by offering space for commercial or industrial projects in the expansion areas is risky and implies a change of livelihood for those currently reliant on this habitat. Natural resources are, hence, a recurring topic of negotiation on various scales. Beginning with the disputes over the use of the Nile water for hydropower or irrigation, which is still the subject of international conflict, the access to natural resources as a livelihood base has become increasingly beset by conflict even on the small scale. Fish, wood, stones, sand and grass are collected and traded in specific locations (the wood harbour) or processed and taken for sale in the neighbourhoods of Bahir Dar. The resources are not systematically administered or monitored, although locally there might be (traditional) responsibilities 
towards their administration. As the population density in the Lake Tana region has risen over the years, traditional livelihoods continue and pressure even on the renewable resources rises. The subsistence gatherers are in increasing competition with the commercial exploitation of the landscape and will not be able to survive without protection. At the same time, contravening interests have arrived in the course of urbanisation in the form of construction. Livelihood strategies based on foraging are outside the scope of taxation. They technically have to be considered informal urban livelihood strategies. So, it happens that widespread practices of foraging and third-party support do not appear in the assumptions of modern and industrially reliant urban development, although they are very contemporary urban lifestyles. Whether they are desirable and to what extent they are sustainable has not been the subject of discussion. Instead, they are dismissed in favour of third-party interests. Thereby, the go-ahead for large-scale developments binds or even destroys natural resources (such as sand, stones, natural habitat, soil, water etc.) to an unspecified amount. It is, hence, not clear to what extent this distribution of scarce resources away from subsistence-based lifestyles aligns with the aim of pro-poor development.

Agriculture as a means of subsistence, shaping the urban area into agricultural land, faces a different situation. Agricultural land use on administratively urban land is found in the villages of the Negede (Wayto) people, whose livelihood is traditionally based on the resources of the Nile, but the insecure and infrequent income situation of the lower income groups also leads to the common practice of urban agriculture. This includes keeping cattle as well as crop activities. The mode of survival is traditionally rural but has become a widespread lifestyle in the city. Being supported as "urban agriculture", this form of land use is allowed to temporarily occupy vacant land and has the support of administrative structures.

Another phenomenon one can observe is the formation of a multitude of collective forms of resource management in the cities. Examples of this are collective saving and insurance groups, which are semi-formal communal institutions, installed for managing livelihood resources (see also Pieterse 2010). In Ethiopia, these are the well-known iqubs and iddirs. Through a joint effort to save or the possibility to take up micro-credits, they provide access to productive assets and employment opportunities. These would have been denied to the individual and are facilitated by the urban socio-economic context in which these assets and opportunities can be easily accessed. These groups are, thereby, also forms of socialisation and, among other things, can be taken as signs of socialisation and social engagement. They act as strong group definitions.

\section{Migration}

The mobile population is a vital part of Bahir Dar's development dynamic. Migrants can be seen as work-seeking daily labourers on the street; they are domestic employees in most established households and form a large proportion of students 
in the city's educational facilities. Although the young are the most visible on the streets and the building sites, the interview material shows that coming to the city is a cross-generational phenomenon. The possibility of entering the city through pre-arranged work and housing or marriage and, thus, joining existing households might have obscured the fact in the common account, as it reduces the visibility of older migrants. Major differences can be established between urban visits, multilocal set-ups and permanent residence. While some residents do take permanent migration decisions, others choose multi-locational set-ups or come into the city temporarily.

The temporary residents come to achieve educational aspirations, follow paths of emancipation from traditional societal roles and pursue personal development. Although the motives of those residents coming for a period of time - whether it is clearly timed or an indefinite limitation - differ strongly. All the "visitors" have in common that their attempts and efforts at interacting with the wider urban community are comparatively low. Ties to other areas are, therefore, maintained, either through contact to the home area or through contact to peers and friends from the home area. Overall, the actions undertaken within these rationales are not generally individualistic but rather aided or enabled by the family and, if successful, result in shared benefits for the family. The family, thereby, often negotiates the stay. This mobility is then embedded in a social structure that actively or passively supports the personal allocation decisions within the suggested frame of time and place.

Urban visits can be the result of multi-local strategies that do not have their base in Bahir Dar and are, therefore, just a temporary stay with no intention of returning regularly or at a given point in time. So, while from the perspective of urban policy these are temporary stays, from the perspective of migration patterns, some can also be considered part of multi-local strategies. The multi-local set-ups encountered in Bahir Dar are extremely diverse. Meant is not a biography of movement but the simultaneous maintenance of various households by an individual or a group. Just as there are students who come to Bahir Dar temporarily for the duration of their course, young people from Bahir Dar move between locations to complete degrees with frequent visits home and the intention to return or to move on after the three, four or five years that the course takes. On the other hand, there are multi-local strategies that are possible to maintain, due to proximity. Bahir Dar can conveniently be reached from the regions surrounding Lake Tana as well as those located along the asphalt roads from Gondar and Addis Ababa. Although high schools can now also be found in many of these areas, Bahir Dar still offers opportunities in trade and employment, access to services and infrastructure (electricity, telephone, internet, banking, transport) and various types of education and qualification that suggest frequent stays to those wanting a share without leaving other commitments behind. The third aspect is that of commitments in the city that cannot be ignored while employment is found elsewhere. 
This reverse situation of finding qualified work in the countryside is largely due to government development programmes for which technically qualified personnel is greatly sought. As the engagements are temporary, it does not make sense for these contractors to shift their sites of residence to their work location, and so they choose to commute on a daily, weekly or monthly basis instead. However, multilocal does not only mean coming from the countryside and moving into the city but also staying on real estate in the city and seeking jobs wherever they are offered in the surrounding area - including working on site in government measures in the countryside.

Nevertheless, there are newcomers who make a final decision to move to the city and choose this as their only and long-term home base. They have taken up permanent residence. Some of those stating that they have no other plan than to stay in Bahir Dar did so out of lack of lack of other opportunity, while for some it is a conscious decision to stay in the city. Some permanent residents have come due to breaks in their previous lives. Since returning to these set-ups is impossible (due to war, divorce, disputes, famine), the city is a refuge. Beyond that, those definitely staying in Bahir Dar named factors for wanting to stay in town mainly as socio-economic dependencies such as house ownership, family ties, professional networks, support of kin, family bonds and marriage but also advantages of the location through income opportunities, better living conditions than elsewhere, qualified employment, possibilities of asset building, etc. It has to be assumed that, as with the other statuses, the answers given on wanting to stay permanently are linked to the current living conditions the interviewees encountered in Bahir Dar. Despite committing themselves in their answers, most of the interviewees had witnessed a lot of structural changes in their lifetimes which affected them to varying degrees. It, therefore, has to be assumed that they are all aware of the rather large uncertainties the current urbanisation developments entail and that they are living under. Investing in housing and other forms of asset building is hence a bet on a stable future in Bahir Dar that will return the investments in cash or use value. Expressing the explicit wish to stay, therefore, can be seen as the optimistic expression that urban development will continue to take a good course for the urbanites personally.

Thereby, population movement into the city cannot be understood as a passing phenomenon. Participating in the country's economic rise means going to the city. Yet, the findings suggest that migration patterns are circular or include movement to and fro. Place-making activities (initially) rely on family structures for support and can seldomly be described as emancipative strategies, as urbanisation in Western contexts occasionally is. They rather follow optimisation decisions for the extended family. Hence, besides the diversification of income strategies within households, individual and household multi-locality is observed. These biographies of temporary stays need further investigation, as do the household structures resulting from these patterns of movement. However, by transcending the 
geographies of rural and urban on a frequent basis, the boundaries of the city and the concept of an "urbanite" are called into question. In the actions of trade, education, seasonal work, etc., behind these movements, social positions are renegotiated without reference to tradition, and resources are re-spatialised by remittances or investment in locations other than the place of income generation, as the labour force finds new and dynamic concentrations.

To date, movement has not been included in the planning conceptualisations of the urban. Thereby, moving for economic, social or educational reasons has to be subsumed under this assumption. While the administration does acknowledge a population influx, it has no further data on the quality or intensity of patterns of movement. Faced with this, the regional political line is to try to keep the population from the rural areas in place and minimise push-factors such as bad living conditions in the rural countryside as factors resulting in rural-urban migration and urban growth. These efforts are rather unsuccessful, as there is currently no promise beyond subsistence in the rural areas. In addition to the restrictions on establishing a substantive livelihood in the rural areas, the city offers prospects of alternative lifestyles and proximity to infrastructures - both considered modern and, therefore, desirable. The motives for coming to the city and also the opportunities taken up are very heterogeneous - they are somewhat diffuse in their formulation as aspirations. Moving into the city is equated with "development" in a personal and cultural sense. Thereby, informally created opportunity as a major factor for securing a livelihood needs recognition. The mix of infrastructure (internet communications), concentration of people, resource accumulation is specific to the city in relation to the rural. These opportunities offered by the city are taken up without pre-knowledge, as they are impossible to anticipate without formal education. All other learning and even the certificates strongly depend on circumstance. Hence, the opportunities actually taken are not restricted to opportunities given in formal employment on arrival but rather widely diverse in the range of finding incomes and subsistence strategies. These individual rationales might not be strategic, due to the high uncertainty of environmental and economic set-ups, but, being based on chance and opportunity, they are highly tactical in aiming for improved living conditions for the person concerned and often also for household or family members. Thus, although land is rare, migration can only seldom be understood as a forced move from the countryside, supposedly grounded in land deprivation of the young.

Unlike the students arriving in Bahir Dar, however, who are fully accommodated, there is no official reception structure for rural-urban migrants. The young migrants coming to the city to engage in wage labour question the rural-urban dichotomy by forming a category of urban residents that does not fully suit the implications of urban "development". Currently, the influx of daily labourers to Bahir Dar is strongly supported by labour opportunities in the construction industry. They are often young people from the rural areas arriving as migrants in the city, 
but due to lack of education they do not have the access to what is associated with the modern and the "developed". Instead, they form the workforce to put in place the structures and secure these items and services for the "middle class" and businesses in a rather exploitative relationship. An increasing socio-economic segregation between socially or economically advantaged urban residents and labouring arrivals becomes evident. Residents arriving outside of education programmes can only access rental housing or buy (on a very dense market), since the land distribution system only allows entry after two years of waiting. In addition to the fact that immediate reception structures for arrivals other than state university students are not in place, it has to be assumed that large parts of the incoming population cannot meet the requirements for entering the land distribution system set by the statutes. Many low-income migrants, therefore, find accommodation in informal hostels, adding overcrowding to the already precarious living situations.

However, the act of moving to the city has implications beyond this, as a gender-specific review reveals. A move to the city also entails personal development. Conflict in the area of origin as a reason for coming to the city is particularly important from a gender perspective, as it can explain some of the contingencies of female migration as well as the phenomenon of street children in the city. While the family network might not be broken, the city still holds roles and identities that migrants can take on only here and not in their immediate family networks. As the examples of prostitution and street children show, these are, however, not always positively connoted socially. So while the modes of entry into the city can vary according to sex, the role that the city takes on in turn, can nevertheless be interpreted as that of a refuge from expulsion from traditional living arrangements. For many of the female migrants, making a living in the city either involves going into exploitative domestic work or becoming one of the many sex workers in Bahir Dar (Bevan et al. 2008: 51). These alternative identities are often accommodated informally.

Although we are seeing the passage from a predominantly rural society to an urban society on the national scale, the distinctions between the two concepts on the city scale are not clear cut. Models of transgression from rural to urban lifestyles are not linear. According to these results, urban areas accommodate a large diversity of livelihoods but also impact on the rural households engaging in exchange (see Abeje Berhanu 2012: 62). A distinction between rural and urban is not clearly possible in the cases of seasonal migrants, in the practice of urban agriculture, in the use of the city's markets for the trade of rural produce and offering of agricultural supply. Although there are purely "urban" lifestyles, many urban residents maintain "rural" modes of income generation or social and cultural connections. The description of the recurring presence of migrants from the rural areas is an empirical proof of the strong rural-urban connections but, at the same time, challenges the distinctiveness of the two concepts. It shows that, here, a clear divide 
of the population into rural and urban is not possible, as the individuals making up the population of both areas are at least partly and temporarily identical. This "urbanity of movement" (Simone 2011) that Bahir Dar is experiencing counters the duality of rural and urban. This research shows that developments in rural and urban areas in Ethiopia are highly connected, as internal migration from the rural areas to the urban centres determines the population growth and spatial development of the urban areas. In this realm, practices and lifestyles undergo a spatial transition and form hybrids. This means that the urbanites do not simply seek ways to survive in the city. Although coping strategies can be found and make up a substantial part of the lifestyles encountered in Bahir Dar, the multi-locational lifestyles and temporary nature of the stays and mobility of the population suggest that, in the sense of manoeuvring, they are playing the city and have a much more active role in using it in their own interests to diversify the livelihoods of their households and grasp formal and informal qualification opportunities than generally assumed in the descriptions of "urbanisation under poverty". Here, opportunities are provided by concentration of infrastructure and social resources, rather than policy intervention. The most obvious examples of these transcending agencies would include subsistence and traditional practices that consequently have to be understood not as rural practices in the city but rather as site-specific urban practices. Looking at these examples, it is evident that a conventional distinction of rural and urban is hardly applicable. Yet, the social concepts of rural and urban can be interpreted through each other. From the perspective of a rural pastoral lifestyle, urban gardening is truly urban. Beyond that, there are interconnections between the divided. Consequently, what makes up the "urban" in Bahir Dar does not necessarily suit existing conceptions of a city but rather develops as locally contingent urbanities. Yet the formation of urban/rural cultures and livelihoods in a socio-cultural sense is overlooked as a factor in shaping the physical structure of the city and its urban practice. Everyday urbanisation, de facto, does hold claims on urban natural resources, which are the basis of urban livelihoods, but this is institutionally not acknowledged. They first have to be described in order to be able to be acknowledged as such and need to be judged by their context of development. Against this, reliance on the formal economy and with it increasing formal reglementation and governmental standards will limit the possibilities of livelihood diversity in the city.

The socio-cultural transformation, thereby, has reached an extent where its requirement for space and resources has brought it into conflict with competing rural lifestyles, especially on the urban fringe. Nigussie Haregeweyn et al. (2012: 150) describe the urban expansion as posing serious threats to the livelihoods of smallscale farmers on the urban fringe, who earn their living by farming the productive agricultural lands under urbanisation pressure (see also chapter 5.5). While the administrative boundaries mark a clear boundary of responsibility between institutions, the physical determination of what belongs to the city and what does not 
is questioned by the practice of informal sub-division on the urban fringe. While some farmers' existence is threatened by urban expansion and the process is not seen as desirable, other actors display agency in using the developments to create new (informal) forms of market access and personal gain. Urbanisation, hence displays a range of survival strategies that are "in-betweens" of rural or urban, but coexist or even depend on each other and make Bahir Dar as a city.

\subsubsection{Questions of Citizenship}

In the course of implementing the IDP, first trials are being made with public participation. As a result, the mutual support of planning institutions and everyday practices is being discussed in the public realm for the first time. Thereby, the question of who is considered a stakeholder and can therefore exercise citizen rights is in need of closer inspection (as described in chapter 7.2.3.). The societal roles are changing within urbanisation and positions of power formerly defined by religion, ethnicity, gender, family and rural or urban origin will be renegotiated in urban society connected to the global. Urbanisation is, hence, seeing new forms of agency and the formation of new urban identities that are an emancipation from traditional role models. In connection with an increasingly large fleeting population, the question has to be posed as to how the different (emerging) social groups can negotiate their interest by participating in urban development.

\section{Access to information}

Beyond traditional understandings of infrastructure, the younger generation pointed out a desire to live in the city, due to the access to information they can gain here. Thereby they do not only refer to the possibilities of education, but rather access to the internet and other communication services. Here, a shift from access to information is visible. While the older generation still relies on oral traditions of knowledge transfer, administration is engaged in party controlled systems of data collection (Gagliardone 2014), the younger generation aims at engaging in a global network of information exchange. Thereby, the exchange of opinion is politically monitored (ibid), leading the state to be in the role of the facilitator but also of the restricting body at the same time (cf. Watson 2002: 36-37). Mobile phone services are uniquely in state hands, contents of the internet (such as search engine results) are filtered and services such as skype were not legal for the longer period of time. Unmonitored forums for the change of critical opinion are, therefore, established outside of state control. They are organised by the diaspora to evade the controlled networks, or have clandestine communication structures and media.

\section{Diversity}

Society in Bahir Dar is made up of a variety of ethnicities, religions and origins as well as hosting different genders. Family structures and the people of the same 
regional origin form loose groups of support within the city. Thereby, not all of the socialities are declared to be in line with local tradition. In Bahir Dar, Amhara culture is dominant, and there are hierarchical conceptions of citizenship based on Amhara ethnicity, Orthodox religion, male gender and urban origin. The patterns are reflected in the spatial set-up of the city. Although their political significance has shrunk to personal influence, the Orthodox Church is recognised as a powerful institution. It is no longer the sole organising element of the city structure and has to comply with the plan, but it has influence on the population and still attracts large numbers of scholars to its grounds. The Muslim community is well established but concentrated in the city centre and around Kebele 13. The Wayto have not been assigned permanent sites of settlement and are segregated from other population groups. The access to land for the Negede (Wayto) population is described as highly contested: The accessible land is either not suitable for permanent construction, as it floods annually, or settlers are in competition with "big people" who can pay the government beyond their own financial capacities. The community does not hold land titles and has to move its huts at the request of the government. Meanwhile, ritual places are contested by other uses and, due to the group's weak position in negotiation, many of them have been claimed and expropriated by others. Their communities are, therefore, in constant expectation of being given notice to leave the land. They have already been displaced several times, which puts them in the position of having to migrate around the urban area of Bahir Dar and leaves them in a precarious and highly vulnerable situation (Ajala 2008: 27, Darmon 2010: 2, Oestigaard 2011: 27) and marginalised. Like the Wayto, rural urban migrants, females and Protestants face frequent discrimination. Labour is still very related to gender roles and accessing the city thereby differs for men and for women, which becomes especially clear at the arrival points at the bus station in the city centre. As domestic work and sex-labour are distinctly female occupations, these are opportunities uneducated females can access on arriving in town. The situation awaiting the unaccompanied women in the city is not protective. Female construction workers coming into the city from the surrounding rural areas, for example, are about four times more likely to engage in risky sexual practices than their male counterparts (Mekibib et al. 2013: 299), and female respondents in a study on street children in Bahir Dar said they had been victims of sexual harassment (Amare Sahile and Sinkinesh Takleargay 2008: 77). As a result of their social situation, the female in-migrants face vulnerability.

The understandings of dominance underlying these occurrences are still strong in the older population, while the younger generations are starting to question them. They have stated "a desire not to be defined by difference". Despite modernisation within Amhara urban society, attempts to extend the urban mix of societies mix beyond a cohabitation with Muslims to a blend of cultures with Wayto and Protestants as well is not represented in the rationales of everyday urbanisation. In this respect, planning is far more considerate than ordinary attitudes. The IDP 
is attempting to counter discrimination based on ethnicities or religion. However, the idea behind this attempt is not solely explained by a wish for peaceful cohabitation, but by the fact that politics is trying to expand its reach in urban areas and increase their governability. In the face of the overwhelming movements and societal transformation evident in the cities as a result of the course of urbanisation, governance is causing substantial problems due to limited capacities and struggles over limited resources. By expanding the area of formalised planning and subjecting urban development to its rules, the state is also seeking to establish its own legitimisation. The suggestion it makes is that, by conforming to state-led development, personal improvement can lead the way out of poverty, for example by entering the state's higher education system. Thereby, the current urban identities newly shaping in the course of urbanisation have not been explored and are hardly anticipated. The current policies still seek to improve understanding between cultures without knowledge of how digitalisation and globalisation will change the citizen's self-understanding. Lifestyles will diversify in the urbanisation process.

Based on this, urbanisation is seeing new forms of agency. Waiting for a green card in the lottery or signing up for domestic work in the United Arab Emirates are, thereby, high-risk strategies in comparison to entering higher education but nevertheless highly popular among the younger population. Urban-rural and modern-traditional clashes can cause individuals to take on a variety of identities to suit different expectations. Moving to the city facilitates taking on roles outside of traditional gender stereotypes, as economic independence is accessible for more women. However, the new roles bring new power issues. In connection with an increasingly large fleeting population, it must be asked how participation in urban development will be exercised in the future.

Social roles are being invented, while a new urban society is being negotiated. Yet, the urban planning mechanisms in place have the potential to increase economic and spatial segregation within Bahir Dar, between what is in danger of being viewed as "deserving and undeserving citizens". However, the reasoning behind the assumptions of how "urbanites" should be defined and rewarded by the system is driven by the question of governability. Thereby, the failure to gain relevance for these lifestyles is interpreted as a "governance void" on behalf of the administration, over which urban planning is still waiting to expand its reach and hence secure power. The question of who defines an urbanite, therefore, has fundamental power implications. Public discussion of this question needs to be encouraged against the current practice of censorship and intimidation. 



\section{Towards a Situated Agenda}

In the context of overall population growth and a shifting proportion of population from the rural areas to the urban, various rationales of urban development, including "everyday" construction and appropriation practices, have to be seen as constitutive of urbanisation. While urbanisation strategies conforming with the state-led agenda for urban development have received considerable support and attention, everyday practices of Bahir Dar's urbanisation so far fell short of attention and are hardly considered by measures accompanying urbanisation. Accordingly, this chapter discusses the empirical findings from the case study on Bahir Dar to explore how the local contingencies found in the sub-cases can contribute to an informative basis for situated urban development (see chapter 2.2.). Dealing with the processes, needs and impacts of urbanisation means considering everyday practices as well as furthering and improving institutional approaches. Based on the description of Bahir Dar's “idiom of urbanisation”, this chapter questions whether the universal aims underlying the state-led development agenda (see chapter 5), not only in Bahir Dar, but for all Ethiopian cities can sufficiently address locally specific needs in the context of urbanisation. As the findings of this research suggest that current development bears the danger of furthering segregation (see chapter 7), this chapter argues for adopting an inclusive approach to urban development in Bahir Dar.

\subsection{BAHIR DAR'S IDIOM OF URBANISATION}

The account of Bahir Dar's urbanisation presented here is a flexible narrative, which can be amended and re-written based on new insights. Discussed against Roy's "idiom of urbanisation" (see Roy 2009 and chapter 2.2) it can be expanded and revised. Urbanisation is therein the term used to describe institutional or individual rationales that encompass formal and informal activities of city building on various materials, social, economic and cultural levels. While the formal/ informal dialectic can be considered key-features of the rationales of urbanisation in Bahir Dar, the account has been expanded to include modernity, urbanity and 
citizenship as further spheres of negotiation within and among planning and everyday urbanisation (see chapter 7.2). Bahir Dar's urbanisation, hence, has multiple rationales, which reflects in the variety of structures and urbanisms found in the town today.

After the parallel development of a market town, monastic life and the Woyto villages in today's location of Bahir Dar, key elements in the urbanisation process for the city can be identified from the establishment of urban administration and selected basic infrastructure by the Italians (see chapter 5.2). Following this, the installation of the textile mill through a reparations payment and the plans for the development of a hydropower centre on the basis of Guther's Master plan triggered large-scale land speculation and a wave of settlement (see chapter 5.3). Thereby, the determinations of the plan are reflected in today's basic layout of the city, although its proposals regarding infrastructure services such as sewerage and exact road patterns were not implemented. The modernist vision on architecture was not able to substantially re-shape local incremental building practices, as many endured during the establishment of the modern city and have continuities until today. Population influx to Bahir Dar continued over the decades. Based on informal land claims and informal or traditional building practice the city grew beyond the intentions of the formal plans. Therein rural-urban migration is only one of various factors of urban growth, filtering into those neighbourhoods with a high permeability. The findings from the city centre (see chapter 7.1.1) and the university (see chapter 7.1.4) thereby suggest that there are strong inequalities among population groups entering Bahir Dar, regarding the assistance and, thus, the opportunities they encounter in the city. Thereby, for many of those not tended to by institutional structures, informal opportunities act as a means of gaining (an irregular) income in Bahir Dar. The city offers easily accessible opportunities and chances arising from density and interaction as well as jobs in the micro-economy. Smallscale building in traditional styles and taking low-level economic opportunities represent common ways of urbanisation that have not sufficiently been accounted for in their own right. Therein, securing subsistence levels and family assets recur as a narrative for living in the city in the urban village and downtown. Living here offers better opportunities than available in the countryside, and in contrast to the formal requirements for access to housing, settling here was easily possible. Urbanisation in Bahir Dar is thus not unplanned, but is in large parts not planned by state authority.

Today, the state-lead urban development agenda with implementation agency through the Regional Urban Planning Institute stands alongside a spectrum of everyday practices of urbanisation, which differed degrees of acknowledgement in urban policy and planning practice. Thereby, urbanisation is made up of professional urban planning activities and everyday practices of the population, in which urban growth and transformation as "urban development" are part of a larger urbanisation process. These, however, are not conducted randomly in an eclectic mix 
of practices, but can rather be described as a combination of planning and everyday rationales of urbanisation that include both tactical elements and forecasting practices. Thereby, the relation of statutory planning and everyday practices and their role in accessing and administering urban resources is a central subject constituting the production of urban structures. Within this, it is acknowledged that administration, politics as well as entrepreneurs are engaged in a mix of formal and informal activities constituting urbanity and are therefore agents of urbanisation.

Overall, the state-city relations in urbanisation vary from neighbourhood to neighbourhood, as their development can be connected to specific circumstances of context according to when they developed in (see chapter 7.1). The discussion of the neighbourhood's spatial structures generated through planning or informal building has to be reviewed in relation to the historical background against which they were created. From the sub-case studies, each site had a very distinct set-up and consequently four different neighbourhood typologies could be identified. The historical mixed-use, the residential area, the urban village and the learning compound thereby expand the typologies of condominium housing, expansion areas, commercial development and industrial areas, legitimised by current planning policies. In these areas the co-actors of everyday urbanisation are distinct according to location (see chapter 6.2) and span from residents, via investors (including ex-pats and those sending remittances), to state institutions (such as the university) and traditional systems of elders. These actors mostly pursue highly individual motives of engaging in/with the urban environment, while each of the neighbourhood had certain rationales of urbanisation that have to be considered typical for the site. The everyday rationales of urbanisation in Bahir Dar vary in scale and quality, as well as materiality and purpose. The investigations prove the dynamic of urbanisation to be far more entangled and multi-directional than the currently still dominant narrative on transition from rural to urban suggests. Within Bahir Dar's “idiom of urbanisation” (see chapter 2.3), urban planning and everyday urbanisation in Bahir Dar cannot conceptually be separated, they have to be viewed as part of a larger institutional ecology involved in urbanisation, which produces parallel orders, leaps and has fallbacks. However, also power relations between statutory planning and everyday practices vary between the locations. As the development of Bahir Dar's neighbourhoods is path-dependent, the relations between urban planning and everyday urbanisation lead to differing actor constellations concerning urbanisation in the four sub-case areas. Rationales of planning and everyday urbanisation are generally competing against and among each other. Prevailing practices from both fields can, hence, be considered equal rationales, but vary their relation and dominance according to local neighbourhood.

Consequently, in this situation of competition, not all practices of urbanisation can be considered equally favoured in the realm of urban development. Across all four sub-case sites it could be observed that rationales of everyday urbanisation conforming to the urban policy's notion of "modernity" are supported by current 
policy, while especially incremental strategies of urbanisation are vulnerable to displacement in the ongoing re-construction of the town (see chapter 7.2). Distinct types of urbanism, such as seen in the city centre and in the village like sub-case, are marginalised. Herein, the concepts of formality and informality defining the everyday activities in the micro-economy and in incremental building are blurred, subject to temporary interpretation and strongly linked to short-term advantages in practice regimes.

This stands in contrast to the official normative of the "developed city", for which the ethics underlying the principle can be named as organizing the urban through infrastructure, ubiquitous and standardized services, passive consumers, sovereign power, and equal accessibility of land. The increased statutory planning activities following the decentralisation of spatial planning responsibilities to the regional level and the set-up of an urban policy by the EPRDF are intended to order the existing urban structures according to developmental aims formulated in the PASDEP (Ministry of Works and Urban Development 2007). Thereby, actors of state-led planning now include the Regional Urban Planning Institute, the sectoral planning offices, the municipality of Bahir Dar, the rural planning authorities, regional government, national government and the National Urban Planning Institute, but also institutions such as the churches, Bahir Dar University, local economy and industry.

The BDIDP has been introduced into a situation in which urban planning administration has a relatively recent tradition. Responsibility for the formulation of standards in urban policy is still in the process of decentralisation and the responsibilities for spatial planning are distributed across different administrative levels (national, regional and municipal), while at the same time a strong competition in spatial planning can be observed across the sectoral institutions. The regional planning institutions, such as the RUPI in Bahir Dar have the mandate to set up the plans, but do not have sovereignty over the other sectoral offices and cannot oblige them to align their plans. Meanwhile the implementation of the IDP actually requires functional sectoral planning in order for it to be integrated on a higher spatial and administrative level. The parallel development of both has to be considered very challenging and opens opportunities for alternative modes of negotiation. Hence, administration and politics have set up the IDP to co-ordinate and negotiate a variety of interest, but de-facto follow differing interests on differing scales of planning.

In the context of Bahir Dar's rapid urbanisation, tactical approaches are dominant and informality is more commonly redefined and utilised as a tool of intervention, also by state institutions. Especially on sites facing high development pressure and unclear planning specifications, such as the lakeshore, politics and investment are engaged in practices of situated administration of resources in formal or informal manners. With the political priorities on development through tourism, investors in this sector can approach administration directly and are fa- 
voured in access to resources, including land and infrastructure provision. Low and middle-income residents are displaced to the less central and accessible locations on the outskirts on the grounds of such evasive negotiations (Ajala 2008; Achamyele Gashu 2014). Thereby the negotiation practice differs from the proposals of public negotiation in the IDP (Interview Gorgens 2013), just as Jenkins and Eskemose suggest with their concept of "Realpraxis" (Jenkins and Eskemose 2011: 14). There are few tools for civil decision-making in place and participation and hence transparent decision-making is still easily excluded from the planning procedures. Consequences against such practice are not to be expected, as the IDP is not legally binding, there are no sanctions in place in case of infringement.

Not all types of development project enjoy such legitimisation. While local authorities in Bahir Dar now refer to traditional, spontaneous or dilapidated structures as "informal", federal organisations continue to label these as "slums" (see chapter 1). By doing so, this analytical stance emphasises difference between desired developments and non-conforming structures. Currently the municipality itself treats Kebele housing structures in the city centre as undesired, labels them as hazardous living conditions and does not engage in improving working conditions. Instead the city prioritises the establishment of formal structures and legitimises the spatial and social marginalisation of incremental building and smallscale economics. Current urban planning is also not inclusive towards informal urbanisation based on social norms and regulations of tradition. Many of the lowincome urbanities are displaced in the name of development.

Many of the low-income neighbourhood structures and practices could also be viewed as traditional building or municipal housing, but lack resources to negotiate such formalisation. The current generalist planning principles, but also the investment practices evading community interests hence implicitly promotes tendencies of economical segregation in the development of Bahir Dar.

However, since the arrival of Italian occupation and the subsequent introduction of generalist planning ideals to further development under Emperor Haile Selassie, in which tradition the current government's idea of the "developed" city also stands, the understanding of "good urban development" is not rooted in the same cultural context for the variety of actors and (mundane) planners involved. The modernist developmental normative of the IDP is reflected in the underlying patterns of land-use planning and relies on ideas of divided functionalities of residential and commercial zones. The urban layout is functionalist and the zoning assumes separate commercial and housing zones. By land-use definition in the BDIDP, the commercial development has the backing of administration to overrule existing mixed-use structures in the city centre and expand onto already otherwise occupied land. The line defining a right to dwell in the city is thereby not so much down to compliance with the law, but rather to compliance with political ideas of modernity and the socio-economic capital to be able to negotiate these requirements. Here everyday practice has hence not been recognised by institutional 
planning and is subject to being overruled on the claim of being illegitimate. The administration and politics are thereby leaving the question open of how to gain a livelihood in the condominiums if the industrial set-up underlying this spatial division of residence and labour does not materialise according to the state-directed economy. The empirical planning material on this issue suggests. however, that statutory planning, investors, entrepreneurs and civilians as well as representatives of international donor organisations are socialised to such distinct understandings of what "good" service provision and urban structure should look like. In current urban development, tools for incremental development and in-situ-upgrading of existing structures have been disregarded in anticipation of industrialisation and on the grounds of housing provision through the state with the national condominium housing programme. The judgements made on requirements of urban development and structural investment are universalist and measure all infrastructure provision, building typologies and land-use specifications to a defined standard.

However, the developmentalist stance on urban development has risks. The anticipated investment in the industrial zones has not been modelled on realistic figures. Based on forecasting the expansion areas and industrial zone were developed, where industrial growth and housing demand were anticipated by the statutory plans - yet have not properly met the actual requirements of investors, nor of local residents.

\subsection{Implications for URban DeVElopment}

In Bahir Dar regulations on urban development construct state legitimacy in the field of urbanisation. It is expressed in the delegation of planning responsibility to the Regional Urban Planning Institute, the choice of the IDP as an instrument of zoning and guiding development, the regular re-definition of building standards, as well as surveys in cooperation with international NGOs and developmental corporations.

Thereby current urban policy does not distinguish between different contexts of planning but rather supplies standardised development aims, focused on the condominium houses, centrally monitored infrastructure delivery, and commercial development in the city centres. State-lead urban development and the technological impetus regarding the underlying principles of the IDP remain publicly undisclosed and, hence, undisputed. Policy documents remain vague on the fact how planners assume that their values of the "developed" city as presented in the PASDEP (Ministry of Works and Urban Development 2007) prove better than that of other planning ethics. The public professional discourse is, thereby, inhibited by restrictive media policies and sanctions against publicly voicing critical opinions. The transfers of planning ideas into urban policies is, consequently, not perpetually questioned and updated in confrontation with existing practices of urbanisa- 
tion. Meanwhile, the findings of this thesis suggest that ideals of the "developed" city actually do not prove better in improving living conditions than more relational principles, of what Jenkins and Eskemose (2011: 14) call "Realpraxis", in which the interplay of formal and informal actions shapes an operational system (see chapter 2.2). Living situations in the urbanising context can, hence, be improved by providing a specified set of planning tools and practical interventions to address the basic needs in the specific neighbourhood set-ups of Ethiopian towns and Bahir Dar, specifically.

As the governmental urban policy suggests, the urban context encountered in fieldwork in Bahir Dar is clearly in need of improving living conditions for many of the urban dwellers and the anticipated population growth. However, the different relations between planning and everyday urbanisation leave certain population groups in disadvantaged positions of negotiation (as described in chapter 8.1) that need to be overcome in order to prevent segregation. New arrivals with low education levels are not considered in current urban planning and access to house ownership and condominiums is only granted after two years of residence. On the basis of the findings, it further has to be assumed that new forms of identities will shape through globalisation, digitalisation and urbanisation in Bahir Dar, which have currently not been considered in planning typologies and whose needs are not possible to anticipate without dialogue with those representing these new interests. These recursive practices need to be part of the conceptual accounts.

Overall, it seems that the current aims of urban policy are focused in such a way that it does not suit the scale and priority of intervention necessary to improve living conditions in for many of the residents in the existing residential areas. Especially the low-income population needs strategies to accompany the ongoing changes through urbanisation beyond plans that respond to their living situation by re-settlement or eviction. While there is a practical share of everyday urbanisation in urban development in the form of formal development and investment and active participation in the redistribution of urban resources, small-scale ordinary practices have to enter the planning conceptualisation in order to prevent a displacement of these largely self-reliant structures and practices. The findings of this research should, therefore, feed into a policy that moves away from the assumption that non-governmental organisations systematically contest state governance and rather works towards a synergetic constellation, in which governmental policy is strengthened by agency. According to Meagher, an important condition for this is that the informal actors control strategic resources and can link these to higher decision-making levels in the economy and the state (Meagher 2011: 68-69). The recurring dualities in conceptualising urbanisation hence need to be dissolved in order to develop practice strategies to deal with highly tactical and flexible rationales. Bahir Dar - as all Ethiopian cities - faces the particular challenge of having to provide these without a stable tax base. Due to tight resources, projects are not strategically coordinated, but administration is on call and acts on third party in- 
itiative or urgency. Under these conditions, an integrated view of urbanisation as being constituted by planning as well as everyday practices seems vital, as administration will not be able to manage the challenges arising in rapid urbanisation without cooperation. It needs to be widely accepted that the actors of everyday practices of urbanisation can take on responsibilities that are relevant for the future of the city. Planning directed by the sovereign can, therein, create synergies with a broad spectrum of popular rationales and needs. Statutory planning can, meanwhile, take a co-ordinating role and is considered vital in the process of urban development due to its political mandate to implement.

The above in mind, looking at Bahir Dar's particular "idiom of urbanisation" (see 8.1.), it needs to be asked what sense the strategic emphasis of the IDP on avoiding fragmentation and prioritising tourist sites make in a rapidly urbanising city with the given diversity of urbanisation rationales. Instead, informal, traditional and vernacular types of urbanisation need to be demystified, by specifying the ordinary and included in development strategies. Just as they have done in the past, the small-scale structures will have to cater for a large proportion of housing in the present and near future, and the scarce resources will have to be administered through community channels. The accounts of "everyday urbanisation" that encompass informal, traditional, agricultural and clan-related elements need to be evaluated alongside the economic criteria for land-use decisions and strategy formulation in the multiple levels of urban development. The small-scale structures need to be acknowledged as the origin of the historical neighbourhoods, arrival sites for low-income settlers and placed in the heart of urban development strategies. To do so, it is suggested to develop practical initiatives to address an amplified range of issues related to urbanisation. Thereby, a shift away from generalistic norms to a pluralistic set of projects developed from local contexts is advised. Urban development strategies need to overcome the focus on standardised housing and commercial development to open it for relational suggestions that need to be negotiated with an amplified range of local stakeholders.

In order to improve living-conditions in the diverse neighbourhood contexts, the urban development strategies to be formulated need to refocus away from overall aims and provide contextualised strategies for the local situation. The effects of general urbanisation are local and need to be addressed locally to consider upgrades of living conditions and capacities available for implementation. Acknowledging the common practice of negotiation in questions of urban development, the role of third party interests, such as those of the donors and investors, needs to be discussed far more critically for the outcome of spatial structures. In order to asses these interests, they will have to be set against a thorough development agenda that needs to exceed the current content of the BDIDP regarding development patterns, as well as the diversity in building typologies regarded as desirable in urban development. The development agenda should be based on wide public participation and decision-making. The empirical findings from this case study dis- 
play that a desire to participate in "development" is inherent in everyday strategies. However, it is currently assumed that planning enacted by the sovereign has power over the other forms of urbanisation and their legitimisation (see chapter 8.1). The question in Bahir Dar is, hence, not only how the poor in informal structures can be protected from being displaced but rather how low-income, as well as middleincome groups, can secure their food supply, businesses and homes in the face of competing interests and lacking representation. It is, therefore, suggested that not all tools for urban development in the sense of an inclusive city lie in the hands of the administration. Factors such as infrastructure, internet, communication technology, professional networks, concentration of people as service customers and, thus, resource accumulation are special features and services that the city has to offer and for which people move. What they promise is access to knowledge, marketing opportunities for goods and the possibility of diversifying a livelihood based on a variety of natural and urban resources and agriculture as well as the possibility of appropriating a space to accommodate these activities and stay. Providing and establishing opportunities in urban development should therefore pick up on these opportunities for personal development and qualification possibilities. These skills provide a basis for establishing livelihoods. The parties involved in such practice, thereby, need consideration as actors of urban development. On these grounds, a recommendation is given to systematically include a larger variety of rationales of everyday urbanisation into urban development, and particularly low income-related ones. The accounts of "everyday urbanisation" need to encompass informal, traditional, agricultural and clan-related elements that can be evaluated alongside the economic criteria for land-use decisions and strategy formulation in the multiple levels of urban development, aiming for inclusiveness. Thereby, the description of "everyday urbanisation" as mundane practices of urbanisation beyond the formal planning agenda is crucial for conceptualising and addressing the widened spectrum of urban lifestyles. Here the neighbourhood typologies identified in chapter 6 can serve as a basis for formulating differentiated and contextualised intervention strategies to improve livelihoods for a wider spectrum of the urban population. Resulting from the identification of the addressees of urban planning, in conjunction with the identification and distribution of local resources, functional spatial designs incorporating the needs of varying livelihood strategies need to be developed. In Bahir Dar questions of income, access to basic infrastructure, equal opportunities, diversity, social connectivity and exchange, transparency, access to education, access to housing and security of shelter, freedom of movement, freedom of communication and food security repeatedly occurred in the accounts of the residents; such aspects of forming systems have to be considered in urban development. At the same time, urban structures in Bahir Dar will have to accommodate a greater variety of lifestyles as the urbanisation process advances. To ground urban planning in the local rationales in Bahir Dar, it is, therefore, not the planning tool of the BDIDP itself that needs revision, but rather a discussion 
on the inherent normatives that needs to be initiated. Thereby, urbanisation needs to be a key-topic on which to ground the plan's paradigm. So far, this negotiation on Bahir Dar's future has not been sufficiently transparent and open. The following chapter will, hence, propose the concept of "inclusive planning" to counter tendencies of segregation in urbanising Bahir Dar by opening the discussion on local urban development aims.

\subsection{InCLUSiVE PLANNING}

Conceptualising rationales of planning and everyday urbanisation as, at times, complementary and, at times, conflicting reveals possibilities for synergetic constellations between different actors in urbanisation based on criteria of distributive justice. Thereby, it is not the aim to make the urbanisation process governable from the top down but rather to improve the livelihood situation of residents by starting from the status quo, including the engagement of a range of actors from the statutory and non-institutional spectrum, addressing the effects of the urbanisation dynamic. However, it remains unanswered so far, how these discrepancies in underpinning ethics between the stakeholder parties can be bridged to overcome the level of "problem-solving" in favour of strategic and yet feasible planning towards a "better future". As described, the stakeholder parties need to agree on a "common good" for urban development in the wider sense. Thereby, the question stands as to how values of normative ethics can be socio-culturally constructed and how common planning ethics can be negotiated among the spectrum of stakeholders in Bahir Dar. It is unlikely that this will be possible under the currently favoured proposals of the "developed" city, because of the fact that it is a "theory out of place". Its "translation" into an operational system as a means of laying it down can, thereby, not replace the negotiation of an underlying shared normative ethic of urban development. In an understanding of urbanisation as an "idiom" (Roy 2009), which views the construction of the urban as an assemblage, urban studies acknowledges, that there are diverse interpretations and representations of a "good city". Urban development, thereby, implies that there is a negotiation of a widely accepted social contract according to which planning interventions can take place. Thereby, the evidence from the sub-cases suggests that Bahir Dar, yet, has to uncover conflicting interpretations of the current development normatives, which it has so far not explicitly negotiated among all affected stake-holders parties.

The fundamental change in approach, therefore, needs to consider the wider underpinnings of planning systems. In order to yield the principles, which basically form the pre-conditions for suitability to their context of implementation, the analysis of context is vital. According to the findings from this research, Bahir Dar, needs to diversify its planning to suit a broader public interest. It needs to uncover its decision-making processes and make them transparent and accessible 
to a wider spectrum of interests, especially from the lower-income groups left out of current considerations.

While the "developed" city's community support in Bahir Dar is in question and deserves further explicit description in the form of state-subject relations, debates on the empirical data will also need to establish, which guiding principles can make the negotiation of a "common good" for Bahir Dar's urban development possible. In the course of urbanisation, the distribution of limited resources among the various livelihood typologies requires decision-making and co-ordination, if criteria of inclusivity are to be considered. To do so, the consideration of categories such as gender, religious or ethnic categories in urban development need to be looked into. Spatial segregation and, thus, unequal social and economic access of different population groups to and distribution of resources among the neighbourhoods need to be prevented. Hence, urban development should take a stance on furthering social and economic cohesion within the city. Thereby, cultural valorisation practice towards difference in everyday life and in building needs to accompany the already established ideas of equality in the existing planning documents and reach also to the most marginalised groups. Picking up the suggestions from chapter 2.2, it is here suggested that inclusiveness be introduced as a development principle. Aiming for inclusiveness means urban development practice needs to be reformed with an inherent demand for granting decision making to local stakeholders. The definition and re-definition of government tasks needs to be undertaken in negotiation with the local population and non-governmental organisations. Thus, by creating a situated agenda and taking the everyday realities and differing practices identified through the description of everyday urbanisation into consideration, a step towards legitimising planning legislation as relevant for the majority can be undertaken. On the basis of the inclusion as the urban development agenda, the widely spread practices of urbanisation can work towards distributive justice. Unlike the "developed" city, the idea of including the ordinary can be based on principles of "equity, respect and inclusiveness" (Winkler and Duminy 2014). The idea is to strongly aim at overcoming principles of inequality and segregational tendencies. Unlike the "developed" city, which is universalist in its proposals for infrastructure supply and construction, the proposal is for a relativist normative ethic that calls for situated improvements based on local negotiation of priorities. Introducing inclusiveness as an evaluating criterion is proposed to counter current tendencies of economic segregation in urban development. Inclusiveness has potential as a characteristic, by which the relation of the urbanisation rationales from planning and everyday urbanisation will be re-configured to accommodate a wider diversity of interests than current land-use determinations can provide.

Addressing spatial set-ups that are not related to industrial understandings of division of labour and residence require an institutional framework more suitable for decision-making at the local level. This analytical viewpoint must, thereby, lead to a new set of policies, plan implementation and thus urban development projects 
that are not based on "theories that are out of place" (Myers 1994: 209), but instead are rooted in urban studies that draw from the full range of practices in the respective cities (Robinson 2006: 164). Urban settlement development must not lead to the disconnection of housing typologies and urban structures from the need for "ephemeral, fluid and invisible" social and economic interactions of the inhabitants (Kihato 2007: 215 and Simone 2004). In other words social, cultural and economic systems of existing and projected neighbourhoods should be recognised as assets and therefore be incorporated into urban development considerations. As described above (see chapter 8.1), planning in Bahir Dar is seldom in partnership with everyday urbanisation and the modern development it postulates refers to an ideal, which is an exception to the social and economic systems of urbanisation relied on by the wider population. In order to arrive at a point where administrative forces increasingly work with and not against such incremental structures, and where urban development can be understood as a "collective governance effort" (see Healy 2012: 192), urban development itself needs to be revised, turning away from following outside prescriptives towards negotiating a local planning ethic (see chapter 8.2). Partnership between statutory planning and everyday urbanisation entails a shift towards responsibility for grass-roots initiatives and civil actors. Thereby, change can be initiated by small-scale pilot-projects that seek to create synergetic constellations between public interest, administrative capacity and local resources. Proposals for such a contextualised approach in Bahir Dar will be given in the concluding chapter 9 . 


\section{Furthering Synergetic Constellations}

The task of this chapter is to make suggestions for locally-grounded urban development tools and measures. Derived from the insights gained through the study of the sub-case locations, pilot-projects suited to the neighbourhood-specific setups are proposed for each of the four sites. This thesis argues for urban development approaches based on the close study of location (see chapter 8.2), in order not to impose pre-conceptualised standards in implementation, which have not been tested for their performance under local conditions (see chapter 2.2). As discussed in chapter 8.2 , the current statutory planning prioritising development of tourism areas marginalises tending to the immediate needs of the wider population and, hence, needs to be questioned in favour of recognising a wider range of local interests. Jobs in the building sector are insufficient legitimisation for giving up sites, networks and resources permanently to exclusively commercial developments. It is, therefore, proposed that a variety of everyday urbanisation practises need to be legitimately acknowledged not as an alternative, but as co-existent to planning (see chapter 8.2) in Bahir Dar's urban development. Managing the process of urbanisation with the aim of inclusiveness regarding such an amplified spectrum of urban planning regimes is therefore proposed. Suggestions are made as to how a wider range of needs can be accommodated in urban development, by widening the target focus of urban policy strategies in the context of the neighbourhoods. Thereby, the toolbox for implementation of the strategies needs to develop to reflect the widened spectrum of contextual strategies based on actor interests. To do so, pilot projects in the neighbourhoods offer the opportunity to explore asset-based approaches to urban development. Drawing from the findings from the sub-case sites and based on the recommendation in chapter 8 to counter tendencies of segregation by introducing a decidedly inclusive stance on urban development, the pilot-projects proposed in this chapter can function as discussion bases on which the actual actors and stake-holders in Bahir Dar can reflect and negotiate their interests.

The institutional setting in which planning takes place, the way content was determined, the strongly limited options of participation and evasive practices in implementation seem to be challenging the BDIDP. However, it is necessary to 
define a strategic vision and it is assumed that BDIDP as an instrument can integrate the measures on the neighbourhood scale. As a reflexive instrument originally intended to incorporate the transparent negotiation of an underlying development principle, it can take on the role as a platform simultaneously to its function as a reference and documentation. However, the BDIDP in its current shape will need substantial revision to fulfil these tasks, will have to be open to renegotiation of its guiding principles and, hence, has to move away from its current set-up as a master plan with strategic projects towards more holistic and participative regimes. It has to resist the temptation to develop standardised plans for different communities and develop local aims for urban development in Bahir Dar. The qualities and internal potentials of neighbourhoods - also of low-income structures - therein need to provide more input to shape a stronger decision-making base. On the grounds of having to integrate competing regulation systems as well as a large variety of residential and commercial interests while facing high population influx, the BDIDP's normative underpinnings should be renegotiated. The underlying paradigm of the plan and the resulting standards should, thereby, be publicly negotiated and participatory, the decision-making process and the result should be made transparent. Although deciding on the guiding principles of urban development in Bahir Dar should remain in local hands, it is suggested here to decide on an inclusive approach towards urban development to replace the development regime. Thereby, the standards the IDP proposes for urban development in the form of building regulations, land-use and action plans, etc., have to be lowered to a level that can actually be met by a majority of the population, in order to make the plan relevant and binding. The idea is to make the IDP function as an integrated planning tool that reflects the values of urban society, by which the majority abides and with which it also engages. The plan needs to develop a manageable framework, allow for private initiative, set local aims and develop not only measures, but monitoring criteria linked to these to suit the local context in Bahir Dar.

Understanding urban development as a "collective governance effort" (see Healy 2012: 192 and chapter 8.3) requires expanding the range of actors in urban development to be understood beyond the actors of statutory urban planning. From the empirical research, it is understood that the major players in the negotiation of Bahir Dar's urbanisation are political figures, private investors, Bahir Dar University acting as a major project developer, rural-urban migrants arriving in town, established communities of various backgrounds and interests, local business and subsistence-oriented households. The different rationales of state and non-governmental actors need to be integrated into constellations in which they can work synergetically, decide on trade-offs, administer resources and address effects of urbanisation. The proposals on contextualised planning need to be broken down into specific sets of action on the neighbourhood scale. Depending on the intervention context, different sub-aims, responsible actors and planning tools 
can be negotiated on the intervention scale and, thereby, address the overall aim of distributive justice.

This calls for a revised role of the institutional planner towards a communicative effort. While the architectural and planning practice can only act within the political and administrative frame that the country provides (Myers 2011: 48), planners have to contribute and coordinate the process of prioritising "action areas", selecting and designing tools adequate for the local context on the basis of the results from local stakeholder negotiation. It needs to monitor that the BDIDP is broken down into smaller units, as already attempted by the current "action plans", but needs to see to it that the plans across various scales are congruent. Thereby, it is further proposed that these smaller plans are understood as community development plans that are set up after priority areas for intervention have been negotiated on the city scale and based on the revised planning paradigm. On the grounds of inclusiveness, marginalised communities, underserviced areas and the unattended rural-urban population influx would deserve particular attention and, hence, neighbourhoods affected by these phenomena would rank high on the project agenda. However, the site-specific situations require problem-specific policy recommendations and planning measures have to be selected accordingly.

Although the sub-case areas might not reflect the outcome of such a participatory prioritisation of intervention areas, they will be discussed as examples of what a contextualised planning approach based on inclusive principles could look like in the following.

\subsection{Mixed-Use Zoning}

The diversity of Bahir Dar's downtown area should be viewed as an asset and supported in its development as such. Urban lifestyles in Ethiopian cities do not necessarily stand for individualisation but are rather tied in to community structures. However, the city as a context for reinventing identities and accepting an increasingly diverse population requires acknowledgement in urban development. There are increasingly different ways of manoeuvring the city that should find a variety of support systems and be awarded recognition. However, the area has problems regarding the quality of building structures, due to overcrowding in housing and lack of adequate infrastructure to create sanitary conditions. Unequal distribution of infrastructure and access to services has to be countered and a basic service provided for all urban dwellers as well as for those expected to move to the city in the mid-term. Also, rising land-use pressure needs to be acknowledged in the negotiation of urban development with the stakes in place. Currently, the low and middle-income occupants of the existing buildings in the inner city do not have tenure-security. Although the houses are Kebele homes or have been built in line with the tenure-regulations the building-standards have been changed to allow for 
a large part of the existing structures to be demolished and replaced by commercial development. Unless the occupants can pay for multi-storey buildings they have to leave their plots.

\section{Aim:}

The aim is the provision and access to diverse typologies of housing and income opportunities in the city centre. Keeping people in place should be a high priority, as relocation presents a risk for the most vulnerable residents, such as the poor and frail. Strategies countering the structural issues in downtown Bahir Dar, such as the eradication of buildings and removals from the city centre, need to avoid contributing to sub-urbanisation and fragmented, segregated land-use patterns. The IDP needs to question the displacement of existing housing and substitution of social and provision structures within the city by preferred medium and large-scale investment more carefully. Instead of relocation, a synergetic approach to tackle the issues of sanitation and densification is suggested, by installing an in-situ-upgrading strategy, thus securing social ties, keeping job-opportunities in the microeconomy in the city centre and improving living conditions for the long-settled residents in low and middle-income housing. In doing so, the personal resilience of the wider urban public would be improved in a context where subsistence levels and low incomes are frequent and irregular incomes are the normal situation. Questions of tenure-security need to be looked into by the municipality and the mix of de-facto land use needs to be acknowledged. This way the current focus on commercial development can shift to a more varied concept of inner-city use.

\section{Tools:}

The inner-city can serve as an implementation site for a pilot-project exploring the effects of a "mixed-use" zoning category in the BDIDP. Mixed-use zoning acknowledges the ties between living space, opportunities of income generation and business operation. The view based on what is the maximum achievement possible regarding construction should, thereby, shift towards defining minimum standards of safety with which buildings have to comply to be legal. Further, the IDP's possibilities of including the residents already in place in upgrading and allowing them to improve their living conditions through participation in the urban development decisions should be considered to devise an inner-city concept meeting a broadened variety of interests. Exact specifications can be negotiated on a neighbourhood scale and an upgrading-plan devised based on existing structures. This plan does not serve for compensation, but as an inventory for conservative construction measures.

The precondition for granting a cosmopolitan outlook on local residence and, thus, allowing participation in central city life for a wide range of population groups including diverse genders, religions and ethnicities, is transparency in the negotiation of urban issues. Within this negotiation, the attractiveness of the in- 
ner-city plots is an asset that can be used for cross-funding in conditions of a weak tax base. In mixed-use areas, cross financing of affordable accommodation and micro-business to benefit low-income households can be made a building requirement in turn for development opportunities for economically strong investors. Here, tourism should lose its exclusive priority status in urban development in favour of a diversified economic strategy. Within these negotiations, urban planning needs to revise its understanding of the micro-economy to see the potential of the agency small-scale business displays. Micro-business and local production need consideration before real-estate development. Recognising the existing (informal) economies not as a sector, but rather as ways of living in the city and as an opportunity to engage in urbanism is fundamental to the set-up of negotiation on land-use interests.

\section{Actors:}

The Municipality of Bahir Dar should take responsibility for this project. While the RUPI can function as the institution devising the plan, negotiations on the actual site needs to be in the hands of an institution closer to the locals. However, to fulfil such tasks, the municipality needs to be equipped with the necessary resources and decision-making powers. Its role however is that of a mediator between land-use interests in the interest of the urban public.

\section{Implementation:}

At the moment, needs and the provision of basic infrastructure (as for example defined in the UN's MDGs) are not systematically approached by the administration and delegated to NGOs. It should be made a priority in political and administrative action, but needs to rely on know-how from technical experts. Their opinion needs to be considered against land-use interests. On this basis, the mixed-use determined in the IDP can be broken down into actual use-patterns for a designated site in the city centre. Residential use, small-scale manufacturing and different types of commercial use (micro- and large-scale) should be allocated according to proportions agreed on in a public document. Success of the project should be measured by its ability to sustain a wide range of diversity across forms of residence, subsistence, production and commercial activity.

\subsection{Arrival Structures and Temporary Housing}

Looking at the sub-case site around the textile factory, the residential area has been successful in consolidating and providing for its residents until now but, considering the current developments Bahir Dar faces due to the population influx, its structure and facilities also need to be questioned in the face of continued urbanisation. Currently, the textile area houses well established long-term residents and 
provides short term housing only for the well qualified staff of the textile factory that can rely on fixed employment. The well-off residents are largely not reliant on having to rent out space to generate income and are, hence, not operating informal hostels, which currently have to provide for the rural-urban arrivals, daily labourers and temporary and seasonal migrants in town. The textile area is, therefore, largely exempt as an area of reception.

Aim:

Phenomena such as multi-locality, temporary residence and rural-urban migration have to be considered not an interim phenomenon of transition but a permanent set-up in the medium term. Under conditions of urban growth, the seclusion of the textile area needs to be questioned regarding its receptiveness towards nonpermanent residence and new arrivals. It is suggested, that established residential areas, such as the textile neighbourhood can accommodate a share of the new and temporary urbanites. As Simone (2011: 390) puts it, "Instead of trying to keep people in place in newly democratic and decentralised localities, perhaps emphasis should be placed on how to make already existent movement more productive and convenient, and to accede to the possibility that urban residents "come to go and go to come", resulting in "making productive use of urbanities of movement as a formal resource". If migration patterns were studied for an estimate of type and amount of required habitat in the foreseeable future, housing delivery could adapt and diversify its quality of housing provision based on these insights to provide new forms of housing for moving households and periodical residence. For the specific case of Bahir Dar, this requires flexible measures for employment and accommodation, suited to the average low levels of education and income of the new urban arrivals (cf. Pieterse 2010). Connected to this issue of non-permanent residence is also the question of representation of a substantial part of urban society in urban life and decision-making bodies, if residents are only staying in town temporarily.

Tools:

A variety of measures can be adopted, to accommodate the different needs of different types of non-permanent settlement in the site of the textile neighbourhood. Temporary housing can be provided as insertion in the consolidated area, rent regulations can be improved to strengthen tenant rights and quality of dwellings, and public representation of non-permanent citizens can be made a policy issue. In the residential neighbourhoods such as the textile area, new opportunities for housing beyond the existing informal hostels, informal housing and often crowded rental situations, could be created. Accommodation for temporary residents can be provided by emergency shelters, new models of shared housing or certified hostels. Thereby, the provision of such can be depended on the private sector, while certi- 
fication needs to be accredited on a pre-defined set of criteria by the authorities. This way, income opportunities are created while the city's tax base is not strained.

However, as part of a range of diversified urban identities and livelihood concepts, temporary residents need acceptance in urban decision-making. They also need to be addressed as part of the urban community by urban policy. Since the rationales of everyday urbanisation have a very fluid and mobile nature, it has to be expected that, as urban planning takes a wider range of practices into account will have to broaden its spectrum of instruments beyond long-term projections and has to deal with target groups that are not necessarily available for long-term engagement and agency or advocate the needs of multi-local set-ups that go beyond a temporary and situation-based need. The competing rationales identified can, therefore, not generally be expected to have spokes-people on urban planning. Urban policies addressing them need to take this into consideration and explore the limits of their reach in such highly dynamic conditions.

\section{Actors:}

As stated, the projects proposed can be run by public institutions. However, services provided by private initiative are a viable model for financing, project development and operation. In this case, administration should engage with architects for developing standards for temporary housing (hostels). A pilot project in the textile area on state land could provide experience on these issues. Beyond this, the municipality should make it its task to look into revising rental regulations to strengthen tenant rights and protect tenants from arbitrary eviction. Grass-roots initiative on representation of temporary residents in decision-making bodies and tenant rights should be welcomed and supported by public administration.

\section{Implementation:}

Information structures for new arrivals would, thereby, best be situated not in the residential areas, but at the arrival points. Currently this is pre-dominantly the bus station in the city centre. Here, information on accommodation available could be provided and the arrivals could be distributed to various neighbourhoods of the town. Assistance in job hunting could be provided, as well as information on access to services.

\subsection{INCREMENTAL BUILDING ZONES}

The residents of the urban village have been resident in town for more than four generations and need to be considered in future urban development. Diversification of livelihoods, with urban agriculture for subsistence and small-scale entrepreneurship, are the current steps in urbanisation in this village. However, the rapid transition from rural to urban society in the location of Bahir Dar is calling local 
tradition into question in favour of modern lifestyles that are considered more "urban". As ethnic ties and family structures are replaced by new sociality and individual roles in an urban setting, the traditional lifestyles and ethnic communities are facing marginalisation in everyday encounters and by systematic exclusion from upgrading proposals. By reading the results from the sub-cases, it has become evident, that traditional practices are not part of the modernisation agenda. While trained architects and urban planners are rare, the formal planning system imposes a negative pre-disposition regarding building practice reliant on traditional expertise. It, thereby, inserts a competition between the informal/traditional urbanisation practice and a new professionalised system, which excludes the wider public from the composition of their urban habitat on the grounds of introducing standards of urban and architectural design. It needs to be questioned, whether the formal system thereby promotes an inclusive approach and whose interests are represented by the regulations. It is possible to obtain standardised house designs from the municipality but, currently, the formal way of building is too complicated or expensive for the majority of inhabitants in Bahir Dar (see chapter 5.5).

\section{Aim:}

The provision and access to housing typologies needs to be amplified by statutory planning, to include simplified criteria of construction as legal. It needs to provide for everyday rationales, without destroying flexibility, resilience and sustainability of local practices. Livelihood strategies found in this area, such as subsistence agriculture, home production, foraging, petty trade and bartering need to be fully accepted as part of city life, as long as alternative livelihoods are not sufficient or adequate for substantial parts of the population. Eventually, Bahir Dar will have to find ways to unite local traditions with cosmopolitan attitudes towards difference. The spatial requirements of these activities, hence, need to be qualified to work towards such an aim. Regarding the existing building structures, the integration of such informal urbanisation into general development strategies is dependent on the fact, whether these structures and processes conform with guiding principles and political strategies and aims. The identification of informal structures does not necessarily have to result in their destruction, as they can be legitimised.

\section{Tools:}

Instead of disrupting the process and dislocating the community, an in-situ upgrading approach can also be implemented here, if also with different building requirements than in the downtown area. For the urban village incremental building zones can be designated, to give them a legal status and allow for their consolidation. As a reference, the city of Cape Town has devised the instrument of the "incremental housing area", within which construction activities are generally allowed and negotiated by the local community (City of Cape Town 2007). Incremental production of space and place through auto-construction signifies that, 
mostly, there is no separation between the design and the production of urban structures but, instead, the product is determined by the availability of material. It allows to learn from traditional building practice by using local material, building in modular shapes and hence increasing resilience and sustainability. In the face of an uncertain economic situation, climate change, changing water levels/ receeding national resources, incremental building can house a lifestyle that does not have to maintain structures in times of uncertain income. This can prove advantageous for the residents, as regular payments for housing do not have to be made. However, the building regulations specify minimum safety standards by which the resulting buildings can be assessed by the administration (ibid). Rules for conforming to these building standards are set for a designated area of land. Through introducing incrementalism to achieve the standard gradually, the specifications can actually be met by the population in place and are not rules that are out of reach of compliance.

\section{Actors:}

The administration of such resources, including the administration of land, can be left to the community leaders on specified conditions (e.g. rules for gender equality). By this, parallel/coexisting practices of land-distribution are acknowledged and incorporated into processes of gaining tenure-security for communities in place. Although it can acknowledge the elders as authorities, this step would also have to re-invent tradition and see it as a cultural value that is changeable.

\section{Implementation:}

It has to be recognised that the natural resources on which the livelihoods of the urban village are still important for income generation and subsistence for many in Bahir Dar. However, these resources (including fish, sand, soil, stones, but also the landscape and animal life as a resource for tourism are not managed. In the condition of population growth around Lake Tana, there is hence a strong danger of over-exploitation. In order to preserve these resources their use should be monitored to sustainability criteria. The criteria should be set, to balance the use and protection of resources with the increasing demand. In the interests of food security, small-scale activities like urban agriculture, line-fishing, or even outtake of drinking water from the lake should not be sanctioned and enjoy a liberal handling within the realm of health standards. However, activities concerning the exploitation of non-renewable resources such as stone mining and larger scale resource exploitation of the lake and forests need to be monitored in the interests of the environment. The administration needs to be responsible for the distribution of these resources by establishing protection standards and overlooking their abidance. Urban policy needs to establish what the resources of the region are, whether they are renewable and how their exploitation impacts on the environmental sys- 
tem. On the basis of such an inventory, land-use, access to resources and development or protection areas can be established.

\subsection{NeTWORKS OF INNOVATION}

A major issue in the discussions documented on urban development is not about the need but rather the desire to modernise and engage in development. This is a risky issue but in the context of rapid urbanisation, development as progressing from the status quo is inevitable. Thereby innovation in urban development through revised building standards and a local development agenda, as well as an innovation policy with spatial elements to accommodate the local economy are in need of re-conceptualisation. These fields have previously been fed by external ideas and can be revised on the grounds of introducing locally contingent standards valid for the specific situation in Bahir Dar. However, knowledge generation and higher education in Bahir Dar University are currently not well connected to civil society, and the exchange of knowledge between the campus and the city can be much improved to work on these questions locally and in communication with the population and other decision makers in the city. The interaction of the university with the rest of the city holds potentials that are, currently, not being used to the full extent.

Aim:

Off-campus accommodation for students as a choice of living can provide income for private hostels and establish personal ties to the city for the graduates. However, it could also counter the idea of an egalitarian treatment of students on the campus. The proposals made for the incorporation of the university into urban development under terms of inclusiveness, therefore, focus on its potentials as a hub of innovation to benefit Bahir Dar's society. If networked with the city, the university can give impulses and benefit urban development far beyond its own campus.

Thereby, the issues of discussion can be manifold. The appearance of the city, for example is a topic of debate at the moment, yet under the aim of innovation, the question of urban design should move from visual ideas to questioning the underlying principles. The provision of serviced urban areas needs qualifications beyond provision for plain quantities of housing units, including new concepts for subsistence. Local start-ups are in need of accompanying structures and advice. Access to information technology and devices needs to be substantially improved and holds potential for co-operation between university projects and private enterprise.

Moving away from sanctuary and engaging in the management of the cultural process of urbanisation actively by supporting the city's society, thus forming networks of innovation, would strongly benefit the town. Therein, not conformity 
to proclaimed standards, but rather free thought for local solutions should be the aim. The idea of a powerful authority will therefore have to be reframed from a controlling and repressive role to that of a facilitator of invention.

Yet, such ideas on adaptability and the embrace of novelty will have to be brought into urban development practice with regard to the precarious economic situation of the urban residents. Therefore, progressive development or modernisation needs implementation strategies that are grounded in local assets and situated measures.

Tools:

Open access to knowledge and the implementation of (digital) learning centres as well as creating mobile learning facilities, can be included in the formulation of a spatial development strategy within the urban development framework. Community learning centres and libraries are, thereby, key institutions to build on for education, training and building community knowledge.

\section{Actors:}

Urban administration in Bahir Dar should consider a municipal strategy by which highly qualified graduates are considered a resource and can be encouraged to stay in the region to engage economically and innovatively in the urban transition. Therefore, the administration should closely co-operate with the University and try to win students and graduates to engage in the projects as volunteers but also as entrepreneurs. Bahir Dar Municipality should hence invest into experts who serve local demands and create synergies among businesses, urban society and university institutions.

\section{Implementation:}

The projects need to be developed in a set of workshops and should eventually be transferred into a city-wide spatialised strategy. Starting with incubator projects, the municipality could incrementally expand the programme and act as a co-ordinator between the interest groups. 



\section{Table of Resident Interviews}

\begin{tabular}{|c|c|c|c|c|c|c|}
\hline Area & Code & Sex & Age & Religion & Occupation & Date \\
\hline \multirow{10}{*}{$\begin{array}{l}\text { Down- } \\
\text { town }\end{array}$} & $\mathrm{A}$ & $\mathrm{m}$ & 21 & Muslim & Student & 11.02 .2013 \\
\hline & B & $\mathrm{m}$ & 19 & Muslim & Student & 11.02 .2013 \\
\hline & $\mathrm{C}$ & $\mathrm{m}$ & 76 & Orthodox & $\begin{array}{l}\text { Guard, informal } \\
\text { guest house host }\end{array}$ & 12.02 .2013 \\
\hline & $\mathrm{D}$ & $\mathrm{m}$ & 32 & Protestant & Carpenter & 11.02 .2013 \\
\hline & $\mathrm{E}$ & $\mathrm{m}$ & 40 & Muslim & Teacher & 12.02 .2013 \\
\hline & $\mathrm{F}$ & $\mathrm{f}$ & 26 & Orthodox & Housewife & 11.02 .2013 \\
\hline & G & $\mathrm{f}$ & 31 & Orthodox & Housewife & 12.02 .2013 \\
\hline & $\mathrm{H}$ & $\mathrm{f}$ & 67 & Orthodox & $\begin{array}{l}\text { Retired for health } \\
\text { reasons, landlord }\end{array}$ & 11.02 .2013 \\
\hline & I & $\mathrm{f}$ & 65 & Orthodox & Housewife, landlord & 12.02 .2013 \\
\hline & $\mathrm{J}$ & $\mathrm{m}$ & 32 & Orthodox & $\begin{array}{l}\text { Tour guide, boat } \\
\text { owner }\end{array}$ & 30.09 .2010 \\
\hline \multirow{5}{*}{$\begin{array}{l}\text { Textile } \\
\text { Worker's } \\
\text { Settlement }\end{array}$} & $\mathrm{K}$ & $\mathrm{m}$ & 25 & Orthodox & Driver BDU & 07.02 .2013 \\
\hline & $\mathrm{L}$ & $\mathrm{m}$ & 69 & Orthodox & Retired textile & 07.02 .2013 \\
\hline & & & & & worker & \\
\hline & M & $\mathrm{f}$ & 22 & Orthodox & Student & 07.02 .2013 \\
\hline & $\mathrm{N}$ & $\mathrm{f}$ & 45 & Orthodox & Home production & 07.02 .2013 \\
\hline \multirow{5}{*}{$\begin{array}{l}\text { Informal } \\
\text { Village }\end{array}$} & $\mathrm{O}$ & $\mathrm{m}$ & 18 & Orthodox & High school student & 08.02 .2013 \\
\hline & $\mathrm{P}$ & $\mathrm{m}$ & 35 & Orthodox & Bajaj driver (owner) & 08.02 .2013 \\
\hline & Q & $\mathrm{m}$ & 66 & Orthodox & $\begin{array}{l}\text { Retired for health } \\
\text { reasons }\end{array}$ & 06.02 .2013 \\
\hline & $\mathrm{R}$ & $\mathrm{f}$ & 21 & Orthodox & Engineer & 08.02 .2013 \\
\hline & S & $\mathrm{f}$ & 35 & Orthodox & $\begin{array}{l}\text { Coffee house owner, } \\
\text { sale of grass }\end{array}$ & 08.02 .2013 \\
\hline University & $\mathrm{T}$ & $\mathrm{m}$ & 39 & Orthodox & Lecturer & 29.01 .2013 \\
\hline \multirow[t]{4}{*}{ Campus } & $\mathrm{U}$ & $\mathrm{f}$ & 18 & Orthodox & Student & 13.02 .2013 \\
\hline & $\mathrm{V}$ & $\mathrm{f}$ & 59 & Orthodox & $\begin{array}{l}\text { Coordinator cafe- } \\
\text { teria }\end{array}$ & 13.02 .2013 \\
\hline & W & $\mathrm{m}$ & 25 & Orthodox & Student, tour guide & 17.10.2010 \\
\hline & $X$ & $\mathrm{f}$ & 24 & Protestant & Student & 06.10 .2010 \\
\hline
\end{tabular}




\section{List of Expert Interviews}

Berrisford, Stephen. Planning Law and Policy Consultant. Cape Town, 18.10.2012. Dirr, Martin. Urban Advisor, GIZ. Addis Ababa, 20.10.09.

Endegena Ejigayehu, Urban Advisor, GIZ, Bahir Dar, 06.02.2011.

Getenew Zewdu. Save the Children Ethiopia. Bahir Dar, 29.10.10.

Getie Gelaye. Lecturer for Ethiopian Studies, University of Hamburg. Hamburg, 16.02.2012.

Girum Mamushet. Head of the Architecture Department at Bahir Dar University. Bahir Dar, 23.02.2013.

Gorgens, Tristan. Lead Researcher, Urban Land Programme, Isandla Institute. Cape Town, 24.10.2012.

Ato Tilahun. Process Owner Urban Planning, Regional Urban Planning Institute. Bahir Dar, 04.09.2010.

Ato Yirsaw. Urban Planner, Regional Urban Planning Institute. Bahir Dar, 02.02.2013.

Zerai Mesfin. Architect. Bahir Dar, 26.01.2013.

Zufan Sodru. NGO worker at Alchemy World. Addis Ababa, 10.03.2013. 


\section{References}

Abdussammad H. Ahmad (1994) Anglo-Italian Conflicting Interests in the Lake Tana Region 1913-1935. In: Lepage, C. (ed.) Études ethiopiennes: Actes de la Xe conferénce internationale des études éthiopiennes, Paris, 24-28 août 1988, Paris, pp. 619-624.

Abeje Berhanu (2012) The rural-urban nexus in migration and livelihoods diversification: A case study of East Esté Wereda and Bahir Dar Town, Amhara Region. Organisation for Social Science Research in Eastern and Southern Africa, Addis Ababa, Ethiopia.

Achamyeleh Gashu Adam (2014) Informal settlements in the peri-urban areas of Bahir Dar, Ethiopia: An institutional analysis. Habitat International 43, 90-97. Ahmed Zekaria, B. Z. T. B. (ed.) (1987) Proceedings of the International Symposium of the Centenary of Addis Abeba, November 24-25, 1986.

Ajala O.A. (2008) Livelihoods Pattern of "Negede Weyto" Community in Lake Tana Shore, Bahir Dar Ethiopia. Ethiopian Journal of Environmental Studies and Management 1 (1), 19-30.

Akademie für Raumforschung und Landesplanung (2015). Informelle Planung/informal planning. http://www.arl-net.de/lexica/de/informelle-planung ?lang=en. Accessed 11/23/2015.

Akola, J., Fransen, J., Kassahun, S. \& van Dijk, M. P. (2010) Formalization and informalization processes in urban Ethiopia: Incorporating informality. Shaker Pub, Maastricht.

Alem, G. (2011) Traditional Use and Meaning of Urban Spaces // Traditional use and meaning of urban spaces. Univ., Diss.--Dortmund, 2011. Verlag Dr. Kovac, Hamburg.

Amare, S. \& Sinkinesh Takleargay (2008) Socio-economic situation of street children in Bahir Dar Town. Ethiopian Journal of Development Research 30 (1), $37-84$.

Amin, A. \& Graham, S. (1997) Ordinary Cities. Transactions of the Institute of British Geographers, 411-429.

Anderson, D. M. \& Rathborne, R. (eds.) (2000) Africa’s urban past. James Currey, Oxford. 
Anderson, D. M. \& Rathborne, R. (2000) Urban Africa. Histories in the Making. In: Anderson, D. M. \& Rathborne, R. (eds.) Africa’s urban past. James Currey, Oxford.

Angélil, M. \& Hebel, D. (eds.) (2010) Cities of Change - Addis Ababa // Cities of change: Addis Ababa Transformation strategies for urban territories in the 21st century. Birkhäuser, Basel.

Appelhans, N. (2009) Livelihood Transformation and the Ethiopian Urbanisation Process in the Lake Tana Region. In: Gelaye, G., Evans, D. \& Pankhurst, A. (eds.) Culture and Development for Amhara Region: Proceedings of the International Workshop on the launching of Amhara Region Culture and Development Research Center (ARCDRC). Bahir Dar University Press, pp. 54-65.

Appelhans, N. (2014) Die Integration informeller Urbanisierung und formeller Stadtentwicklung: Lernen vom globalen Süden. Informationen zur Raumentwicklung 2, 103-111.

Architects Association of Tanzania (ed.) (2005) Modern Architecture in East Africa around Independence, Utrecht.

Bahir Dar City Administration Integrated Spatial Development Framework: Planning for the Future. http://bahirdarcity.net/index.php?option=com_content\& view $=$ article\&id=32\&Itemid=67\&lang=en. Accessed 1st Febuary 2012.

Bahru Zewde (1988) Some Aspects of Post-Liberation Ethiopia. In: Taddese Beyene (ed.) Proceedings of the Eight International Conference of Ethiopian Studies // Proceedings of the eighth International Conference of Ethiopian Studies: University of Addis Ababa. Inst. of Ethiopian Studies, Addis Ababa, pp. 277-289.

Bahru Zewde (2005) The city centre: A shifting concept in the history of Addis Ababa. In: Simone, A. \& Abouhani, A. (eds.) Urban Africa: Changing contours of survival in the city. Codesria Books, Dakar, pp. 120-137.

Baumgart, S. \& Kreibich, V. (2011) Informal Urbanization - Historical and Geographical Perspectives: Guest Editorial. disP 4 (187), 12-23.

Benti Getahun (1994) The Overurbanization of a Metropolis: A Preliminary Survey of Migration to Addis Ababa, 1941 - 1974. In: Marcus, Harold G. Ed \& Hudson, G. (eds.) New trends in Ethiopian studies: Ethiopia 94. Vol 2, Social sciences, pp. 515-529.

Berrisford, S. (2011) Why It Is Difficult to Change Urban Planning Laws in African Countries. Urban Forum 22 (3), 209-228.

Bevan, P. \& Pankhurst, A. (2008) A Sociological Perspective on the Causes of Economic Poverty and Inequality in Ethiopia, Addis Ababa.

Bjerén, G. (1985) Migration to Shashemene: Ethnicity, gender and occupation in urban Ethiopia. Scandinavian Institute of African Studies, Uppsala.

Bjur, H. \& Azimzadeh, M. (2007) The Urban Palimpsest: The interplay between the historically generated layers in urban spacial systems and the urban life. In: Proceedings, the 6th International Space Syntax Symposium. 
Bocquier, P. (2008) Analyzing Urbanization in Sub-Saharan Africa. In: Champion, A. G. \& Hugo, G. (eds.) New forms of urbanization: Beyond the urban-rural dichotomy, Reprinted. Ashgate, Aldershot, pp. 133-150.

Boden, H. (1962) Bericht über meine Erfahrungen und meine Tätigkeit als Kommunalsachverständiger in Bahar Dar, Äthiopien.

Böll, V. e. a. (ed.) (2004) In Studia Aethiopica: Festschrift für Siegbert Uhlig zum 65. Geburstag. Harrassowitz, Wiesbaden.

Bundesinstitut für Bau-, Stadt, und Raumforschung (ed.) (2014) Informeller Urbanismus, Bonn.

Canadian Urban Institute (2011) Public Hearing for the Waterfront Development Plan, Bahir Dar.

Central Statistical Agency (CSA) (2003) Report on Urban Infomal Sector Sample Survey, Addis Ababa.

Central Statistical Agency (CSA) (2008) Summary and Statistical Report of the 2007 Population and Housing Census, Addis Ababa.

Chakrabarty, D. (2009) Provincializing Europe: Postcolonial Thought and Historical Difference (New Edition). Princeton University Press, Princeton.

Champion, A. G. \& Hugo, G. (eds.) (2008) New forms of urbanization: Beyond the urban-rural dichotomy, Reprinted. Ashgate, Aldershot.

City of Cape Town (2007) Zoning Scheme Regulations.

Consociazione Turistica Italiana (1938) Guida dell' Africa Orientale Italiana, Milan.

Coquery-Vidrovitch, C. (1991) The Process of Urbanization in Africa (From the Origins to the Beginning of Independence). African Studies Review 34 (1), $1-98$.

Crewett, Wibke, Ayalneh Bogale \& Korf, B. (2008) Land Tenure in Ethiopia: Continuity and Change, Shifting Rulers, and the Quest for State Control.

Crummey, D. (1987) Towns in Ethiopia: The eighteenth and nineteenth centuries. In: Ahmed Zekaria, B. Z. T. B. (ed.) Proceedings of the International Symposium of the Centenary of Addis Abeba, November 24-25, 1986., pp. 130-144.

Daniel Weldegebriel Ambaye (2011) Informal Settlement in Ethiopia, the Case of two Kebeles in Bahir Dar City. In: TS06 D - Informal Settlement Issues, Spatial Development, Planning and Governance (ed.) Bridging the Gap between Cultures.

Darmon, C. (2010) The Wayto Language of Ethiopia: State of the Art. In: Workshop: Language Isolates in Africa.

Dixon, A., Afework Hailu \& Wood, A. (eds.) (2001) Proceedings of the Wetlands Awareness Creation and Activity Identification Workshop in Amhara National Regional State.

Egli, E. (1967) Geschichte des Städtebaus: Die neue Zeit. Eugen Rentsch Verlag, Erlenbach-Zürich. 
Evans, D. (2011) Presentation on the Abbay Research Centre, Management Institute, Bahir Dar.

Fasil Giorghis (2010) Capitals on the move - An urban history of Ethiopia. In: Angélil, M. \& Hebel, D. (eds.) Cities of Change - Addis Ababa // Cities of change: Addis Ababa Transformation strategies for urban territories in the 21st century. Birkhäuser, Basel, pp. 48-54.

Fasil Giorghis \& Gérard, D. (2007) The city \& its architectural heritage: Addis Ababa $1886-1941=$ La ville \& son patrimoine architectural. Shama Books, Addis Ababa.

Federal Urban Planning Institute (FUPI) (2008) Bahir Dar Integrated Development Plan Final.

Fereya Abdissa \& Terefe Degefa (2011) Urbanization and Changing Livelihoods: The Case of Farmer's Displacement in the Expansion of Addis Ababa. In: Teller, C. H., Assefa Hailemariam \& Butz, W. (eds.) The demographic transition and development in Africa: The unique case of Ethiopia. Springer, Dordrecht, pp. 215-235.

Freeman, D. (2003) Conclusion I - Understanding Marginalization in Ethiopia. In: Freeman, D. \& Pankhurst, A. (eds.) Peripheral people: The excluded minorities of Ethiopia. Hurst, London, pp. 301-333.

Freeman, D. \& Pankhurst, A. (eds.) (2003) Peripheral people: The excluded minorities of Ethiopia. Hurst, London.

Fukui, K. (1997) Decentralisation and Changing Local and Regional Development Planning in Ethiopia. In: Fukui, K. \& et al. (eds.) Ethiopia in broader perspective: Papers of the XIIIth International Conference of Ethiopian Studies, Kyoto, 12-17 December 1997. Shokado Book Sellers, Kyoto, pp. 691-715.

Fukui, K. \& et al. (eds.) (1997) Ethiopia in broader perspective: Papers of the XIIIth International Conference of Ethiopian Studies, Kyoto, 12-17 December 1997. Shokado Book Sellers, Kyoto.

Gagliardone, I. (2014) New media and the developmental state in Ethiopia. African Affairs 113 (451), 279-299.

Gamst, F. (1979) Wayto Ways: Change from Hunting to Peasant Life. Session B. In: Hess, R. (ed.) Proceedings of the fifth International Conference on Ethiopian Studies, pp. 233-238.

Gebeyaw Walle (2003) A comparative analysis of the housing conditions of owneroccupied and Kebele-administered dwelling units in Bahir Dar. Master of Arts in Geography, Addis Ababa.

Gelaye, G., Evans, D. \& Pankhurst, A. (eds.) (2009) Culture and Development for Amhara Region: Proceedings of the International Workshop on the launching of Amhara Region Culture and Development Research Center (ARCDRC). Bahir Dar University Press.

Genet GebreEgziabher (2011) Urbanization and Urban Planning in Amhara Region, Management Institute, Bahir Dar. 
Gesellschaft für Internationale Zusammenarbeit (GIZ) University Capacity Building Programme (UCBP): Programme Description. https:/www.giz.de/en/ worldwide/18963.html. Accessed 12/8/2015.

Göckede, R. (2010) Der Architekt als kolonialer Technokrat dependenter Modernisierung: Ernst Mays Planung für Kampala. In: Pinther, K., Förster, L. \& Hanussek, C. (eds.) Afropolis: Stadt, Medien, Kunst [Kairo, Lagos, Nairobi, Kinshasa, Johannnesburg]. Verlag der Buchhandlung Walther König, Köln, pp. 52-63.

Golini, A. (2001) Urbanization and Urban Population. In: Central Statistical Authority (CSA) \& Institute for Population Research - National Research Council (Irp-Cnr) (eds.) Migration and Urbanisation in Ethiopia with special reference to Addis Ababa: In-depth studies from the 1994 population and housing census in Ethiopia, pp. 91-185.

Golini, A., Said, M., Casacchia, O. \& Reynaud, C. (2001) Migration and Urbanisation in Ethiopia with special reference to Addis Ababa: In-depth studies from the 1994 population and housing census in Ethiopia.

Guther, M. ([around 1962]) Berichtigtes Handexemplar Denkschrift Bahir Dar. Nachlass Max Guther, Darmstadt.

Guther, M. (1966) Stadtplanung in Afrika, am Beispiel der Neuen Stadt Bahar Dar am Tana-See in Aethiopien. Referat am 1.6.1966 bei der 3. Deutschen AfrikaWoche in Berlin. Typed manuscript with handwritten comments by the author., Darmstadt.

Guther, M. \& et al. (1961) Stadtgründung Bahar-Dar, Äthiopien 1961. Final version of the Master Plan for Bahir Dar., Darmstadt.

Habtemariam Tesfaghiorghis (1986) The Growth of Urbanization in Ethiopia 1966-1984. Eastern Africa Economic Review 2 (2), 157-167.

Haile M. Larebo (1994) The building of an empire: Italian land policy and practice in Ethiopia, 1935-1941. Clarendon Press, Oxford.

Haile Selassie, Marcus, H. G., Ezekiel Gebissa \& Tibebe Eshete (1994) My life and Ethiopia's progress: Haile Sellassie I, King of Ethiopia. Michigan State University Press, East Lansing.

Haimanot Mebratu (2007) Temporal Urban Growth Analysis and Potential Site Identification for High Rise Buildings in Bahir Dar City. M. Sc. Thesis, Addis Ababa.

Hall, S. (2012) City, Street and Citizen: The Measure of the Ordinary. Taylor and Francis, Hoboken.

Hansen, K. T. \& Vaa, M. (eds.) (2004) Reconsidering informality: Perspectives from urban Africa. Nordic Africa Institute, Uppsala.

Harbeson, J. W. (1988) The Ethiopian transformation: The quest for the post-imperial state. Westview Press, Boulder.

Hassenpflug, D., Giersig, N. \& Stratmann, B. (eds.) (2012) Reading the city: Developing urban hermeneutics. Verl. der Bauhaus-Univ. Weimar; Bauhaus-Univ, Weimar, Weimar. 
Healey, P. (2012) The universal and the contingent: Some reflections on the transnational flow of planning ideas and practices. Planning Theory 11 (2), 188-207.

Hess, R. (ed.) (1979) Proceedings of the fifth International Conference on Ethiopian Studies.

Hoben, A. (1973) Land Tenure among the Amhara of Ethiopia: The Dynamics of Cognatic Descent. Chicago University Press, Chicago.

Janowicz, C. (2008) Zur Sozialen Ökologie urbaner Räume: Afrikanische Städte im Spannungsfeld von demographischer Entwicklung und Nahrungsversorgung, 1st edn. transcript, Bielefeld.

Jenkins, P. (2004) Beyond the Formal/Informal Dichotomy: Access to Land in Maputo; Mozambique. In: Hansen, K. T. \& Vaa, M. (eds.) Reconsidering informality: Perspectives from urban Africa. Nordic Africa Institute, Uppsala, pp. 210-226.

Jenkins, P. \& Eskemose Andersen, J. (2011) Developing cities inbetween the Formal and Informal. In: African Engagements: On Whose Terms?, Uppsala.

Koehn, P. (1979) Development of Urban Systems in Africa, New York.

Küng, L. \& Hebel, D. (2007) Lernen von Addis Abeba. Betrachtungen zur äthiopischen Kapitale. Archithese (2), 26-31.

Lamnek, S. (2005) Qualitative Sozialforschung: Lehrbuch, 4., vollst. überarb. Aufl. Beltz, PVU, Weinheim, Basel.

Lepage, C. (ed.) (1994) Études ethiopiennes: Actes de la Xe conferénce internationale des études éthiopiennes, Paris, 24-28 août 1988, Paris.

Levine, D. N. (2014) Wax \& gold: Tradition and innovation in Ethiopian culture. University of Chicago Press.

Lindner, U. (2011) Neuere Kolonialgeschichte und Postcolonial Studies. http://docupedia.de/zg/. Accessed 11/23/2015.

Livsey, T. (2014) 'Suitable lodgings for students': Modern space, colonial development and decolonization in Nigeria. Urban History 41 (04), 664-685.

Liyew Adamu Anteneh (1994) Untersuchung des Standes der Stadtentwicklung in Äthiopien., Weimar.

Marcus, H. G. (1994) Haile Sellassie's Development Policies and Views 1916-1960. In: Lepage, C. (ed.) Études ethiopiennes: Actes de la Xe conferénce internationale des études éthiopiennes, Paris, 24-28 août 1988, Paris, pp. 641-648.

Marcus, Harold G. Ed \& Hudson, G. (eds.) (1994) New trends in Ethiopian studies: Ethiopia 94. Vol 2, Social sciences.

Martínez D’Alos-Moner, A. (2004) Christian Ethiopia: The temptation of an African polity. In: Böll, V. e. a. (ed.) In Studia Aethiopica: Festschrift für Siegbert Uhlig zum 65. Geburstag. Harrassowitz, Wiesbaden, pp. 165-176.

Meagher, K. (2011) Informal Economies and Urban Governance in Nigeria: Popular Empowerment or Political Exclusion? African Studies Review 54 (2), 47-72. 
Meheret Ayenew (2008) A review of the FDRE's Urban Development Policy. In: Taye Assefa \& Assefa, T. (eds.) Digest of Ethiopia's national policies, strategies and programs. Forum for Social Studies, pp. 451-467.

Meinardus, O. (1965) Ein portugiesischer Altar in Bahar Dar Georgis. Annales d'Ethiopie 6 (1), 281-284.

Mekibib Kassa, Eleni Tesfaye \& Zelalem Alamrew (2013) Risky Sexual Behaviour among Big Construction Enterprise Workers; Bahir Dar City, Amhara Regional State, Northwest Ethiopia. International Journal of Clinical Medicine 4, 296-303.

Mengistu Woube \& Sjöberg, Ö. (1999) Socialism an Urbanization in Ethiopia, 1975-90: A Tale of Two Kebeles. International Journal of Urban and Regional Research 23 (1).

Ministry of Federal Affairs (MoFed) (2005) Urban Develpment Policy (Approved by Council of Ministers).

Ministry of Works and Urban Development (2007) Plan for Urban Development and Urban Good Governance.

Ministry of Works and Urban Development (2008) Rural Kebele Centre Parcelation Plan Manual.

Mohammed Girma (2011) Whose Meaning? The Wax and Gold Tradition as a Philosophical Foundation for an Ethiopian Hermeneutic. Sophia 50 (1), 175-187.

Müller, F. (2015) Model Transfer in the Making: Changing Development Strategies of and Expectation towards, the State in Ethiopia and Ghana, Leipzig and Halle.

Mulugeta Kibret \& Bayeh Abera (2012) The Sanitary Conditions of Food Service Establishments and Food Safety Knowledge and Practices of Food Handlers in Bahir Dar Town. Ethiopian Journal of Health Sciences 22 (1), 27-35.

Mulugeta Tadesse, Betre Alemu, Gashaw Bekele, Tewodros Tebikew, Chamberlin, J. \& Benson, T. (2006) Atlas of the Ethiopian Rural Economy. International Food Policy Research Institute.

Myers, G. (1994) Eurocentrism and african urbanization: The case of Zanzibar's other side. Antipode, 195-215.

Myers, G. (2011) African cities: Alternative visions of urban theory and practice. Zed Books, London.

Nigussie Haregeweyn, Genetu Fikadu, Tsunekawa, A. \& Tsubo, M. (2012) The dynamics of urban expansion and its impacts on land use/land cover change and small-scale farmers living near the urban fringe: A case study of Bahir Dar, Ethiopia. Landscape and Urban Planning 106 (2), 149-157.

Nijman, J. (2007) Introduction - Comparative Urbanism. Urban Geography 28 (1), 1-6.

(2011) African Engagements: On Whose Terms?, Uppsala.

Oestigaard, T. (2011) Richness and Poverty Through Rituals. The Rise of Africa: Miracle or Mirage? Annual Report 2010 The Nordic Africa Institute, 26-27. 
Ofcansky, T. P. k. \& Berry, L. (1991) Country Study Ethiopia. GPO for the Library of Congress. http://countrystudies.us/ethiopia/.

Pankhurst, A. \& Piguet, F. (eds.) (2004) People, Space and the State: Migration, Resettlement and Displacement in Ethiopia, Addis Ababa.

Pankhurst, R. (1979) Three Urban Precursors of Gondar: Emfraz, Gorgora and Danqaz. In: Hess, R. (ed.) Proceedings of the fifth International Conference on Ethiopian Studies, pp. 415-429.

Pankhurst, R. (1985) History of Ethiopian towns - From the mid-nineteenth century to 1935 . Steiner, Wiesbaden.

Parnell, S. \& Simon, D. National Urbanization and Urban Policies: Necessary but Absent Policy Instruments in Africa. In: Pieterse, E. (ed.) Urbanization Imperatives for Africa: Transcending Impasses, Cape Town, pp. 39-46.

Perotti, E. (2010) An Imperial Colonial City in Africa: Italian City Planning For Addis Ababa (1936-40). In: Angélil, M. \& Hebel, D. (eds.) Cities of Change Addis Ababa // Cities of change: Addis Ababa Transformation strategies for urban territories in the 21st century. Birkhäuser, Basel, pp. 61-65.

Persoon, J. (2006) The Monastry as a Nexus of Ethiopian Culture. In: Uhlig, S. (ed.) Proceedings of the XVth International Conference of Ethiopian Studies, Hamburg, July 20-25, 2003. Harrassowitz, Wiesbaden, pp. 679-686.

Pieterse, E. Filling the Void: Towards an Agenda for Action on African Urbanization. In: Pieterse, E. (ed.) Urbanization Imperatives for Africa: Transcending Impasses, Cape Town.

Pieterse, E. Urbanization Imperatives for Africa: Transcending Impasses, Cape Town.

Piguet, F. \& Dechassa Lemessa (2004) Review of voluntary migration and resettlement programmes up to the end of 2001. In: Pankhurst, A. \& Piguet, F. (eds.) People, Space and the State: Migration, Resettlement and Displacement in Ethiopia, Addis Ababa, pp. 133-161.

Pinther, K., Förster, L. \& Hanussek, C. (eds.) (2010) Afropolis: Stadt, Medien, Kunst [Kairo, Lagos, Nairobi, Kinshasa, Johannnesburg]. Verlag der Buchhandlung Walther König, Köln.

Podestá, G. (2013) Building the Empire. Public Works in Italian East Africa (19361941). Enterprises et histoire 70 (1), 37-53.

Podestà, G. L. (2013) Building the empire. Public works in Italian East Africa (1936-1941). Entreprises et histoire 70 (1), 37.

Potts, D. (2009) The slowing of sub-Saharan Africa's urbanization: evidence and implications for urban livelihoods. Environment and Urbanization 21 (1), 253-259.

Rakodi, C. (2002) Economic Development, Urbanization and Poverty. In: Rakodi, C. (ed.) Urban livelihoods: A people-centred approach to reducing poverty. Earthscan, London, pp. 23-34. 
Rakodi, C. (ed.) (2002) Urban livelihoods: A people-centred approach to reducing poverty. Earthscan, London.

Redepennig, M. (2012) Reading the Urban through the Rural: Comments on the Significance of Space-related Distinctions and Semantics. In: Hassenpflug, D., Giersig, N. \& Stratmann, B. (eds.) Reading the city: Developing urban hermeneutics. Verl. der Bauhaus-Univ. Weimar; Bauhaus-Univ, Weimar, Weimar, pp. 85-101.

Regional Urban Planning Institute (RUPI) ([date unknown b]) Integrated Development Plan, Land-Use.

Regional Urban Planning Institute (RUPI) ([date unknown a]) Land-use plan.

Regional Urban Planning Institute (RUPI) ([date unknown c]) Map of Bahir Dar Town by Kebele.

Regional Urban Planning Institute (RUPI) (2000 E.C.) Rural Kebele Centre Parcelation Plan Manual (Draft).

Regional Urban Planning Institute (RUPI) (2003 E.C.) Study to enable farmers who are living in the rural kebeles which are included under the Bahir Dar city administration (Proposal), Bahir Dar.

Rifkind, D. (2011) Gondar. Architecture and Urbanism for Italy's Fascist Empire // Gondar. Journal of the Society of Architectural Historians 70 (4), 492-511.

Robinson, J. (2006) Ordinary cities: Between modernity and development. Routledge, London.

Robinson, J. (2011) Cities in a World of Cities: The Comparative Gesture. International Journal of Urban and Regional Research 35 (1), 1-23.

Roy, A. (2011b) Commentary: Placing Planning in the World--Transnationalism as Practice and Critique. Journal of Planning Education and Research 31 (4), 406-415.

Roy, A. (2011a) Slumdog Cities: Rethinking Subaltern Urbanism. International Journal of Urban and Regional Research 35 (2), 223-238.

Roy, A. (2005) Urban Informality - Towards an epistomology of planning. Journal of the American Planning Association 71 (2), 147-158.

Roy, A. (2009) Why India cannot plan its Cities: Informality, Insurgence and the Idiom of Urbanization. Planning Theory 76 (8), 76-87.

Roy, A. \& AlSayyad, N. (eds.) (2004) Urban informality: Transnational perspectives from the Middle East, Latin America, and South Asia. Lexington Books, Lanham.

Sbacchi, A. (2004) Ethiopia under Mussolini: Fascism and the colonial experience. Africa World; Turnaround, Trenton, N.J., London.

Schmidt-Kallert, E. (2009) A New Paradigm of Urban Transition: Tracing the Livelihood Strategies of Multi-Locational Households. Die Erde 140 (3), 319-336.

Scholz, W. (2008) Challenges of informal urbanisation: The case of Zanzibar/Tanzania. Univ., Diss--Dortmund, 2008. SPRING Centre, Dortmund. 
Seleshi Sisaye (1979) Urban Migration and the Labour Movement in Ethiopia. In: Hess, R. (ed.) Proceedings of the fifth International Conference on Ethiopian Studies, pp. 679-700.

Seltene Seyoum (2000) Land Alienation and the Urban Growth of Bahir Dar 193574. In: Anderson, D. M. \& Rathborne, R. (eds.) Africa’s urban past. James Currey, Oxford.

Seltene Seyoum (2003) Bahir Dar. In: Uhlig, S. (ed.) A - C. Harrassowitz, Wiesbaden, pp. 442-444.

Shack, W. A. (1973) Urban Ethnicity and the Cultural Process of Urbanization in Ethiopia. In: Southall, A. W. (ed.) Urban anthropology. Cross-cultural studies of urbanization. Oxford U. P., New York, pp. 251-285.

Simone, A. (2004) For the city yet to come: Changing African life in four cities. Duke University Press, Durham.

Simone, A. (2011) The Urbanity of Movement: Dynamic Frontiers in Contemporary Africa. Journal of Planning Education and Research 31 (4), 379-391.

Simone, A. \& Abouhani, A. (eds.) (2005) Urban Africa: Changing contours of survival in the city. Codesria Books, Dakar.

Solomon Mulugeta (1997) Policy Responses to the Urban Shelter Problem in Ethiopia: The Case of Pre-1991 Addis Ababa. In: Fukui, K. \& et al. (eds.) Ethiopia in broader perspective: Papers of the XIIIth International Conference of Ethiopian Studies, Kyoto, 12-17 December 1997. Shokado Book Sellers, Kyoto, pp. 188-205.

Southall, A. W. (ed.) (1973) Urban anthropology. Cross-cultural studies of urbanization. Oxford U. P., New York.

Taddese Beyene (ed.) (1988) Proceedings of the Eight International Conference of Ethiopian Studies // Proceedings of the eighth International Conference of Ethiopian Studies: University of Addis Ababa. Inst. of Ethiopian Studies, Addis Ababa.

Taye Assefa \& Assefa, T. (eds.) (2008) Digest of Ethiopia's national policies, strategies and programs. Forum for Social Studies.

Tegegne Gebre-Egziabher (1997) Decentralization and Changing Local and Regional Development Planning in Ethiopia. In: Fukui, K. \& et al. (eds.) Ethiopia in broader perspective: Papers of the XIIIth International Conference of Ethiopian Studies, Kyoto, 12-17 December 1997. Shokado Book Sellers, Kyoto, pp. 691-720.

Tegegne Gebre-Egziabher (2007) Geographically differentiated Strategy, the Urbanisation Agenda, and Rural-Urban Linkages: An Assessment of the Emerging Regional Development Strategies in Ethiopia. Regional Development Dialogue 28 (1), 131-150.

Tegegne Gebre-Egziabher (2010) Livelihood and urban poverty reduction in Ethiopia: Perspectives from small and big towns / Tegegne Gebre-Egziabher. Or- 
ganisation for Social Science Research in Eastern and Southern Africa, Addis Ababa, Ethiopia.

Teller, C. H., Assefa Hailemariam \& Butz, W. (eds.) (2011) The demographic transition and development in Africa: The unique case of Ethiopia. Springer, Dordrecht.

Teshale Tibebu (1995) The making of modern Ethiopia. 1896 - 1974. Red Sea Press, Lawrenceville, NJ.

TS06 D - Informal Settlement Issues, Spatial Development, Planning and Governance (ed.) (2011) Bridging the Gap between Cultures.

Tvedt, T. (2004) The River Nile in the age of the British: Political ecology and the quest for economic power. I.B. Tauris, London, New York.

Uhlig, S. (ed.) (2003) A - C. Harrassowitz, Wiesbaden.

Uhlig, S. (ed.) (2006) Proceedings of the XVth International Conference of Ethiopian Studies, Hamburg, July 20-25, 2003. Harrassowitz, Wiesbaden.

United Nations Educational Scientific and Cultural Organisation (2002) Address by Mr Koïchiro Matsuura Director-General of the United Nations Educational, Scientific and Cultural Organization on the occasion of the award of the UNESCO Cities for Peace Prize and the confirmation of the proclamation of Jemaâ el-Fna Square as an oral and intangible masterpiece of humanity. http:// unesdoc.unesco.org/images/0012/001252/125255e.pdf. Accessed 4/19/2013.

United Nations Human Settlement Programme (UN-Habitat) (2008) The State of African Cities 2008. A Framework for Adressing Urban Challenges in Africa., Nairobi.

United Nations Human Settlements Progamme (UN-Habitat) (2007) Situation Analysis of informal settlements in Addis Abeba. Cities without Slums: SubRegional Programme for Eastern and Southern Africa - Addis Abeba Slum Upgrading Programme, Nairobi.

United Nations Population Fund (2007) UNFPA state of world population, 2007: Unleashing the potential of urban growth. United Nations Population Fund, New York.

Watson, V. (2002) The Usefulness of Normative Planning Theories in the Context of Sub-Saharan Africa. Planning Theory 1 (1), 27-52.

Watson, V. (2009) Seeing from the South: Refocusing Urban Planning on the Globe's Central Urban Issues. Urban Studies 46 (11), 2259-2275.

Watson, V. (2009) 'The Planned City sweeps the Poor away.... Urban planning and 21st Century Urbanisation. Progress in Planning 72 (3), 151-193.

Wendwosen Demrew Addissie (2007) Housing Development and Urban Renewal. Integrated Approach of Inner City Revitalization. A Case Study of Addis Ababa, Ethiopia, Lund.

Winkler, T. \& Duminy, J. (2014) Planning to change the world? Questioning the normative ethics of planning theories. Planning Theory 1473095214551113, first published on September 19, 2014, 1- 19. 
Woldie Assaw, Degefa Tolossa \& Gete Zeleke (2010) Causes and impacts of seasonal migration on rural livelihoods: Case studies from Amhara Region in Ethiopia. Norsk Geografisk Tidsskrift - Norwegian Journal of Geography 1 (68), 58-70.

Y. Abebe \& M. Fantahun (1999) Shift Work and Sleep Disorder Among Textile Mill Workers in Bahir Dar, Northwest Ethiopia. East African Medical Journal 76 (7), 407-410.

Yin, R. K. (2009) Case study research: Design and methods, 4th edn. Sage Publications, Los Angeles, Calif.

Zegeye Cherenet (2010) The Portrait of an Isolated Nation - Ethiopia/Abyssinia. In: Angélil, M. \& Hebel, D. (eds.) Cities of Change - Addis Ababa // Cities of change: Addis Ababa Transformation strategies for urban territories in the 21st century. Birkhäuser, Basel, pp. 30-38.

Zelalem Yirga Adamu (2012) Institutional Analysis of Condominium Management System in Amhara Region: The Case of Bahir Dar City. African Review of Economics and Finance 3 (2), 13-48.

Zur Heide, F. (2012) Feasibility Study for a Lake Tana biosphere reserve, Ethiopia. Bundesamt für Naturschutz, BfN, Bonn. 